Aus der Abteilung Virologie

(Prof. Dr. med. F. Hufert)

Im Zentrum Hygiene und Humangenetik

der Medizinischen Fakultät der Universität Göttingen

\title{
Entwicklung und Optimierung \\ eines Cytometric Bead Array zum Nachweis \\ von afrikanischen hämorrhagischen Fieberviren
}

\author{
INAUGURAL-DISSERTATION \\ zur Erlangung des Doktorgrades \\ der Medizinischen Fakultät \\ der Georg-August-Universität zu Göttingen
}

vorgelegt von

Tamara Nordmann

aus Köln

Göttingen 2011 
Dekan: Prof. Dr. med. Frömmel

1. Berichterstatter: Prof. Dr. med. Hufert

2. Berichterstatter: Prof. Dr. rer. nat. PöhImann

3. Berichterstatter: Prof. Dr. med. Oppermann

Tag der mündlichen Prüfung: 24.04.2012 


\section{Inhaltsverzeichnis}

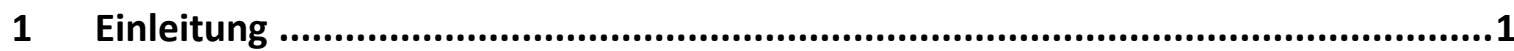

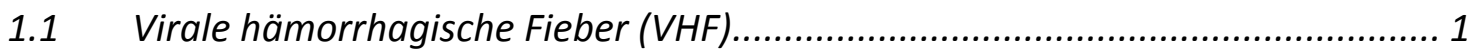

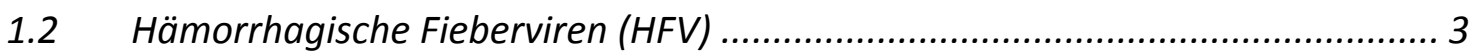

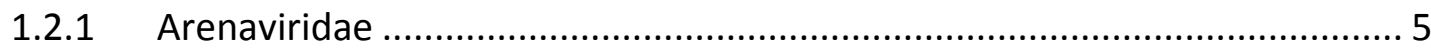

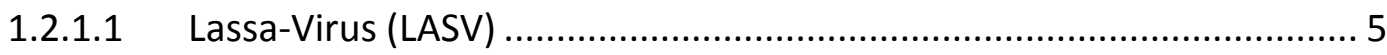

1.2.1.2 Genom und Strukturaufbau der Arenaviridae ....................................... 5

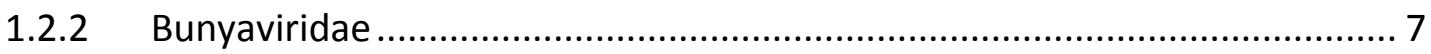

1.2.2.1 Krim-Kongo-Hämorrhagisches-Fieber-Virus (CCHFV) ......................... 7

1.2.2.2 Rift-Valley-Fever-Virus (RVFV) ..................................................... 7

1.2.2.3 Genom und Strukturaufbau der Bunyaviridae................................... 8

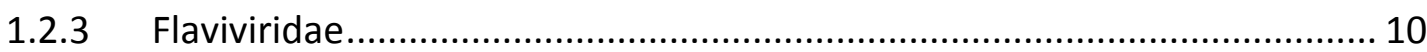

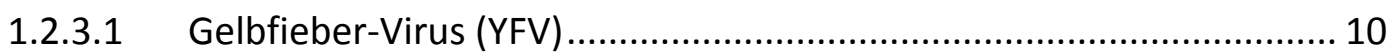

1.2.3.2 Dengue-Virus (DENV) .................................................................. 10

1.2.3.3 Genom und Strukturaufbau der Flaviviridae .................................... 12

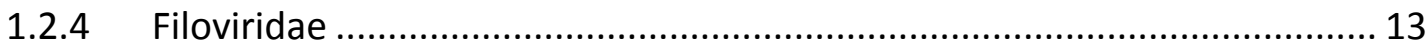

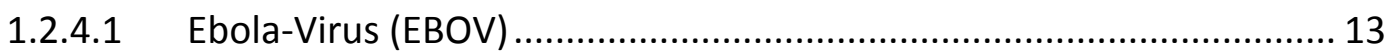

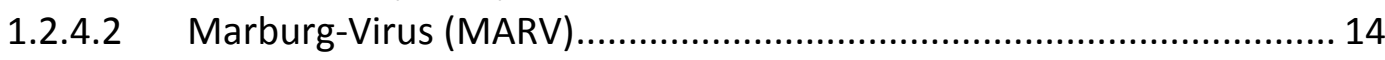

1.2.4.3 Genom und Strukturaufbau der Filoviridae ..................................... 15

1.3 Bestehende Diagnostikverfahren für hämorrhagische Fieberviren................... 16

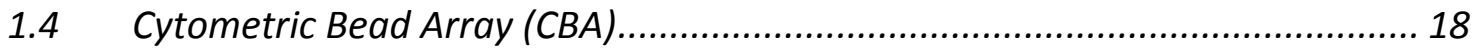

1.4.1 Aufbau und Prinzip des Durchflusszytometers ........................................... 18

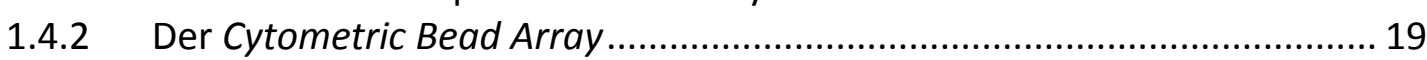

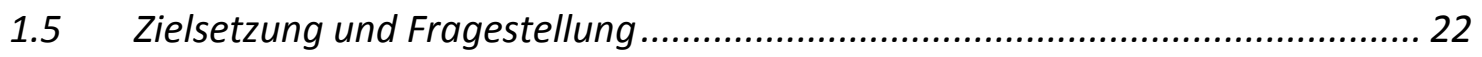

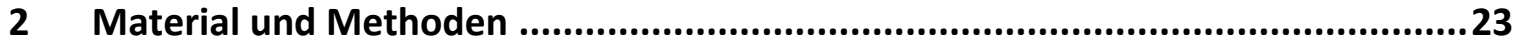

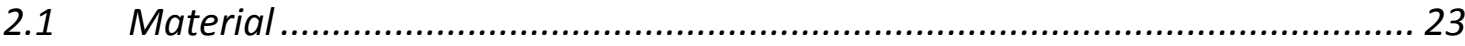

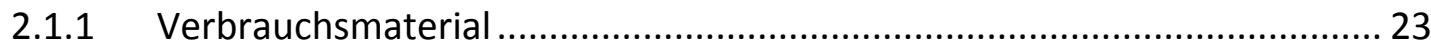

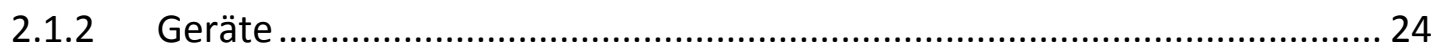

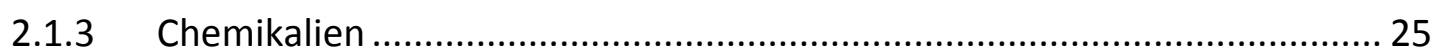

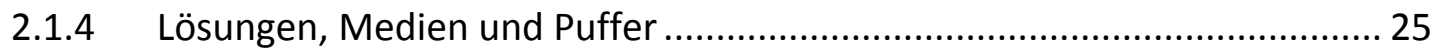

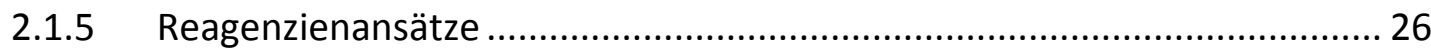

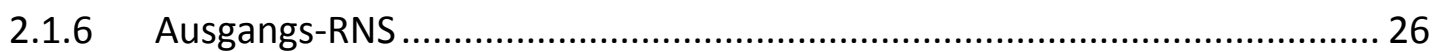

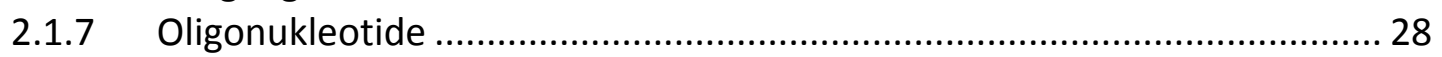

2.1.8 Verwendete Computerprogramme........................................................... 30

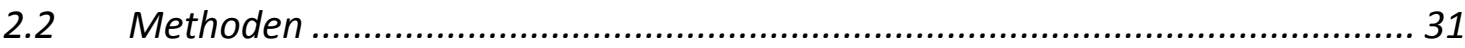

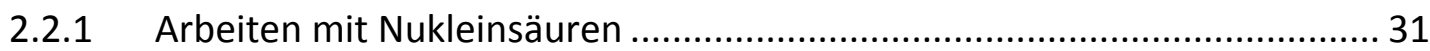

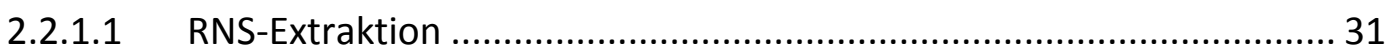

2.2.1.2 Spektrophotometrische Konzentrationsbestimmung ........................ 32

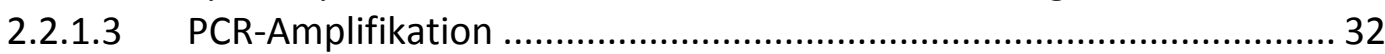


2.2.1.3.1 Polymerase-Kettenreaktion (PCR) .......................................... 32

2.2.1.3.2 Reverse-Transkriptase-PCR (RT-PCR) …......................................... 34

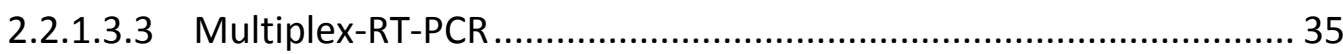

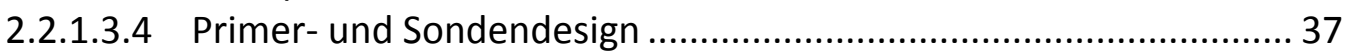

2.2.1.3.5 Gelelektrophoretische Auftrennung von DNS............................... 38

2.2.1.3.6 Quantitative Real-Time PCR (qRT-PCR) ...................................... 39

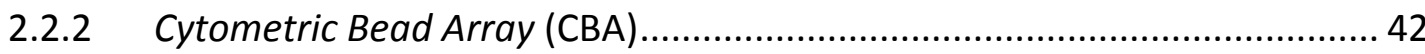

2.2.2.1 Aufreinigung der PCR-Produkte mit MinElute-Purifikation-Kit ........... 42

2.2.2.2 Kopplung von Sonden an carboxylierte Beads................................. 43

2.2.2.3 Hybridisierung an Beads und Detektion ........................................... 44

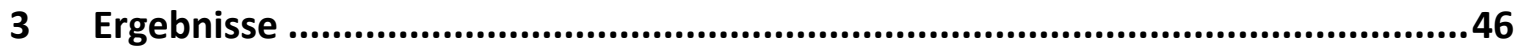

3.1 Amplifikation des Virusgenoms mittels PCR ................................................... 46

3.1.1 Bestimmung der optimalen Primerkonzentration .................................... 46

3.1.2 Bestimmung der optimalen Primerkombination ..................................... 48

3.1.3 Vergleich der Primerdimerbildung in den Primermischungen ................... 51

3.1.4 Bestimmung des optimalen Primerverhältnisses........................................ 52

3.1.5 Aufreinigung der PCR-Produkte mit dem MinElute-Purifikation-Kit............ 55

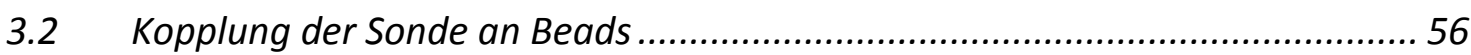

3.2.1 Reproduzierbarkeit der Kopplung ......................................................... 59

3.3 Hybridisierung an bead-gekoppelte Sonden und Detektion............................ 59

3.3.1 Optimierung der Hybridisierungsbedingungen ........................................6 60

3.3.1.1 Optimierung der Hybridisierungstemperatur ......................................6 60

3.3.1.2 Bedeutung der Lagerungsbedingungen der Beads für die

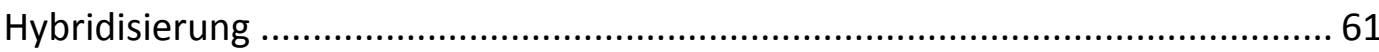

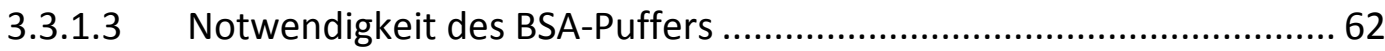

3.3.2 Qualitativer Beweis im Uniplex-Hybridisierungsverfahren .........................63 63

3.3.3 Qualitativer Beweis im Multiplex-Hybridisierungsverfahren........................65 65

3.3.4 Sensitivitätsmessung im Uniplex-Hybridisierungsverfahren...................... 70

3.3.5 Sensitivitätsmessung im Multiplex-Hybridisierungsverfahren .................. 73

3.3.6 Analyse der Ergebnisse und Grenzwertbestimmung ............................... 76

3.3.7 Kreuzreaktionstestung im Multiplex-Hybridisierungsverfahren.................. 80

3.4 Vergleich der Sensitivität der verschiedenen Nachweisverfahren für

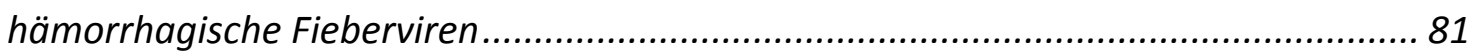

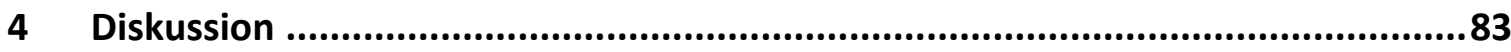

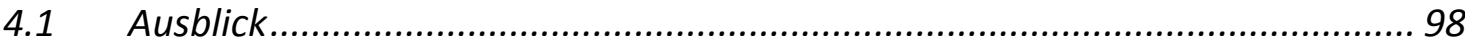

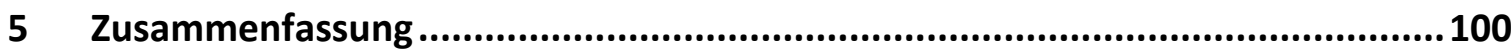

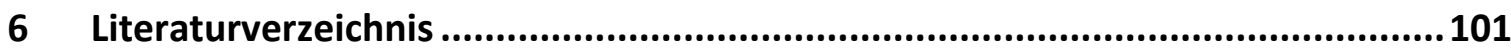




\section{Abkürzungsverzeichnis}

$\begin{array}{ll}\text { A } & \text { Adenosin } \\ \text { Abb. } & \text { Abbildung } \\ \text { ad } & \text { auffüllen auf } \\ \text { AK } & \text { Antikörper } \\ \text { APC } & \text { Allophycocyanin } \\ \text { ATP } & \text { Adenosin-Triphosphat } \\ \text { bp } & \text { Basenpaar(e) } \\ \text { BP } & \text { Mikrokugelpopulation (engl: beadpopulation) } \\ \text { BSA } & \text { Rinderserumalbumin (engl.: bovine serum albumin) } \\ \text { BSL } & \text { Biosicherheitsstufe (engl.: biosafty level) } \\ \text { C } & \text { Cytosin } \\ \text { CBA } & \text { zytometrischer Kugel-Test (engl.: cytometric bead array) } \\ \text { CCHF } & \text { Krim-Kongo-Hämorrhagisches-Fieber } \\ & \text { (engl.: crimean-congo-hemorrhagic-fever) } \\ \text { CCHFV } & \text { Krim-Kongo-Hämorrhagisches-Fieber-Virus } \\ & \text { (engl.: crimean-congo-hemorrhagic-fever-virus) } \\ \text { DHF } & \text { hämorrhagisches Dengue-Fieber } \\ \text { cDNS } & \text { komplementäre Desoxyribonukleinsäure } \\ \text { cm } & \text { Zentimeter } \\ \text { COOH } & \text { Carboxyl } \\ \text { CSF } & \text { Cerebrospinalflüssigkeit } \\ \text { Ct } & \text { Zyklusschwellenwert (engl.: cycle threshold) } \\ \text { Cy } & \text { Carbocyanin } \\ \text { Da } & \text { Dalton } \\ \text { Dengulfoxid }\end{array}$




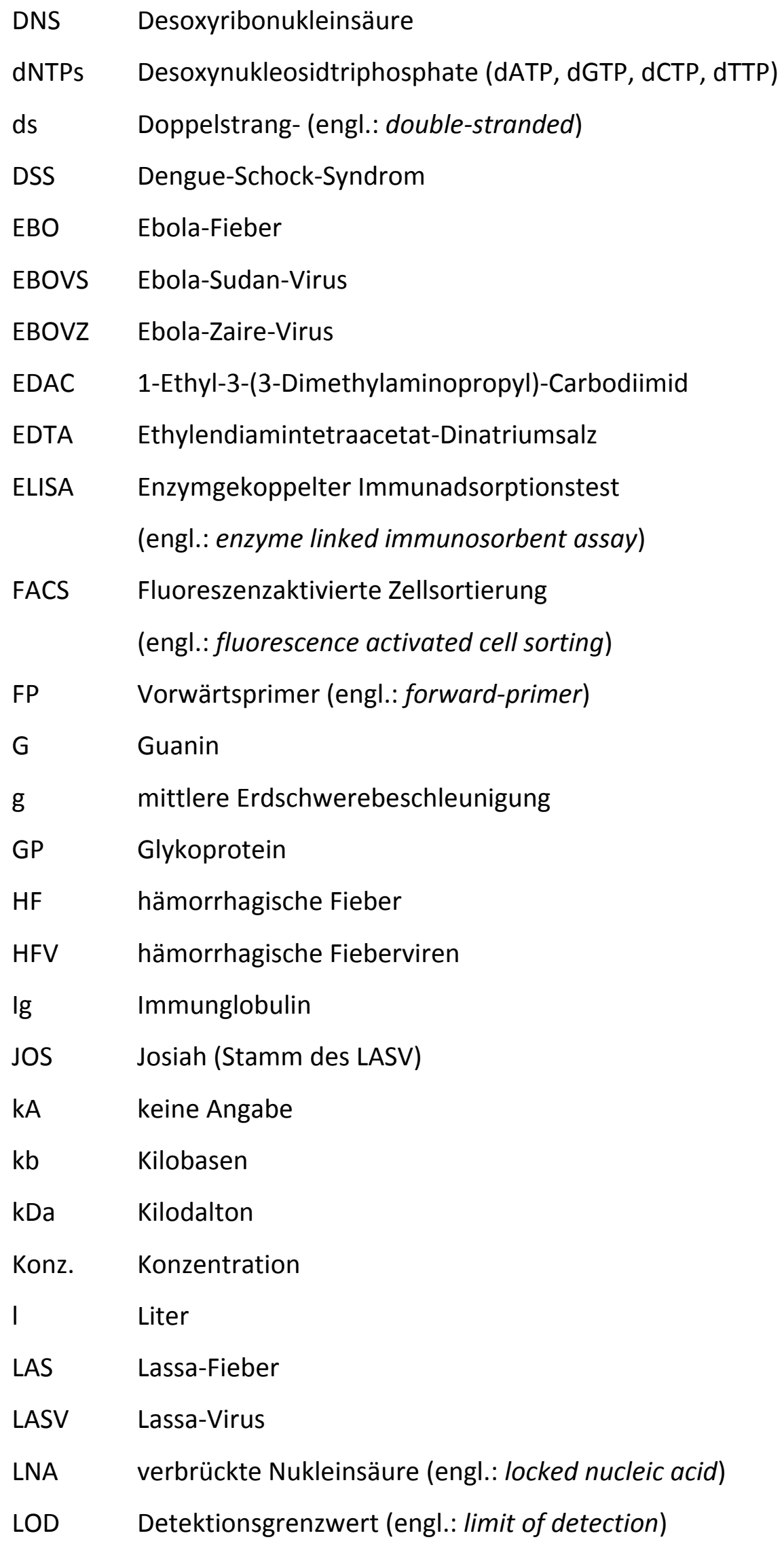




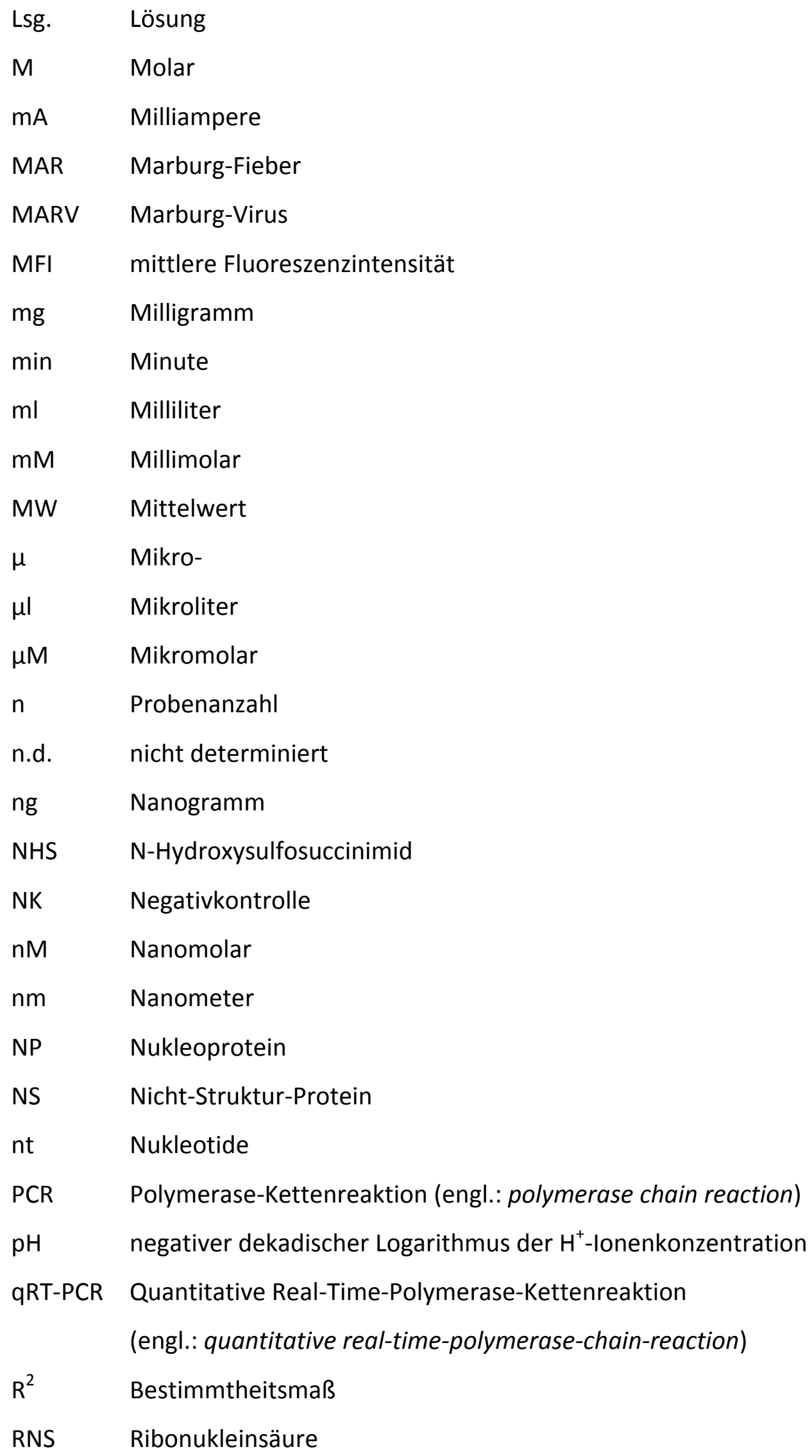


RP Rückwärtsprimer (engl.: reverse-primer)

RT Reverse Transkriptase

RVF Rift-Tal-Fieber (engl.: rift valley fever)

RVFV Rift-Tal-Fieber-Virus (engl.: rift valley fever virus)

SARPE Streptavidin-R-Phycoerythrin

SD Standardabweichung (engl.: standard deviation)

SDS Sodiumdodecylsulfat

sek Sekunde

SM SkimMilk (engl.: skimmed milk, deut.: Magermilch)

ss $\quad$ Einzelstrang- (engl.: single-stranded)

T Thymin

$\mathrm{T}_{\mathrm{a}} \quad$ Renaturierungstemperatur (engl.: annealing temperature)

$\mathrm{T}_{\mathrm{m}} \quad$ Schmelztemperatur (engl.: melting temperature)

Tab. Tabelle

TAE Tris-Acetat-EDTA-Puffer

Taq Thermus aquaticus

TE Tris-EDTA-Puffer

Tris Tris-(hydroxymethyl)-aminomethan

tRNS Transfer-Ribonukleinsäure

U Unit

ü.N. über Nacht

UpM Umdrehungen pro Minute

UV Ultraviolett

V Volt

VHF virale hämorrhagische Fieber

VP virales Protein

w/v Gewichtsverhältnis (weight/volume)

YF Gelbfieber (engl.: yellow fever)

YFV Gelbfieber-Virus

Alle chemischen Elemente wurden mit den üblichen Symbolen abgekürzt. 


\section{$1 \quad$ Einleitung}

\subsection{Virale hämorrhagische Fieber (VHF)}

Der Sammelbegriff "Virale hämorrhagische Fieber" (VHF) bezeichnet eine Gruppe infektiöser Fiebererkrankungen, die in schweren Fällen zu generalisierten Hämorrhagien führen können.

Klinische Manifestationen der VHF sind unspezifisch und zeigen eine große Vielfalt. Typischerweise können die Symptome in eine frühe und späte Phase unterteilt werden. In der frühen Phase der Infektion treten Fieber, Hypotension, Bradykardie, Tachypnoe, Konjunktivitis, Pharyngitis und ein Exanthem, das stark variieren kann, auf. Spätere Zeichen sind eine progressive hämorrhagische Diathese, Schleimhaut- und Konjuntivalhämorrhagien, Hämaturie, Hämatoemesis und Melena, intravaskuläre Koagulation und Schock. Die zentralnervöse Beteiligung manifestiert sich durch Konvulsionen, Delirium oder Koma und geht mit einer schlechten Prognose einher.

Die Erreger der VHF gehören zu 4 verschiedenen Virusfamilien, die alle einsträngige RNS-Genome besitzen: Arenaviridae, Bunyaviridae, Filoviridae und Flaviviridae. Zur Übertragung auf den Menschen kommt es meist durch Kontakt mit kontaminierten tierischen Reservoiren (z.B. Nagetiere) oder durch Vektoren (z.B. Stechmücken, Zecken). Vom Lassa-Virus (LASV) ist bekannt, dass es den Menschen sogar durch kontaminierte Exkremente von Tieren infizieren kann (McCormick et al. 1987). Die natürlichen Reservoire und Vektoren von Ebola-Virus (EBOV) und Marburg-Virus (MARV) sind unbekannt, doch es sind Viren in Fruchtfledermäusen (Rousettes aegypticus) in Afrika nachgewiesen worden (Towner et al. 2009). Mit Ausnahme von Rift-Valley-Fieber-Virus (RVFV) und allen Flaviviren können hämorrhagische Fieberviren (HFV) auch direkt von Mensch zu Mensch übertragen werden, was zu nosokomialen Infektionen und Ausbrüchen führen kann. Die Inkubationszeit beträgt einige Tage (z.B. Gelbfieber: 3-6 Tage) bis Wochen (z.B. Ebola-Fieber: 2 Tage - 3 Wochen). 
Die HFV können geographisch gut umschrieben werden. Die meisten HFV beschränken sich auf Afrika, Südamerika und Asien. Lediglich das Krim-Kongo-Hämorrhagische-FieberVirus (CCHFV) ist auch in Europa endemisch.

Das klinische und epidemiologische Wissen über VHF ist spärlich. Aufgrund ihrer hohen Morbidität und Mortalität haben die VHF zwar beträchtliche Aufmerksamkeit in den Medien erhalten, dennoch kommt es nur sporadisch zu Ausbrüchen von VHF.

Die letzten größeren VHF-Ausbrüche waren im Dezember 2008 bis Januar 2009 ein Ausbruch des Ebola-Zaire-Virus (EBOVZ) in der Demokratischen Republik Kongo (32 Personen, 12 Tote)(WHO 2009a) und im Februar 2010 ein RVF-Ausbruch in Südafrika (172 Personen, 15 Tote)(CDC 2011).

Durch die erhöhte Anzahl von Flugreisenden werden die HFV sporadisch von endemischen Gebieten nach Europa und Nordamerika exportiert. So wurde z.B. das MARV im Jahr 2008 von zwei Personen aus Uganda in die Niederlande und die Vereinigten Staaten von Amerika exportiert (Timen et al. 2009).

Der Verdacht auf VHF besteht bei allen Patienten, die schwer erkrankt sind und vaskuläre Symptome aufweisen, nachdem sie sich in einem HFV-endemischen Gebiet aufgehalten haben oder sie auf andere Weise in Kontakt mit dem Virus gekommen sind (z.B. Kontakt zu einer mit HFV infizierten Person oder Tieren bzw. Kadavern). Zur endgültigen Diagnose dienen die Virusisolation oder die IgM- / IgGAntikörperbestimmung durch einen enzym-linked immunosorbent-assay (ELISA) und die Antigendetektion durch einen gegen virale Antigene gerichteten ELISA (engl: antigencapture ELISA). Soll ein direkter Nachweis des Virusgenoms vorgenommen werden, können die Reverse-Transkriptase-Polymerase-Kettenreaktion (RT-PCR) oder die quantitative Real-Time-Polymerase-Kettenreaktion (qRT-PCR) verwendet werden.

Die Hauptaufgabe der Behandlung von VHF ist die kreislaufunterstützende Therapie. Es sollte ein ausgeglichener Flüssigkeits- und Elektrolythaushalt erhalten bleiben und für ein ausreichendes Zirkulationsvolumen und einen stabilen Blutdruck gesorgt werden. Zusätzlich muss die Verabreichung von Vasopressoren, antiinflammatorisch wirksamen Medikamenten und Antikoagulatien in Erwägung gezogen werden. Die Anwendung von künstlicher Beatmung und renaler Dialyse kann notwendig sein (Jahrling 1989). Bisher ist 
kein antivirales Medikament von der „US Food and Drug Administration“ (FDA) zur Therapie von VHF bestätigt worden. Nur Ribavirin, ein Nukleosidanalogon, wird zur Therapie und Prophylaxe bei Arenaviren und Bunyaviren empfohlen (Bray,Huggins 1998, Bray,Paragas 2002, EMEA 2002). Ein Effekt von Ribavirin auf Filoviridae und Flaviviridae ist nicht bekannt. Durch eine Kombination mit Interferon-alpha könnte möglicherweise die Schutzwirkung von Ribavirin verstärkt werden (Bray,Paragas 2002).

Abgesehen von der 17D-Impfung, die höchsteffektiv gegen YFV wirkt, gibt es keinen zugelassenen VHF-Impfstoff. Potentiellen Impfstoffe für RVFV, EBOV, MARV und LASV befinden sich im experimentellen Stadium (EMEA 2002, NIH 2002).

Die meisten HFV erfüllen die Hauptkriterien, die von der „Working Group on Civilian Biodefense" entwickelt wurden, um biologische Stoffe auf ihr Risiko als biologische Kampfstoffe missbraucht zu werden, einzuschätzen: (1) hohe Mortalität und Morbidität, (2) potentielle Mensch-zu-Mensch-Übertragung, (3) hohe Infektiosität bei Aersolübertragung, (4) keine effektive Impfung vorhanden oder nur begrenzt verfügbar und (5) Möglichkeit zur Produktion in großen Mengen. Aufgrund dieser Kriterien geht laut der "Working Group on Civilian Biodefense" ein besonderes Risiko von EBOV, MARV, LASV, RVFV, YFV, Omsk-Hämorrhagisches-Fieber-Virus und Kyasanur-ForestFieber-Virus aus (Borio et al. 2002).

\subsection{Hämorrhagische Fieberviren (HFV)}

Die Erreger des viralen hämorrhagischen Fiebers gehören zu vier verschiedenen Virusfamilien: den Arenaviridae, Bunyaviridae, Filoviridae und Flaviviridae. Die Viren weisen unterschiedliche Replikationsmechanismen, Epidemiologie und Interaktionen mit dem Wirt auf. Da die Arbeit mit HFV eine Einrichtung der Sicherheitsstufe BSL3 bis BSL4 und gut ausgebildetes Laborpersonal verlangt, ist das Wissen über molekulare Eigenschaften und Pathogenese der Viren sehr begrenzt. Die Diagnostik für VHF muss zeitnah erfolgen, damit VHF-Fälle früh isoliert und behandelt werden können. Nur mit Hilfe von Schnelldiagnostik können große Ausbrüche eines VHF verhindert werden.

In der vorliegenden Doktorarbeit wurde ein CBA zur Diagnostik der acht wichtigsten afrikanischen HFV entwickelt. Diese sind das Lassa-Virus (Arenaviridae), das Krim-KongoVirus, das Rift-Valley-Fever-Virus (Bunyaviridae), das Ebola-Sudan-Virus, das Ebola-Zaire- 
Virus, das Marburg-Virus (Filoviridae), das Dengue-Virus und das Gelbfieber-Virus (Flaviviridae).

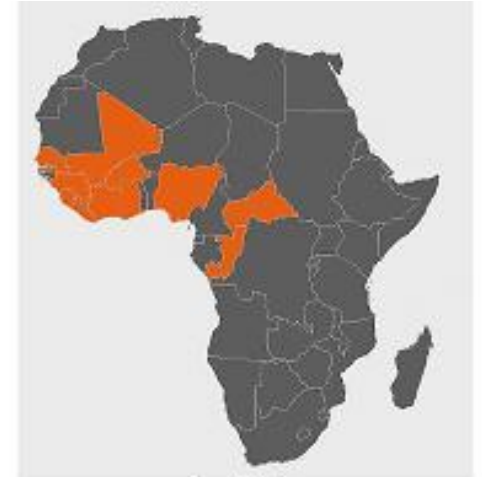

LASV

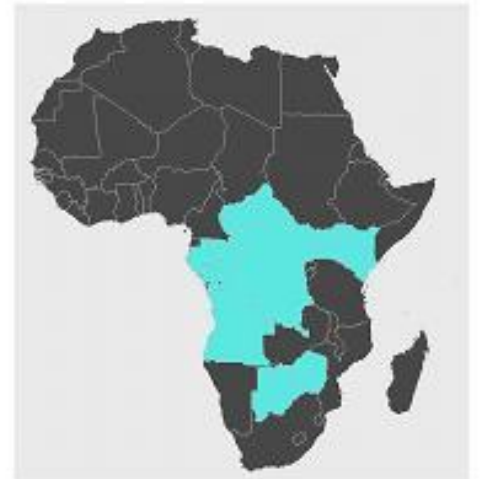

MARV

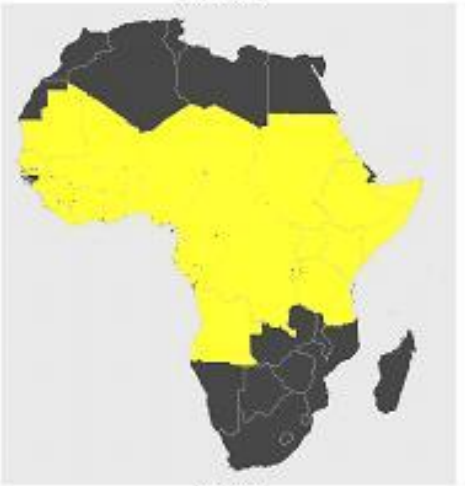

YFV

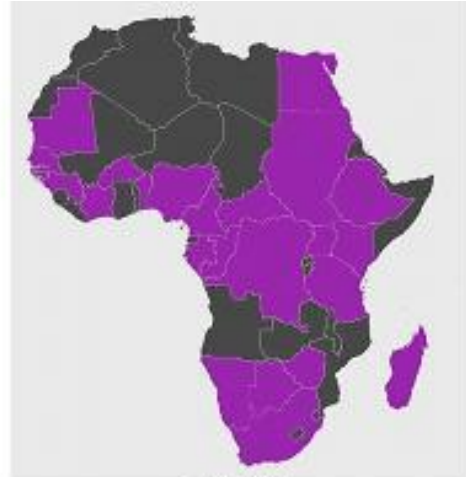

CCHF

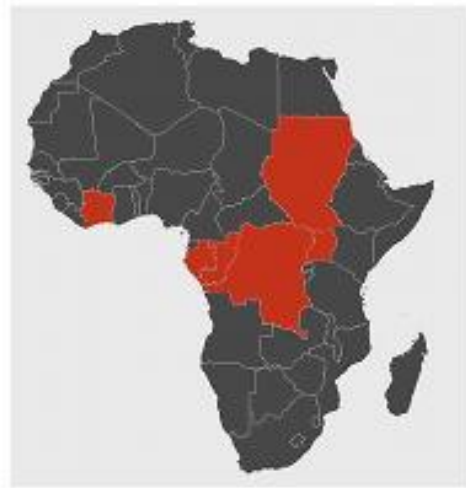

EBOV

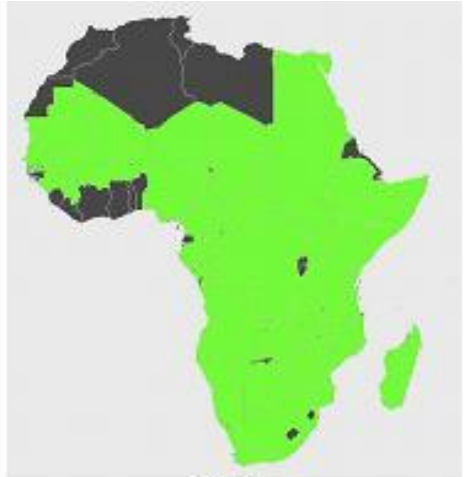

RVF

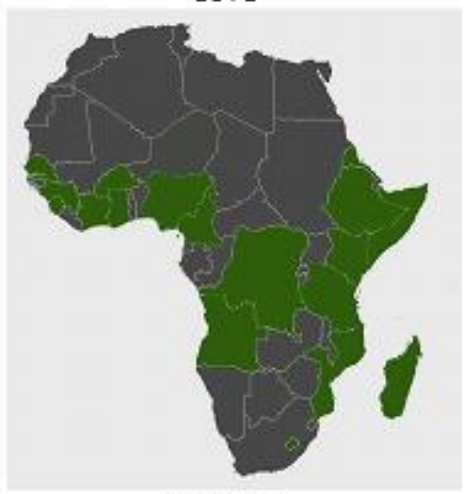

DENV

Abb. 1.1: Epidemiologie der HFV in Afrika dargestellt wird die dokumentierte Lokalisation von Ausbrüchen und der serologische Nachweis der HFV (CDC 2011, GloballncidentMap.com 2011, McCormick et al. 1999, WHO 2011). 


\subsubsection{Arenaviridae}

\subsubsection{Lassa-Virus (LASV)}

Das Lassa-Virus wurde erstmalig 1970 von Frame (Frame et al. 1970) beschrieben und konnte im selben Jahr von Buckley und Casals isoliert werden (Buckley,Casals 1970). Das LASV gehört zu der Familie der Arenaviridae und wird der biologischen Sicherheitsstufe 4 zugeordnet. LASV ist in West-Afrika endemisch und wird in vier Subtypen unterteilt: Typ Nigeria und Typ LP (beide aus Nigeria) (Clegg et al. 1991, Demby et al. 1994, Ter Meulen et al. 1998), Typ Josiah (Sierra Leone)(Auperin,McCormick 1989) und Typ AV (Ghana, Côte D'Ivoire, Burkina Faso)(Gunther et al. 2000). Einige Studien schätzen, dass in Westafrika LASV jährlich 300.000 bis 500.000 Erkrankungen und bis zu 5000 Todesfälle verursacht (Ogbu et al. 2007).

Das Lassa-Fieber ist eine Zoonose, dh. als natürliche Reservoirs dienen den Lassa-Viren Nagetiere (Mastomys natalensis). Menschen können sich durch Inhalation von Aerosolen von Nagetierurin, durch Verdauung von durch Nagetiere kontaminiertem Essen oder durch direkten Kontakt mit Nagetierexkrementen infizieren (McCormick et al. 1987). Nosokomiale Transmissionen oder die direkte Mensch-zu-Mensch-Übertragung sind bei Lassa-Fieber ebenfalls aufgetreten (Mertens et al. 1973). 80\% der infizierten Menschen bleiben asymptomatisch (WHO 2005a). In den übrigen 20\% der Fälle tritt eine schwere systemische Erkrankung ein, die vor allem Leber, Niere und Milz betrifft. Die Mortalität liegt bei 15-20\% (Monath et al. 1973). Die Inkubationszeit kann 3 bis 21 Tage betragen (Gunther et al. 2000). Als effektive Therapie hat sich Ribavirin bei Gabe im frühen Stadium erwiesen (Jahrling et al. 1980). Unterstützende Therapie ist oft nötig und beinhaltet Flüssigkeitsgabe, Bluttransfusionen, Chinin und Breitspektrumantibiotika (Holmes et al. 1990).

\subsubsection{Genom und Strukturaufbau der Arenaviridae}

Die Partikel der Arenaviridae haben eine sphärische Form mit einem Durchmesser, der zwischen 50 bis $300 \mathrm{~nm}$ variiert. Das Genom der Arenaviridae besteht aus zwei Segmenten einzelsträngiger RNS, die sogenannten L- (engl.: large) und S-Segmente (engl.: small). Zusammen ergeben sie eine Gesamtlänge von 3,4-7 kB. Das S-Segment 
kodiert für das Vorläuferprotein GPC (Glycoprotein Precursor) der G1- und G2-Proteine (Glycoproteine) in positiver Orientierung und für das NP-Protein (Nukleoprotein) in negativer Orientierung. Das L-Segment besteht aus zwei Sequenzen in AmbisenseOrientierung. So wird an der 3'-Region in negativer Orientierung das L-Protein, die virale Polymerase (Gunther et al. 2000), kodiert und an der 5'-Region das Z-Protein, ein $\mathrm{Zn}^{2+}$ Ionen bindendes Polypeptid. (s. Abb. 1.2)
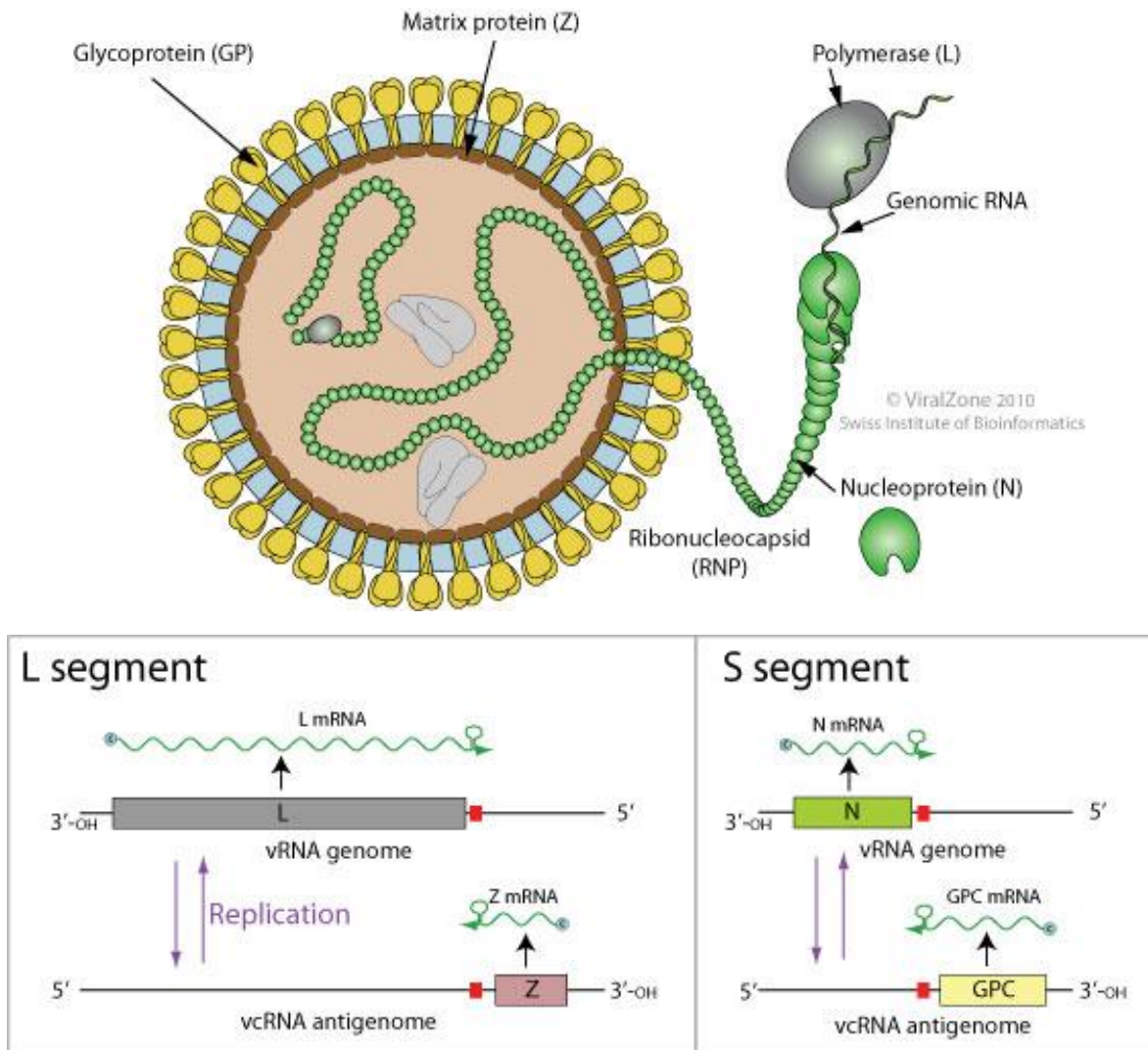

Abb. 1.2: Struktur und Genom der Arenaviridae oben: Darstellung der Struktur eines Viruspartikels, unten: Darstellung des Virusgenoms mit den RNS-Segmenten L- und S-Segment in ambisense Orientierung (Expasy 2011). 


\subsubsection{Bunyaviridae}

\subsubsection{Krim-Kongo-Hämorrhagisches-Fieber-Virus (CCHFV)}

Die ersten beschriebenen Ausbrüche des CCHFV traten auf der Halbinsel Krim 1944 (Ergonul 2006) und 1956 im Kongo auf und gaben dem Virus seinen Namen (Casals 1969). Heutzutage gilt das CCHFV als weitverbreitet.

Aufgrund der Daten, die bei verschiedenen Ausbrüchen von CCHF gesammelt wurden, konnte das CCHFV in sieben genetisch verschiedene Gruppen eingeteilt werden, von denen drei in Afrika, zwei in Europa und zwei in Asien vorkommen (Burney et al. 1980, Drosten et al. 2002b, Dunster et al. 2002, el-Azazy,Scrimgeour 1997, Nabeth et al. 2004a, Nabeth et al. 2004b, Papa et al. 2002a, Papa et al. 2002b, Papa et al. 2004, Sheikh et al. 2005, Williams et al. 2000).

Das CCHFV wird durch Zecken (besonders durch Hyalomma marginatum marginatum), (Watts 1988) übertragen. Die Transmission durch infiziertes Blut und Körperflüssigkeiten bzw. Gewebe von Tieren und Menschen ist ebenfalls bewiesen (Swanepoel et al. 1985, van de Wal et al. 1985, van Eeden et al. 1985).

Nach einer Inkubationszeit von einem Tag bis zu einer Woche folgt eine prähämorrhagische Phase mit Fieber, Kopfschmerzen und Erbrechen, die dann ab dem 3.-5. Tag in eine hämorrhagische Verlaufsform übergehen kann. Diese kann durch Multiorganversagen zum Tod führen oder nach spätestens 20 Tagen ausheilen. Die Symptome können individuell stark variieren (Weber,Mirazimi 2008). Insgesamt schwankt die Mortalität zwischen 30-70\% (Baskerville et al. 1981, Schwarz et al. 1997, Swanepoel et al. 1989)

\subsubsection{Rift-Valley-Fever-Virus (RVFV)}

Das RVFV konnte 1931 zum ersten Mal aus moribunden Schafen in Kenia isoliert werden (Daubney et al. 1931). Inzwischen ist das RVFV auf dem gesamten afrikanischen Kontinent südlich der Sahara verbreitet und gelangte im Jahr 2000 über Saudi Arabien und Yemen auf den asiatischen Kontinent. Die jüngsten Ausbrüche wurden aus Madagaskar 2008 (Corso et al. 2008) und aus Südafrika im Juli 2010 (228 Fälle, 26 Tote) (NICD 2010) gemeldet und im April 2011 (27 Fälle, keine Toten)(NICD 2011). 
Obwohl RVFV zum Genus der Phleboviren, Familie der Bunyaviridae, gehört, wird es nicht von Sandfliegen (Phlebotomen), sondern von verschieden Stechmücken (Culexund Aedesarten) übertragen. Außerdem kann es zur Aerosolübertragung und zur Infektion durch kontaminiertes Blut oder Gewebe von Tieren kommen. Eine Mensch-zuMensch-Übertragung ist bisher nicht bekannt.

Nach einer Inkubationszeit von 2-6 Tagen treten die ersten typischen Symptome auf: Fieber, Myalgien, retro-orbitale Schmerzen, Photophobie und Ikterus. Hämorrhagien oder Enzephalitiden entwickeln sich bei weniger als 1\% der Patienten, von denen 50\% versterben.

In Experimenten hat sich Ribavirin in Kombination mit Interferon bei RVFV-infizierten Mäusen, Ratten oder Affen als effizient erwiesen (Peters et al. 1986). Bislang ist diese Therapie noch nicht an infizierten Patienten getestet worden.

Es wurde ein effektiver, hoch immunogener und günstiger inaktivierter Impfstoff entwickelt, der sich in Tierversuchen jedoch als teratogen erwies (Davies 2006). Neue Hoffnungen ruhen deshalb auf einem Klon des RVFV, dem Klon 13, der sich nicht nur als hoch immunogen in Schafen und Ziegen erwiesen hat (Muller et al. 1995), sondern bisher auch keine teratogene Wirkung zeigte (Hunter,Bouloy 2001).

\subsubsection{Genom und Strukturaufbau der Bunyaviridae}

Die Bunyaviridae sind eine der größten Virenfamilien und umfassen mehr als 350 Mitglieder weltweit. Sie wurden unterteilt in fünf verschiedene Genera: Phlebovirus, Orthobunyavirus, Hantavirus, Tospovirus und Nairovirus (Fauquet,Fargette 2005), zu denen auch das CCHFV und das RVFV zählen. Die Viren dieser Familie sind behüllte, sphärische (-)ss-RNA-Viren mit einem Durchmesser von ca. 100nm.

Das Genom der CCHFV setzt sich aus drei Segmenten mit Negativ-Strang-Orientierung zusammen, die als S-, M- und L-Segment bezeichnet werden. Wie alle Bunyaviren besitzt auch das CCHFV vier Strukturproteine: die zwei Hüllproteine Gc und Gn, die auf dem MSegment kodiert sind, dem Nukleokapsidprotein $N$ auf dem S-Segment und einer RNSabhängigen Polymerase $L$, die auf dem L-Segment kodiert wird. Außerdem wurden auf den S- und M-Segmenten noch Nicht-Strukturproteine (NSs, NSm) gefunden (Altamura et al. 2007, Blakqori et al. 2007, Fuller et al. 1983, Pollitt et al. 2006) (s. Abb. 1.3). 


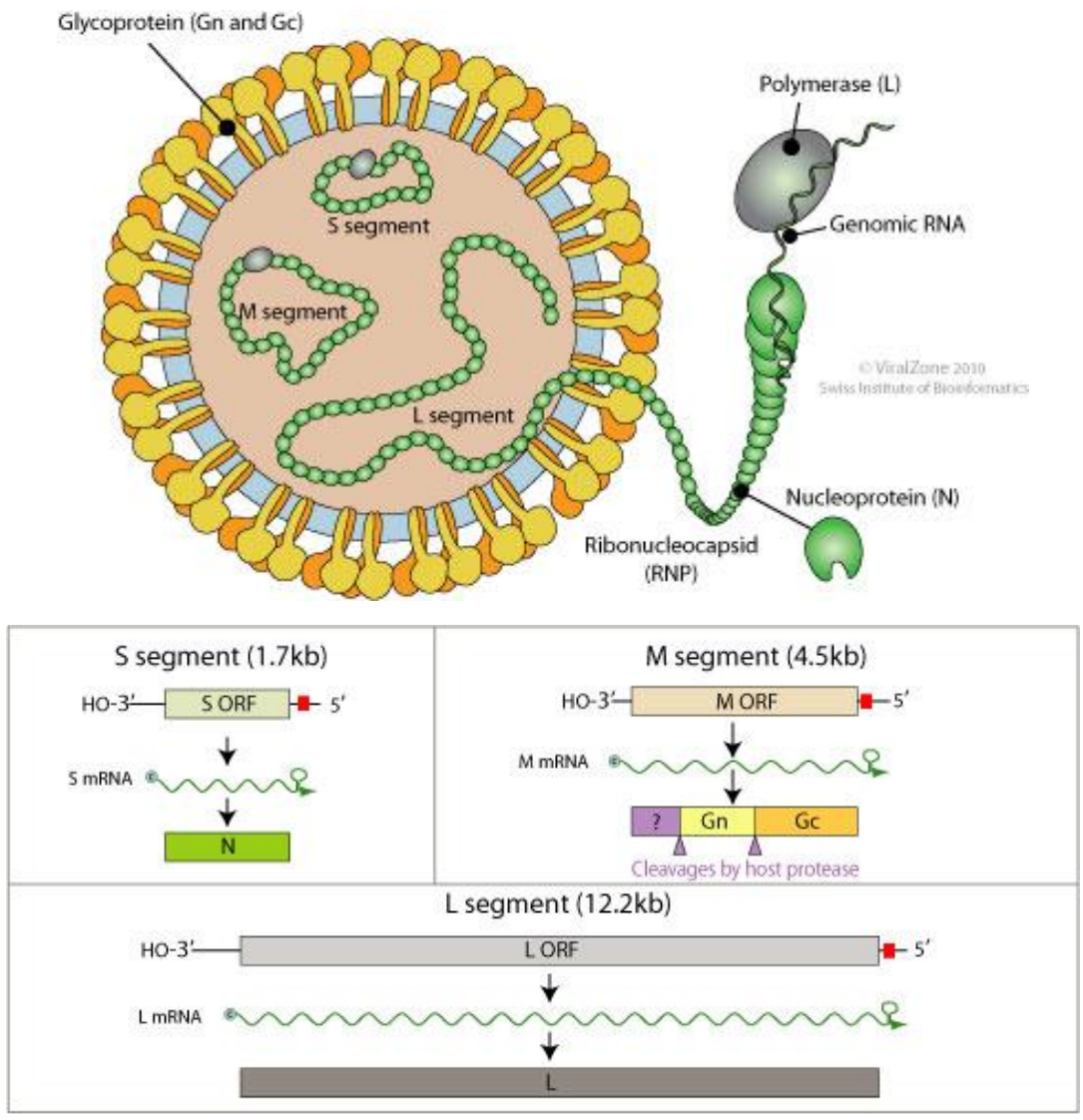

Abb. 1.3: Struktur der Bunyaviridae und Genom der CCHFV oben: Darstellung der Struktur eines Viruspartikels, unten: Darstellung des CCHF-Virusgenoms mit 3 negativen RNS-Segmenten: S- , M- , L-Segment (Expasy 2011).

Bei dem RVFV zeigen das L- und M- Segment eine negative Polarität. Sie kodieren für die RNA-Polymerase und die Glykoproteine Gn und Gc. Das S-Segment ist ambisense organisiert, sodass in $5^{\prime}$-Richtung das Nukleoprotein $\mathrm{N}$ und in $3^{\prime}$-Richtung ein NichtStrukturprotein NSs kodiert werden (Giorgi et al. 1991) (s. Abb. 1.4).

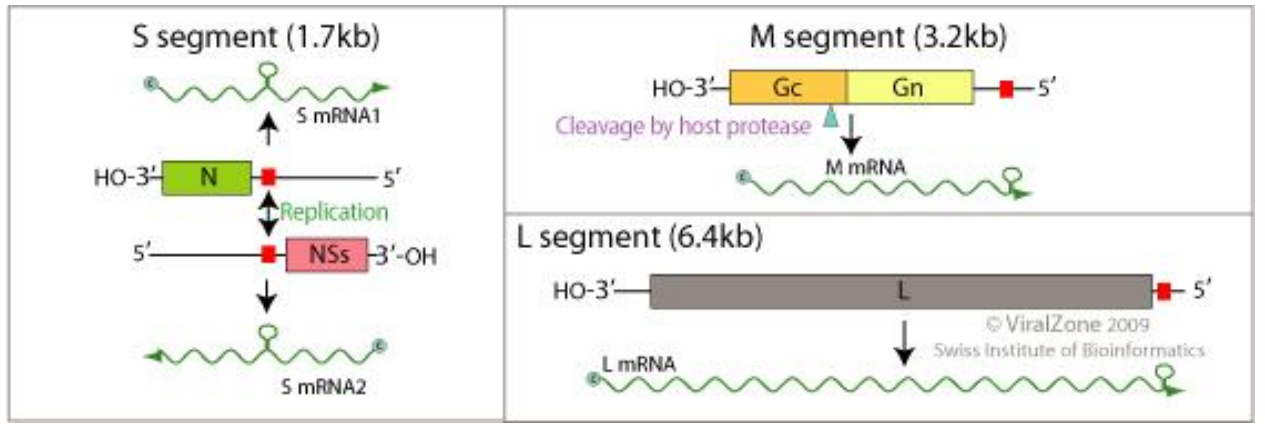

Abb. 1.4: Genom des RVFV Darstellung des RVFV-Virusgenoms mit den negativen RNS-Segmenten: $M$ und $\mathrm{L}$ und dem S-Segment mit ambisense Orientierung (Expasy 2011). 


\subsubsection{Flaviviridae}

\subsubsection{Gelbfieber-Virus (YFV)}

Die ersten historisch gesicherten Fälle von Gelbfieber traten 1648 in Mexiko auf. Ursprünglich wurde das YFV vom afrikanischen Kontinent über den Sklavenhandel nach Amerika importiert. Heute ist YF in Afrika und Südamerika endemisch.

Im Zeitraum zwischen Dezember 2008 bis April 2009 kam es in Brasilien zu dem jüngsten gemeldeten Ausbruch, bei dem 48 Personen an YF erkrankten und davon 20 Menschen (CDC 2010) verstarben.

Erstmals gelang es im Jahr 1900 Walter Reed zu beweisen, dass YF durch die Stechmücke Aedes aegypti übertragen wird (Bean 1983). Es sind darüber hinaus weitere Vektoren bekannt: Aedes africanus (in Afrika), Stechmücken der Gattungen Haemagoggus und Sabethes (in Südamerika) (Barrett,Higgs 2007). Es sind keine Fälle von Mensch-zuMensch-Übertragung oder nosokomialer Übertragung bekannt.

Drei bis sechs Tage nach dem Mückenstich treten Fieber, Übelkeit, Kopf- und Gliederschmerzen als erste Symptome auf. Nach einer kurzzeitigen Besserung kommt es entweder zur Ausheilung oder zur Remission mit einem Wiederanstieg des Fiebers, Hämatemesis, Hypotonie, Bauchschmerzen, Nierenversagen und Leberversagen mit Ikterus. Ungefähr 50\% der Patienten, die in die zweite Phase eintreten, versterben an Organversagen und Schock. Insgesamt beträgt die Mortalität der YF-Infektionen 20\% (Monath 2001).

YF ist das einzige VHF, für das bisher ein Impfstoff entwickelt werden konnte. Für die erstmalige Entwicklung dieses Lebendimpfstoffes (Stamm 17D) wurde Max Theiler im Jahre 1951 mit dem Nobelpreis ausgezeichnet. Bei einer Infektion mit YFV ist bisher keine effektive Therapie bekannt, sodass lediglich unterstützende Maßnahmen wie Elektrolyt- und Flüssigkeitsersatz oder Bluttransfusionen unternommen werden können.

\subsubsection{Dengue-Virus (DENV)}

Das Dengue-Virus (DENV) ist 1944 von Albert Sabin und J. Schlesinger als Krankheitserreger des Dengue-Fiebers (DF) identifiziert worden. Historische Berichte über das DF datieren mehr als 200 Jahre zurück, 1779 in Jakarta, Indonesien und Kairo, 
Ägypten. Die erste im englischsprachigen Raum berichtete Epidemie fand 1780 in Philadelphia, USA, statt, weitere 1934 in Florida und 1945 in New Orleans (Tsai TF et al. 2005). Große Epidemien mit hämorrhagischem Schock (Dengue fever virus haemorrhagic shock syndrome - DHSS) liefen in Australien 1897, in Griechenland 1928 und in Formosa $1921 \mathrm{ab}$.

Inzwischen ist DENV in über 100 Ländern in Asien und Afrika, am Pazifik und in der Karibik (Freedman et al. 2006) endemisch und laut World Health Organization (WHO) kommt es jährlich zu 50-100 Millionen Infektionen, von denen 500.000 Patienten ein hämorrhagisches Dengue-Fieber (DHF) entwickeln, von denen 2,5\% versterben (WHO 2009b). Dengue gehört zur Familie der Flaviviridae und wird antigenetisch in vier Serotypen unterteilt: DENV 1-4 (Halstead 1988, Webster et al. 2009), die durch die Stechmücke Aedes aegypti oder Aedes albopictus übertragen werden (Halstead 2007). In einigen Regionen kommen noch weitere Mückenarten in Frage: Aedes polynesiensis (Polynesien), Aedes scutellaris (Südpazifik) (Mackerras 1946, Rosen et al. 1954). Eine Mensch-zu-Mensch-Übertragung ist bisher nicht bekannt geworden.

Das DENV kann zwei Ausprägungen einer Erkrankung verursachen: Dengue-Fieber (DF) oder das hämorrhagische Dengue-Fieber (DHF), das in seiner schwersten Form in das Dengue-Schock-Syndrom (DSS) übergehen kann.

Die klinischen Symptome des DF, das hauptsächlich bei älteren Kindern und Erwachsenen beobachtet wird, beginnen mit einem abrupten Fieberanstieg nach einer 4-7 tägigen Inkubationszeit. Häufig wird das Fieber von Kopfschmerzen und starken retro-orbitalen Schmerzen begleitet (Endy et al. 2002, Kabra et al. 1999). Die schweren Muskel- und Gliederschmerzen, die bei einigen Patienten auftreten, erklären den historischen Namen „break bone fever" („Knochenbrecherfieber“) (McBride 1999). Bei schwerem Verlauf lassen sich Hautausschläge und Petechien erkennen. Haut- und Schleimhautblutungen können sowohl bei schweren als auch bei milden Verläufen beobachtet werden (Tsai CJ et al. 1991).

Das DHF, das meist Kinder unter 15 Jahren befällt, beginnt wie das DF, verschlechtert sich dann aber nach wenigen Tagen dramatisch. Es wird charakterisiert durch 
Hämorrhagien, Thrombozytopenie und Organschädigung, evtl. Krampfanfälle und allgemeine Zeichen eines Schocks (DSS).

Es wird vermutet, dass es bei einer Zweitinfektion durch eine sogenannte infektionsverstärkende Antikörperbildung (engl: antibody-dependent enhancement of infection) zu den schweren Verläufen kommt (Pierson,Diamond 2008). Nachdem das DF ausgeheilt ist, bleibt nur eine Immunität gegen den Serotypen, der diese Infektion verursacht hat. Sie bietet keinen Schutz vor einer Infektion mit anderen DENVSerotypen. Es gibt allerdings auch Hinweise darauf, dass die Serotypen aus verschiedenen Genotypen bestehen, die mit unterschiedlichen Virulenzen assoziiert sind (Leitmeyer et al. 1999, Sanchez,Ruiz 1996).

\subsubsection{Genom und Strukturaufbau der Flaviviridae}

Die Familie der Flaviviridae setzt sich zusammen aus den Genera: Herpacivirus, Pestvirus und Flavivirus, zu denen auch das DENV und YFV gehören.

Flaviviren besitzen einen Durchmesser von 40 bis $50 \mathrm{~nm}$. Das sphärische Kapsid ist von einer Hüllmembran umgeben. Die einzelsträngige RNS liegt in Plusstrangorientierung vor und weist am 5'-Ende eine Cap-Struktur auf. Die Strukturproteine C, PrM und E bilden die Hüllmembran und zwei Oberflächenantigene. Die Nicht-Strukturproteine NS1, NS2A, NS2B, NS3, NS4A, NS4B und NS5 kodieren für die RNS-Polymerase und eine ProteaseFunktion für das virale Polyprotein (Chambers et al. 1990) (s. Abb. 1.5). 


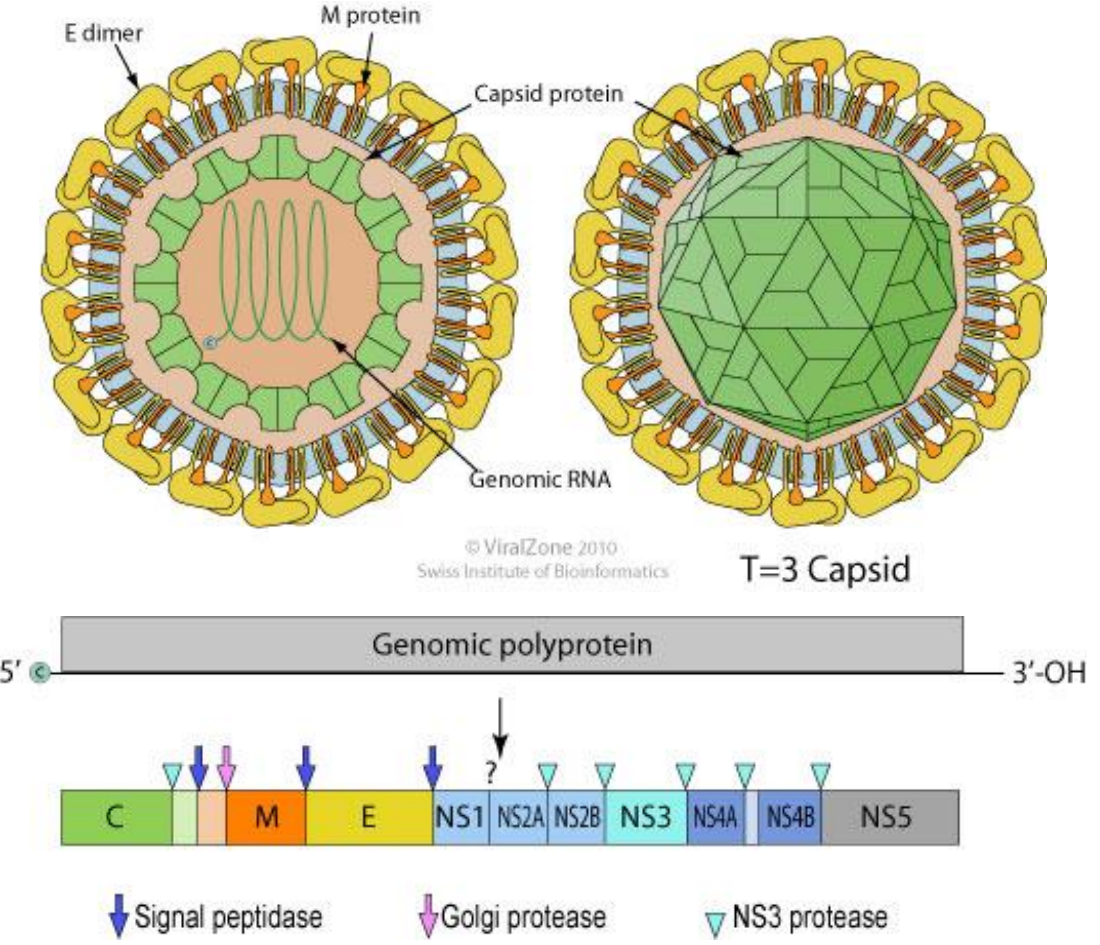

Abb. 1.5: Struktur und Genom der Flaviviridae oben: Darstellung der Struktur eines Viruspartikels, Durchmesser: $50 \mathrm{~nm}$, unten: Darstellung des Virusgenoms mit einem linearen, einsträngigen RNS-Segment, das ein Polyprotein kodiert (Expasy 2011).

\subsubsection{Filoviridae}

\subsubsection{Ebola-Virus (EBOV)}

Das EBOV wurde 1976 bei Epidemien in Yambuku, in der Demokratischen Republik Kongo, (318 Fälle, 280 Tote) und im Sudan (284 Fälle, 151 Tote) entdeckt (Bardi 2002). Weltweite Aufmerksamkeit bekam das Virus erst 1995 bei einem Ausbruch in Kikwit in der Demokratischen Republik Kongo (315 Fälle, 244 Tote). Auch die letzten großen Ausbrüche des EBOV wurden in der Demokratischen Republik Kongo im Dezember 2008 bis Februar 2009 (32 Fälle, 15 Tote) und im Dezember 2007 bis Januar 2008 (149 Fälle, 37 Tote) gemeldet (CDC 2011). Bisher ist das EBOV in Afrika und das verwandte Restonvirus (EBOVRE) in Südostasien beobachtet worden.

Das EBOV gehört, genauso wie das MARV, zu der Familie der Filoviridae und lässt sich in vier Spezies unterteilen: (1) Sudan Ebolavirus (EBOVS), (2) Zaire Ebolavirus (EBOVZ), (3) Cote d'Ivoire Ebolavirus (EBOVIC), (4) Reston Ebolavirus (EBOVRE). Eine fünfte Spezies wurde bei einem Ausbruch in Uganda 2007 beschrieben: Bundibugiyo Ebolavirus (BDBV) (Towner et al. 2008, Wamala et al. 2010). Außerdem ist 2011 von Negredo et al. ein 
Ebola-verwandtes Filovirus, das Lloviu-Virus (LLOV) in Langflügelfledermäusen (Miniopterus schreibsii) aus Asturien detektiert worden (Negredo et al. 2011).

Das natürliche Reservoir und Vektoren der EBOV sind unbekannt, doch es sind Viren in Fruchtfledermäusen (Hypsignathus monstrosus, Epomops franqueti, Myonycteris torquata) in Afrika nachgewiesen worden (Leroy et al. 2005, Swanepoel et al. 1996). Beobachtete Fälle, bei denen eine Infektion auf den Menschen stattgefunden hat, sind meist durch Kontakt mit Blut infizierter Tiere zu erklären (Leroy et al. 2009). Aerogene Transmission, Schmierinfektion oder neonatale Transmission sind ebenfalls möglich.

Die Inkubationszeit wird mit 2-21 Tagen angegeben (Seiler 2008). Zu den ersten Symptomen gehören hohes Fieber, Kopf- und Gliederschmerzen und abdominale Beschwerden. Bereits früh treten Blutungen in den Konjunktiven oder Schleimhäuten auf. Hämorrhagien im Gastrointestinaltrakt und in der Lunge sind häufig. Die Mortalitätsrate beträgt zwischen $50-90 \%$. Der Tod tritt nach fünf bis neun Tagen durch schwere Blutungen oder Schock ein (Formenty et al. 1999, Richards et al. 2000, WHO 1978).

Ein Impfstoff für EBOV ist bisher noch nicht produziert worden. Es laufen jedoch Versuche für eine Vakzine, die auf einem rekombinanten vesikulären Stomatitis-Virus (VSV) basiert, das ein Glykoprotein (GP) von Filoviren exprimiert (Geisbert et al. 2009). Davon abgesehen sind erste Therapieansätze für EBOZ veröffentlicht worden. Mit Hilfe von siRNS-Molekülen (eng: "small interfering RNA" = kurze interferierende RNS) konnte die Virusvermehrung bei mit EBOVZ infizierten Meerschweinchen aufgehalten werden (Geisbert et al. 2010). In der Praxis beschränkt sich die Therapie bei einer EBOV-Infektion beim Menschen auf unterstützende Maßnahmen.

\subsubsection{Marburg-Virus (MARV)}

Werner Slenczka, Rudolf Siegert und Dietrich Peters gelang es 1967 in Marburg erstmals, das MARV aus Personen zu isolieren, die sich beim Umgang mit Grünen Meerkatzen (Cercopithecus aethiops) aus Uganda infiziert hatten. Darauf folgend wurde das MARV bei Personen in Angola, Demokratische Republik Kongo, Kenia und Südafrika nachgewiesen. 
Genau wie das EBOV gehört das MARV zur Familie der Filoviridae. Auch für MARV gelten Fledermäuse als Vektoren, seitdem MARV-Sequenzen in Fruchtfledermäusen (Rosettus aegypticus) und insektenfressenden Fledermäusen (Rhinolophus eloquens, Miniopterus inflatus) nachgewiesen worden (Swanepoel et al. 2007, Towner et al. 2009).

Bei engem Kontakt zu infizierten Personen kann es zu einer Mensch-zu-MenschÜbertragung durch Kontakt mit kontaminierten Körperflüssigkeiten, neonatale Transmission oder durch Tröpfcheninfektion kommen.

3-14 Tage nach der Infektion treten hohes Fieber, Kopfschmerzen und Myalgien ein. Makulopapulöse Ausschläge sind, wie bei EBOV, an den Schleimhäuten frühe Symptome. Häufige Komplikationen sind Hämorrhagien. Die Mortalität beim MARV ist mit $30 \%$ jedoch etwas niedriger als bei EBOV (Gear et al. 1975, Slenczka 1999, Smith et al. 1982). Bisher ist kein Impfstoff gegen eine Infektion mit MARV vorhanden. Doch es ist eine Vakzine entwickelt worden, die in den Tierversuchen bereits einen effektiven Schutz gegen EBOVZ, EBOVS, EBOVCI und MARV aufwies. (s. Kap. 1.2.4.1, S.13) In der Praxis beschränkt sich die Therapie bei einer MARV-Infektion, wie bei EBOV (s. Kap. 1.2.4.1, S.13), bis jetzt auf unterstützende Maßnahmen.

\subsubsection{Genom und Strukturaufbau der Filoviridae}

Zu den Filoviridae gehören Marburg- und Ebolaviren. Die Virionen der Filoviren haben eine pleomorphe, fadenförmige Gestalt (lat: „filum“= Faden). Während die Länge variabel sein kann (MARV: 665nm, EBOV: 804nm), haben die Partikel einen konstanten Durchmesser von 80nm. Die Filamente bestehen aus einem helikalen Nukleokapsid, das von einer Membranhülle umgeben ist.

Die einzelsträngige, nichtsegmentierte RNA liegt in Negativstrangorientierung vor (EBOV: 18957bp, MARV: 19099bp) (Modrow et al. 2003). An den 3'- und 5'-Enden befinden sich nichtkodierende Sequenzen und dazwischen das Nukleoprotein (NP), die viralen Proteine (VP40, VP35, VP30) und die RNA-Polymerase, die das Nukleokapsid bilden. Außerdem gibt es Glykoproteine (GP) zur Fusion der viralen Membran mit der Membran der Wirtszelle und ein weiteres Polypeptid, VP24, das mit der Membran assoziiert ist (s. Abb. 1.6). 


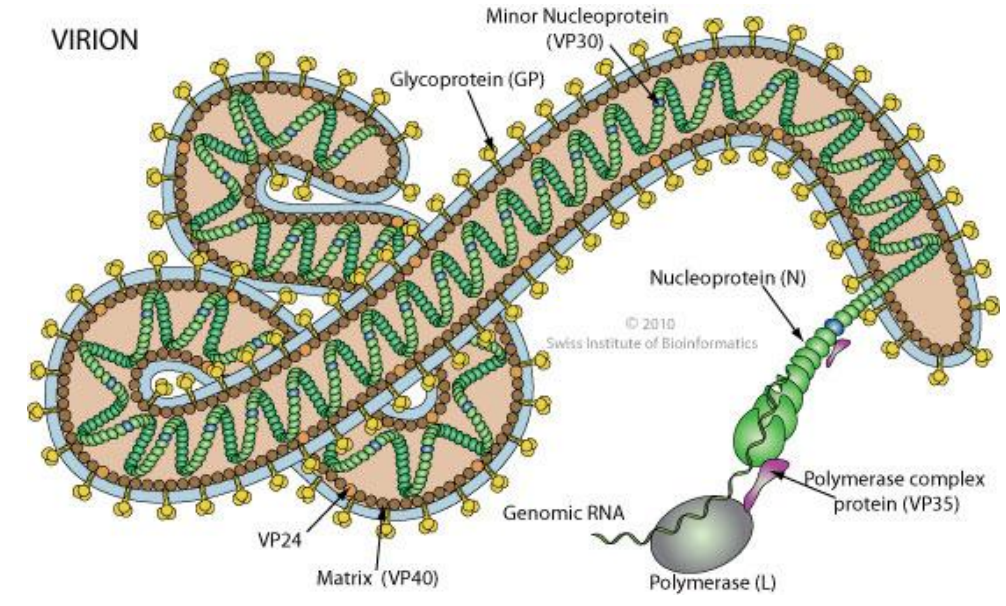

$(-)$ strand RNA genome

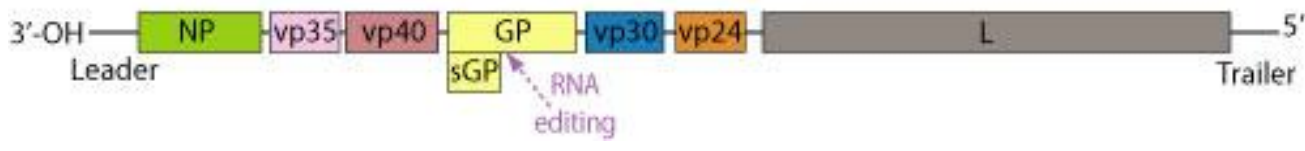

Abb. 1.6: Struktur und Genom der Filoviridae oben: Darstellung der Struktur eines fadenförmigen Viruspartikels, unten: Darstellung des Virusgenoms mit einem linearen, einsträngigen RNSSegment, das ein Polyprotein kodiert (Expasy 2011).

\subsection{Bestehende Diagnostikverfahren für hämorrhagische Fieberviren}

Um eine Virusinfektion nachzuweisen, gibt es verschiedene Methoden, die zu unterschiedlichen Zeitpunkten nach der Infektion angewendet werden können. Zum besseren Verständnis ist in Abb. 1.7 das sogenannte „Diagnostische Fenster“ dargestellt. Nach einer Virusinfektion kommt es zuerst zu einer Vermehrung der Viren und damit zu einem erhöhten Titer im Blut (Virämie). In dieser Phase kann das Virusgenom direkt detektiert werden. Verfahren, die hierfür verwendet werden, sind die PCR-Technik oder ein gegen virale Antigene gerichteter ELISA. Die Probenentnahme gestaltet sich recht schwierig, da diese virämische Phase nur von kurzer Dauer ist und die Symptome einer Infektion meist erst später auftreten.

Durch die Immunantwort werden im Verlauf der Erkrankung Antikörper gebildet. Erst kommt es zu einem Anstieg der IgM- und später zu einem Anstieg der IgG-Antikörper. Mittels EIA (engl: enzyme immuno assay, deut: Enzymimmunoassay) basierender Technologien inklusive des ELISA und des sog. IFT (İmmunfluoreszenzțest) können diese Antikörper im Serum detektiert werden und Rückschlüsse auf eine stattgefundene Infektion geben. 


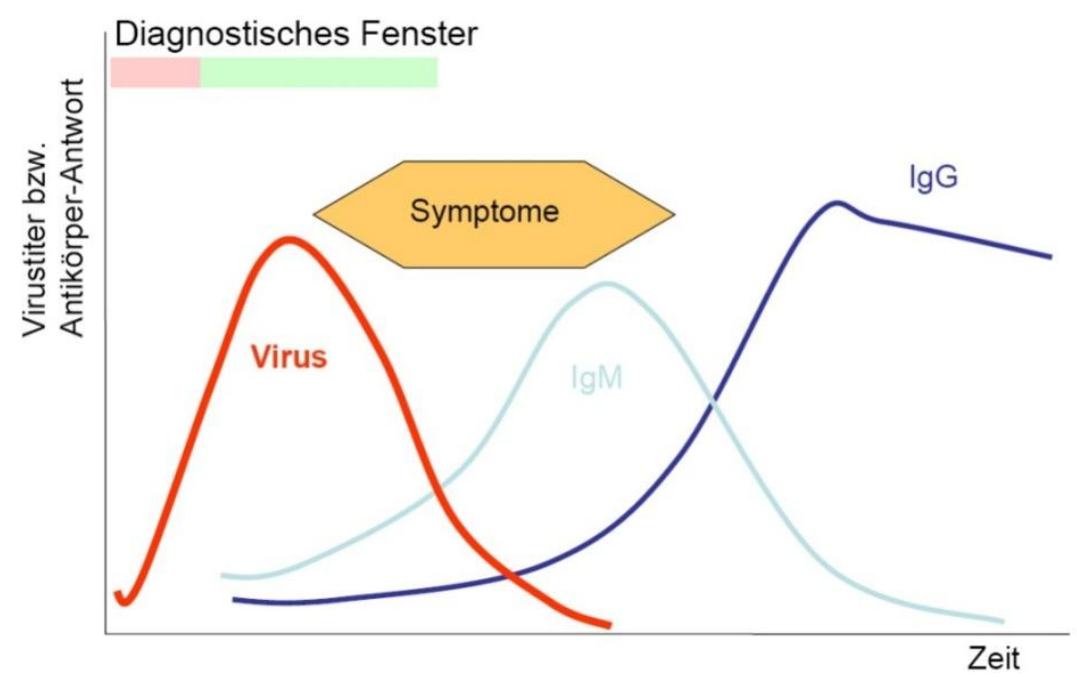

Abb. 1.7: Diagnostisches Fenster. Darstellung des Virustiters bzw. der Antikörper-Antwort nach Infektion mit einem Erreger (Molekulare Virologie Heidelberg 2010).

Die Diagnose von HFV basiert auf der Kombination von Virusisolation (Digoutte et al. 1992), molekularen (z.B. RT-PCT)(Drosten et al. 2002a, Palacios et al. 2006, Sudiro et al. 2001) und serologischen Nachweisverfahren (z.B. ELISA) (Saluzzo,Le Guenno 1987). In der akuten klinischen Phase sind die Antigendetektion und die qRT-PCR die geeignetsten Verfahren. Jedoch geht die VHF-Diagnostik mit bestimmten Herausforderungen einher: (1) Aufgrund eher unspezifischer Symptome müssen die Proben bei Verdacht auf VHF auf mehrere HFV getestet werden. (2) Um das gesamte diagnostische Fenster abzudecken, müssen molekulare und serologische Methoden miteinander kombiniert werden. (3) Bei einem Ausbruch eines HFV kann es zu einer schnellen Verbreitung der Infektion kommen, sodass eine große Anzahl an Proben gleichzeitig getestet werden muss.

Ein ideales Verfahren zur Detektion von HFV sollte deshalb möglichst (i) zeitsparend sein (Burger et al.),(ii) eine hohe Spezifität, (iii) eine hohe Sensitivität (Sudiro et al. 2001), (iv) eine gute Reproduzierbarkeit (Sudiro et al. 2001) und (v) einen hohen Probendurchlauf mit (vi) simultaner Detektion eines ganzen Spektrums verschiedener Viren aufweisen. Der CBA ermöglicht den gleichzeitigen Nachweis von multiplen Analyten und hat sich als sensitives, präzises und effizientes Mittel zur Virusdiagnostik erwiesen (Bellisario et al. 2001). In der VHF-Diagnostik ist bisher jedoch nur ein CBA für den Antikörpernachweis für DENV entwickelt worden (Shu,Huang 2004). Ein CBA, der im Multiplex-System 
mehrere HFV gleichzeitig auf molekularer und serologischer Ebene detektiert, wäre deshalb wünschenswert.

\subsection{Cytometric Bead Array (CBA)}

\subsubsection{Aufbau und Prinzip des Durchflusszytometers}

Die Durchflusszytometrie ist ein Messverfahren, mit dem verschiedene physikalische Eigenschaften einzelner Partikel (z.B. Zellen oder Beads (deut.: Mikrokugeln) in einem Flüssigkeitsstrom gleichzeitig gemessen und analysiert werden können. Entwickelt wurde die fluoreszenzbasierte Durchflusszytometrie 1968 von Wolfgang Göhde (Goehde,Dittrich 1971) an der Wilhelms-Universität Münster und ist seitdem ein Standardmessverfahren in der Immunologie, Onkologie und allgemeinen Forschung.

Die Technologie beruht auf der Messung von optischen Signalen, welche die Partikel, beim Passieren eines Laserstrahls emittieren. In einer laminaren Strömung werden die zu untersuchenden Partikel hintereinander aufgereiht und mit verschiedenen Laserstrahlen unterschiedlicher Emissionsmaxima, z.B. 585nm oder 660nm, angestrahlt (s. Abb. 1.9). Wenn ein Partikel das einfallende Laserlicht ablenkt, kommt es zu Lichtstreuung (Tyndall-Effekt). Dabei hängt das Maß der Streuung von der Größe und der internen Komplexität ab. Das Vorwärtsstreulicht (Forward Scatter, FSC) ist proportional zur Zell- oder Partikeloberfläche, während das Seitwärtsstreulicht (Side Scatter, SSC) proportional zur internen Komplexität bzw. Zellgranularität ist. Die gleichzeitige Messung und deren korrelierte Darstellung am Computer erlauben eine Differenzierung von Zelltypen in einem heterogenen Gemisch. 


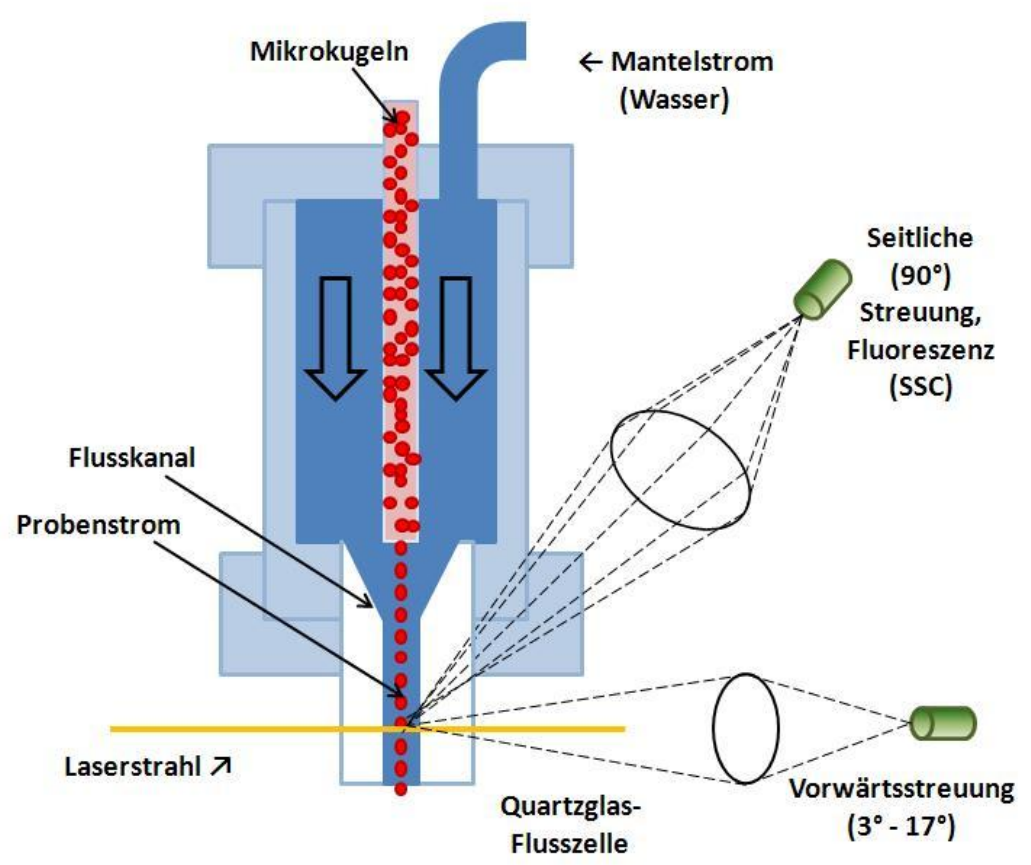

Abb. 1.8: Prinzip der Durchflusszytometrie

Durch Markierung bestimmter Strukturen mit Fluoreszenzfarbstoffen kann die Identifizierung eines bestimmten Zelltyps erfolgen. Dabei sollten für die gleichzeitige Messung mehrerer Fluoreszenzfarbstoffe beachtet werden, dass die Farbstoffe zwar gleiche Absorptionsspektren besitzen dürfen, sich jedoch in ihren Emissionsspektren unterscheiden sollten.

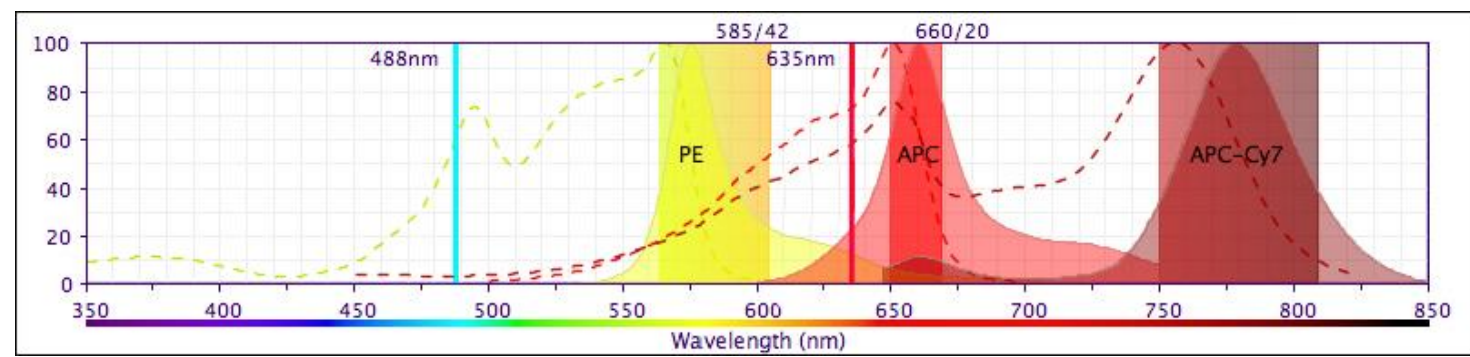

Abb. 1.9: Darstellung der Absorptions- und Emissionsmaxima der verwendeten Fluoreszenzfarbstoffe. Dargestellt sind die Absorptionsmaxima von PE $(480 \mathrm{~nm})$, APC (650 nm), APC-Cy7 (650 nm) als gestrichelte Linien, die Emissionsmaxima von PE (585nm), APC (660 nm), APC-Cy7 (775 nm) als schraffierte Bereiche. Zusätzlich sind die anregenden Laserstrahlen der Wellenlängen von 488 $\mathrm{nm}$ und $635 \mathrm{~nm}$ angegeben. (BD 2011)

\subsubsection{Der Cytometric Bead Array}

Der Cytometric Bead Array (CBA) nutzt fluoreszierende Beads (Mikrokugeln) in der Durchflusszytometrie zur simultanen Analyse in einer einzigen Probe. Es konnte gezeigt 
werden, dass der CBA sogar eine höhere Sensitivität, bessere Reproduzierbarkeit, kürzere Vorbereitungszeit und höhere Datendurchsatzleistung aufweist als bisher verwendete Diagnostikverfahren (Carson,Vignali 1999, Dasso et al. 2002). Ein weiterer Vorteil des CBAs, den man sich besonders in der Diagnose zunutze macht, ist eine gleichzeitige Detektion verschiedener Parameter: Antikörper (IgM, IgG), lösliche Zytokine, virale Antigene und virales Genom.

Der CBA, der in der vorliegenden Arbeit entwickelt wurde, dient dem direkten Nachweis der viralen Genome hämorrhagischer Fieberviren. Die verwendeten Beads (BioPlex$\mathrm{COOH}$-Beads, BioRad Laboratories $\mathrm{GmbH}$, München, Deutschland) besitzen einen Durchmesser von 5,6 $\mathrm{m}$ und sind mit verschiedenen Verhältnissen zweier verschiedener Fluoreszenzfarbstoffe gefüllt (xMap-Technologie), z.B. mit APC und APC-Cy7. Diese Farbstoffe können aufgrund ihrer unterschiedlichen Emissionsspektren (s. Abb.1.11) unterschieden werden. Durch unterschiedliche Verhältnisse dieser beiden Farbstoffe zueinander ist es theoretisch möglich, bis zu 100 Beadpopulationen gleichzeitig zu differenzieren und simultan zu verwenden. In der Praxis scheint die Obergrenze aber eher bei 30 verschiedenen Beadpopulation zu liegen.

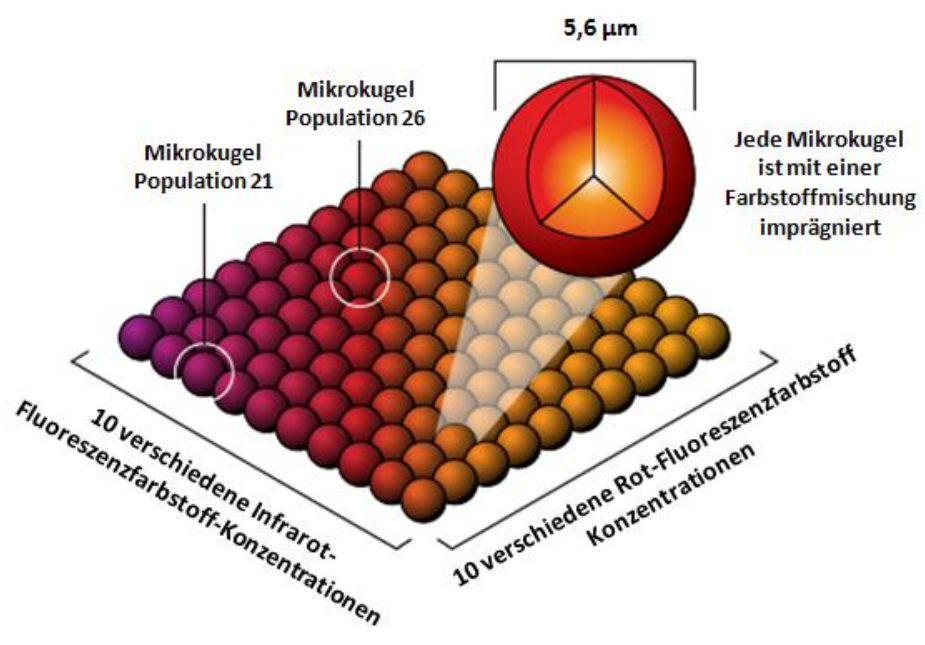

Abb.1.10: Fluoreszenzfarbstoffspektrum der Beads Durch unterschiedliche Mischungen des roten und infraroten Fluoreszenzfarbstoffes können bis zu 100 Beadpopulationen unterschieden werden. Luminex Technology Overview (Panomics 2011) 
Auf ihrer Oberfläche sind die Beads mit Carboxylgruppen beschichtet, die es ermöglichen aminierte Oligonukleotidsonden durch Peptidbindungen kovalent an die Beads zu koppeln. Wenn in einer vorgeschalteten PCR biotinylierte Primer verwendet werden, können diese PCR-Produkte nach Hybridisierung an die beadgekoppelten Sonden mit Hilfe von Phycoerythrin (PE, Fluoreszenzfarbstoff Emissionsmaximum: 585nm), nachgewiesen werden (Armstrong et al. 2000, Deregt et al. 2006, Hindson et al. 2008, Jiang et al. 2006, Oh et al. 2007, Schmitt et al. 2006).

Um die notwendige Sensitivität zu erreichen, die der Sensitivität einer Real-Time-PCR entspricht, ist der Präamplifikationsschritt notwendig. Hierin ähnelt die CBA-Technik der Mikroarray-Technik. Sie besitzt jedoch eine bessere Hybridisierungskinetik, da die Hybridisierung in einer Flüssigphase und nicht an einer festen Oberfläche stattfindet. Multiplex-PCRs mit der Hybridisierung der Amplifikate an spezifische Bead-Sonden sind bereits mehrfach erfolgreich getestet worden (Deregt et al. 2006, Horejsh et al. 2005, Lee et al. 2007).

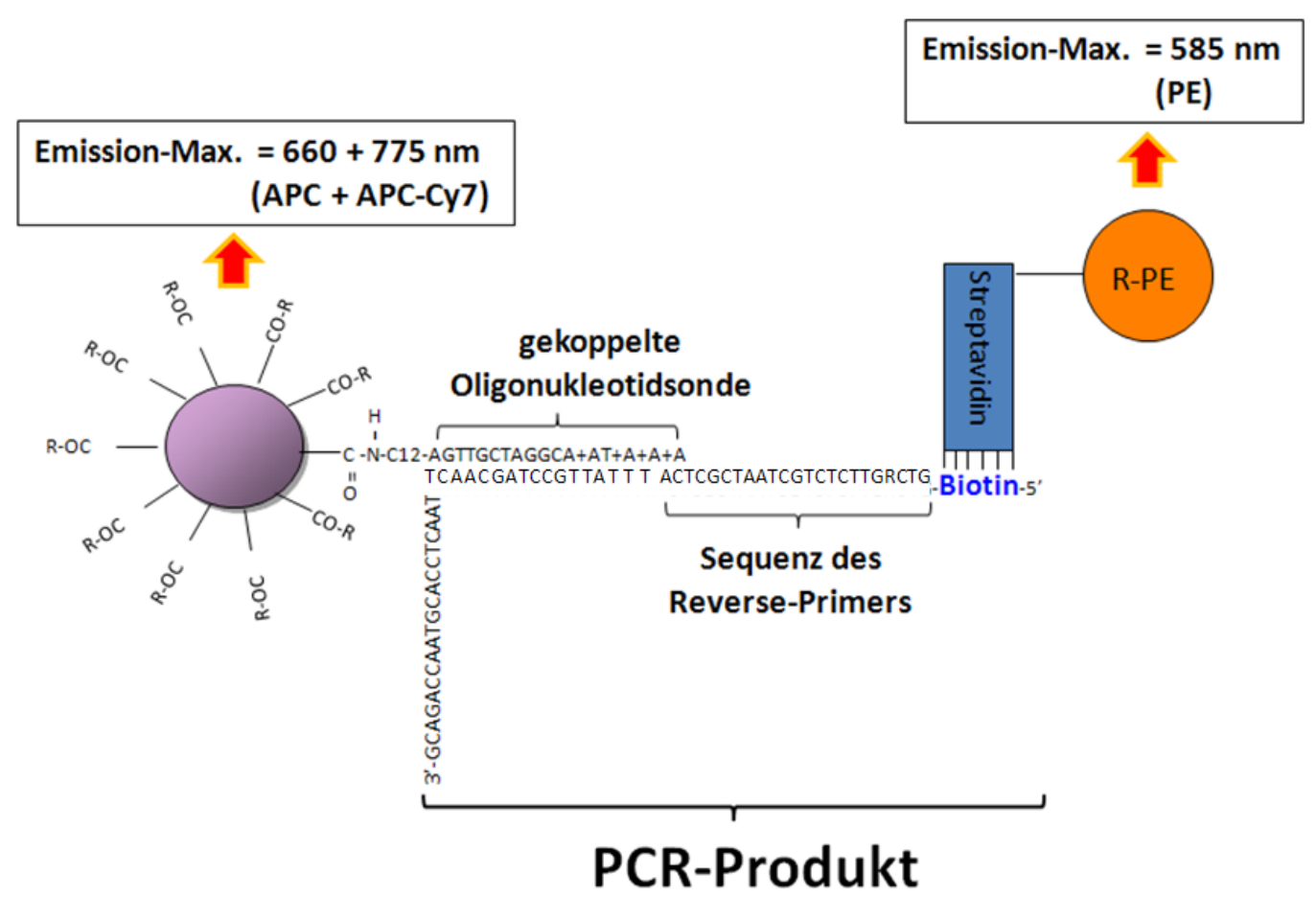

Abb.1.11: Cytometric Bead Array (CBA) Darstellung des Aufbaus eines CBAs: an das carboxylierte Bead ist mit einer Peptidbindung eine Oligonukleotidsonde gekoppelt, die an biotinylierte DNS hybridisiert, im Zytometer nachweisbar durch die Fluoreszenzfarbstoffe: APC (Emissionsmaximum: 660nm), APC-Cy7 (Emissionsmaximum: 775nm) und Strept.-PE (Emissionsmaximum: 585nm) 


\subsection{Zielsetzung und Fragestellung}

Ziel der vorliegenden Arbeit war die Entwicklung eines Cytometric Bead Array zum Nachweis der Virusgenome der acht afrikanischen HFV: LASV, CCHFV, RVFV, EBOVZ, EBOVS, MARV, DENV, YFV.

Um den CBA entwickeln zu können, sollten Multiplex-PCR Mischungen erstellt und optimiert werden.

Für die simultane Amplifikation der verschiedenen afrikanischen HFV musste zuerst eine Multiplex-RT-PCR aufgebaut und mit Hilfe synthetischer RNSStandards optimiert werden. Bei der Erstellung der Primermischungen musste besonders auf die Bildung von Primerdimeren geachtet werden, welche die Sensitivität des Testsystems beeinträchtigen konnten. Diese Optimierung sollte durch eine SYBR-Green-qRT-PCR getestet werden. Um die bestmögliche Sensitivität zu erzielen sollten symmetrische und asymmetrische Amplifikationen verglichen werden und die optimale Primerkonzentration bestimmt werden.

Anschließend sollten aminierte DNS-Sonden an die caboxylierten Beads gekoppelt werden. Diese Kopplung musste mit Fluoreszenz-markierten Oligonukleotidsonden am Durchflusszytometer überprüft werden.

Mithilfe der Sonden sollten die biotinylierten Produkte der Multiplex-RT-PCR an die Beads hybridisiert werden

Zum Schluss musste die Detektion der erfolgreichen Hybridisierung mit Hilfe des Durchflusszytometers (FACS-Canto ${ }^{T M}$ II) durchgeführt werden und die analytische Sensitivität und Spezifität des Verfahrens bestimmt werden. 


\section{Material und Methoden}

\section{$2.1 \quad$ Material}

\subsubsection{Verbrauchsmaterial}

Tab.2.1: Verwendete Verbrauchsmaterialien

\begin{tabular}{|c|c|}
\hline Material & Bezugsquelle/ Hersteller \\
\hline 96 K Microplatte U-Form & Greiner Bio-One GmbH, Frickenhausen, Deutschland \\
\hline Falkonröhrchen (15ml, 50ml) & Sarstedt AG \& Co, Nümbrecht, Deutschland \\
\hline Handschuhe - Latex & Mikroflex Corporation, Wien, Österreich \\
\hline Handschuhe - Nitril & GE Healthcare Europe NV, Brüssel, Belgien \\
\hline Labortücher $(20,5 \mathrm{~cm} \times 20 \mathrm{~cm})$ & Kimberly-Clark Europe Limited, Kings Hill, UK \\
\hline Mikroschraubgefäße $(2,0 \mathrm{ml})$ & Sarstedt AG \& Co, Nümbrecht, Deutschland \\
\hline Parafilm & American National Can, Chicago, USA \\
\hline PCR- Reaktionsgefäße $(0,2 \mathrm{ml})$ & Biozym, Scientific GmbH, Oldendorf, Deutschland \\
\hline $\begin{array}{l}\text { Pipetten mit Spitzen } \\
(1 \mathrm{ml}, 2 \mathrm{ml}, 5 \mathrm{ml}, 10 \mathrm{ml}, 25 \mathrm{ml})\end{array}$ & Greiner Bio-One GmbH, Frickenhausen, Deutschland \\
\hline $\begin{array}{l}\text { Pipettenspitzen mit Filter }(0,1- \\
10 \mu \mathrm{l}, 1,0-100 \mu \mathrm{l}, 101-1000 \mu \mathrm{l})\end{array}$ & Starlab GmbH, Ahrensberg, Deutschland \\
\hline $\begin{array}{l}\text { Pipettenspitzen ohne Filter } \\
(0,1-10 \mu \mathrm{l}, 1,0-100 \mu \mathrm{l}, 101- \\
1000 \mu \mathrm{l})\end{array}$ & Starlab GmbH, Ahrensberg, Deutschland \\
\hline Protein-Lo-bind Tubes $(0,5 \mathrm{ml})$ & Eppendorf AG, Hamburg, Deutschland \\
\hline $\begin{array}{l}\text { Vernichtungsbeutel } \\
(300 \mathrm{~mm} \times 200 \mathrm{~mm})\end{array}$ & Lab Logistic Group GmbH, Meckenheim, Deutschland \\
\hline
\end{tabular}




\subsubsection{Geräte}

Tab.2.2: Verwendete Geräte

\begin{tabular}{|c|c|}
\hline Geräte & Bezugsquelle/ Hersteller \\
\hline Chemidoc $^{\text {TM }}$ XRS System & Bio Rad Laboratories GmbH, München, Deutschland \\
\hline FACS Canto $^{\mathrm{TM}}$ II & BD Biosciences, Heidelberg, Deutschland \\
\hline Gefrierschrank $\left(-20^{\circ} \mathrm{C}\right)$ & Liebherr GmbH, Ochsenhausen, Deutschland \\
\hline Gefrierschrank $\left(-80^{\circ} \mathrm{C}\right)$ & Thermo Scientific, Rockford, USA \\
\hline Gefriertruhe $\left(-140^{\circ} \mathrm{C}\right)$ & Thermo Scientific, Rockford, USA \\
\hline Gelelektrophoresekammer & Invitrogen Corporation, Kalifornien, USA \\
\hline Kühlschrank $\left(5^{\circ} \mathrm{C}\right)$ & Liebherr GmbH, Ochsenhausen, Deutschland \\
\hline LightCycler ${ }^{\circledast} 2.0$ & Roche Diagnostics GmbH, Mannheim, Deutschland \\
\hline Mikrowelle & AFK Elektro Vertriebs GmbH, Düsseldorf, Deutschland \\
\hline Nano Drop ${ }^{\circledR}$ ND-1000 & Thermo Scientific, Rockford, USA \\
\hline \multicolumn{2}{|l|}{ Spektralphotometer } \\
\hline Rotator & Snijders, Tilburg, Niederlande \\
\hline Sterilbank & Heraeus Sepatech GmbH, Osterode, Deutschland \\
\hline SpeedCycler & Analytic Jena, Jena, Deutschland \\
\hline ThermoCycler & Biometra GmbH, Göttingen, Deutschland \\
\hline Ultraschallbad & Bandelin electronic, Berlin, Deutschland \\
\hline Vortex & Bender \& Hobein AG, Zürich, Schweiz \\
\hline \multirow[t]{2}{*}{ Waage } & Satorius, Stedim biotech $\mathrm{GmbH}$, \\
\hline & Deutschland \\
\hline Wippe & Schuett24 GmbH, Göttingen, Deutschland \\
\hline Zentrifuge & Eppendorf AG, Hamburg, Deutschland \\
\hline Zentrifuge (Megafuge 1.0R) & Thermo Scientific, Rockford, USA \\
\hline
\end{tabular}




\subsubsection{Chemikalien}

Tab.2.3: Verwendete Chemikalien

\begin{tabular}{|c|c|}
\hline Substanzen & Bezugsquelle/ Hersteller \\
\hline Agarose & Biozym Scientific GmbH, Oldendorf, Deutschland \\
\hline Albumin Fraktion V (BSA) & Carl Roth GmbH + Co. KG, Karlsruhe, Deutschland \\
\hline Difco $^{\mathrm{TM}}$ Skim Milk & BD Biosciences, Heidelberg, Deutschland \\
\hline $\begin{array}{l}\text { DNS- Längenstandard (ultra- } \\
\text { low-range, 100kbp) }\end{array}$ & Fermentas GmbH, Leon-Rot, Deutschland \\
\hline Ethanol & Merck KG aA, Darmstadt, Deutschland \\
\hline Ethidiumbromid- Lsg. & Carl Roth GmbH + Co. KG, Karlsruhe, Deutschland \\
\hline $\begin{array}{l}\text { Etylendiamintetraessigsäure } \\
\text { (EDTA) }\end{array}$ & $\begin{array}{l}\text { Serva Electrophoresis GmbH, Heidelberg, } \\
\text { Deutschland }\end{array}$ \\
\hline Natriumlaurylsulfat (SDS) & Carl Roth GmbH + Co. KG, Karlsruhe, Deutschland \\
\hline $\begin{array}{l}\mathrm{N} \text {-(3-dimethylaminopropyl)-N- } \\
\text { ethylcarbodiimid (EDAC) }\end{array}$ & Invitrogen $\mathrm{GmbH}$, Karlsruhe, Deutschland \\
\hline $\begin{array}{l}\text { Orange Loading Dye }(6 \mathrm{x}) \\
\text { peqGOLD TriFast }{ }^{\mathrm{TM}} \mathrm{FL}\end{array}$ & $\begin{array}{l}\text { Fermentas GmbH, Leon-Rot, Deutschland } \\
\text { peqLab Biotechnologie GmbH, Erlangen, Deutschland }\end{array}$ \\
\hline Tris & Carl Roth GmbH + Co. KG, Karlsruhe, Deutschland \\
\hline Tween 20 & $\begin{array}{l}\text { Sigma- Aldrich Chemie GmbH, Steinheim, } \\
\text { Deutschland }\end{array}$ \\
\hline
\end{tabular}

\subsubsection{Lösungen, Medien und Puffer}

Tab.2.4: Verwendete Lösungen, Medien und Puffer

\begin{tabular}{|c|c|}
\hline Name & Zusammensetzung \\
\hline Agarosegel [2\%ig] & $\begin{array}{l}\text { 100ml TAE }[1 \times], 2 \mathrm{~g} \text { Agarose, } 5 \mu \mathrm{l} \text { Ethidiumbromid- } \\
\text { Lösung (Endkonzentration } 0,5 \mathrm{ml} / \mathrm{ml} \text { ) }\end{array}$ \\
\hline Ethidiumbromid-Lösung & $10 \mathrm{mg} / \mathrm{ml}$ in $\mathrm{H}_{2} \mathrm{O}$ \\
\hline $\begin{array}{l}\text { (N-morpholino)ethanesulfon- } \\
\text { Säure (Holmes et al.) }\end{array}$ & $0,1 \mathrm{M}, \mathrm{pH} 4,5$ \\
\hline FACS-Flow-Trägerflüssigkeit & $\begin{array}{l}\mathrm{NaCl} \text { Di-Natrium-EDTA, Kaliumphosphat, } \\
\text { Natriumphosphat, Konservierungsmittel }\end{array}$ \\
\hline
\end{tabular}


Probenpuffer [2X] (SDS-PAGE) 2,5ml Tris pH6,8 [0,5M], $2 \mathrm{ml}$ SDS [10\%], $1 \mathrm{ml} \beta-$ Mercaptoethanol, 2,3ml Glycerin [87\%], 2,2 $\mathrm{ml} \mathrm{H}_{2} \mathrm{O}$, 10mg Bromphenolblau

$\operatorname{TAE}[1 \times]$ 40ml TAE $[50 x]$ ad $1960 \mathrm{ml} \mathrm{H}_{2} \mathrm{O}$

TAE $[50 x]$ 242g Tris: 57,1ml Essigsäure, 100ml EDTA pH8,0 $[0,5 \mathrm{M}]$

TGS $[10 X]$ 30,22g Tris, 144,13g Glycin, $1 \mathrm{~g} \mathrm{NaN}$, ad $11 \mathrm{H}_{2} \mathrm{O}$

\subsubsection{Reagenzienansätze}

Tab.2.5: Verwendete Reagenziensätze

\begin{tabular}{ll}
\hline Name & Bezugsquelle/ Hersteller \\
\hline Bio-Plex COOH Beads & Bio Rad Laboratories GmbH, München, \\
Multiplex-RT-PCR-Kit (NoRox-Master) & QIAGEN, Hilden, Deutschland \\
LightCycler ${ }^{\circledR}$ RNA Master SYBR Green I- & Roche, Mannheim, Deutschland \\
Kit & \\
Agilent RNA 6000 Nano Reagents Part I & Agilent, Santa Clara, USA \\
MinElute PCR-Purification-Kit (50) & QIAGEN, Hilden, Deutschland \\
SP6/T7 Transcription-Kit & Roche, Mannheim, Deutschland \\
Turbo-DNA-Free- Kit & Ambion, Austin, USA \\
\hline
\end{tabular}

\subsubsection{Ausgangs-RNS}

Als Matrize für das RT-PCR-Protokoll (s. Kap. 2.2.1.3.3, S.35) wurde ein rekombinanter RNS-Standard mittels in-vitro-Transkription erzeugt. Der hierbei genutzte Vektor, das pCRII-Plasmid, besitzt einen Promotor für die T7-RNS-Polymerase und einen Promotor für die SP6-RNS-Polymerase. Nach Überprüfung der Orientierung der cDNS, die durch TA-Klonierung in den pCRII-Vektor integriert wurde, konnte mittels des SP6/T7 Transkription $^{\mathrm{TM}}{ }^{-K i t}$ von Roche eine RNS transkribiert werden. Diese wurde nach DNaseVerdau mit dem Turbo-DNA-Free ${ }^{T M}{ }_{-K i t}$ von Ambion quantifiziert und für eine 
Standardreihe in den Verdünnungsstufen $10^{7}$ bis $10^{1}$ Moleküle/ $\mu$ l unter Zugabe von tRNS als Carrier aliquotiert.

Für diese Arbeit sind lediglich die RNS-Standards von EBOVS (EBOSNORF UP und EBOSNORF DP) und die RNS-Standards für DENV (DEN-FP und DEN-RP) mittels in-vitroTranskription neu hergestellt worden. (Für eine ausführliche Beschreibung der in-vitroTranskription s. Weidmann et al. von 2003)

Einige der benötigten pCRII-Plasmide für diese Arbeit sind bereits in früheren Projekten der AG Weidmann im Virologischen Institut der Universität Göttingen entwickelt worden. So stammten die RNS-Standard der Filoviren EBOVZ, MARV aus einer Veröffentlichung von Weidmann et al. von 2004, die RNS-Standards des YFV von 2010 (Weidmann et al. 2010) und die RNS-Standards des Phlebovirus RVFV von 2008 (Weidmann et al. 2008). Das CCHFV S-Segment wurde von der AG Weidmann im Rahmen des Projektes „InSan I 0301-V-4303 März 2001 - Juni 2004, Quantitativer Schnellnachweis von Bunyavirdae mittels TaqMan ${ }^{\text {TM }}$-PCR-Technologie" hergestellt.

Für das LASV wurde virale RNS aus Proben vom Bernhard-Nocht-Institut nach der "Acid Guanidinium-Thiocyanate-Phenol-Chloroform-Extraktion"-Methode von Chomczynski und Sacchi (Chomczynski,Sacchi 1987) gewonnen und als Matrize für die PCRAmplifikation verwendet (s. Kap.2.2.1.1, S.31).

Tab. 2.6: Verwendete Standard-Primer

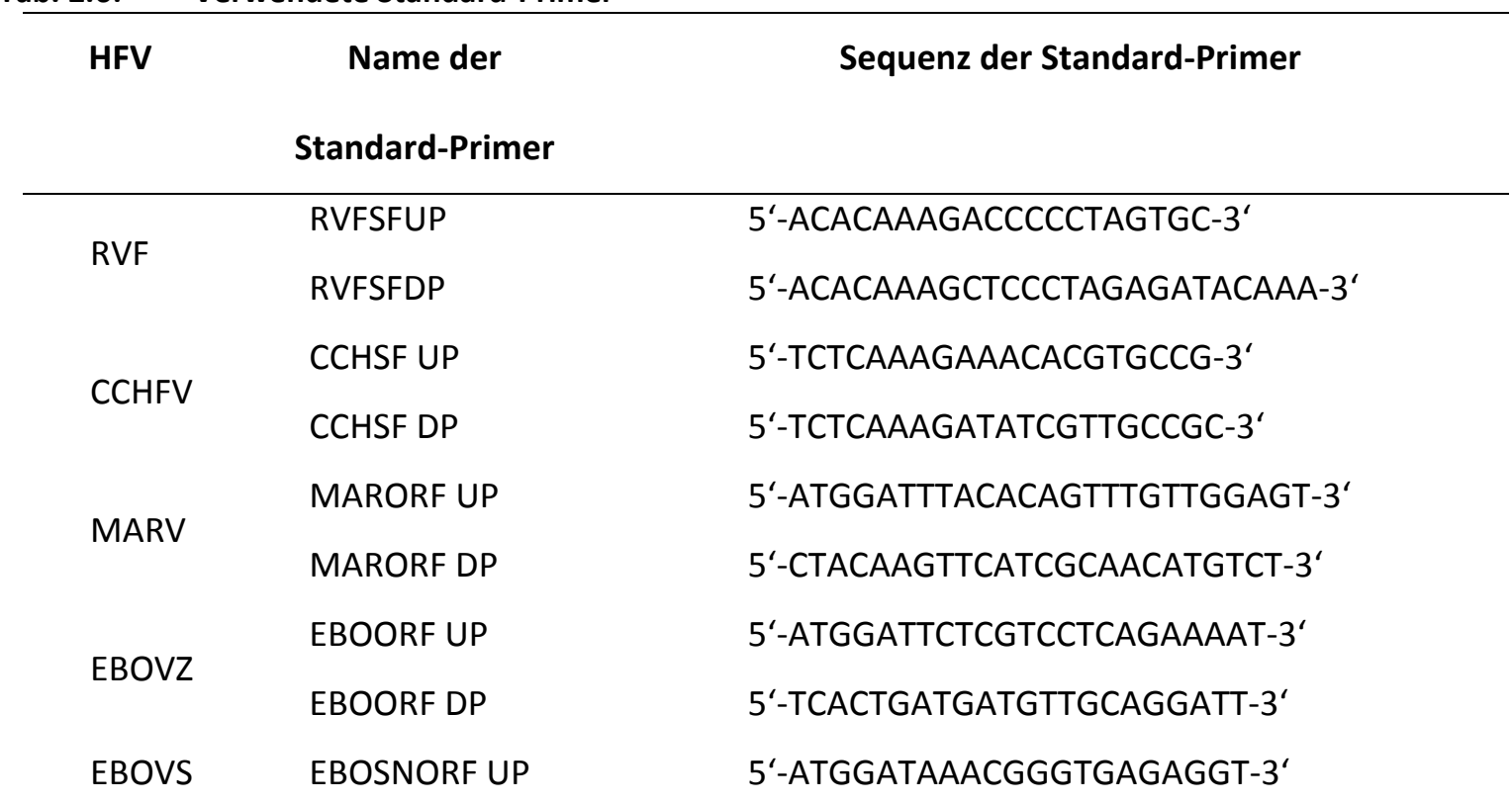




$\begin{array}{lll} & \text { EBOSNORF DP } & 5^{\prime} \text {-TCAGTCATGTTGAAGAACAGCA-3' } \\ \text { YFV } & \text { YFV STD UP } & 5^{\prime} \text {-AGTAAATCCTGTGTGCTAATTGAGG-3' } \\ & \text { YFV STD DP } & 5^{\prime} \text {-AGCCACTGTGAGTTTCAGCA-3' } \\ \text { DENV } & \text { DEN FP } & 5^{\prime} \text {-AAGGACTAGAGGTTAKAGGAGACCC-3' } \\ & \text { DEN RP } & 5^{\prime} \text {-GCGYTCTGTGCCTGGAWTGAT-3' }\end{array}$

\subsubsection{Oligonukleotide}

Tab. 2.7: Verwendete Primer

\begin{tabular}{|c|c|c|c|}
\hline Name der Primer & Sequenz der Primer & $\begin{array}{l}\text { Länge der } \\
\text { Zielregion } \\
\text { in bp }\end{array}$ & Zielstruktur \\
\hline RVF-FP & 5'-TGCCACGAGTYAGAGCCA-3' & 128 & S-Segment \\
\hline RVF-RPptr-Biotin & 5'-Biotin-GTGGGTCCGAGAGTYTGC-3' & & $\begin{array}{l}\text { (Weidmann et } \\
\text { al. 2008) }\end{array}$ \\
\hline CCSMW-FP & 5'-GGYACYAAGAAAATGAAGAAGG-3' & 172 & S-Segment \\
\hline CCSMW-RP-Biotin & 5'- Biotin-CRGGGAKTGTYCCRAAGCA-3' & & \\
\hline MBR-FP2 & 5'-ACTGARATYACACACAGTCAGACA-3 & 88 & Nukleoprotein \\
\hline MBR-RP2- Biotin & 5'- Biotin-TRTTGTTTTCAATTTCTGCAGC-3' & & $\begin{array}{l}\text { (Weidmann et } \\
\text { al. 2004) }\end{array}$ \\
\hline EBOZ-FP2 & 5'-TGATCCYGATGATGGAAGCTAC-3' & 91 & Nukleoprotein \\
\hline EBOZ-RP2- Biotin & $\begin{array}{l}\text { 5'-Biotin- } \\
\text { GTCTAGATCGAATAGGACCAAGTCATCT-3' }\end{array}$ & & $\begin{array}{l}\text { (Weidmann et } \\
\text { al. 2004) }\end{array}$ \\
\hline EBOS(ENS)-FP & 5'-TTGACCCGTATGATGATGAGAGTA-3' & 89 & Nukleoprotein \\
\hline EBOS(ENS)-RP-Biotin & 5'-Biotin-CAAATTGAAGAGATCAAGATCTCCT-3' & & \\
\hline YFV-FP & 5'-ATTGAGGTGCATTGGTCTGC-3' & 94 & 5' UTR \\
\hline YFP-RP- Biotin & 5'-Biotin-GTCRRTTCTCTGCTAATCGCTCA-3' & & $\begin{array}{l}\text { (Weidmann et } \\
\text { al. 2010) }\end{array}$ \\
\hline DEN-FP & 5'-AAGGACTAGAGGTTAKAGGAGACCC-3' & 87 & 3' UTR \\
\hline DEN-RP2- Biotin & 5'-Biotin-CTGHRGAGACAGCAGGATCTCTG-3' & & \\
\hline LAS-LNA-FP1 & 5'-GGTGCTGTGAACCTAG+AT-3' & 127 & Josiah(JOS), \\
\hline LAS-LNA-RP1-Biotin & 5'-Biotin-GGAATGCAGATTTGT+T+GA-3' & & L-Segment \\
\hline
\end{tabular}




$\begin{array}{llll}\text { LAS-LNA-FP2 } & \text { 5'-AACCGATCATTTACACT+G+AT-3' } & 136 & \text { CSF, L- } \\ \text { LAS-LNA-RP2-Biotin } & \text { 5'-Biotin-TGAACACCAGAAGA+A+ACG-3' } & & \text { Segment } \\ \text { LAS-LNA-FP3 } & \text { 5'GTTTGTGCTTTAGAGATT+A+TG-3' } & 130 & \text { Mopeia, } \\ \text { LAS-LNA-RP3-Biotin } & \text { 5'-Biotin-AATTGATTCCCCTCTT+C+T+T-3' } & & \text { L-Segment } \\ \text { LAS-LNA-FP4 } & \text { 5'-CTGACTCACCAGTTTA+A+GA-3' } & 151 & \text { AV, (Z) } \\ \text { LAS-LNA-RP4-Biotin } & \text { 5'-Biotin-TCCTCAACGACTT+A+A+CTT-3' } & & \text { Zinkfinger- } \\ & & & \text { Protein, } \\ & & & \text { L-Segment }\end{array}$

Tab. 2.8: Verwendete Sonden

Name der Sequenz der Sonde $\quad$ Schmelztemperatur $T_{M}$

Sonde

\begin{tabular}{|c|c|c|}
\hline RVFV-Sonde & 5'-TCCTTCTCCCAGTCAGCCCCAC-3' & $65,3^{\circ} \mathrm{C}$ \\
\hline CCSMW-Sonde & 5'-CTGAGCACHCCAATGAARTGGGG-3' & $65,3^{\circ} \mathrm{C}$ \\
\hline MARV-Sonde & 5'-CCGTCCTCAGCCAGAAACGAGA-3' & $65,3^{\circ} \mathrm{C}$ \\
\hline EBOVZ-Sonde & 5'-CCAGAGTTACTCGGAAAACGGCATG-3' & $65,3^{\circ} \mathrm{C}$ \\
\hline EBOVS-Sonde & 5'-CCTGACTACGAGGATTCGGCTGAAGG-3' & $65,3^{\circ} \mathrm{C}$ \\
\hline YFV-Sonde & 5'- AGTTGCTAGGCA+AT+A+A+A-3' & $65,3^{\circ} \mathrm{C}$ \\
\hline DENV-Sonde & 5'-ACAGCATATTGACGCTGGGARAGACC-3' & $65,3^{\circ} \mathrm{C}$ \\
\hline LASV-Sonde1 & 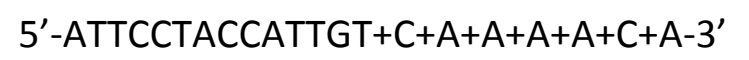 & $68,0^{\circ} \mathrm{C}$ \\
\hline LASV-Sonde2 & 5'-TTTGACACAATGATACTC+C+T+T+G-3' & $67,0^{\circ} \mathrm{C}$ \\
\hline LASV-Sonde3 & 5'-TAACATAAGCCTCTCGTA+A+C+T+G+T-3' & $67,0^{\circ} \mathrm{C}$ \\
\hline LASV-Sonde4 & 5'-TTCTGGATCGTCTTAA+C+A+A+T+G-3' & $67,0^{\circ} \mathrm{C}$ \\
\hline LASV-Sonde 5 & 5'-GTCCTCTTCTCCCTCAA+T+A+T+C+T-3' & $67,0^{\circ} \mathrm{C}$ \\
\hline
\end{tabular}




\subsubsection{Verwendete Computerprogramme}

Tab.2.9: Verwendete Computerprogramme für die Erstellung der Arbeit

\begin{tabular}{lll}
\hline Name & Hersteller & Anwendung \\
\hline Adobe-Photoshop & Adobe Systems Inc. & Bildbearbeitung \\
Adobe-Illustrator & Adobe Systems Inc. & Bildbearbeitung \\
BLAST (Basic Local & National Center for & Sequenzvergleich mit \\
Alignment Search Tool) & Biotechnology Information & Sequenzdatenbank von \\
& (NCBI 2011b) & allen öffentlich \\
& & verfügbaren Genom- \\
BD FACSDiva & & Sequenzen \\
Version 6.1.2 & BD Biosciences & Primäre Auswertung der \\
& & durchflusszytometrischen \\
DNAStar LaserGene & DNAStar Inc., Madison WI, USA & Sequenzanalyse \\
EndNote X3 & Thomson Reuters & Literaturverwaltung \\
Microsoft Office 2007 & Microsoft Inc. & Text- und Daten- \\
& & verarbeitung \\
NCBI GenBank & National Center for & Sequenzdatenbank aller \\
& (NCBI 2011a) & öffentlich verfügbaren \\
& & Genom-Sequenzen \\
& & Primer Entwicklung \\
\hline
\end{tabular}




\subsection{Methoden}

\subsubsection{Arbeiten mit Nukleinsäuren}

\subsubsection{RNS-Extraktion}

Bei der RNS-Extraktion wurde die RNS von DNS und Proteinen getrennt um im Anschluss für weitere Experimente (z.B. Transkription in cDNS) verwendet werden zu können.

Die Isolierung der RNS wurde in der vorliegenden Arbeit mit dem peqGOLD TriFast ${ }^{\mathrm{TM}} \mathrm{FL}-$ Reagenz durchgeführt, das auf der sogenannten “Acid Guanidinium-Thiocyanate-PhenolChloroform-Extraktion"-Methode von Chomczynski und Sacchi basiert (Chomczynski,Sacchi 1987).

Hierzu wurden $100 \mu \mathrm{l}$ Probe (z.B. Zellkulturüberstand von infizierten Zellen) mit $300 \mu \mathrm{l}$ Trizol (peqGOLD TriFast ${ }^{\mathrm{TM} F L}$ von peqLab) versetzt. Dabei wurden die Viren inaktiviert und durch das Guanidinisothiocyanat, ein chaotropes Salz im Trizol, gleichzeitig RNasen und andere Enzyme deaktiviert. Im Anschluss wurden die Proben 5 min gevortext. Nach einer Inkubation von $5 \mathrm{~min}$ bei Raumtemperatur wurden $80 \mu \mathrm{l}$ Chloroform hinzugegeben. Daraufhin wurden die Proben nach kurzem Vortexen ein weiteres Mal bei Raumtemperatur für $10 \mathrm{~min}$ inkubiert. Nach einer Zentrifugation (12.000xg, $5 \mathrm{~min}$ ) ließen sich drei Phasen im Eppendorfgefäß unterscheiden. Proteine und kleinere DNSFragmente wurden durch Phenol entfernt. Größere DNS-Fragmente sammelten sich nach der Zentrifugation in der Interphase, während die RNS nach der Zentrifugation in der wässrigen Phase blieb. Dieser wässrige Überstand wurde abgenommen, in ein neues Eppendorfgefäß gefüllt und $2 \mu \mathrm{l}$ Glykogen (35 $\mu \mathrm{g} / \mu \mathrm{l}$ ) hinzugegeben. Die Probe wurde im Anschluss mit dem gleichen Volumen Isopropanol bei $-20^{\circ} \mathrm{C}$ über Nacht präzipitiert.

Am nächsten Tag konnte die RNS nach zwei Waschschritten mit 70\%igem Ethanol in DEPC-behandeltem Wasser gelagert werden und stand für weitere Experimente zur Verfügung.

In dieser Arbeit wurde die RNS aus den LASV-Proben (LASV AV, CSF und Josiah), die vom Bernhard-Nocht-Institut gespendet wurden, auf beschriebene Weise gewonnen. 


\subsubsection{Spektrophotometrische Konzentrationsbestimmung}

Die spektrophotometrische Konzentrationsbestimmung erfolgte anhand der optischen Dichte (OD) mithilfe des Nanodrop Spektrophotometers. Ermittelt wurde die Absorption bei den Wellenlängen $260 \mathrm{~nm}$ und $280 \mathrm{~nm}$. Für RNS entspricht eine $A_{260}$-Einheit von 1,0 OD einer Konzentration von $40 \mathrm{ng} / \mu \mathrm{l}$ einzelsträngiger RNS/ml (ssDNS: $33 \mathrm{ng} / \mu \mathrm{l}$; dsDNS: $50 \mathrm{ng} / \mu \mathrm{l})$. Anhand der Absorption konnte somit die Nukleinsäurekonzentration ermittelt werden. Die Reinheit der Probe ließ sich dabei durch das Verhältnis von A260nm/A280nm errechnen. Nukleotide, ssDNS, dsDNS und RNS haben ein Absorptionsmaximum von 260nm, während das Absorptionsmaximum der Proteine bei $280 \mathrm{~nm}$ liegt. Der Quotient $\mathrm{OD}_{260} / \mathrm{OD}_{280}$ sollte für relativ proteinfreie DNS- bzw. RNSPräparationen zwischen 1,8 und 2,0 liegen (Sambrook 1989). Ein Wert unterhalb von 1,8 lässt eine Proteinverunreinigung vermuten.

Zur Bestimmung der RNS-Konzentration wurden jeweils 1,5 $\mu \mathrm{l}$ der extrahierten LASVRNS (LAS-AV1, LAS-Lib) (Kap. 2.2.1.1, S.31) verwendet und die gemessenen Werte vom Gerätecomputer (Nano Drop ${ }^{\circledR}$ ND-1000 Spektralphotometer, Thermo Scientific, Rockford, USA) abgelesen.

\subsubsection{PCR-Amplifikation}

\subsection{Polymerase-Kettenreaktion (PCR)}

Die Polymerase-Kettenreaktion ist eine effektive Methode zur in-vitro-Vervielfältigung von DNS (Mullis,Faloona 1987). Notwendige Materialien für die PCR sind:

1) Zwei Oligonukleotidprimer (Vorwärts- und Rückwärtsprimer), die auf den gegenüberliegenden Strängen der DNS jeweils den Startpunkt der DNS-Synthese festlegen und damit die zu vervielfältigende Sequenz begrenzen. Die Primer sollten wichtige Eigenschaften, z.B. die richtige Schmelztemperatur $T_{M}$ und GCGehalt, erfüllen (s. Kap. 2.2.1.3.4, S.37). Durch die freien $\mathrm{OH}^{\prime}$-Gruppen wird dabei der Startpunkt für die DNS-Polymerase-Reaktion festgelegt. Die DNS-Polymerase verknüpft die freien Nukleotide mit der $\mathrm{OH}^{\prime}$-Gruppe am 3'-Ende. 
2) Eine DNS-Matrize, die den zu vervielfältigenden Abschnitt beinhaltet und 100 bis 5000 bp lang sein sollte. Bei dieser Arbeit wurden RNS-Matrizen verwendet, die erst durch eine reverse Transkription in cDNS umgeschrieben wurden.

3) Eine thermostabile DNS-Polymerase. Meist wird die Taq-Polymerase, die aus dem thermophilen Bakterium Thermus aquaticus gewonnen wurde, verwendet.

4) Die 4 Desoxyribonukleotide (dNTPs).

5) $\mathrm{Mg}^{2+}$-Ionen, die bei der PCR mehrere Funktionen erfüllen: sie stabilisieren die spezifische und unspezifische Anlagerung der Primer an die Templates, sie bilden lösliche Komplexe mit den dNTPs und sie wirken als Cofaktoren der DNSPolymerase.

Diese spezifische primer-abhängige Amplifizierung der DNS findet in sich wiederholenden Zyklen statt, die in drei Stufen unterteilt werden: Denaturierung, Renaturierung („Annealing“) und Synthese (Elongation):

1. Denaturierung:

Zur thermischen Denaturierung der DNS-Probe wird der Reaktionsansatz auf $95^{\circ} \mathrm{C}$ erhitzt. Auf diese Weise wird der Doppelstrang in zwei Einzelstränge getrennt.

\section{Renaturierung (engl.: annealing):}

Zur Primeranlagerung (engl.: primer annealing) muss der Ansatz nun auf eine Temperatur gebracht werden, die abhängig von der Länge und Basenzusammensetzung der jeweiligen Primersequenzen ist. Meist entspricht sie einer Temperatur von ca. 55$65^{\circ} \mathrm{C}$.

3. Synthese (Elongation):

Zuletzt kommt es zur Verlängerung des komplementären DNS-Stranges. Die Polymerase beginnt am 3'OH-Ende der Primer die DNS-Sequenz zu verlängern, indem sie die 4 dNTPs entlang der einzelsträngigen denaturierten DNS-Matrize komplementär anlagert. Meist wird hier $72^{\circ} \mathrm{C}$ als optimale Temperatur für die Taq-Polymerase gewählt. 
Jeder Zyklus bedeutet eine weitere Verdopplung der bereits bestehenden DNSDoppelstränge, da auch die neusynthetisierten Stränge als Matrize dienen. Auf diese Weise kommt es zu einem exponentiellen Konzentrationsanstieg der zu amplifizierenden Sequenz.

In dieser Arbeit wurde das PCR-Verfahren zur Amplifikation von RNS von acht HFV (RVFV, CCHFV, MARV, EBOZV, EBOSV, YFV, DENV, LASV) verwendet, die anschließend an beadgekoppelte Sonden hybridisiert wurden. Dabei wurde eine Multiplex-PCR-Technik verwendet, die die simultane Amplifikation mehrerer Sequenzen gleichzeitig ermöglicht (s. Kap .2.2.1.3.3, S.35).

Die Reaktion erfolgte in dünnwandigen 0.5-ml-Reaktionsgefäßen in einem automatischen Thermocycler (Biometra GmbH, Göttingen, Deutschland) oder Speedcycler (Analytic Jena, Jena, Deutschland) mit beheizbarem Deckel. Im Anschluss wurden die Amplifikationsprodukte durch TAE-Agarose-Gelelektrophorese analysiert.

\subsection{Reverse-Transkriptase-PCR (RT-PCR)}

Um die Amplifikation und Detektion von RNS-Viren zu ermöglichen wurde die RT-PCR (Reverse-Transkriptase-Polymerase-Kettenreaktion) angewendet.

Die RT-PCR besteht aus zwei Schritten: der reversen Transkriptionsreaktion und der PCRAmplifikation (s. Kap.2.2.1.3.1, S.32). Zuerst wurde dabei die virale RNS durch ein Enzym, die Reverse-Transkriptase, in cDNS umgeschrieben. Diese cDNS diente in der darauf folgenden PCR als Matrize für die Amplifikation.

In der vorliegenden Arbeit wurde mit dem QuantiTect ${ }^{\circledR}$-Multiplex-RT-PC-Kit gearbeitet. Durch die Reverse-Transkriptase, die im QuantiTect ${ }^{\circledR}-R T-M i x$ enthalten war, wurde in einem 20 minütigen Schritt bei $50^{\circ} \mathrm{C}$ zu Beginn des PCR-Programms die virale RNS in cDNS umgeschrieben. 


\subsection{Multiplex-RT-PCR}

Für den simultanen Nachweis von mehreren Viren in einem PCR-Ansatz wurde die Amplifikation im Multiplex-System durchgeführt.

Durch die Zusammenstellung von multiplen Primerpaaren konnten auf diese Weise mehrere Proben in einem einzigen Ansatz analysiert werden, die sonst in mehrere zeitaufwendige Einzelversuche aufgeteilt werden müssten. Für eine effiziente MultiplexPCR mussten verschiedene Bedingungen erfüllt werden:

Für die Multiplex-PCR musste die Renaturierungstemperatur ( $T_{a}$ ) (engl.: annealing temperature) so gewählt werden, dass sie den jeweiligen Eigenschaften aller Primerpaare in einem Ansatz entspricht. In der vorliegenden Arbeit wurde eine Renaturierungstemperatur von $60^{\circ} \mathrm{C}$ ausgewählt.

$>$ Die Amplikons sollten sich in der Länge unterscheiden, damit sie bei der gelelektrophoretischen Auftrennung im Anschluss an die PCR differenziert werden konnten. Die Amplikons in dieser Arbeit wiesen eine Länge von ca. 70 bp180 bp auf.

Die Primer durften keine homologen Sequenzen amplifizieren und mussten bei jedem Primermix auf Primerdimerbildung mit Hilfe der SYBR-Green-qRT-PCR (s.Kap. 2.2.1.3.6.2, S.41) kontrolliert werden. Um die Spezifität und Sensibilität der einzelnen Primerpaare zu überprüfen wurde die qRT-PCR verwendet (s. Kap. 2.2.1.3.6.1, S.41)

Insgesamt wurden drei Primermischungen für Multiplex-PCR-Reaktionen entwickelt: Mix 1 setzte sich aus drei Primerpaaren für RVFV, CCHFV, MARV zusammen, Mix 2 aus vier Primerpaaren für EBOZV, EBOSV, YFV, DENV und Mix 3 aus fünf Primerpaaren für LASV. 
Tab. 2.10: Primermixe für Multiplex-PCR

\begin{tabular}{lll}
\hline MIX 1 & MIX 2 & MIX 3 \\
\hline RVF-FP & EBOZ-FP2 & LAS-LNA-FP1 \\
RVF-RPptr & EBOZ-RP2 & LAS-LNA-RP1 \\
& & \\
CCSMW-FP & EBOS (ENS)-FP & LAS-LNA-FP2 \\
CCSMW-RP & EBOS (ENS)-RP & LAS-LNA-RP2 \\
MAR-FP2 & YFV-FP & LAS-LNA-FP3 \\
MAR-RP2 & YFV-RP & LAS-LNA-RP3 \\
& DEN-FP & LAS-LNA-FP4 \\
& DEN-RP2 & LAS-LNA-RP4 \\
\hline
\end{tabular}

Die Multiplex-PCRs in der vorliegenden Arbeit wurden mit dem QuantiTect ${ }^{\circledR}$-MultiplexRT-PCR-Kit von QIAGEN durchgeführt, das die optimale Konzentration an $\mathrm{Mg}^{2+}$, Taq DNS Polymerase und Reverse-Transkriptase bereits enthielt. Dieses Reaktionskit enthielt die HotStar Taq DNS Polymerase, eine chemisch modifizierte DNS Taq-Polymerase, die erst ab $95^{\circ} \mathrm{C}$ aktiviert wurde. Zur Aktivierung wurde deshalb ein Schritt von 15 min bei $95^{\circ} \mathrm{C}$ vor den PCR-Zyklen eingefügt.

Für sämtliche Polymerase-Kettenreaktionen der vorliegenden Arbeit wurde dabei folgendes PCR-Programm gewählt:

Temperaturprogramm der PCR:

\begin{tabular}{|c|c|c|c|}
\hline $50^{\circ} \mathrm{C}$ & $(20 \mathrm{~min})$ & & Reverse Transkription \\
\hline $95^{\circ} \mathrm{C}$ & (15 min) & & Aktivierung der HotStar Taq Polymerase \\
\hline $94^{\circ} \mathrm{C}$ & (45 sek) & & Denaturierung \\
\hline $60^{\circ} \mathrm{C}$ & (75 sek) & 455 & Renaturierung und Polymerisierung \\
\hline $40^{\circ} \mathrm{C}$ & (30 sek) & & Abkühlung \\
\hline $12^{\circ} \mathrm{C}$ & $(\infty)$ & & Stand-by \\
\hline
\end{tabular}


Beispiel: PCR-Ansatz für MIX 1 (Master Mix 4:1 FP/RP-Verhältnis):

\begin{tabular}{lllc}
\hline & $\begin{array}{c}\text { Stock- } \\
\text { konzentration }\end{array}$ & $\begin{array}{c}\text { End- } \\
\text { konzentration }\end{array}$ & $\begin{array}{c}\text { 1x Ansatz } \\
(\boldsymbol{\mu} \mathbf{l})\end{array}$ \\
\hline $\mathrm{H}_{2} \mathrm{O}$ & & & 5,8 \\
QuantiTect ${ }^{\circledR}$ NoRox Master & $2 \mathrm{x}$ & & 10 \\
RVF-FP & $10 \mu \mathrm{M}$ & $400 \mathrm{nM}$ & 0,8 \\
RVF-RPptr-Biotin & $10 \mu \mathrm{M}$ & $100 \mathrm{nM}$ & 0,2 \\
CCSMW-FP & $10 \mu \mathrm{M}$ & $400 \mathrm{nM}$ & 0,8 \\
CCSMW-RP-Biotin & $10 \mu \mathrm{M}$ & $100 \mathrm{nM}$ & 0,2 \\
MAR-FP & $10 \mu \mathrm{M}$ & $400 \mathrm{nM}$ & 0,8 \\
MAR-RP-Biotin & $10 \mu \mathrm{M}$ & $100 \mathrm{nM}$ & 0,2 \\
QuantiTect ${ }^{\circledR}$ RT Mix & $100 \mathrm{x}$ & $100 \mathrm{nM}$ & 0,2 \\
$\Sigma$ Volumen & & & 20 \\
\hline
\end{tabular}

\subsection{Primer- und Sondendesign}

Die in der vorliegenden Arbeit verwendeten Primer und Sonden beruhen auf durch die AG Weidmann veröffentlichten Einzelamplikons zum Nachweis von DENV, RVFV, EBOZV, EBOSV, MARV, YFV (Kap 2.1.7) (Carhan et al. 2010, Wagner et al. 2004, Weidmann et al. 2004, Weidmann et al. 2008), die wie beschrieben unter der Verwendung folgender Software entworfen wurden (Alignments mit DNAstar Lasergene Software, Primer Entwicklung mit Primer Express). Im Einzelfall wurden Primer verändert (RVFV-RVptr, EBOVZ-FP2 und EBOVZ-RP2) und angepasst. Die Primer und die Sonde für CCHFV wurden neu synthetisiert. Für LASV wurden die Primer und Sonden nach dem Algorithmus von Gardner et al. ausgewählt (Gardner et al. 2004) und von Prof. Stephan Günther vom Bernhard-Nocht-Institut in Hamburg zur Verfügung gestellt. Um die Variationsbreite der LASV abzudecken wurden Primerpaare für Amplikons basierend auf 5 LASV-LNA Sonden mit der genomischen RNS der LASV-Stämme LASV JOS, LASV LANT (westliches WestAfrika), LASV AV (zentrales West-Afrika), LASV CSF (östliches West-Afrika) getestet.

Die Virus-RNS-Proben waren großzügige Spenden des Robert-Koch-Instituts (AV1, Stamm Liberia (Lib)), des Bernhard-Nocht-Instituts (Josiah (JOS), Cerebrospinalflüssigkeit (CSF), AV) und von Dr. Ali Mirazimi vom Department of Virology des „Swedish Institute for Infectious Disease Control“ in Solna, Schweden (Josiah (JOS), LANT).

Zum Nachweis einer erfolgreichen Hybridisierungsreaktion an die gekoppelten Beads wurden biotinylierte RP verwendet. Durch das Biotin wurde eine Bindung an den 
Fluoreszenzfarbstoff SARPE (Streptavidin-R-Phycoerythrin) ermöglicht, der in der Durchflusszytometrie detektiert werden konnte.

Synthetisiert wurden diese Primer und Sonden von der Firma TIB MOLBIOL (Berlin, Deutschland). Nach dem Erhalt der lyophilisierten Primer und Sonden mussten diese in $\mathrm{H}_{2} \mathrm{O}$ gelöst werden. Die Aufbewahrung der aliquotierten Primer (Konzentration: $10 \mu \mathrm{M}$ ) und Sonden (Konzentration: $100 \mu \mathrm{M}$ ) fand bei $-20^{\circ} \mathrm{C}$ statt.

\subsection{Gelelektrophoretische Auftrennung von DNS}

Zur analytischen Trennung von DNS-Fragmenten werden die Amplifikationsprodukte im Anschluss an das PCR-Verfahren auf ein Agarose-Flachbettgel aufgetragen. Da die DNSFragmente negativ geladen sind, wandern sie im elektrischen Feld zur Anode. Die Wanderungsgeschwindigkeit der doppelsträngigen DNS ist dabei umgekehrt proportional zum Logarithmus des Molekulargewichtes (Helling et al. 1974).

Abhängig von der Größe der zu trennenden DNS-Fragmente wird die Agarosekonzentration gewählt.

$\begin{array}{cr}\begin{array}{c}\text { Agarose- } \\ \text { konzentration }\end{array} & \begin{array}{r}\text { Größe der DNA- } \\ \text { Fragmente }\end{array} \\ 0.7 \% & 12 \mathrm{~kb}-800 \mathrm{bp} \\ 1.0 \% & 10 \mathrm{~kb}-500 \mathrm{bp} \\ 1.5 \% & 3 \mathrm{~kb}-200 \mathrm{bp} \\ 2.0 \% & 2 \mathrm{~kb}-50 \mathrm{bp}\end{array}$

Da die Länge der Amplifikationsprodukte in dieser Arbeit bei 70bp -180bp lag, wurde eine Agarosekonzetration von 2\% (w/v) verwendet. Durch Aufkochen wurde die Agarose in TAE-Puffer gelöst. Nachdem sie auf ca. $60^{\circ} \mathrm{C}$ abgekühlt war, wurde Ethidiumbromid in einer Endkonzentration von 0,5 $\mathrm{gg} / \mathrm{ml}$ zugegeben. Beim Gießen der gelösten Agarose in eine entsprechende Gelkammer werden durch das Aufsetzen eines Kammes Taschen für den Probenauftrag freigehalten.

Die Amplifikationsprodukte wurden mit 1/6 Volumen Auftragspuffer (Orange Loading Dye $(6 x)$ ) versetzt und in die Taschen des TAE-Puffer-bedeckten Gels pipettiert. Dieser Auftragspuffer enthielt zwei Farbstoffe, die es ermöglichten die DNS-Fragmente bei ihrer 
Bewegung im elektrischen Feld zu verfolgen. Zur anschließenden Analyse der Größe der DNS-Fragmente dienten zwei zusätzlich aufgetragene Längenstandards (100bp, Ultralow-range).

Die Elektrophorese erfolgte bei einer konstanten Spannung von 95V in 1x TAE-Puffer. Da das Ethidiumbromid in die Doppelstränge der DNS interkaliert, konnten die DNSFragmente durch den Chemidoc ${ }^{T M}$ XRS bei einer Bestrahlung mit UV-Licht (302nm) sichtbar gemacht werden. Die Nachweisgrenze der Ethidiumbromid-gefärbten Gele lag bei 10 ng DNS pro Bande. Die Agarosegele wurden auf dem Chemidoc ${ }^{\mathrm{TM}}$ XRS System mit Hilfe eines Videosystems dokumentiert

50x TAE-Puffer

$242,2 \mathrm{~g}$ Tris

18,61g EDTA

Mit Eisessig auf pH 7,9 einstellen

Auf 11 mit $\mathrm{H}_{2} \mathrm{O}$

\section{6x Auftragspuffer}

$10 \mathrm{mM}$ Tris- $\mathrm{HCl}(\mathrm{pH} \mathrm{7,6)}$

$0,15 \%$ Orange $\mathrm{G}$

0,03\% Xylene Cyanol FF

$60 \%$ Glycerol

$60 \mathrm{mM}$ EDTA

\subsection{Quantitative Real-Time PCR (qRT-PCR)}

Die quantitative Real-Time-PCR bietet die Möglichkeit bereits während des Amplifikationsvorganges die aktuelle Verfältigung der DNA-Fragmente zu beobachten. Die qRT-PCR basiert auf dem gleichen Verfahren wie die klassische PCR und macht sich dabei die 5'-Exonukleaseaktivität der Taq-Polymerase zu nutze. Die sogenannte Taqman Sonde besteht aus einem Oligonukleotid, dessen 5'-Ende mit einem fluoreszenten Reporter-Farbstoff (Fluoreszin-Derivat, FAM) und dessen 3'-Ende mit einem LöschFarbstoff (engl.: quencher-dye, Rhodamin-Derivat, TAMRA) markiert ist. Wird die Sonde mit einer spezifischen Wellenlänge $(488 \mathrm{~nm})$ bestrahlt, bleibt das ReporterFluoreszenzsignal durch die räumliche Nähe zum Quencher unterdrückt. Es kommt zu einen Fluoreszenz-Energietransfer (FRET). Während der PCR hybridisiert die TaqmanSonde an den Matrizenstrang. In der Extensionsphase verdrängt die Polymerase mit ihrer 5'-3'-Exonuklaeseaktivität die Sonde und baut diese ab, wodurch es zu einer 
Trennung von Reporter und Quencher kommt und die Reporterfluoreszenz freigesetzt wird.

Die Taq-Polymerase baut nur gebundene Sonden ab, sodass Einzelstränge, an die keine Sonde hybridisiert hat, unbeschadet bleiben. Die Reporterfluoreszenz ist proportional zu den DNS-Templates in der Probe und wird nach jedem Zyklus gemessen.

Zur Datenvalidierung wurde der Zyklus-Schwellenwert (engl.: cycle-threshold, Ct) analysiert, da dieser Wert den Punkt in der Phase des exponentiellen Wachstums beschreibt, an dem die Fluoreszenzintensität der Reaktion oberhalb der Negativkontrollwerte liegt.

In dieser Arbeit ist die quantitative Real-Time-PCR zur Sensitivitätskontrolle der drei Primermixe (MIX 1, MIX 2, MIX 3 s. Kap. 3.1.2, S.48) genutzt worden. Darüber hinaus konnten durch den Einsatz von SYBR-Green anstelle der TaqMan-Sonde in der qRT-PCR mögliche Primerdimerbildung der verschiedenen Primerkombinationen ausgeschlossen werden (s. Kap. 2.2.1.3.6.2, S.41).

Tab. 2.11: Beispielprotokoll für qRT-PCR

\begin{tabular}{|c|c|c|c|}
\hline & $\begin{array}{l}\text { Stock- } \\
\text { Konz. }\end{array}$ & $\begin{array}{l}\text { End- } \\
\text { Konz. }\end{array}$ & $\begin{array}{l}\text { 1x } \\
\text { Ansatz } \\
(\mu l)\end{array}$ \\
\hline QuantiTect ${ }^{\circledR}$ Multipex NoRox Master & $2 x$ & $1 x$ & 10,0 \\
\hline $\mathrm{H}_{2} \mathrm{O}$ & & & 8,0 \\
\hline Primer-FP & $10 \mu \mathrm{M}$ & 100nM & 0,2 \\
\hline Primer-RP & $10 \mu \mathrm{M}$ & 100nM & 0,2 \\
\hline Sonde $\mathrm{P}$ & $10 \mu \mathrm{M}$ & $200 \mu \mathrm{M}$ & 0,4 \\
\hline QuantiTect ${ }^{\circledR}$ Multiplex-RT-Mix & & & 0,2 \\
\hline RNS-Standard & & & 1,0 \\
\hline$\Sigma$ Volumen & & & 20,0 \\
\hline
\end{tabular}

Tab. 2.12: $\quad$ PCR-Programm für qRT-PCR

\begin{tabular}{|c|c|c|c|}
\hline $50^{\circ} \mathrm{C}$ & ( 5 min) & & Reverse Transkription \\
\hline $95^{\circ} \mathrm{C}$ & (15 sek) & & Aktivierung der HotStar Taq Polymerase \\
\hline $94^{\circ} \mathrm{C}$ & ( 5 sek) & & Denaturierung \\
\hline $60^{\circ} \mathrm{C}$ & (50 sek) & $45 x$ & Renaturierung und Polymerisierung \\
\hline $40^{\circ} \mathrm{C}$ & (30 sek) & & Abkühlung \\
\hline $12^{\circ} \mathrm{C}$ & $(\infty)$ & & Stand-by \\
\hline
\end{tabular}




\subsection{Sensitivitätstestung mittels Real-Time PCR}

Die Validierung der entwickelten Primermixe erfolgte anhand von seriellen Verdünnungsreihen der RNA-Standards. Die Ausgangskonzentration betrug $10^{7}$ RNSMoleküle/ $\mu \mathrm{l}$, woraus eine Verdünnungsreihe von $10^{6}$ bis $10^{1}$ erstellt wurde. Mit diesen RNS-Standards konnten im Anschluss qRT-PCRs (s. Kap. 3.1.1, S.46) im Multiplex-System für die drei Primermixe durchgeführt werden. Mithilfe des Zyklus-Schwellenwertes (CT) der einzelnen Ansätze mit verschiedenen Konzentrationen konnte die Sensitivität des gesamten Mixes ermittelt werden.

\subsection{Detektion von Primerdimerbildung mittels Real-Time PCR}

Zum Nachweis von Primerdimeren kann der Farbstoff SYBR-Green in der Real-Time-PCR verwendet werden. Dieser Cyanin-Farbstoff bindet unspezifisch an doppelsträngige DNS und emittiert grünes Licht bei der Bestrahlung einer Wellenlänge von 521nm. Der qRTPCR-Ansatz wird zur Primerdimerkontrolle nur mit Primern und ohne DNS-Fragmente durchgeführt, sodass mögliche detektierte dsDNS nur durch Primerdimerbildung entstehen kann. Dabei wird der CT-Wert gemessen, der Angaben über die Menge des Produktes gibt. Die Primermischungen werden dabei stufenweise durch einen zusätzlichen Primer ergänzt. Bei einer Verschiebung des CT-Wertes kann somit der Dimer-bildende Primer sofort ermittelt werden. Das bei der SYBR-Green-qRT-PCR verwendete PCR-Programm entsprach dem Protokoll in Tab. 2.13.

Tab. 2.13: Beispielprotokoll für SYBR-Green-qRT-PCR

\begin{tabular}{lllc}
\hline & $\begin{array}{l}\text { Stock- } \\
\text { Konz. }\end{array}$ & $\begin{array}{l}\text { End- } \\
\text { Konz. }\end{array}$ & $\begin{array}{l}\mathbf{1 x} \\
\text { Ansatz } \\
(\boldsymbol{\mu l )})\end{array}$ \\
\hline RNA Master SYBR Green & $2,7 \mathrm{x}$ & $1 \mathrm{x}$ & 7,5 \\
$\mathrm{Mn}(\mathrm{OAc})_{2}$ & $50 \mathrm{nM}$ & $3,25 \mathrm{nM}$ & 1,3 \\
$\mathrm{H}_{2} \mathrm{O}$ & & & 9,8 \\
Primer-FP & $10 \mu \mathrm{M}$ & $100 \mathrm{nM}$ & 0,2 \\
Primer-RP & $10 \mu \mathrm{M}$ & $100 \mathrm{nM}$ & 0,2 \\
RNS-Standard & & & 1,0 \\
$\Sigma$ Volumen & & & 20,0 \\
\hline
\end{tabular}


Tab. 2.14: PCR-Programm für SYBR-Green-qRT-PCR

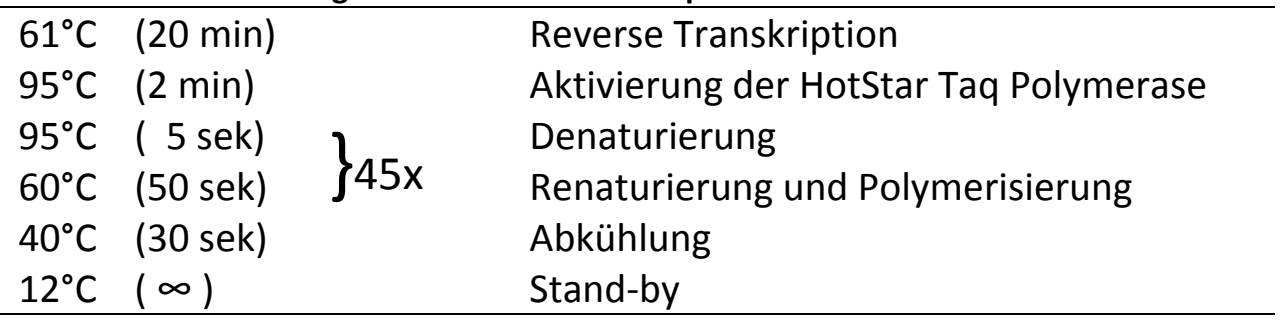

\subsubsection{Cytometric Bead Array (CBA)}

\subsubsection{Aufreinigung der PCR-Produkte mit MinElute-Purifikation-Kit}

Um spezifische DNS-Fragmente nach der PCR-Reaktion zu isolieren, wurden PCRAmplifikate mit dem MinElute-Purification-Kit von QIAGEN gereinigt. Während dieses Vorganges wurden alle Nukleinsäuren, kleiner als 70 bp bzw. größer als 4kb, entfernt. Zusätzlich wurden alle Enzyme, unabhängig von ihrer Größe, aus der Probe gefiltert. Das gereinigte Produkt wurde im Anschluss für weitere Versuche wie Ligation, Transkription, Amplifikation oder Hybridisierung verwendet.

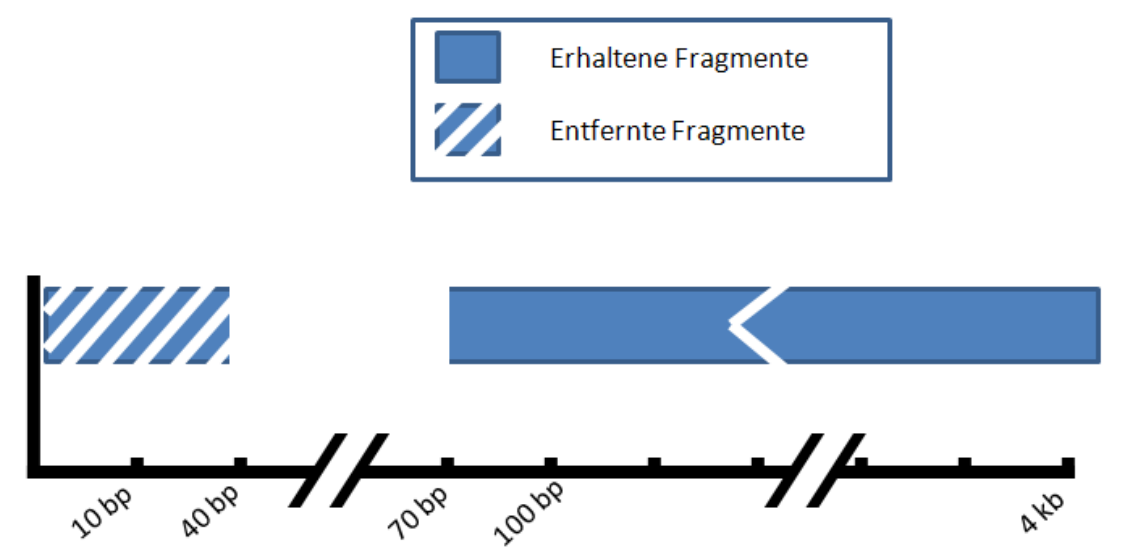

Abb. 2.1: Reinigung der DNS mit dem MinElute-Purification-Kit von QIAGEN, Nukleinsäuren <70bp und $>4 \mathrm{~kb}$ werden aus der Probe entfernt.(QIAGEN 2010)

Im Rahmen dieser Arbeit wurde während der Reinigung mit dem MinElute-PurificationKit ein weiterer Waschschritt mit $750 \mu$ l Guanidiniumhydrochlorid (35\%) durchgeführt, um Primerdimere, die >20bp waren, effizienter zu entfernen. 


\subsubsection{Kopplung von Sonden an carboxylierte Beads}

Zur Hybridisierung der PCR-Produkte an die Beads mussten zuerst Oligonukleotidsonden an die Beads gekoppelt werden. Das dabei verwendete Verfahren zur Kopplung basierte auf den Erfahrungen von Deregt et al. aus 2006.

$\mathrm{Zu}$ Beginn wurden die carboxylierten Beads (Bio-Plex $\mathrm{COOH}$-Beads) in der Originalverpackung erst für 30 sek gevortext und dann für 30 sek ins Ultraschallbad (Bandelin electronic) gestellt. Danach wurden 1,25 Mio. Beads $\left(=100 \mu \mathrm{l}\right.$ of 1,25 x $10^{7}$ Beads/ml) in ein Eppendorfgefäß überführt um für $4 \mathrm{~min}$ in der Zentrifuge (14.000xg) pelletiert zu werden. Das Pellet wurde in $100 \mu \mathrm{l}$ 0,1M 2-Morpholinoethan Sulfonsäure (MES, $\mathrm{pH} 4,5$ ) resuspendiert. Von der aminierten Oligonukleotidsonde wurden 400 pmol hinzugefügt. Gefolgt wurde dieser Schritt von der Zugabe von $10 \mu \mathrm{l}(=200 \mu \mathrm{g}$ ) 1-Ethyl-33-dimethylaminopropyl carbodiimid (EDAC) (20 mg/ml), das zuvor in 0,1 M MES, pH 4,5 aufgelöst worden war. Das EDAC wirkt als Carboxylgruppenaktivator, da es die $\mathrm{COOH}-$ Gruppen in den instabilen O-Acylsäureester überführt, der eine kovalente Bindung mit dem primären Amid eingeht. Ergänzend kann durch die Zugabe von NHydroxysuccinimid (NHS) ein Übergang in den halb-stabilen NHS-Ester-Zustand herbeigeführt werden, der ebenfalls eine kovalente Amid-Verbindung mit einem primären Amin bildet. Dieser stabilisierende Übergang ist allerdings nicht zwingend notwendig zur Ausbildung der Amid-Bindung.

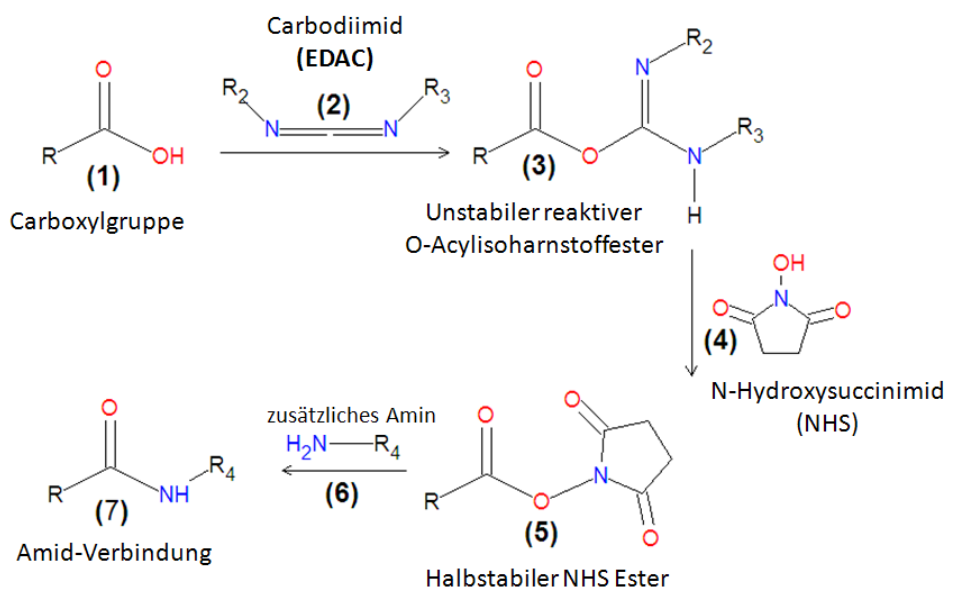

Abb. 2.2: Kopplungsreaktion von Carboxylsäure an ein primäres Amin über die Zwischenprodukte OAcylsäureester und NHS-Ester, die Kopplung in Form einer Peptidbindung geschieht durch die Bildung eines unstabilen Zwischenprodukts, dem O-Acylisoharnstaffester, durch die Reaktion der Carboxylgruppe mit dem Carbodiimid des EDACs. Zur Stabilisierung des OAcylisoharnstoffesters wird häufig NHS hinzugegeben, sodass durch die Zugabe eines weiteren Amins die stabile Amidverbindung entsteht. (Volk 2009) 
Die Reaktion wurde bei Raumtemperatur für 30 min auf dem Rotator inkubiert. Die Inkubation wurde dabei nach 15 min kurz unterbrochen um die Probe auf dem Vortexer ein weiteres Mal zu mischen. Um die Effizienz der Konjugation abzusichern, wurde die Zugabe von EDAC (200 $\mu \mathrm{g}$ ), die Inkubation (30 min, Raumtemperatur) und die kurze Unterbrechung zum Vortexen wiederholt. Da EDAC auf Raumtemperatur äquilibriert werden musste, sollte es 1 Stunde vor Gebrauch auf Raumtemperatur gelagert werden und vor jeder Zugabe neu angesetzt werden. EDAC ist ein aminreaktiver Kreuzvernetzer (engl: cross-linker), der die Peptid-Bindung zwischen den Carboxylgruppen der Beads und den Aminogruppen der Oligonukleotidsonden erleichert.

Nach der zweiten Inkubation wurde die Probe wieder für 4 min zentrifugiert. Der Überstand wurde verworfen und dann mit 0,5 ml 0,02\% Tween 20 gewaschen, d.h. nach der Zugabe von Tween 20 wurde die Probe gevortext, wieder pelletiert (14.000xg, $4 \mathrm{~min}$ ) und der Überstand verworfen. Im Anschluss wurde die Reaktion in 0,5 ml 0,1\% SDS (w/v) (Sodiumdodecylsulfat) resuspendiert und ein weiteres Mal zentrifugiert (14.000xg, 4 min). Nach der Abnahme des Überstandes, wurden die Beads zum Schluss in $50 \mu$ l TrisEDTA $(\mathrm{pH} 8,0)$ resuspendiert und bei $4^{\circ} \mathrm{C}$ lichtgeschützt gelagert.

Zur Kontrolle der Kopplungsreaktion wurde in einer Parallelreaktion statt der üblichen Oligonukleotidsonde eine Sonde verwendet, die den Farbstoff Cy3 (Emissionsmaximum: $575 \mathrm{~nm}$ ) enthielt. Mit hHilfe dieses Flourenszenssignals konnte eine positive Kopplungsreaktion mit dem Durchflusszytometer (FACS Canto ${ }^{\mathrm{TM}}$ II) nachgewiesen werden.

\subsubsection{Hybridisierung an Beads und Detektion}

Zum Direktnachweis von Virusgenomen im Serum per CBA (s. Kap. 2.2.2, S.42) wurde wie folgt verfahren.

Die PCR Produkte wurden zuerst 1:2 mit Tris-EDTA (ph 8,0) verdünnt. Je Ansatz wurden dann $5 \mu$ l der verdünnten PCR-Produkte für 5 min bei $96^{\circ} \mathrm{C}$ im ThermoCycler denaturiert. Um die Reaktion zu stoppen wurden die Proben im Anschluss sofort für 1-2 min auf Eis gestellt. Danach wurden $5 \mu$ der mit Sonden gekoppelten Beads (s. Kap.2.2.2.2, S.43) zugegeben und durch Agitation mit der Pipette vermischt. Der Hybridisierungsschritt 
erfolgte im Anschluss bei $60^{\circ} \mathrm{C}$ für eine Stunde im SpeedCycler oder im ThermoCycler. Um den Beadverlust während der folgenden Waschschritte zu verringern, wurden die Proben nach der Hybridisierung in eine 96-well-Platte überführt. Nachdem der Zugabe von je $50 \mu \mathrm{l}$ 0,02\% Tween 20 in FACS-Flow hinzugegeben worden waren, wurden die 96well-Platte bei $14.000 x g$ für $4 \mathrm{~min}$ in einer Megafuge 1.0R zentrifugiert. Durch die Zugabe von je $50 \mu \mathrm{l}$ 10\% BSA wurden die Carboxylgruppen der Beads abgesättigt, um unspezifische Bindungen im weiteren Verlauf des Experiments zu verhindert (Kap. 3.3.1.1, S.60). Nach einer Inkubation von $30 \mathrm{~min}$ auf der Wippe lichtgeschützt durch Alufolie, wurden nochmals $50 \mu \mathrm{l}$ 0,02\% Tween in FACS-Flow zugegeben. Zur späteren Detektion der hybridisierten Proben wurden $100 \mu$ l Streptavidin-R-phycoerythrin (SARPE), das zuvor in 0,02\% Tween 20 in FACS-Flow $(10 \mu \mathrm{g} / \mathrm{ml})$ verdünnt worden war, verwendet. Auf diesen Schritt folgten eine Inkubation auf der Wippe von 15 min und zwei Waschschritte mit jeweils $100 \mu$ 0,02\% Tween 20 in FACS-Flow mit einer Zentrifugation (14.000xg für $4 \mathrm{~min}$ ). Zum Schluss wurden die Pellets in $200 \mu \mathrm{l}$ 0,02\% Tween 20 in FACS-Flow resuspendiert.

Die durchflusszytometrischen Messungen wurden an einem FACS Canto ${ }^{\text {TM II }}$ durchgeführt. Dieses acht-parametrische Analysegerät ermöglichte die gleichzeitige Messung von Streulichteigenschaften, Zellgröße, Zellgranularität und Fluoreszenz bei bis zu sechs Wellenlängen gleichzeitig. Mithilfe der BD FACS Diva ${ }^{\mathrm{TM}}$ Software Version 6.1.2. konnten die gewonnen Daten ausgewertet werden. Dabei musste man berücksichtigen, dass es sich bei den im Durchflusszytometer ermittelten Werten nicht um Absolutwerte, sondern um relative Signalgrößen handelte, die lediglich einen Vergleich der gemessenen Werte untereinander erlaubte.

In der vorliegenden Arbeit wurden die internen Fluoreszenzsignale (APC, APC-Cy7) der Beads zur Detektion von 1000 Kugeln pro Ansatz verwendet und jeweils die mittlere Fluoreszenzintensität (MFI) des SARPE zum Nachweis von viralen Genomen von HFV bestimmt. 


\section{$3 \quad$ Ergebnisse}

\subsection{Amplifikation des Virusgenoms mittels PCR}

\subsubsection{Bestimmung der optimalen Primerkonzentration}

Da Primerdimere eine Multiplex-PCR kompetitiv inhibieren können, sollte durch die Bestimmung der optimalen Primerkonzentration in der Multiplex-PCR die Primerdimerentwicklung minimiert werden. Die Entwicklung von Primerdimeren konnte in den verschiedenen Primermischungen mit SYBR-Green-qRT-PCR (Kap. 2.2.1.3.6.2, S.41) analysiert werden, da der Farbstoff SYBR-Green unspezifisch in doppelsträngige DNS interkaliert. Da es sich bei dieser SYBR-Green-qRT-PCR um eine UniplexAmplifikation handelte, enthielten die Proben jeweils nur ein Primerpaar mit einem symmetrischen Verhältnis von Forward-Primer zu Reverse-Primern (FP/RP-Verhältnis: 1:1) in unterschiedlichen Konzentrationen (100nM-200nM-300nM-400nM-500nM). Anstatt eines RNS-Standards wurde zu den Proben je $1 \mu \mathrm{l} \mathrm{H}_{2} \mathrm{O}$ hinzugefügt. Die Primerdimerbildung bei den PCR-Mischungen wurde für EBOVZ, EBOVS und MARV ermittelt.

Die geringste Primerdimerbildung trat bei einer symmetrischen Primerkonzentration von $100 \mathrm{nM}$ auf. 

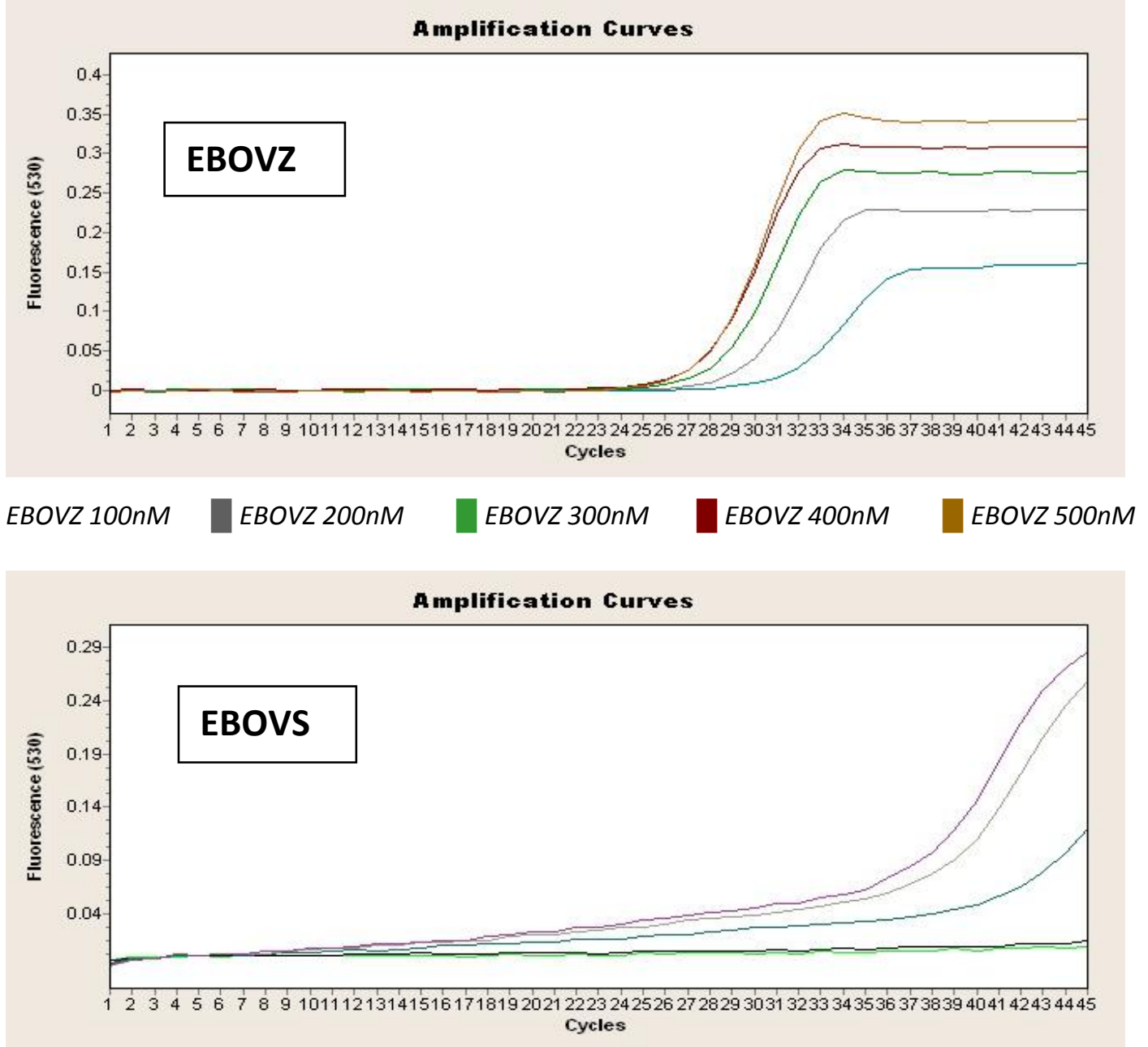

EBOVS 100nM

EBOVS 200nM

EBOVS 300nM

EBOVS 400nM

EBOVS 500nM

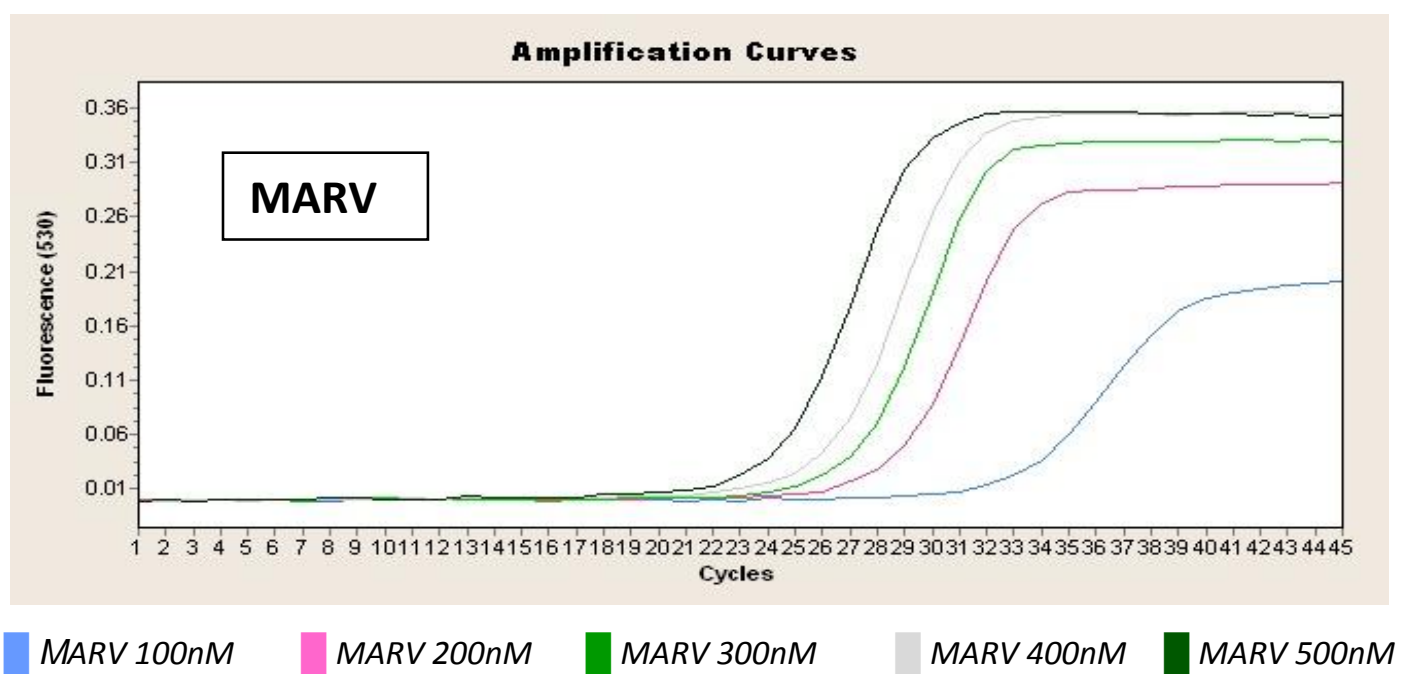

Abb. 3.1: Bestimmung der optimalen Primerkonzentration in der Uniplex-PCR von EBOVZ, EBOVS und MARV mittels SYBR-Green-qRT-PCR. Pro HFV wurden jeweils 5 Primerpaare mit unterschiedlichen Konzentrationen (100nM, 200nM, 300nM, 400nM, 500nM) am LightCycler $^{\circledR}$ ausgewertet. 


\subsubsection{Bestimmung der optimalen Primerkombination}

Mit der Anzahl der Primerpaare in einer Multiplex-PCR steigt das Risiko der Primerdimerbildung. Um die Anzahl von Primerpaaren gering zu halten (3-5 Paare/Multiplex-PCR) wurden die Mischungen sorgfältig aufeinander abgestimmt. Nachdem in der Uniplex-PCR für die Konzentration von 100nM eine minimale Primerdimerentwicklung nachgewiesen wurde (s. Kap. 3.1.1, S.46), konnte diese Konzentration als Grundlage für die Testung der optimalen Primermischungen der Multiplex-PCRs festgelegt werden. In einer SYBR-Green-qRT-PCR ohne Templates nach dem Protokoll in Kap. 2.2.1.3.6.2 (S.41) wurden die Primerkombinationen miteinander verglichen. Ursprünglich war ein Ansatz (Mix 1-a) für die Bunyaviren (RVFV, CCHFV) und dem Flavivirus (YFV) und ein weiterer Ansatz (Mix 1-b) für die Filoviren (EBOVZ, EBOVS, MARV) geplant. Um die Dimerbildung innerhalb dieser Ansätze zu verringern, wurden die Primer von YFV und MARV nach der Analyse der SYBR-Green-qRT-PCR gegeneinander ausgetauscht (Mix 1-b und Mix 2-b).

Bei der genaueren Betrachtung der quantitativen Analyse in Abb 3.2 fällt ein Sprung des Ct-Wertes in Mix 1-a bei der Zugabe von RVFV-RP auf, in Mix 1-b bei der Zugabe von dem CCSMW-RP. Bei Mix 2 treten ebenfalls Ct-Sprünge auf: ein Sprung im Ct-Wert bei Mix 2-a durch die Zugabe von MBR-RP2 und bei Mix 2-b durch die Zugabe von YFV-FP. Doch durch das Austauschen von MARV mit YFV konnte die Dimerbildung in Mix 1-b im Vergleich zu Mix 1-a verringert werden, während sie bei Mix 2-b unverändert zu Mix 2-a war. Für die endgültigen Primermixe wurden aus diesem Grund folgende Kombinationen festgelegt: RVFV, CCHFV und MARV als Mix 1 und EBOVZ, EBOVS und YFV als Mix 2 (s. Abb. 3.3 ). 


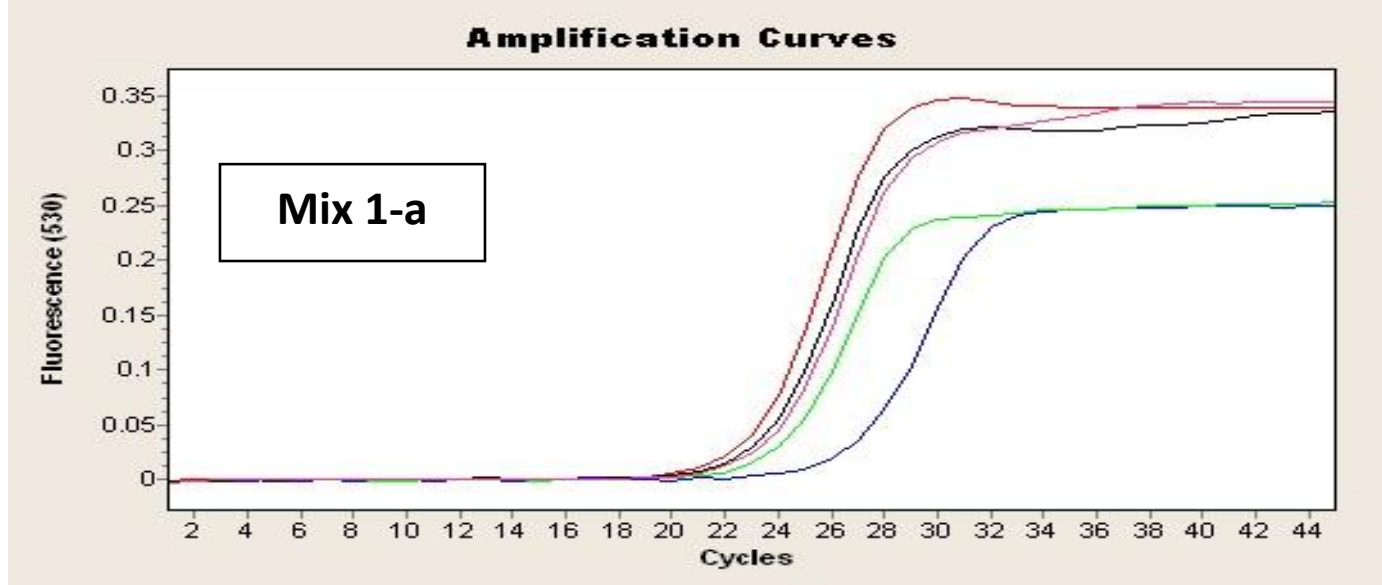

$Y F V-F P+Y F V-R P$

$Y F V-F P+Y F V-R P+R V F V-F P$

$Y F V-F P+Y F V-R P+R V F V-F P+R V F V-R P$

$Y F V-F P+Y F V-R P+R V F V-F P+R V F V-R P+C C S M W-F P$

$Y F V-F P+Y F V-R P+R V F V-F P+R V F V-R P+C C S M W-F P+C C S M W-R P$

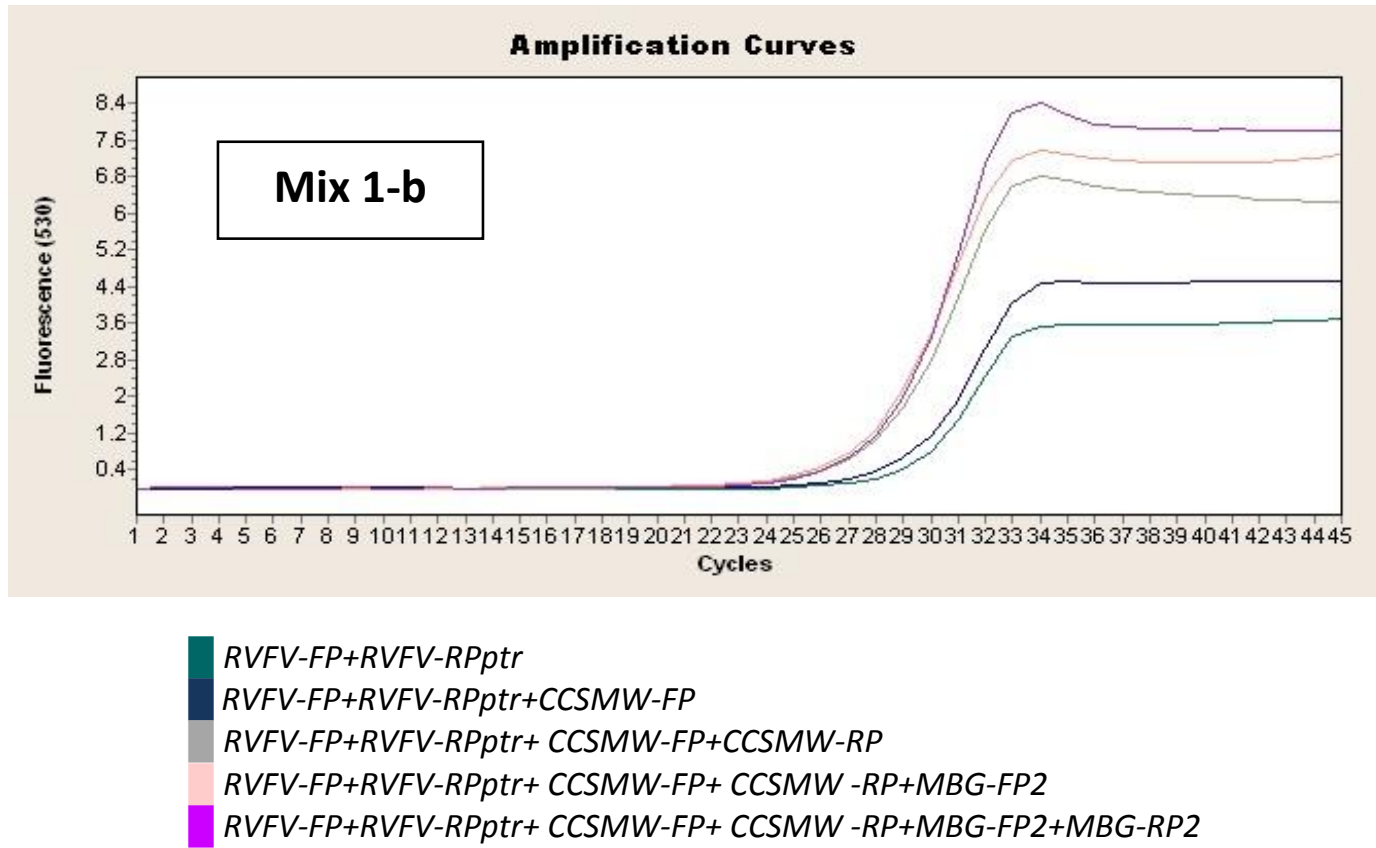

Abb. 3.2: Bestimmung der Primerdimerbildung einer SYBR-GREEN-qRT-PCR für unterschiedliche Primerkombinationen in Mix 1. Mix 1-a enthält eine Primerkombination aus RVFV-CCHFV-YFV und Mix 1-b besteht aus den Primern für RVFV-CCHFV-MARV. Die Primer wurden in einer Konzentration von $100 \mathrm{nM}$ verwendet. Der Versuch wurde ohne RNS-Templates durchgeführt. 


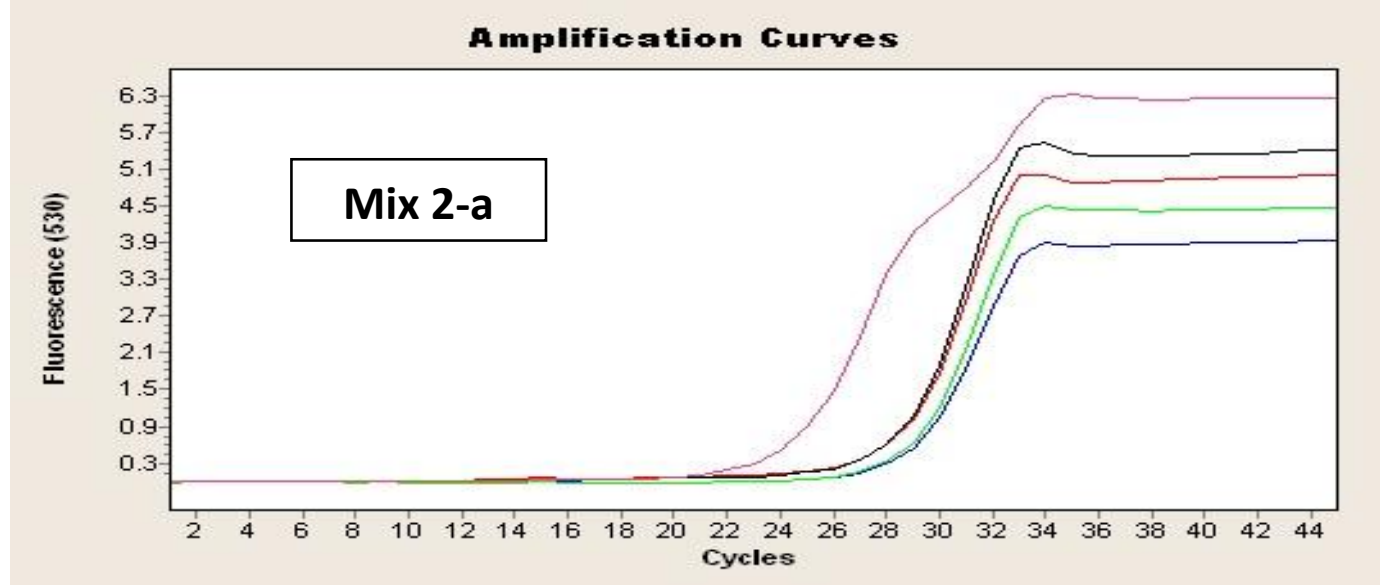

$E B O V Z-F P+E B O V Z-R P$

$E B O V Z-F P+E B O V Z-R P+E B O V S-F P$

$E B O V Z-F P+E B O V Z-R P+E B O V S-F P+E B O V S-R P$

$E B O V Z-F P+E B O V Z-R P+E B O V S-F P+E B O V S-R P+M B R-F P 2$

$E B O V Z-F P+E B O V Z-R P+E B O V S-F P+E B O V S-R P+M B R-F P 2+M B R-R P 2$

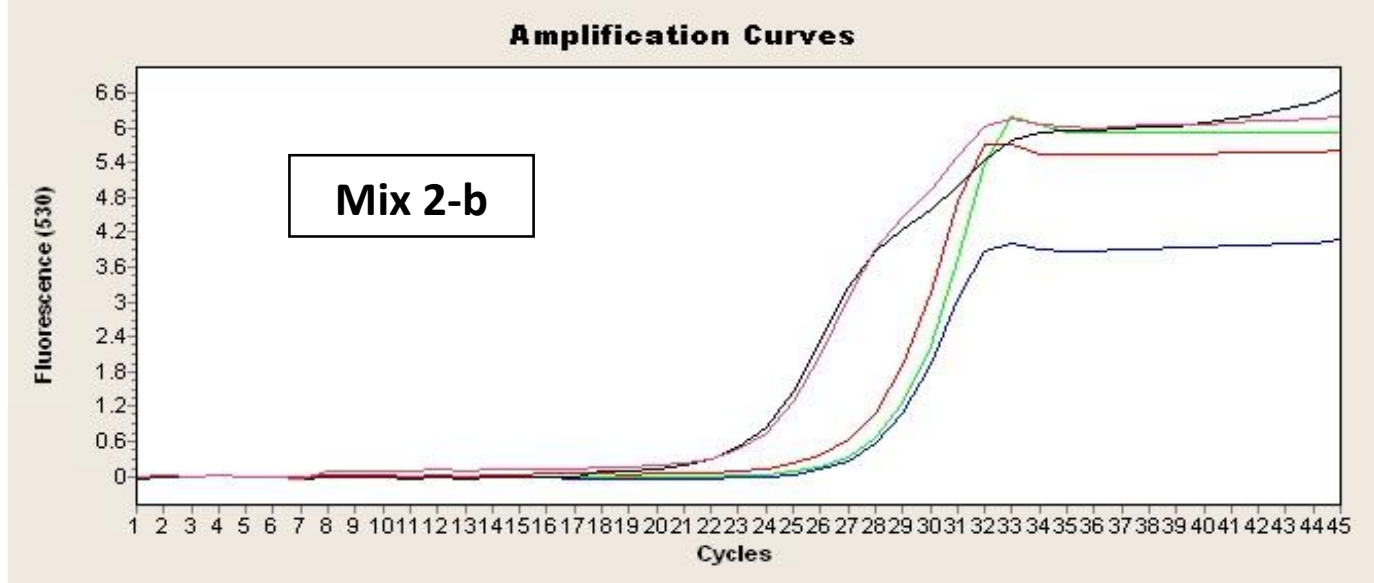

$E B O V Z-F P+E B O V Z-R P$

$E B O V Z-F P+E B O V Z-R P+E B O V S-F P$

$E B O V Z-F P+E B O V Z-R P+E B O V S-F P+E B O V S-R P$

$E B O V Z-F P+E B O V Z-R P+E B O V S-F P+E B O V S-R P+Y F V-F P$

$E B O V Z-F P+E B O V Z-R P+E B O V S-F P+E B O V S-R P+Y F V-F P+Y F V-R P 4$

Abb. 3.3: Bestimmung der Primerdimerbildung einer SYBR-GREEN-qRT-PCR für unterschiedliche Primerkombinationen in Mix 2. Mix 2-a enthält eine Primerkombination aus EBOVZ-EBOSMARV und Mix 2-b besteht aus den Primern für EBOVZ-EBOVS-YFV. Die Primer wurden in einer Konzentration von $100 \mathrm{nM}$ verwendet. Der Versuch wurde ohne RNS-Templates durchgeführt.

DENV wurde verspätet in den CBA mit aufgenommen, sodass Mix 1 und Mix 2 nach Zuführen der zusätzlichen Primer erneut auf Dimerbildung getestet wurden. Um zu entscheiden, in welchen Mix die zusätzlichen DENV-Primer mit aufgenommen werden 
sollte, wurden Multiplex-RT-PCRs nach dem Protokoll in Kap. 2.2.1.3.3 (S.35) mit Primermix 1 (RVFV, CCHFV, MARV) und mit Primermix 2 (EBOVZ, EBOVS, YFV) angesetzt. Als Template diente der DENV-Standard in zwei Konzentrationen $\left(10^{4}\right.$ Moleküle/ $\mu$ und $10^{6}$ Moleküle/ $\left.\mu \mathrm{l}\right)$. Auf dem Agarosegel zeigten die Amplifikationsprodukte des DENVNachweises in Mix 2 deutliche spezifische Banden (87bp) und gleichzeitig schwächere unspezifische Banden als in der Kombination mit Mix 1. Die unspezifischen Banden, die vermutlich durch eine Primerdimerbildung entstanden, waren in Mix 1 stärker ausgeprägt (s. Abb. 3.4). Aus diesem Grund wurden die Primer von DENV in den Mix 2 mit aufgenommen.

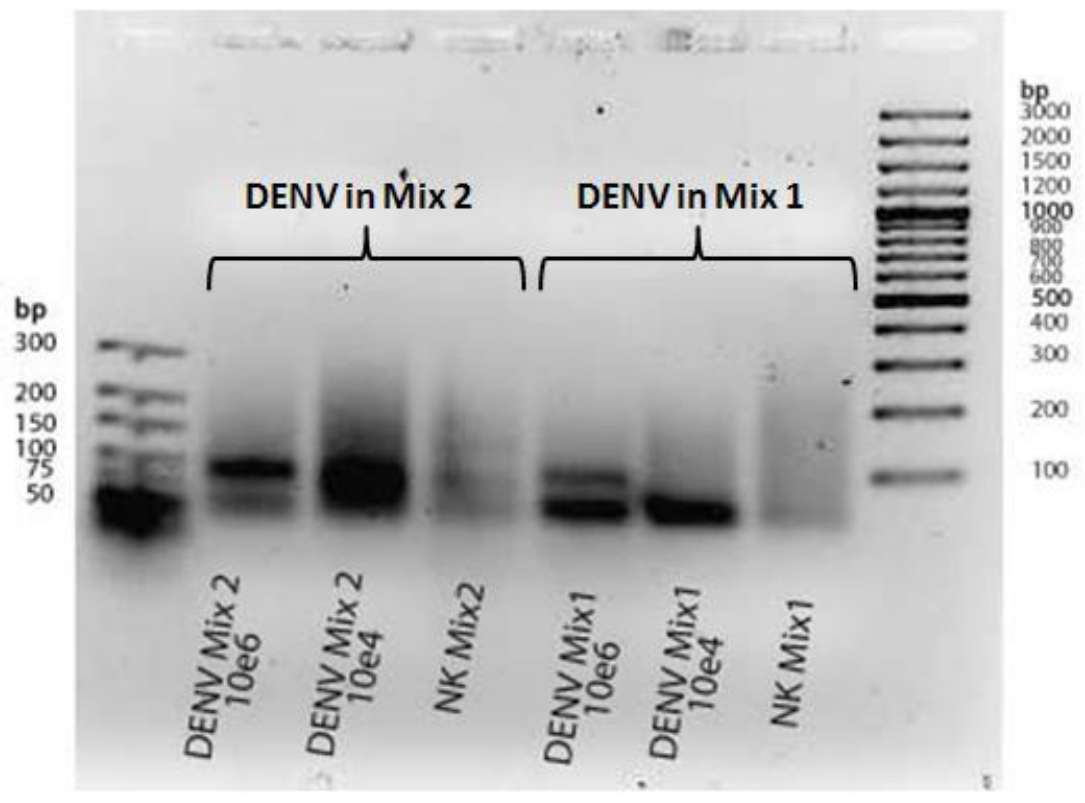

Abb. 3.4: Vergleich der Multiplex-RT-PCR für DENV mit Primermix 1 (RVFV, CCHFV, MARV) und mit Primermix 2 (EBOVZ, EBOVS, YFV). Der Vergleich wurde mit dem DENV-Standard in den Konzentrationen von $10^{4}$ Moleküle/ $\mu$ und $10^{6}$ Moleküle/ $\mu$ l durchgeführt. Die Kombination mit den Primern aus Mix 2 erwies sich als sensitiver und zeigte deutlichere spezifischere DENVBanden (87bp). Es wurden pro Spur $10 \mu \mathrm{l} \mathrm{PCR-Probe} \mathrm{bzw.} 5 \mu$ DNA-Ladder (Größe 10-300 bp bzw. 100-3000 bp) auf 2\%iges Agarosegel aufgetragen.

\subsubsection{Vergleich der Primerdimerbildung in den Primermischungen}

Zur Überprüfung der Primerdimerbildung in den drei Primermischungen (Mix 1, 2, 3) wurde eine SYBR-Green-qRT-PCR nach dem Protokoll aus Kap. 2.2.1.3.6.2 (S.41) durchgeführt. Insgesamt wurden für jeden Mix eine Probe und eine Negativkontrolle angesetzt und im Anschluss im LightCycler ${ }^{\circledR}$ ausgewertet. Die Proben enthielten jeweils die entsprechenden Forward- und Reverse-Primer des Mixes (Konzentration von 100nM) 
(Kap. 3.1.1, S.46 und Kap. 3.1.2, S.48). Die Negativkontrolle enthielt ausschließlich $\mathrm{H}_{2} \mathrm{O}$. Es wurden keine RNS-Templates zugefügt.

Durch die Auswertung der Ct-Werte am LightCycler $^{\circledR}$ (s. Abb. 3.5), konnte auf Primerdimerbildung geschlossen werden. Der Ct-Wert (12) von Mix 1 (RVFV, CCHFV, MARV) war deutlich niedriger als der Ct-Wert (20) von Mix 2 (EBOVZ, EBOVS, YFV, DENV) und Mix 3 (LASV) (26). Das lässt darauf schließen, dass es in Mix 1 zu mehr Primerdimerbildung kam als in den anderen Mischungen.

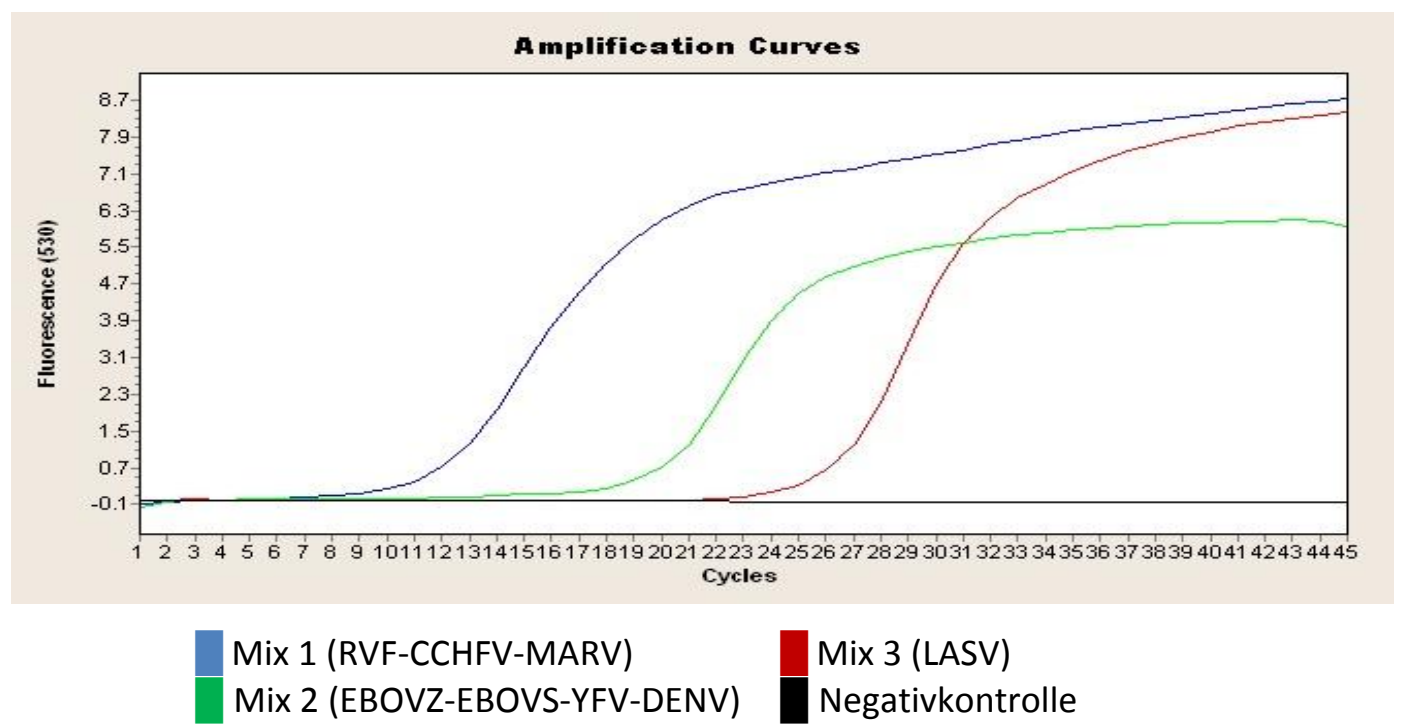

Abb. 3.5: Bestimmung der Primerdimerbildung einer SYBR-GREEN-qRT-PCR für Mix 1 (RVFV, CCHFV, MARV) und Mix 2 (EBOVZ, EBOVS, YFV) und Mix 3 (LASV). Die Primermischungen wurden mit einer Konzentration von $100 \mathrm{nM}$ angesetzt. Es wurden keine RNS-Templates zugefügt.

\subsubsection{Bestimmung des optimalen Primerverhältnisses}

Wie die SYBR-Green-qRT-PCR zeigt (s. Kap. 3.1.1, S.46) waren in der symmetrischen Multiplex-PCR mit einer Primerkonzentration von 100nM am wenigsten Primerdimere aufgetreten. Deregt et al. (Deregt et al. 2006) und Horejsh et al. (Horejsh et al. 2005) beschrieben jedoch, dass bei Multiplex-RT-PCRs die Produkte einer asymmetrischen PCR im anschließenden CBA zu wesentlich höheren mittlere Fluoreszenzintensitäten (MFI) führen als Produkte einer symmetrischen PCR.

Aus diesem Grund wurden alle Primermixe als asymmetrischen PCRs durchgeführt und im Agarosegel analysiert. Dabei wurden Multiplex-RT-PCRs für jeden Primermix in 
asymmetrischen PCRs mit FP/RP-Verhältnissen von 1:4 und 4:1 (Primerkonzentration von 400nM: 100nM bzw. 100nM: 400nM) angesetzt und mit dem PCR-Programm aus Kap. 2.2.1.3.3 (S.35) amplifiziert. Als Template der entsprechenden Viren wurde $1 \mu \mathrm{l}$ des RNS-Standards in einer Konzentration von $10^{6}$ Molekülen/ $\mu$ l verwendet. In der Gelelektrophorese wurden die Produkte auf 2\%igem Agarosegel aufgetrennt und das effizientere Mischverhältnis zur Amplifikation der viralen RNS bestimmt.

Abb. 3.6 zeigt die Ergebnisse der Multiplex-RT-PCR auf dem Agarosegel von Primermix 1. Sowohl beim FP/RP-Verhältnis 1:4 als auch beim FP/RP-Verhältnis 4:1 ließen sich die Banden bei spezifischer Größe erkennen: RVFV 128 bp, CCHFV 172 bp und MARV 88 bp. Beim FP/RP-Verhältnis von 4:1 erscheinen die Banden in diesem Mix jedoch stärker. Aus diesem Grund wurde in der Multiplex-PCR für den CBA der vorliegenden Arbeit das 4:1Primer-Verhältnis für Mix 1 angewendet.

Auch beim Primermix 2 (Abb. 3.7) traten die spezifischen Banden (EBOVZ 91 bp, EBOVS 89 bp, YFV 94 bp und DENV 87 bp) auf. Das FP/RP-Verhält 1:4 führt in diesem Primermix zu wesentlich deutlicheren Banden. Somit wurde für die Multiplex-PCR von Mix 2 das 1:4-Primer-Verhältnis ausgewählt.

Um die Multiplex-PCR für den Primermix 3 auszutesten wurde die RNS der LASV-Stämme AV und CSF vom Bernhard-Nocht-Institut verwendet. Dabei ließen sich nur im FP/RPVerhältnis 1:4 die spezifischen Banden (LASV-AV 127 bp, LASV-CSF 136 bp) abbilden (s. Abb. 3.8), sodass die Multiplex-PCR von Mix 3 in der vorliegenden Arbeit mit einem 1:4Primer-Verhältnis durchgeführt wurde.

Alle drei Primermischungen wiesen außer den Banden der spezifischen PCR-Amplifikate auch Banden unspezifischer Produkte (bei ca. 60-70bp) auf. Zur Entfernung dieser unspezifischen Produkte in Mix 1 wurde das MinElute-Purifikation-Kit von QIAGEN verwendet (Kap. 2.2.2.1, S.42). 


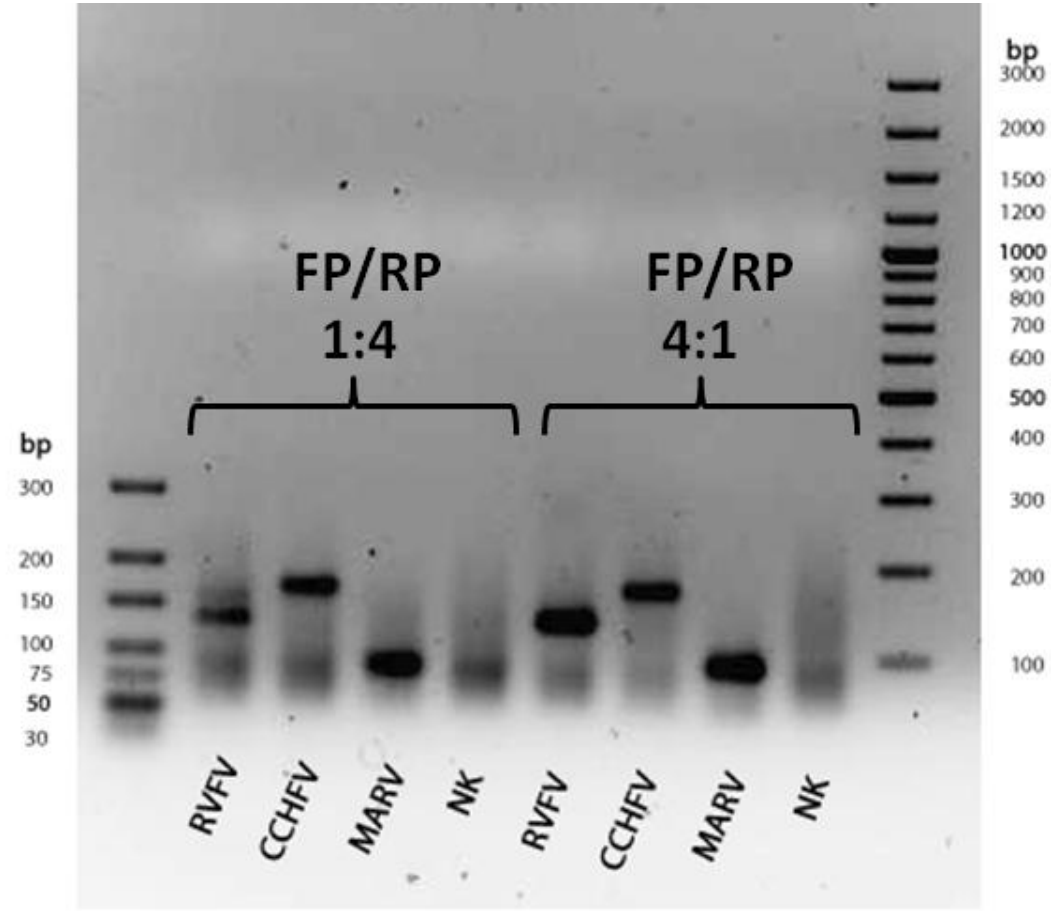

Abb. 3.6: Vergleich der asymmetrischen Multiplex-RT-PCR für Primermix 1 (RVFV, CCHFV, MARV), die asymmetrische Multiplex-RT-PCR mit einem FP/RP-Verhältnis von 4:1 erwies sich bei Primermix 1 als sensitiver. Es wurden pro Spur $10 \mu \mathrm{l}$ PCR-Probe bzw. $5 \mu$ I DNA-Ladder (Größe 10-300 bp bzw. 100-3000 bp) auf 2\%iges Agarosegel aufgetragen. Als Template der entsprechenden Viren wurde $1 \mu \mathrm{l}$ des RNS-Standards in einer Konzentration von $10^{6}$ Molekülen/ $\mu$ l verwendet.

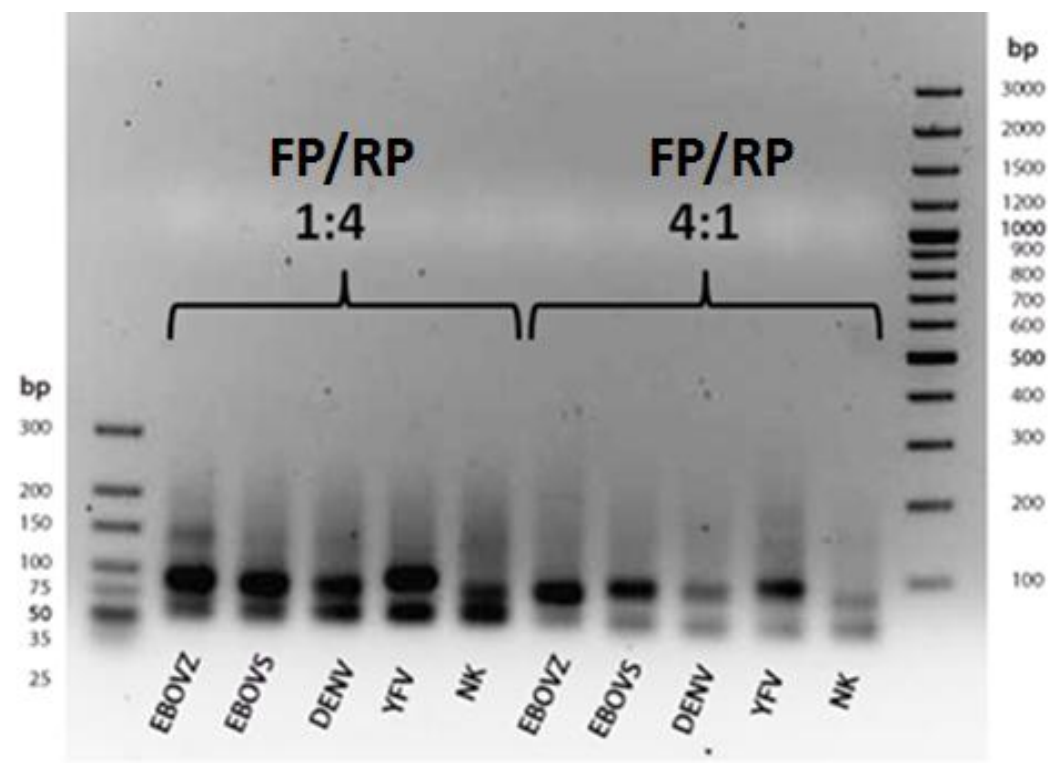

Abb. 3.7: Vergleich der asymmetrischen Multiplex-RT-PCR für Primermix 2 (EBOVZ, EBOVS, YFV), die asymmetrische Mutiplex-RT-PCR mit einem FP/RP-Verhältnis von 1:4 erwies sich als sensitiver bei Primermix 2. Es wurden pro Spur $10 \mu \mathrm{l}$ PCR-Probe bzw. $5 \mu$ INA-Ladder (Größe 10-300 bp bzw. 100-3000 bp) auf ein 2\%iges Agarosegel aufgetragen. Als Template der entsprechenden Viren wurde $1 \mu$ l des RNS-Standards in einer Konzentration von $10^{6}$ Molekülen/ $\mu$ l verwendet. 


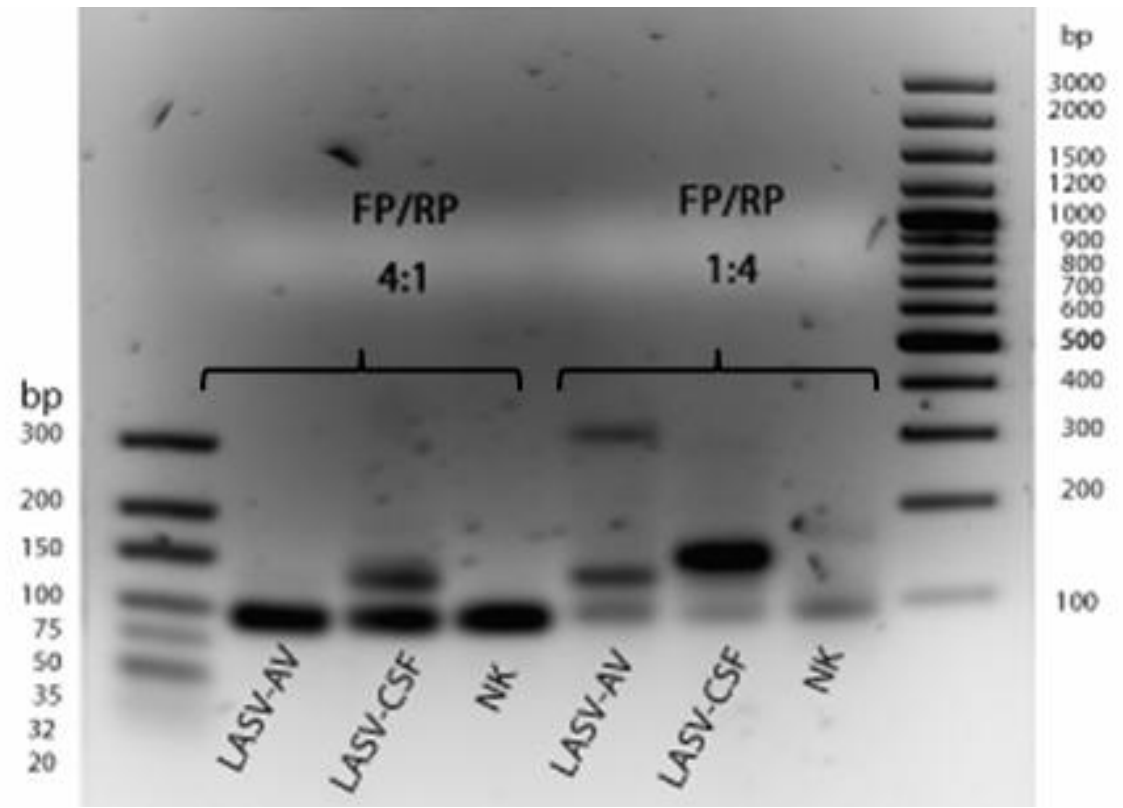

Abb. 3.8: Vergleich der asymmetrischen Multiplex-RT-PCR für Primermix 3 (LASV), die asymmetrische Mutiplex-RT-PCR mit einem FP/RP-Verhältnis von 1:4 erwies sich als sensitiver bei Primermix 3. In diesem FP/RP-Verhältnis trat zusätzlich in der LASV-AV-Probe eine unspezifische Bande bei 300bp auf. Es wurden pro Spur $10 \mu \mathrm{l}$ PCR-Probe bzw. $5 \mu$ l DNA-Ladder (Größe 10-300 bp bzw. 100-3000 bp) auf ein 2\%iges Agarosegel aufgetragen. Als Template der entsprechenden Viren wurde $1 \mu \mathrm{l}$ des RNS-Standards in einer Konzentration von $10^{6}$ Molekülen/ $\mu$ l verwendet.

\subsubsection{Aufreinigung der PCR-Produkte mit dem MinElute-Purifikation-Kit}

Zur Isolierung spezifischer PCR-Produkte wurden die PCR-Proben nach der Multiplex-RTPCR mit dem MinElute-Purifikation-Kit (QIAGEN) aufgereinigt. Durch den Reinigungsvorgang wurden alle Nukleinsäuren, die <70bp bzw. $>4 \mathrm{~kb}$ waren und alle Proteine aus der Probe entfernt. Ergänzend zum Herstellerprotokoll wurde während der Reinigung mit dem MinElute-Purification-Kit vor dem Bindungsschritt ein zusätzlicher

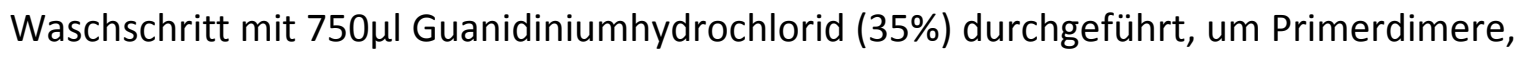
die >20bp waren, effizienter zu entfernen (s.Kap. 2.2.2.1, S.42).

Es zeigte sich, dass eine erfolgreiche Hybridisierung der PCR-Produkte aus Mix 1 an die bead-gekoppelten Oligonukleotidsonden erst nach der Aufreinigung mit dem MinElutePurifikation-Kit möglich war. Bei Mix 2 und Mix 3 ließ sich bei der Hybridisierungsreaktion kein Unterschied $z u$ den unbereinigten PCR-Produkten erkennen. Deshalb wurde die Aufreinigung durch das MinElute-Purification-Kit in der vorliegenden Arbeit nur für Mix 1 durchgeführt.

In Abb. 3.9 wird der Vergleich der PCR-Produkte mit und ohne Aufreinigung durch das MinElute-Purifikation-Kit dargestellt. Dabei zeigt sich deutlich, dass durch die 
Aufreinigung alle unspezifischen PCR-Produkte entfernt werden konnten. Bei den Proben, die über MinElute-Purifikation aufgereinigt wurden, lassen sich lediglich die spezifischen Banden der spezifischen Produkte erkennen, allerdings in geringerer Konzentration.

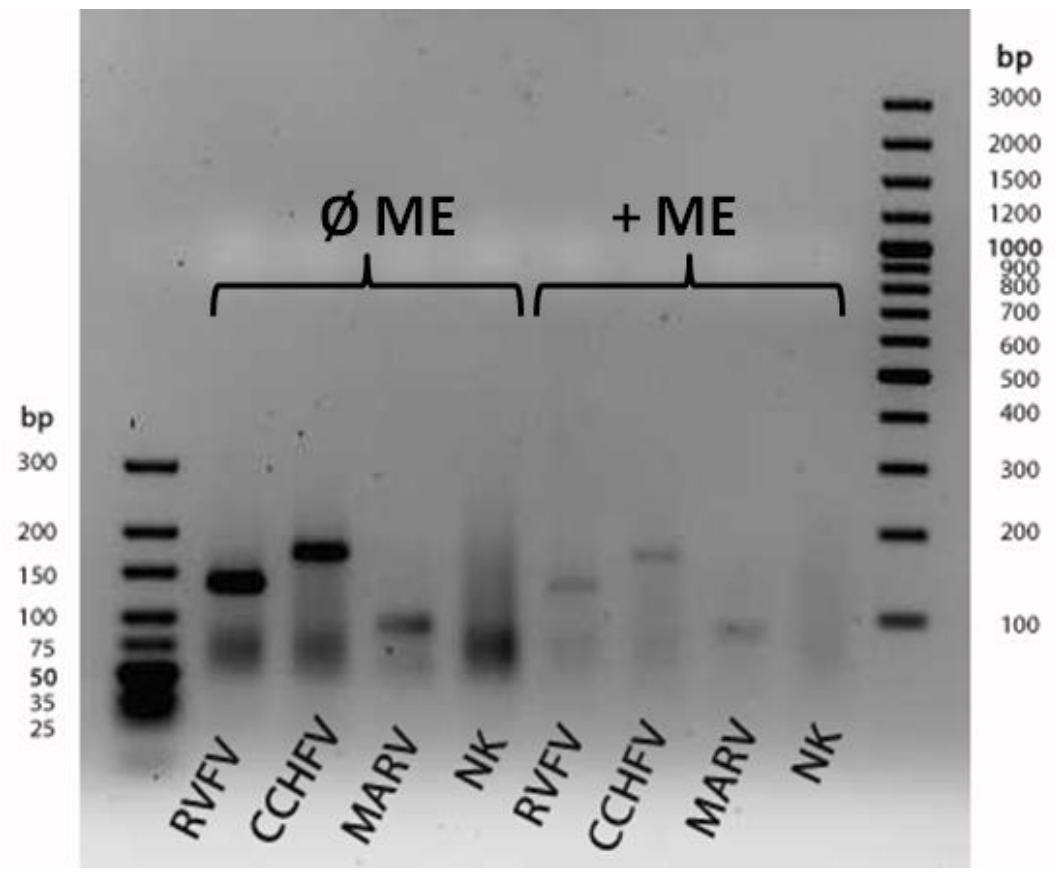

Abb. 3.9: Vergleich der PCR-Produkte für Primermix 1 mit und ohne Aufreinigung mit MinElutePurifikation-Kit, in den Proben, die mit MinElute-Purifikation gereiningt wurden, lassen sich nur noch die Banden der spezifischen PCR-Produkte erkennen, es wurden pro Spur $10 \mu \mathrm{l}$ PCR-Probe bzw. $5 \mu$ l DNA-Ladder (Größe 10-300 bp bzw. 100-3000 bp) auf ein 2\%iges Agarosegel aufgetragen.

\subsection{Kopplung der Sonde an Beads}

Um die biotinylierten PCR-Produkte an die Beads binden zu können, mussten zuvor aminierte Oligonukleotidsonden an die carboxylierten Kugeln gekoppelt werden. Durch Hybridisierung an diese immobilisierten Oligonukleotidsonden wurde anschließend die Bindung der PCR-Produkte an die Beads ermöglicht.

Die Kopplungsreaktion erfolgte über eine Carbodiimid-Reaktion, in der die funktionellen Carbonsäuregruppen der Beads durch den Kreuzvernetzer EDAC aktiviert wurden und daraufhin eine kovalente Bindung mit den freien Aminogruppen der aminierten DNSSonden eingingen (s. Kap.2.2.2.2, S.43).

Für sechs der zu untersuchenden HFV (RVFV, CCHFV, MARV, EBOVZ, EBOVS, DENV) wurde die Sequenz der TaqMan-Sonden synthetisiert und als Sonde an die Beads 
gekoppelt (Länge 25-35nt). Bei YFV und LASV wurden kurze locked-nucleic-acid (LNA)Sonde synthetisiert, die aufgrund ihrer LNA-Basen eine erhöhte $T_{M}$ besitzen (Länge 422nt) (Weidmann et al. 2010).

Die Sonden der einzelnen HFV-Nachweise wurden an verschiedene BPs mit unterschiedlichen Mischungsverhältnissen der Fluoreszenzfarbstoffen (APC, APC-Cy7) gekoppelt um die einzelnen Populationen und die daran gekoppelten Sonden im Durchflusszytometer voneinander zu unterscheiden. Für die Kopplungsreaktion von 1,25 x $10^{6}$ Beads (s. Kap.2.2.2.2, S.43) wurde eine Sondenmenge von je 400 pmol eingesetzt. Dabei wurden die einzelnen BPs so aufeinander abgestimmt, dass sich die Emissionspektren ihrer Fluoreszenzfarbstoffe (APC, APC-Cy7) in den drei Mixen nicht überschnitten. Insgesamt wurden 13 verschiedene Oligonukleotidsonden synthetisiert.

Tab. 3.1: Eingesetzte Oligonukleotidsonden und zugehörige Beadpopulationen

\begin{tabular}{|c|c|c|c|c|c|c|c|c|}
\hline & $\begin{array}{c}\text { Name der } \\
\text { Sonde }\end{array}$ & BP & & $\begin{array}{c}\text { Name der } \\
\text { Sonde }\end{array}$ & BP & & $\begin{array}{c}\text { Name der } \\
\text { Sonde }\end{array}$ & BP \\
\hline MIX 1 & $\begin{array}{l}\text { RVFV } \\
\text { CCSMW-TM } \\
\text { MARV }\end{array}$ & $\begin{array}{l}\text { Nr. } 1 \\
\text { Nr. } 6 \\
\text { Nr. } 36\end{array}$ & MIX 2 & $\begin{array}{l}\text { EBOVZ } \\
\text { EBOVS } \\
\text { YFV } \\
\text { DENV }\end{array}$ & $\begin{array}{l}\text { Nr. } 8 \\
\text { Nr. } 23 \\
\text { Nr.50 } \\
\text { Nr. } 44\end{array}$ & MIX 3 & $\begin{array}{l}\text { LASV-LNA } 1 \\
\text { LASV-LNA } 2 \\
\text { LASV-LNA } 3 \\
\text { LASV-LNA } 4 \\
\text { LASV-LNA } 5\end{array}$ & $\begin{array}{l}\text { Nr. } 3 \\
\text { Nr. } 15 \\
\text { Nr. } 29 \\
\text { Nr. } 32 \\
\text { Nr. } 40\end{array}$ \\
\hline $\begin{array}{l}\text { Kon- } \\
\text { trolle }\end{array}$ & CCHF-Cy3 & Nr.17 & & & & & & \\
\hline
\end{tabular}

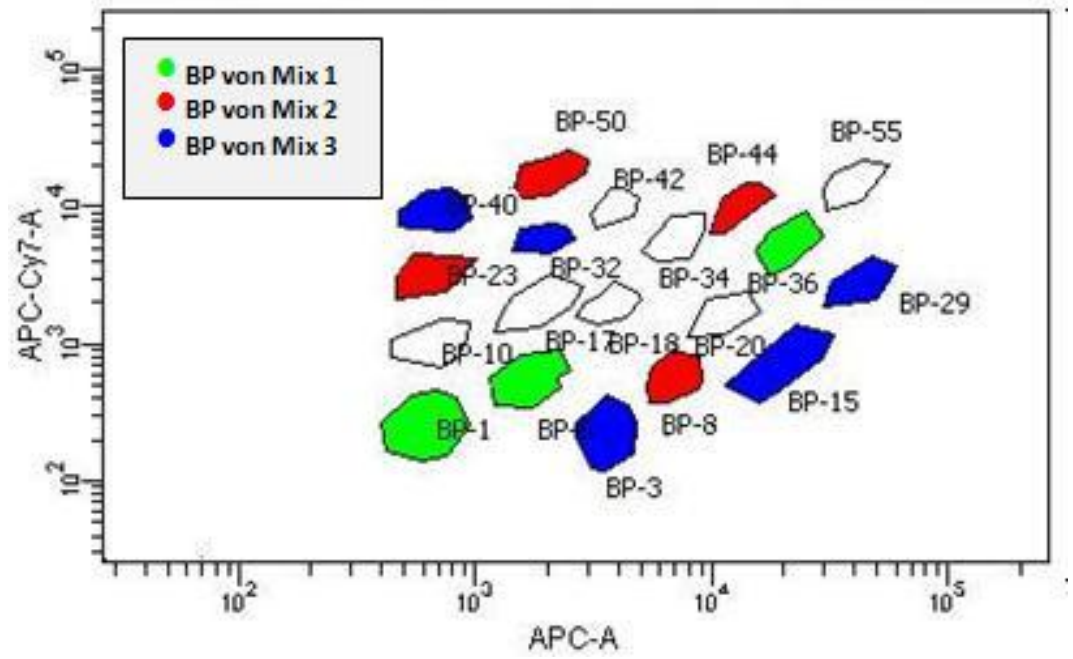

Abb. 3.10: Darstellung eines Dot-Plot-Diagramms, in dem die Verteilung der Beadpopulationen (BP) von Mix 1, 2, und 3 abhängig vom internen Mischverhältnis der Fluoreszenzfarbstoffe APC und APCCy7 abgebildet wird. Die BPs wurden für jeden Mix so aufeinander abgestimmt, dass Überschneidungen bei den Emissionsmaxima der Farbstoffe APC und APC-Cy7 vermieden wurden. 
Zur Überprüfung der Kopplung wurde in einem Parallelansatz eine CCHFVOligonukleotidsonde eingesetzt, die mit dem Fluoreszenzfarbstoff Cy3 markiert war. Durch wiederholtes Mitführen dieser Kontrolle mit Cy3-markierter Sonde bei den Versuchen konnte die Effizienz der Kopplungen überwacht und miteinander verglichen werden (s. Kap 3.2.1, S.59).

Nach der Kopplung erfolgte die Analyse der Fluoreszenzintensität des Cy3Fluoreszenzfarbstoffes am Durchflusszytometer. Das Emissionsmaximum dieses Fluoreszenzfarbstoffes (Сy3) liegt mit $575 \mathrm{~nm}$ dicht am Emissionsmaximum von PE (Phycoerythrin), das bei $585 \mathrm{~nm}$ emittiert und konnte deswegen im PE-Fluoreszenzkanal des FACS Canto ${ }^{\mathrm{TM}}$ II detektiert und mit der FACS-Diva-Software analysiert werden.

Für die Kopplungskontrolle wurden in einem ersten Experiment 400 pmol der Cy3markierten CCHFV-Sonde an 1,25 × 106 Beads der BP Nr. 17 mithilfe von EDAC gekoppelt (s. Kap.2.2.2.2, S.43) und im Anschluss an die Kopplung im FACS analysiert. Zum Vergleich wurde eine Negativprobe mitgeführt, die Beads derselben Population (BP Nr.17) und, anstelle der Cy3-markierten Sonde, $\mathrm{H}_{2} \mathrm{O}$ enthielt. Die Probe mit der Cy3markierten Sonde wies eine deutlich höheres Fluoreszenzsignal im PE-Kanal (MFI-PE: 27.437) auf als die Negativkontrollprobe (MFI-PE: 331). Dieses Ergebnis (MFI-PE 82,9x höher als NK) beweist eine erfolgreiche Kopplung der Oligonukleotidsonde an die Beads.

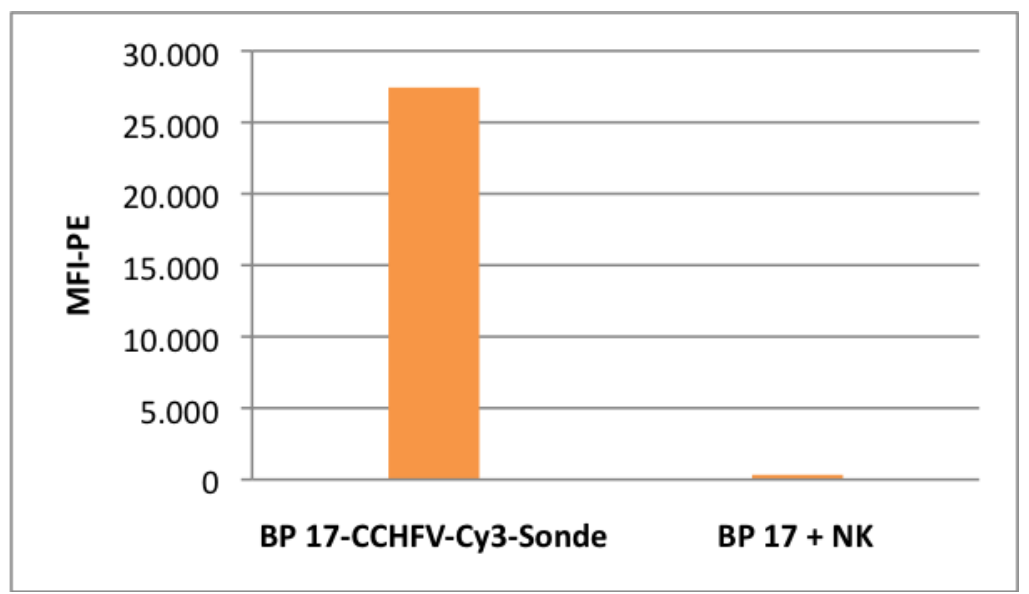

Abb. 3.11:Qualitative Kontrolle der Kopplung mit einer Cy3-markierten CCHFV-Sonde: Vergleich der Fluoreszenzsignale der an die BP Nr. 17 gekoppelten Cy3-markierten Sonde (MFI-PE: 27.437) mit der Negativkontrolle (MFI-PE:331). 


\subsubsection{Reproduzierbarkeit der Kopplung}

Um die Reliabilität und Reproduzierbarkeit der Kopplung zu überprüfen, wurde zu jeder Versuchsreihe eine Kopplungskontrolle parallel mit einer Cy3-markierten Sonde durchgeführt. Eine direkte Kontrolle der Kopplungsreaktion der Oligonukleotidsonde an die carboxylierten Kugeln war nicht möglich (s. Kap 3.2).

Der Mittelwert der Fluoreszenzsignale der Cy3-markierten Sonden lag bei MFI-PE: $27.502 \pm 3762$ (s. Abb. 3.2Fehler! Verweisquelle konnte nicht gefunden werden..). Der Maximalwert (MFI-PE: 39.480) wurde bei der Kopplungskontrolle vom 17.06.09 ermittelt. Durch die mehrfache Überprüfung der Kopplung konnte ein hoher Grad an Reproduzierbarkeit für die Kopplungsreaktion nachgewiesen werden.

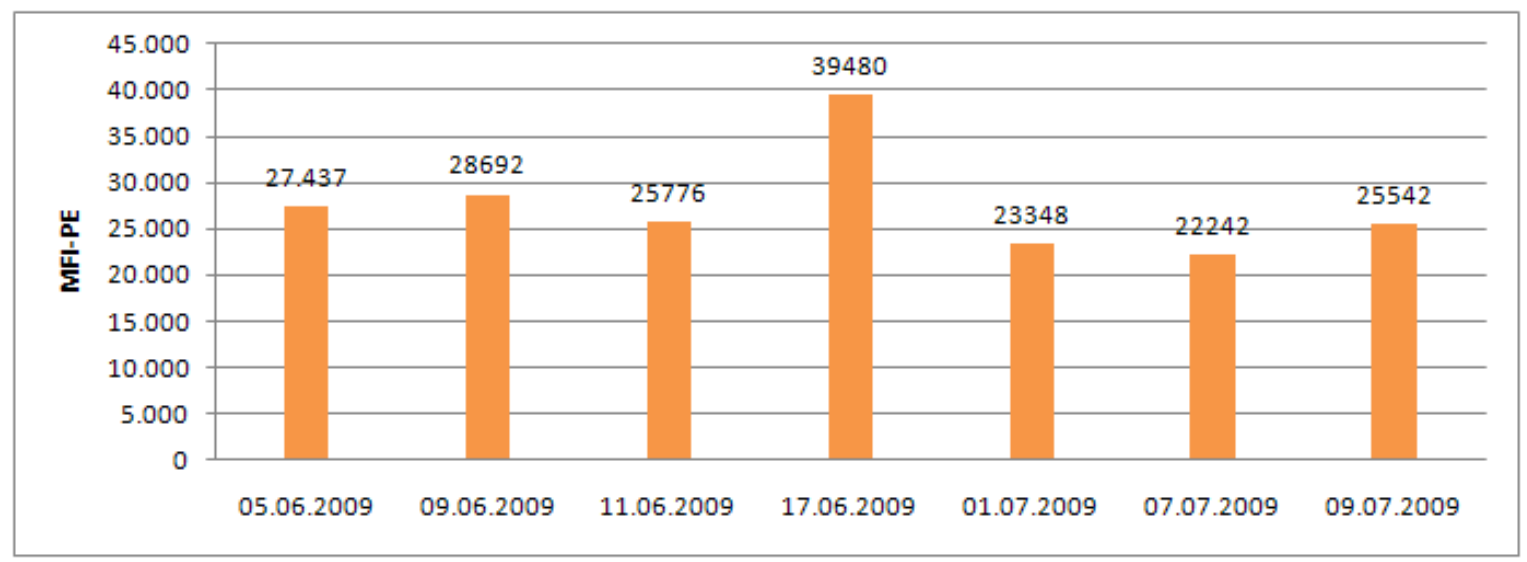

Abb. 3.12:Effizienzkontrolle der Kopplung mit einer Cy3-markierten CCFHV-Sonde, ein Vergleich der MFIPE-Signale der fluoreszenzmarkierten Cy3-Sonde von verschiedenen Versuchsreihen

\subsection{Hybridisierung an bead-gekoppelte Sonden und Detektion}

Im Anschluss an die erfolgreiche kovalente Kopplung der Oligonukleotidsonden an die Beads konnten die PCR-Amplifikate an die gekoppelten Oligonukleotidsonden hybridisiert werden.

Für diese Hybrdisierungsreaktionen wurden je $5 \mu \mathrm{l}$ der PCR-Amplifikate (1:2 mit TrisEDTA, $\mathrm{pH} 8,0$, verdünnt) bei $96^{\circ} \mathrm{C}$ für 5 min denaturiert und danach sofort auf Eis gekühlt um eine Renaturierung zu verhindern. Die PCR-Produkte wurden im Anschluss für eine Stunde bei $60^{\circ} \mathrm{C}$ mit $5 \mu \mathrm{l}$ der gekoppelten Beads inkubiert. Der qualitative Nachweis der Hybridiserung erfolgte durch die Bindung von $10 \mu \mathrm{g} / \mathrm{ml}$ SARPE (Streptavidin-R-Phycoerythrin) an die biotinylierten PCR-Produkte. Individuelle Proben 
wurden zuerst im Uniplex-Hybridisierungsverfahren untersucht (s. Kap. 3.3.2, S.63). Dann erfolgte die Analyse der einzelnen Mixe (Mix 1-3) im MultiplexHybridisierungsverfahren (s. Kap. 3.3.3, S.65).

Die Sensitivität des CBAs wurde im Uniplex- und Multiplex-Hybridisierungsverfahren ermittelt und miteinander verglichen (s. Kap. 3.3.4, S.70 und Kap. 3.3.5, S.73). Im Anschluss erfolgte eine statistische Analyse der Ergebnisse und die Entwicklung einer Methode zur Grenzwertbestimmung (s. Kap. 3.3.6, S.76). Um die Spezifität zu überprüfen wurden die Mixe 1, 2, 3 schließlich auf Kreuzreaktivität getestet (s. Kap. 3.3.7, S.80).

\subsubsection{Optimierung der Hybridisierungsbedingungen}

Zur Verbesserung der Sensitivität und Spezifität der Hybridisierungsreaktion wurden während der experimentellen Versuchsreihen verschiedene Parameter optimiert: die Hybridisierungstemperatur (s. Kap. 3.3.1.1), die Lagerungstemperatur, die Lagerungsdauer (s. Kap. 3.3.1.2, S.61) und die Hybridisierungspuffer (s. Kap. 3.3.1.3, S.62).

\subsubsection{Optimierung der Hybridisierungstemperatur}

Um die PCR-Amplifikate an die Oligonukleotidsonden hybridisieren zu können, musste die optimale Hybridisierungstemperatur gewählt werden. Da die Hybridisierung im Multiplex-System aus Mischungen mit bis zu vier BPs erfolgen sollte, musste die Hybridisierungstemperatur den Bedingungen aller beteiligten Oligonulkleotide entsprechen. Auf Zusätze wie apolares Formamid 20\% oder DMSO sollte in dem Multiplex-System verzichtet werden. Eine Zugabe weiterer Substanzen hätte das komplexe Multiplex-System komplizierter gemacht und damit die Überführung in die Routinediagnostik erschwert.

Bei der Betrachtung der Schmelztemperaturen der Oligonukleotidsonden (s. Tab. 2.8, S.29) wurde deutlich, dass Temperaturen $>61^{\circ} \mathrm{C}$ die Hybridisierung der spezifischen PCRAmplifikate an die Sonden verhinderten. Dem gegenüber bestand die Gefahr, dass Temperaturen $<60^{\circ} \mathrm{C}$ die Wahrscheinlichkeit falsch-positiver Hybridisierungen erhöhen. 
Folgende Hybridisierungstemperaturen wurden getestet: $55^{\circ} \mathrm{C}, 57^{\circ} \mathrm{C}, 60^{\circ} \mathrm{C}, 65^{\circ} \mathrm{C}$. Bei einer Temperatur von $60^{\circ} \mathrm{C}$ wurde eine optimale Hybridisierung der PCR-Produkte aller Viren an die Sonden erzielt, die ausreichend hohe MFI-PE-Werte erreicht und unspezifische Bindungen durch Hybridisierung minimiert.

\subsubsection{Bedeutung der Lagerungsbedingungen der Beads für die Hybridisierung}

Um den Einfluss der Lagerungstemperatur auf die Sensitivität des CBAs zu bestimmen, wurden PCR-Produkte von DENV in unterschiedlichen Konzentrationen $\left(10^{7}-10^{1}\right.$

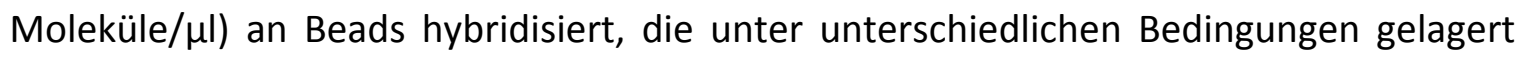
wurden: eine Versuchsreihe wurde nach der Kopplung mit Oligonukleotidsonden über Nacht bei $-20^{\circ} \mathrm{C}$ gelagert und erst am folgenden Tag fand die Hybridisierung an die PCRAmplifikate statt. Eine weitere Versuchsreihe wurde direkt im Anschluss an die Kopplung zur Hybridisierung weiterverwendet.

Die erzielten Fluoreszenzintensitäten der verschiedenen Ansätze wurden am FACS Canto $^{\mathrm{TM}}$ II verglichen. Im Liniendiagramm (s. Abb. 3.13.) in Fehler! Verweisquelle konnte nicht gefunden werden. sind die MFI-PE-Werte dargestellt. Es wird deutlich, dass die Fluoreszenzintesitäten bei Lagerung der gekoppelten Beads über Nacht bei $-20^{\circ} \mathrm{C}$ (MFIPE: 50913) im Vergleich zu Proben, die direkt nach der Kopplung zur Hybridisierung verwendet wurden (MFI-PE: 14654), auf das 3,5-Fache erhöht ist.

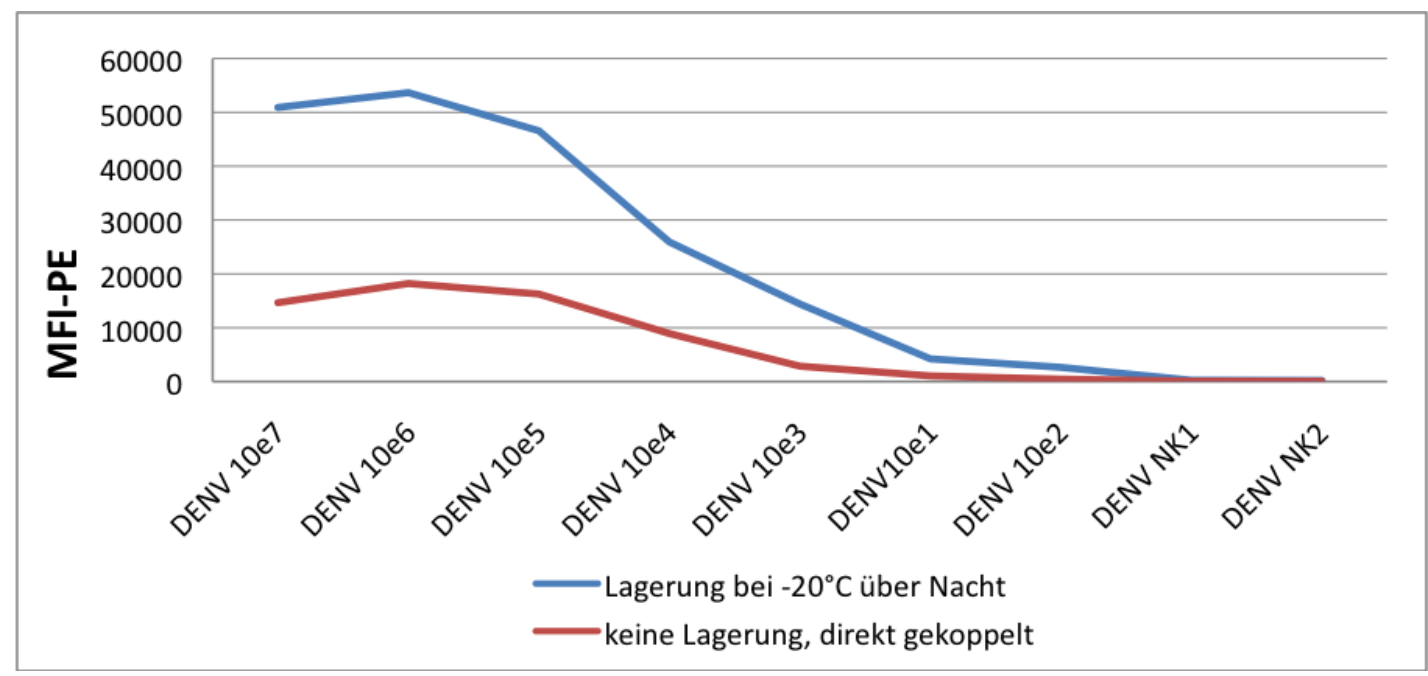

Abb.3.13: Uniplex-Sensitivitätmessung von DENV bei unterschiedlichen Lagerungsbedingungen: Bei Sensitivitätsmessung 1 (blau) wurden die Beads über Nacht bei $-20^{\circ} \mathrm{C}$ nach der Kopplungsreaktion gelagert, bei Sensitivitätsmessung 2 (rot) wurden die Beads direkt im Anschluss an die Kopplung zur Hybridisierung verwendet. 


\subsubsection{Notwendigkeit des BSA-Puffers}

Um unspezifische MFI-PE-Signale bei der Hybridisierungsreaktion zu vermeiden, mussten die freien Carboxylgruppen der Beads abgesättigt sein. Da durch die Oligonukleotidsonden in dem vorausgehenden Kopplungsschritt die Carboxylgruppen der Beads nicht vollständig besetzt wurden, war es nötig diese freien, zum Teil noch durch das EDAC aktivierten $\mathrm{COOH}-G r u p p e n$ durch die Zugabe eines Blockierungspuffers abzusättigen, damit diese $\mathrm{COOH}-G r u p p e n$ nicht unspezifisch mit dem Reporter Streptavidin-Phycoerythrin reagierten. Bovines Serumalbumin (BSA) und Difco ${ }^{\mathrm{TM}}$ Skim Milk (SM) sind Blockpuffer, die mit ihren Amin-Gruppen kovalente Peptidbindungen mit Carbxoylgruppen ausbilden können und somit eine stabilisierende Wirkung erzielen. Es wurden zwei verschiedenen Blockpuffer getestet: 10\% BSA (in 0,02\% Tween) und 10\% SM (in 0,02\% Tween). Die Beads wurden ohne gekoppelte Sonden nach der Methode, die in Kap. 2.2.2.2 (S.43) beschrieben ist, bei $60^{\circ} \mathrm{C}$ erhitzt und in $100 \mu \mathrm{SARPE}$, das zuvor in $0,02 \%$ Tween 20 in FACS-Flow $(10 \mu \mathrm{g} / \mathrm{ml})$ verdünnt wurde, inkubiert. Statt der PCRAmplifikate wurden $5 \mu \mathrm{l} \mathrm{H}_{2} \mathrm{O}$ hinzugegeben. Insgesamt wurden in drei Durchläufen jeweils zwei Proben angesetzt: 1) Beadpopulation (BP) mit $\mathrm{H}_{2} \mathrm{O}$ und $50 \mu \mathrm{l} 10 \%$ BSA (in Tween 20) und 2) BP mit $\mathrm{H}_{2} \mathrm{O}$ und 50 $\mu \mathrm{l}$ 10\% SM (in Tween 20). Als Vergleich diente 3) die Negativkontrolle mit BP und $\mathrm{H}_{2} \mathrm{O}$ anstelle von Blockpuffer.

Die Ansätze, die einen Blockpuffer (BSA oder SM) enthielten, zeigten nur schwache Fluoreszenzsignale (Abb. 3.14). Bei der Kontrollprobe ohne Blockpuffer hingegen wurde im Vergleich zu der Probe mit BP+ $\mathrm{H}_{2} 0+B S A$ ein 49,11-fach stärkeres und im Vergleich zu den Proben mit $\mathrm{BP}+\mathrm{H}_{2} \mathrm{O}+\mathrm{SM}$ ein 62,08-fach stärkeres MFI-PE-Signal gemessen. Somit konnte demonstriert werden, dass durch die Zugabe von Blockpuffer hohe Fluoreszenzsignale durch unspezifische Bindungen des SARPE an die Beads verhindert werden konnten.

Im Rahmen dieser Arbeit wurde für die Blockierung der freien Carboxylgruppen der BSAPuffer ausgewählt, da SM als Proteingemisch in verschiedenen Produktionsreihen starke Variationen in seiner Zusammensetzung aufweist, während BSA nur reines bovines Serum enthält. 


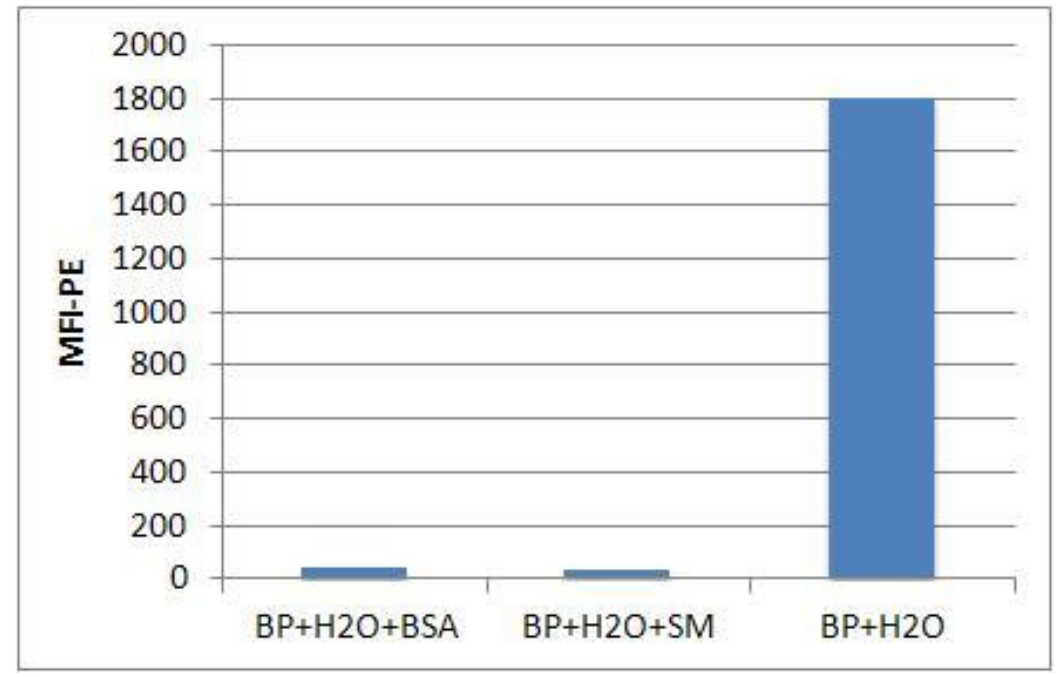

Abb. 3.14: Notwendigkeit des Blockpuffers. Pro Probe wurden 1000 Beads im FACS Canto ${ }^{\mathrm{TM}}$ II analysiert, jede Probe enthielt jeweils $5 \mu$ l ungekoppelte Beads (1:2 mit Tris-EDTA, pH 8,0, verdünnt) mit $5 \mu l$ $\mathrm{H}_{2} \mathrm{O}$ und $50 \mu \mathrm{l}$ Blockpuffer (Bovines Serumalbumin, BSA/ Difco ${ }^{\text {TM }}$ SkimMilk, SM), die Negativkontrolle enthielt lediglich $5 \mu$ l ungekoppelte Beads und $5 \mu \mathrm{H}_{2} \mathrm{O}(n=3)$. Die Messung erfolgte nach Inkubation in in $100 \mu \mathrm{SARPE}$, das zuvor in 0,02\% Tween 20 in FACS-Flow (10 $\mu \mathrm{g} / \mathrm{ml}$ ) verdünnt wurde

\subsubsection{Qualitativer Beweis im Uniplex-Hybridisierungsverfahren}

Für den qualitativen Nachweis des Hybridisierungsverfahrens wurden die biotinylierten PCR-Amplifikate im Uniplex-System an Beads hybridisiert.

Für jedes Virus wurden drei Ansätze zusammengestellt: (1) eine Probe mit einem PCRAmplifikat der spezifischen Virus-RNS, (2) eine Probe mit einem PCR-Amplifikat einer unspezifischen Virus-RNS und (3) die Negativkontrolle (NK) mit negativem Humanserum. Die Ansätze wurden, wie in Kap. 2.2.2.3 (S.44) beschrieben, bei $60^{\circ} \mathrm{C}$ für eine Stunde hybridisiert. Im Anschluss wurden die Ansätze mit einem SARPE inkubiert und am FACS Canto $^{\text {TM }}$ II gemessen. Es wurden jeweils 1000 Beads pro Probe gezählt und ausgewertet. Abb. 3.15 zeigt ein Säulendiagramm der MFI-PE für die Proben von sieben HFV aus Mix 1 und Mix 2. Für Mix 3 wäre eine Hybridisierung im Uniplex-System nur wenig aussagekräftig gewesen, da das LASV aufgrund seiner genetischen Variabilität nur im Multiplex-System zuverlässig nachgewiesen werden kann. Aus diesem Grund wurde auf eine Uniplex-Hybridisierung in Mix 3 verzichtet. Der Ansatz mit der spezifischen VirusRNS erzielte jeweils eine deutlich höhere Fluoreszenzintensität als die Negativkontrollen und die Ansätze mit der unspezifischen viralen RNS. Da die absoluten MFI-PE-Werte der 
Viren sich im Intra-Assay-Vergleich stark unterschieden, konnte eine Aussage nur in Relation zur NK getroffen werden.

Die Ansätze für RVFV, CCHFV, MARV, erreichten eine respektive MFI-PE von 7.428, 768, 5.519 in der hybridisierten Probe, dh. die spezifische Probe erreichte 30,2-fach (RVFV), 13,3-fach (CCHFV) und 20,4-fach (MARV) höhere Werte als die Kontrollprobe.

Für die Viren aus Mix 2 ergaben sich ebenfalls wesentlich höhere MFI-PE in den spezifischen Proben als in der NK: EBOVZ-MFI-PE: 1.403 (9,5-fach), EBOVS-MFI-PE: 1.484 (6,3-fach), YFV-MFI-PE: 3.388 (33,5-fach) und DENV-MFI-PE: 5.569 (43,9-fach).

Für die Uniplex-Hybridisierungen mit unspezifischen Viren wurde jeweils die Ziel-RNS eines anderen Virus, der zum selben Mix wie das spezifische Virus gehörte, verwendet. Es traten keine Hinweise auf Kreuzreaktionen auf. Die Fluoreszenzintensitäten der unspezifischen viralen RNS glichen den Fluoreszenzintensitäten der NK. Damit ist ein erfolgreicher Nachweis der spezifischen Uniplex-Hybridisierung gelungen. 

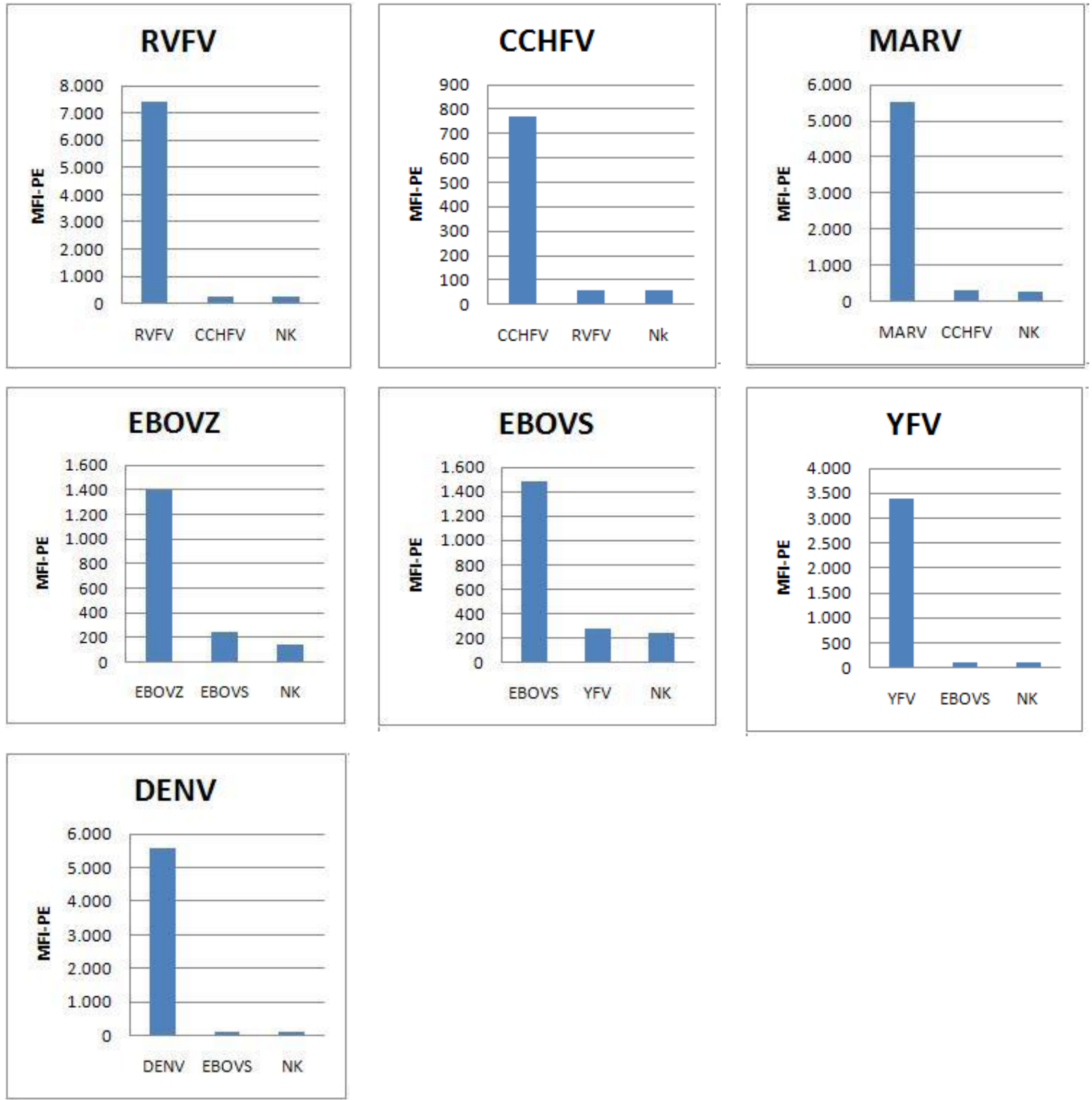

Abb. 3.15: Uniplex-Hybridisierungsverfahren. Pro Virus wurden drei Ansätze getestet: (1) Probe mit PCRAmplifikaten der spezifischen Virus-RNS, (2) Probe mit PCR-Amplifikaten einer unspezifischen Virus-RNS, (3) NK mit negativem Humanserum. Nach Inkubation mit dem Reporter-FarbstoffKonjugat SARPE konnte eine spezifische Hybridisierung an die Beads detektiert werden. Pro Ansatz wurden 1000 Beads zytometrisch gemessen.

\subsubsection{Qualitativer Beweis im Multiplex-Hybridisierungsverfahren}

Nachdem der CBA für die sieben HFV erfolgreich im Uniplex-Hybridisierungsverfahren angewendet wurde, sollte das Multiplex-Hybridisierungsverfahren zur simultanen Analyse mehrerer BPs und der daran hybridisierten PCR-Amplifikate in einem Ansatz getestet werden. Die Zusammenstellung der drei Multiplex-Mixe wurden durch qRT-PCR 
aufeinander abgestimmt und auf Dimerbildung untersucht (s. Kap 3.1.2, S.48). Die Kopplung der spezifischen Oligonukleotidsonden an unterschiedliche BPs wurde für die drei Multiplex-Mixe abhängig von den Emissionsmaxima der unterschiedlichen BPs bestimmt und nach dem Protokoll aus Kap. 3.2. (S. 56) durchgeführt.

Jeder Ansatz des Multiplex-Systems enthielt je $5 \mu$ l aller BPs des jeweiligen Mixes, die an spezifische Oligonukleotidsonden gekoppelt waren, und wurde mit je $5 \mu$ l eines biotinylierten PCR-Amplifikats aus dem Spektrum des entsprechenden Multiplex-Mixes (1:2 mit Tris-EDTA, pH 8,0, verdünnt) getestet. Als NK wurde, wie im Uniplex-System, negatives Humanserum anstelle der PCR-Amplifikate verwendet.

Die Hybridisierung erfolgte nach der gleichen Methode wie im UniplexHybridisierungsverfahren bei $60^{\circ} \mathrm{C}$ und nachfolgender Inkubation mit SARPE (s. Kap 3.3.2, S.63).

Die Ergebnisse der Auswertung am FACS Canto ${ }^{\text {TM }}$ ॥ wurden in Abb. 3.16 und Abb.3.17 dargestellt. Da Mix 1 aus drei verschiedene BP für drei Viren (RVFV, CCHFV, MARV) bestand, wurden insgesamt 3000 Beads ausgewertet (1000 Beads/Population). In Abb. 3.16 waren die wesentlich höheren Fluoreszenzsignale der spezifischen Sonden offensichtlich. Bei der Analyse wurden die Ergebnisse der spezifischen Sonden im Verhältnis zum Mittelwert der Negativkontrollen (MFI-PE: 85,2) gesetzt. So ergeben sich für RVFV 33,9-fach, für CCHFV 9-fach und für MARV 26,1-fach höhere Fluoreszenzen als für die negativen Kontrollproben. Die unspezifischen Sonden erreichten MFI-PE-Werte, die wesentlich niedriger waren und nicht über den 3-fachen Wert der Negativkontrollen reichten.

Da Mix 2 aus vier verschiedenen BPs für vier Viren (EBOVZ, EBOVS, YFV, DENV) bestand, wurden insgesamt 4000 Beads am FACS Canto $^{\mathrm{TM}}$ ॥ ausgewertet. Bei dem MultiplexHybridisierungsverfahren von Mix 2 wurde ein Mittelwert für die MFI-PE der Negativkontrollen von 136 ermittelt. Die spezifischen Sonden zeigten auch in diesem Mix vergleichsweise hohe Fluoreszenzen: EBOVZ 54,7-fach, EBOVS 22,5-fach, YFV 13-fach und DENV 29,8-fach erhöhte MFI-PE. Die erzielten Fluoreszenzwerte der unspezifischen Sonden erreichten maximal eine 1,8-fache MFI-PE im Vergleich zu den negativen Kontrollproben. 
Diese Ergebnisse zeigten, dass die Hybridisierungsreaktion zusätzlich zum UniplexSystem (s. Kap. 3.3.2, S.63) auch im Multiplex-System erfolgreich umgesetzt werden konnte.

Auffällig war, dass BP8-EBOVZ im Ansatz mit dem EBOVS-Amplifikat eine 8,6-fach MFI-PE im Vergleich zur NK erreichte. Dies ließ auf eine eventuelle Kreuzreaktion zwischen der EBOVZ-Sonde und dem RNS-Standard von EBOVS schließen.

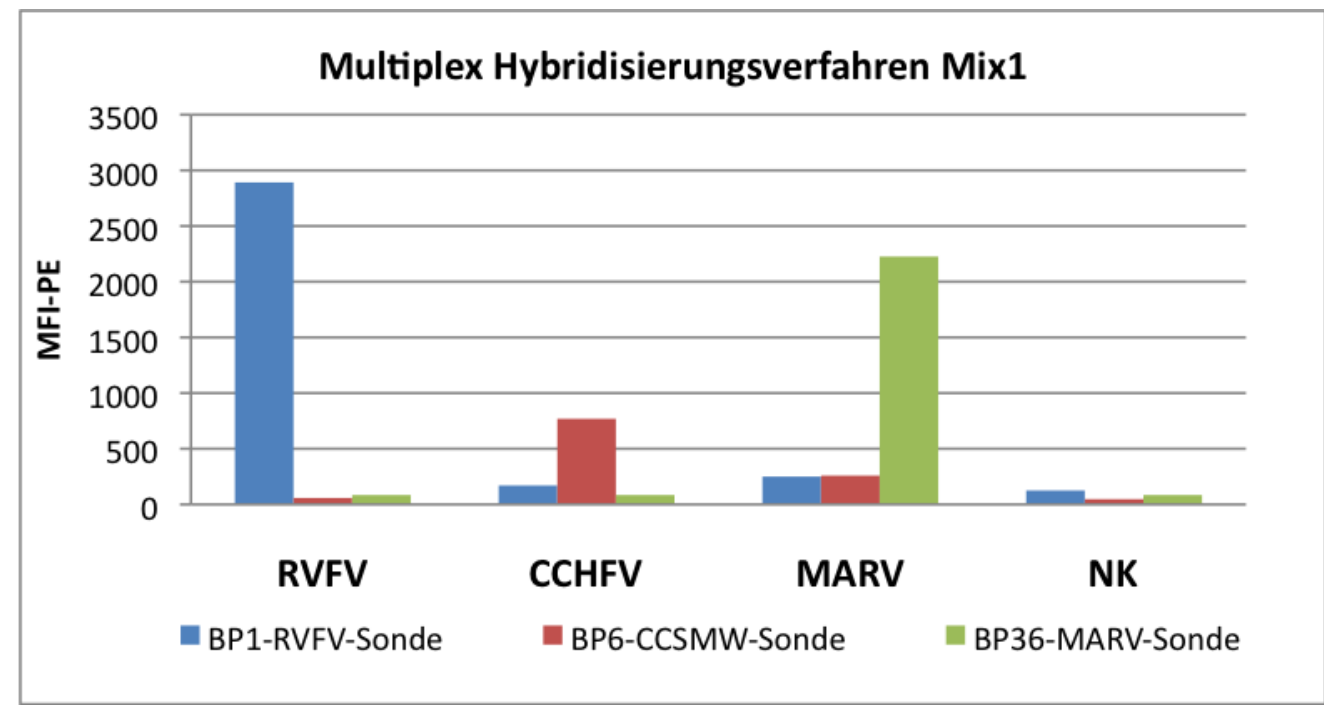

\begin{tabular}{lrrrr}
\hline MFI-PE & RVFV & CCHFV & MARV & NK \\
\hline BP1-RVFV-Sonde & $\mathbf{2 8 9 2}$ & 170 & 250 & 125 \\
BP6-CCSMW-Sonde & 58 & $\mathbf{7 6 9}$ & 259 & 47 \\
BP36-MARV-Sonde & 84 & 84 & $\mathbf{2 2 2 6}$ & 84 \\
\hline
\end{tabular}

Abb. 3.16:Multiplex-Hybridisierungsverfahren mit den BPs von Mix 1. Pro Probe wurden 3000 Beads zytometrisch gemessen, jede Probe enthielt jeweils $5 \mu$ l gekoppelte Beads von BP1-RVFV-Sonde, BP6-CCSMW-TM-Sonde und BP36-MARV-Sonde) und je ein biotinyliertes PCR-Amplifikat aus der Multiplex-RT-PCR von Mix 1 (RVFV $10^{6}$ Kopien/ $\mu \mathrm{l}$, CCHF $10^{6} \mathrm{Kopien} / \mu \mathrm{l}$, MARV $10^{6} \mathrm{Kopien} / \mu \mathrm{l}$ ). 


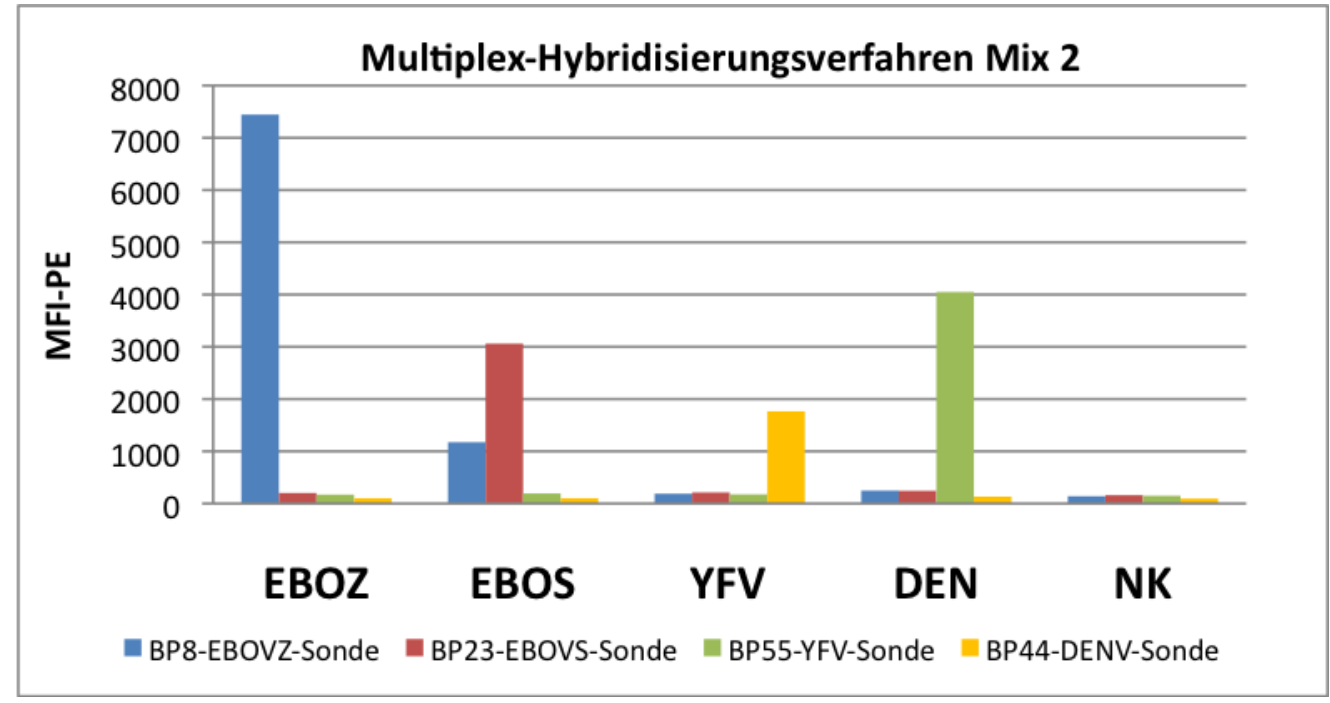

\begin{tabular}{lrrrrr}
\hline MFI-PE & EBOVZ & EBOVS & YFV & DENV & \multicolumn{1}{c}{ NK } \\
\hline BP8-EBOVZ-Sonde & $\mathbf{7 4 4 4}$ & 1174 & 189 & 248 & 141 \\
BP23-EBOVS-Sonde & 203 & $\mathbf{3 0 6 1}$ & 213 & 244 & 161 \\
BP44-DENV-Sonde & 171 & 194 & 176 & $\mathbf{4 0 4 9}$ & 149 \\
BP50-YFV-Sonde & 103 & 103 & $\mathbf{1 7 6 6}$ & 133 & 95 \\
\hline
\end{tabular}

Abb.3.17: Multiplex-Hybridisierungsverfahren mit den BPs von Mix 2. Pro Probe wurden 4000 Beads zytometrisch gemessen, jede Probe enthielt jeweils $5 \mu$ l gekoppelte Beads von BP6-EBOVZ, BP23-EBOVS, BP44-DENV und BP50-YFV und $5 \mu$ l eines biotinylierten PCR-Amplifikates aus der Multiplex-RT-PCR von Mix 2 (EBOVZ $10^{6}$ Kopien/ $\mu \mathrm{l}$, EBOVS $10^{6} \mathrm{Kopien} / \mu \mathrm{l}$, YFV $10^{6} \mathrm{Kopien} / \mu \mathrm{l}$, DENV $10^{6}$ Kopien/ $\left.\mu \mathrm{l}\right)$.

Im Mix 3 sollte das LASV im CBA detektiert werden. Aufgrund der genetischen Variabilität dieses Virus wurden fünf verschiedene Oligonukleotidsonden in einem Multiplex-Hybridisierungsverfahren kombiniert, um das gesamte Spektrum der Variabilität der LASV-Stämme erfassen zu können. Aus diesem Grund wurde auch kein Uniplex-Hybridisierungsverfahren für LASV durchgeführt (s. Kap. 3.3.2, S.63). Hybridisierungsversuche mit den einzelnen LASV-Sonden hätten nur geringe Aussagekraft gehabt.

Repräsentativ für die Variationsbreite der LASV wurden die fünf LASV-LNA-Sonden in Multiplex-Hybridisierungen mit der genomischen RNS der LASV-Stämme LASV JOS, LASV LANT, LASV AV, LASV CSF getestet. Bei der Detektion am FACS Canto ${ }^{\text {TM }}$ || wurden jeweils 4000 Beads pro Probe ausgewertet. 
Abb.3.18 zeigt ein Säulendiagramm mit den Ergebnissen dieses MultiplexHybridisierungslaufes von Mix 3. Wie erwartet weist LASV-LNA-Sonde1 bei Zugabe von LASV-JOS sehr hohe MFI-PE (62-fache MFI-PE der NK: 101,8) auf. Die Sonde ist zur spezifischen Detektion der Sequenz des L-Segmentes des Josiah-Virus entwickelt worden. Die gleiche Sonde zeigt auch bei LASV-LANT ähnlich hohe MFI-PE-Signale (33fach). Die Fluoreszenzsignale der übrigen LASV-Sonden sind vergleichsweise schwach (MFI-PE: 112-254). Obwohl sich die Zielregionen der LASV-LNA-Sonde5 auf dem LSegment des Lassa AV-Stammes befand, lassen sich nur schwache Fluoreszenzsignale in den Proben mit AV und AV1 messen, die vergleichbar mit den MFI-PE der Negativkontrolle (MFI-PE: 80-112) waren. Die LASV-LNA-Sonde2, die zur Detektion des LSegmentes des CSF-Stammes synthetisiert worden ist, zeige ebenfalls schwache Emission (MFI-PE:79) bei der Zugabe von CSF. Auf der anderen Seite ist die Fluoreszenz der LASV-LNA-Sonde1 bei CSF dezent erhöht (MFI-PE: 280).

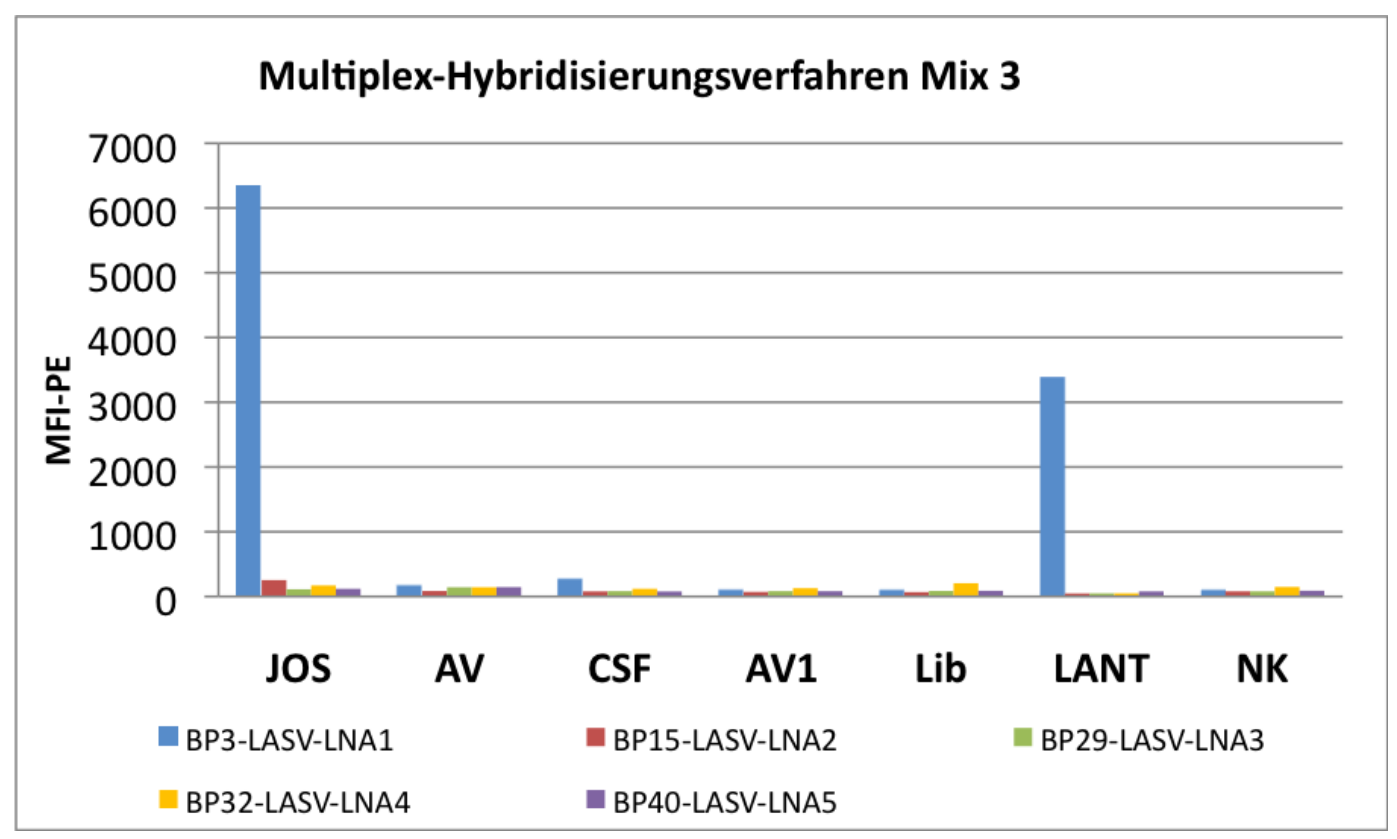

\begin{tabular}{lrrrrrrr}
\hline \multicolumn{1}{c}{ MFI-PE } & JOS & \multicolumn{1}{c}{ AV } & CSF & AV1 & Lib & LANT & NK \\
\hline BP3-LNA1-Sonde & $\mathbf{6 3 1 9}$ & 180 & 280 & 114 & 112 & $\mathbf{3 3 7 7}$ & 112 \\
BP15-LNA2-Sonde & 254 & 85 & 79 & 71 & 68 & 47 & 80 \\
BP29-LNA3-Sonde & 112 & 143 & 83 & 83 & 86 & 49 & 80 \\
BP32-LNA4-Sonde & 171 & 143 & 119 & 128 & 206 & 49 & 148 \\
BP40-LNA5-Sonde & 119 & 145 & 78 & 82 & 88 & 79 & 89 \\
\hline
\end{tabular}


Abb.3.18: Multiplex-Hybridisierungsverfahren mit den BPs von Mix 3. Pro Probe wurden 4000 Beads zytometrisch gemessen, jede Probe enthielt jeweils $5 \mu$ l gekoppelte Beads der 5 LASV-LNASonden (BP3-LASV-LNA1, BP15-LASV-LNA2, BP29-LASV-LNA3, LASV-LNA4, BP40-LASV-LNA5) und ein $5 \mu \mathrm{l}$ PCR-Amplifikat aus Multiplex-RT-PCRs (1:2 mit Tris-EDTA, pH 8,0, verdünnt) mit verschiedenen LASV-Proben (JOS, AV, CSF, AV1, Lib, LANT).

\subsubsection{Sensitivitätsmessung im Uniplex-Hybridisierungsverfahren}

Zur Evaluierung der Sensitivität des CBAs wurden Hybridisierungen mit quantitativen RNS-Standardreihen $\left(10^{1}-10^{7}\right.$ Moleküle/ $\mu$ l) durchgeführt. Nach der Multiplex-RT-PCR wurden die PCR-Amplifikate der RNS-Standardreihen wie in Kap. 2.2.2.3 (S.44) beschrieben bei $60^{\circ} \mathrm{C}$ für eine Stunde an die Beads hybridisiert. Im Anschluss wurden die Ansätze mit einem SARPE inkubiert und am FACS Canto ${ }^{\mathrm{TM}}$ II gemessen. Für jedes Virus wurden die Ansätze in dreifacher Ausführung $(n=3)$ durchgeführt, um die Reproduzierbarkeit des Verfahrens zu validieren.

Im Punktdiagramm in Abb. 3.19 sind die MFI-PE der einzelnen HFV in Bezug zur Probenkonzentration aufgetragen. Die Fluoreszenzintensität variierte zwischen den einzelnen Viren zum Teil deutlich. Während EBOVS Maximalwerte bei der Hybridisierung des $10^{7}$-Standards mit MFI-PE von 13.231 erreichte, traten bei CCHFV nur Maximalwerte bis 503 auf. Die statistische Analyse der Ergebnisse und die Bestimmung der Grenzwerte zur Detektion einer positiven Probe wurden nach den Methoden für jedes HFV individuell errechnet (s. Kap. 3.3.6, S. 76). Dabei wurde ein Grenzwert (LOD = MW (NK) + $6 \times$ SD (NK)) bestimmt und in der Grafik als rote Linie gekennzeichnet. Der polynome Zusammenhang zwischen den Variablen wurden durch das Bestimmtheitsmaß $R^{2}$ angegeben. Dabei fiel auf, dass die Werte aller HFV, abgesehen von RVFV, ein vergleichsweise hohes Bestimmtheitsmaß von $R^{2}>0,93$ aufwiesen.

Wie sich aus den SD in der Abb. 3.19 ebenfalls entnehmen lässt, zeigten die Ergebnisse einen hohen Grad an Intra-Assay-Reproduzierbarkeit. 
MIX 1:

RVFV

$R^{2}=0,3793$

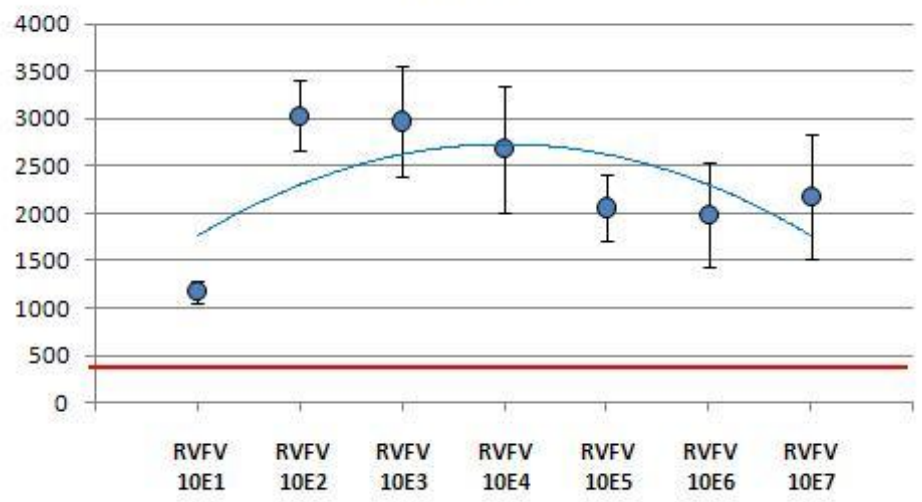

CCHFV $\quad R^{2}=0,9634$

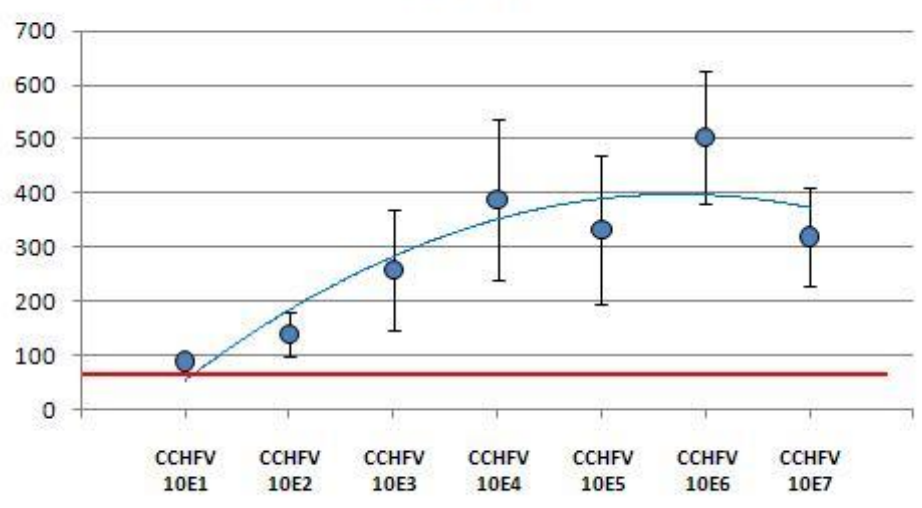

MARV $\quad R^{2}=0,9634$

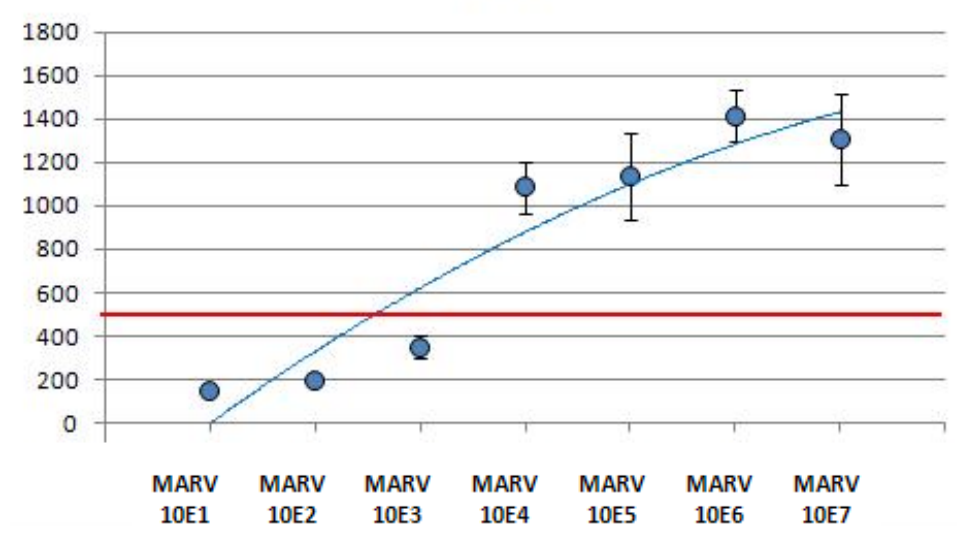


MIX 2:

EBOVZ

$R^{2}=0,9394$

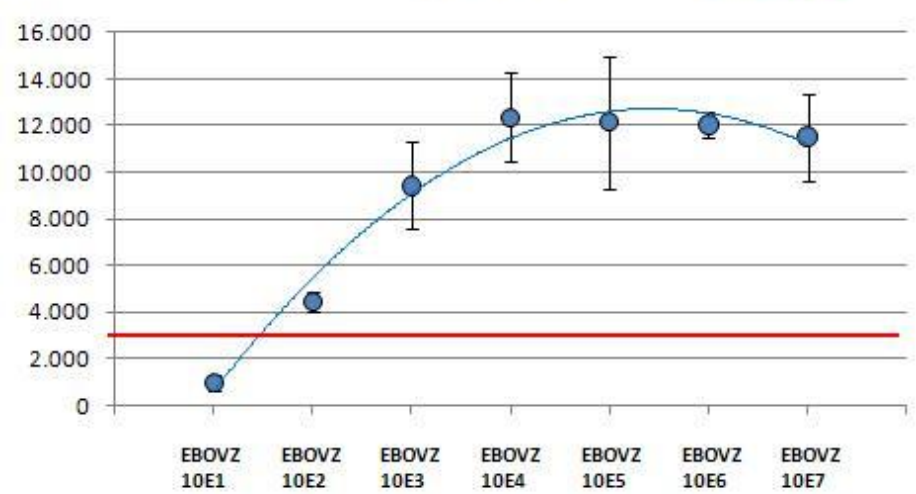

EBOVS $\quad R^{2}=0,9339$

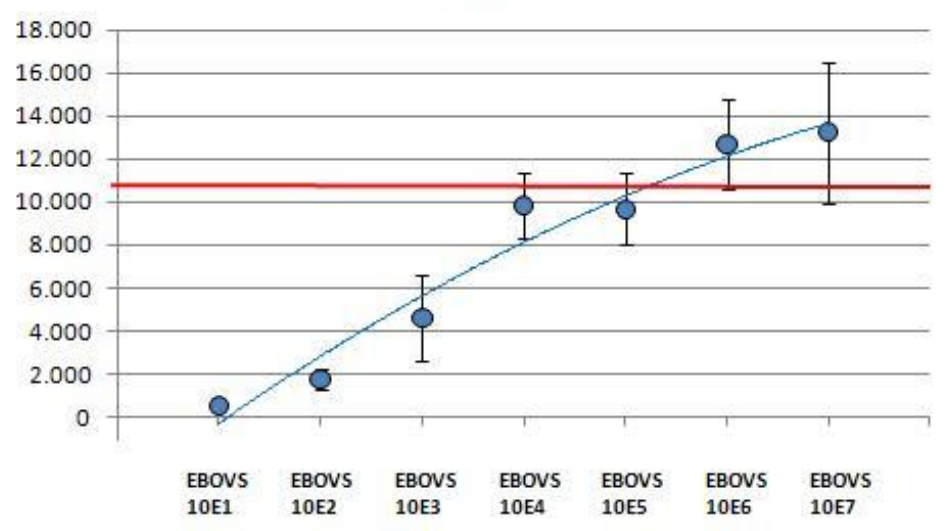

YFV $\quad R^{2}=0,9634$

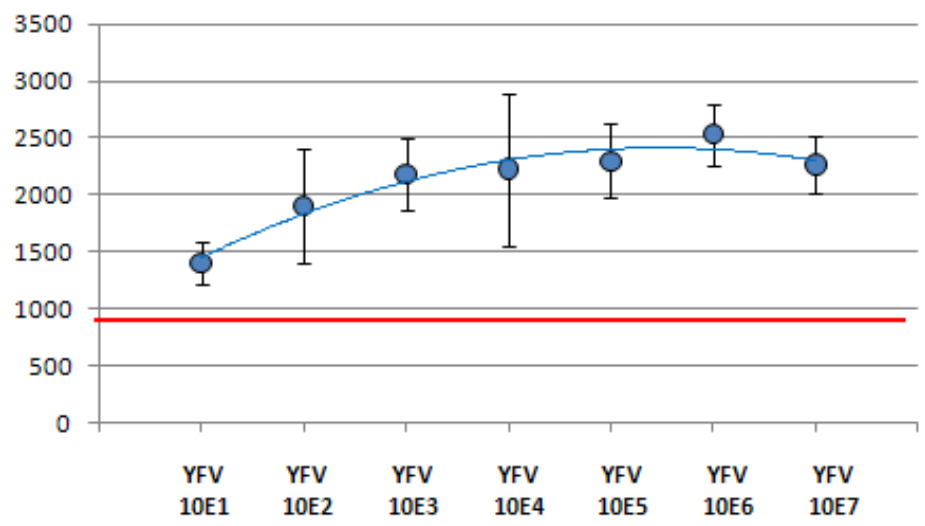




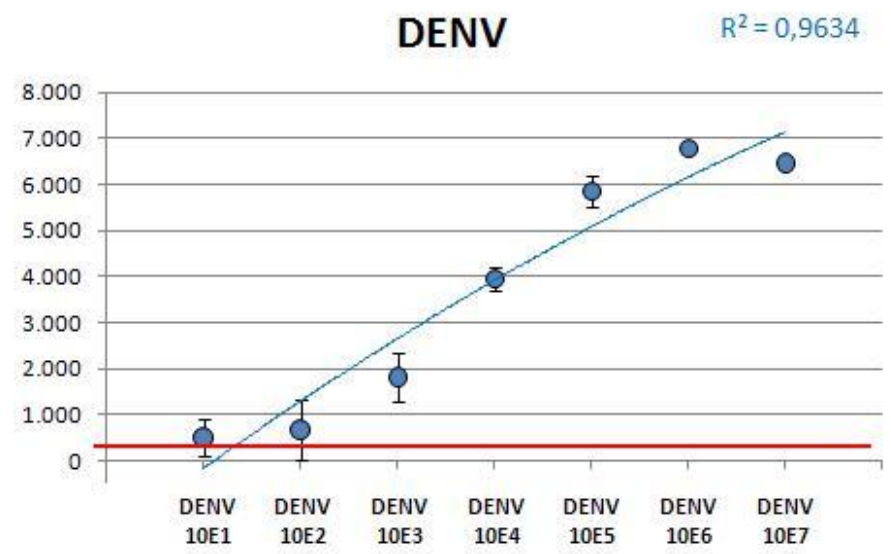

Abb. 3.19: Sensitivitätsmessungen im Uniplex-Hybridisierungsverfahren der HFV aus Mix 1 und Mix 2. Aufgetragen wurden die medianen Fluoreszenzintensitäten von Phycoerythrin (MFI-PE) der untersuchten Proben (pro Virus: $n=3$ ). Das Bestimmtheitsmaß $R^{2}$ wird durch eine polynomische Trennlinie definiert. Der Grenzwert (engl: limit of detection, LOD = MW (NK) + 6xSD (NK)) ist durch die rote Linie gekennzeichnet.

\subsubsection{Sensitivitätsmessung im Multiplex-Hybridisierungsverfahren}

Ergänzend zu Sensitivitätsmessung im Uniplex-System (s. Kap. 3.3.4, S.70) wurde die Sensitivität der einzelnen CBA-Nachweisverfahren im MultiplexHybridisierungsverfahren ermittelt. Die Zusammenstellungen für die MultiplexHybridisierung entsprachen den Mixen (Mix 1, Mix 2, Mix 3), die bereits in der MultiplexRT-PCR (s. Kap. 3.1.2, S.48) und im Multiplex-Hybridisierungsverfahren (s. Kap. 3.3.3, S.65) verwendet wurde. Genau wie bei der Uniplex-Sensitivitätsmessung wurden die PCR-Produkte der RNS-Standardreihen $\left(10^{1}-10^{6}\right.$ Moleküle/ $\mu$ l) an die Beads hybridisiert. Jeder Ansatz enthielt wie bei der Multiplex-Hybridisierung in Kap. 3.3.3 (S.65) außer 5 $\mu \mathrm{l}$ der BP mit der spezifischen Sonde noch $5 \mu$ l von den übrigen gekoppelten Sonden des Mixes. Außerdem wurden je $5 \mu \mathrm{l}$ PCR-Produkt von der Multiplex-RT-PCR der Standards $\left(10^{1}-10^{7}\right.$ Moleküle/ $\left.\mu l\right)$ eines Virus hinzugegeben.

Im Säulendiagramm in Abb. 3.20 werden die Fluoreszenzsignale der Proben aus Mix 1 dargestellt. Auch im Multiplex-System erreichen die Sonden des Mix 1 vergleichbare Fluoreszenzintensitäten wie in der Uniplex-Sensitivitätsmessung: RVFV erzielt MFI-PEHöchstwerte bis 2.892, CCHFV ist mit einer maximalen MFI-PE von 769 wieder vergleichbar niedrig und die MFI-PE-Maximalwerte von MARV liegen bei 2.370 . 


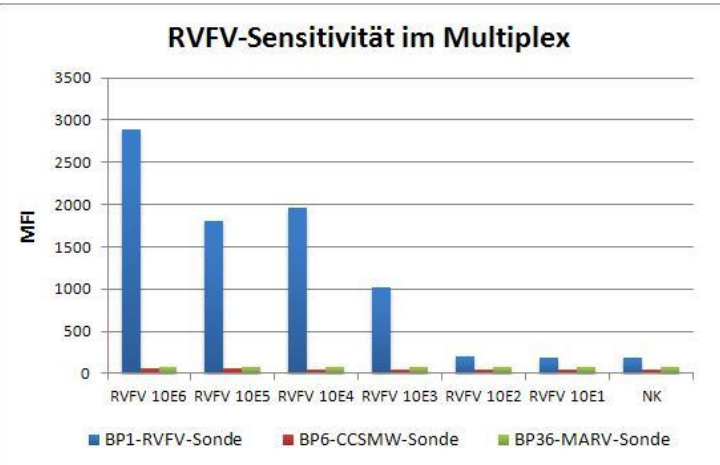

\begin{tabular}{lrrr}
\hline & \multicolumn{1}{c}{$\begin{array}{l}\text { BP1 } \\
\text { (RVFV) }\end{array}$} & \multicolumn{1}{l}{ BP6 } & \multicolumn{2}{l}{ BP36 } \\
& (CCSMW) & \multicolumn{1}{l}{ (MARV) } \\
\hline RVFV 10E6 & $\mathbf{2 8 9 2}$ & 58 & 84 \\
RVFV 10E5 & $\mathbf{1 8 1 0}$ & 55 & 76 \\
RVFV 10E4 & $\mathbf{1 9 6 1}$ & 47 & 72 \\
RVFV 10E3 & $\mathbf{1 0 2 2}$ & 54 & 73 \\
RVFV 10E2 & $\mathbf{2 0 8}$ & 53 & 74 \\
RVFV 10E1 & $\mathbf{1 9 0}$ & 50 & 76 \\
NK & $\mathbf{1 8 1}$ & 53 & 79 \\
\hline
\end{tabular}

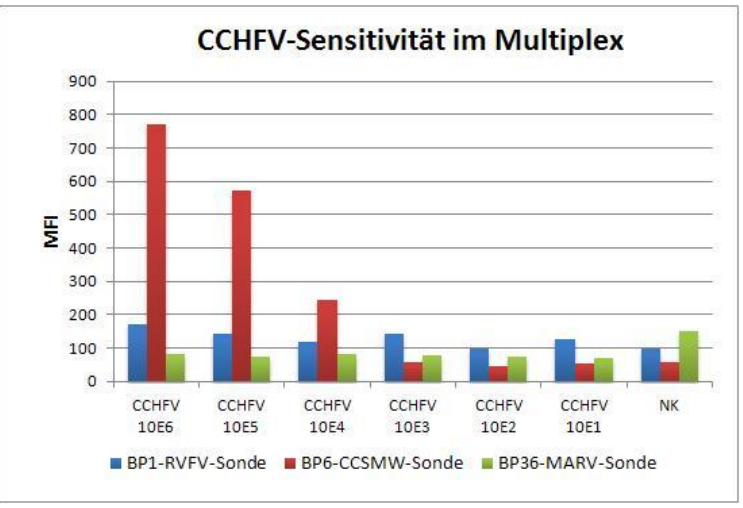

\begin{tabular}{lrrr}
\hline & \multicolumn{2}{c}{$\begin{array}{l}\text { BP1 } \\
\text { (RVFV) }\end{array}$} & \multicolumn{2}{l}{ BP6 } \\
& (CCSMw) & \multicolumn{2}{l}{ (MARV } \\
\hline CCHFV 10E6 & 170 & $\mathbf{7 6 9}$ & 84 \\
CCHFV 10E5 & 142 & $\mathbf{5 7 1}$ & 73 \\
CCHFV 10E4 & 119 & $\mathbf{2 4 3}$ & 83 \\
CCHFV 10E3 & 143 & $\mathbf{5 9}$ & 78 \\
CCHFV 10E2 & 100 & $\mathbf{4 7}$ & 76 \\
CCHFV 10E1 & 128 & $\mathbf{5 5}$ & 69 \\
NK & 97 & $\mathbf{5 8}$ & 153 \\
\hline
\end{tabular}

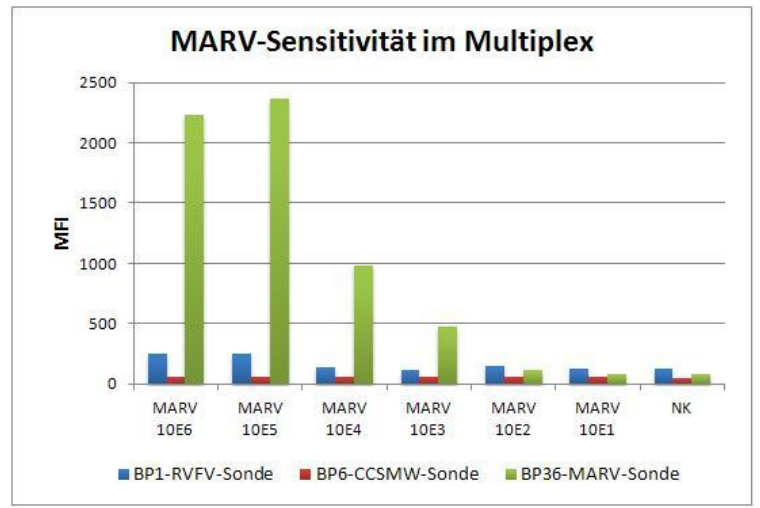

\begin{tabular}{lrrr}
\hline & \multicolumn{1}{l}{$\begin{array}{l}\text { BP1 } \\
\text { (RVFV) }\end{array}$} & \multicolumn{1}{l}{$\begin{array}{l}\text { BP6 } \\
\text { (CCSMW) }\end{array}$} & \multicolumn{1}{l}{$\begin{array}{l}\text { BP36 } \\
\text { (MARV) }\end{array}$} \\
\hline MARV 10E6 & 250 & 59 & $\mathbf{2 2 2 6}$ \\
MARV 10E5 & 251 & 58 & $\mathbf{2 3 7 0}$ \\
MARV 10E4 & 140 & 61 & $\mathbf{9 8 0}$ \\
MARV 10E3 & 119 & 55 & $\mathbf{4 7 9}$ \\
MARV 10E2 & 154 & 59 & $\mathbf{1 1 9}$ \\
MARV 10E1 & 130 & 55 & $\mathbf{8 4}$ \\
NK & 125 & 47 & $\mathbf{8 0}$ \\
\hline
\end{tabular}

Abb. 3.20:Sensitivitätsmessung im Multiplex-Hybridisierungsverfahren von Mix 1. Aufgetragen wurden die medianen Fluoreszenzintensitäten von Phycoerythrin (MFI-PE) der untersuchten Proben (pro Virus: $n=1$ ), die Ergnisse der spezifischen Sonde sind jeweils dick gedruckt.

Abb. 3.21 zeigt in einem Säulendiagramm die gemessenen Fluoreszenzsignale der Proben aus Mix 2. Bei EBOVZ zeigte die Probe mit dem $10^{6}$-Standard einen Maximalwert von MFI-PE: 14.598. Bei EBOVS wurde die höchste MFI-PE (5.182) bei der Probe des $10^{5}$ Standards erreicht und bei YFV erst bei der Probe des $10^{4}$-RNS-Standard (MFI-PE: 1.125). Der Maximalwert in der Sensitivitätsbestimmung beim DENV im Multiplex-System ist 
von der Probe des $10^{6}$-Standards mit einer MFI-PE von 8494 erreicht. Die statistische Analyse und die Berechnung eines Grenzwertes zur Sensitivitätsbestimmung des CBAs werden in Kap. 3.3.6 beschrieben.

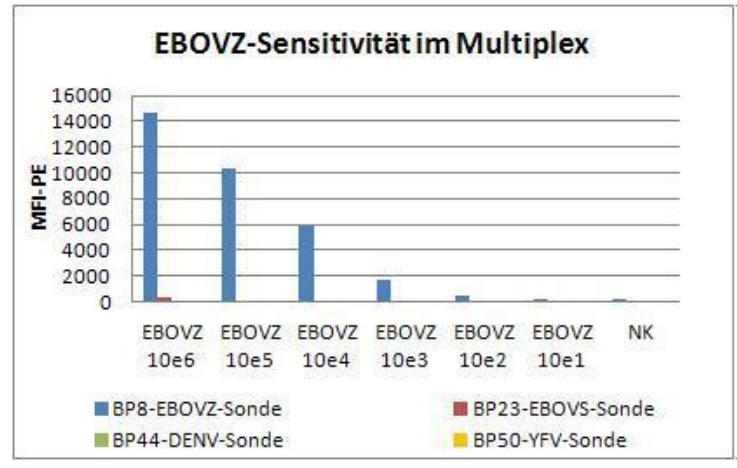

\begin{tabular}{lllll}
\hline & $\begin{array}{l}\text { BP8 } \\
\text { (EBOVZ) }\end{array}$ & $\begin{array}{l}\text { BP23 } \\
\text { (EBOVS) }\end{array}$ & $\begin{array}{l}\text { BP44 } \\
\text { (DENV) }\end{array}$ & $\begin{array}{l}\text { BP50 } \\
\text { (YFV) }\end{array}$ \\
\hline EBOVZ 10E6 & 14598 & 379 & 93 & 110 \\
EBOVZ 10E5 & 10386 & 324 & 112 & 126 \\
EBOVZ 10E4 & 5874 & 271 & 96 & 106 \\
EBOVZ 10E3 & 1704 & 228 & 114 & 109 \\
EBOVZ 10E2 & 488 & 233 & 99 & 112 \\
EBOVZ 10E1 & 177 & 225 & 80 & 113 \\
NK & 162 & 158 & 101 & 127 \\
\hline
\end{tabular}

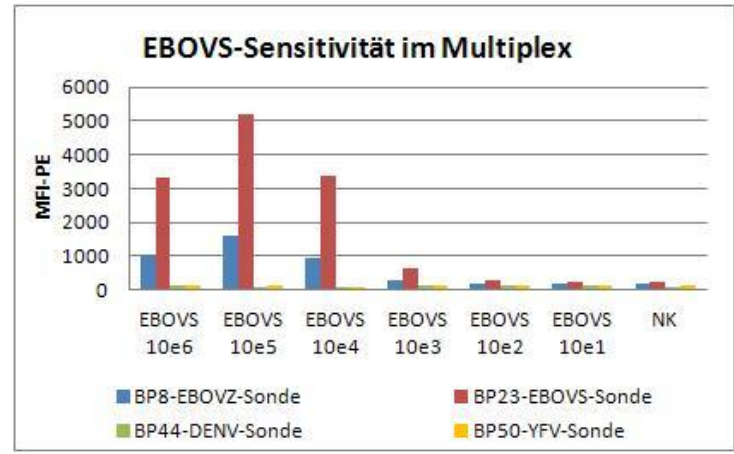

\begin{tabular}{lllll}
\hline & $\begin{array}{l}\text { BP8 } \\
\text { (EBOVZ) }\end{array}$ & $\begin{array}{l}\text { BP23 } \\
\text { (EBOVS) }\end{array}$ & $\begin{array}{l}\text { BP44 } \\
\text { (DENV) }\end{array}$ & $\begin{array}{l}\text { BP50 } \\
\text { (YFV) }\end{array}$ \\
\hline EBOVS10E6 & 1069 & 3319 & 112 & 136 \\
EBOVS 10E5 & 1590 & 5182 & 104 & 122 \\
EBOVS 10E4 & 939 & 3363 & 104 & 101 \\
EBOVS 10E3 & 290 & 620 & 138 & 135 \\
EBOVS 10E2 & 190 & 293 & 115 & 112 \\
EBOVS 10E1 & 179 & 234 & 109 & 119 \\
NK & 187 & 227 & 98 & 125 \\
\hline
\end{tabular}

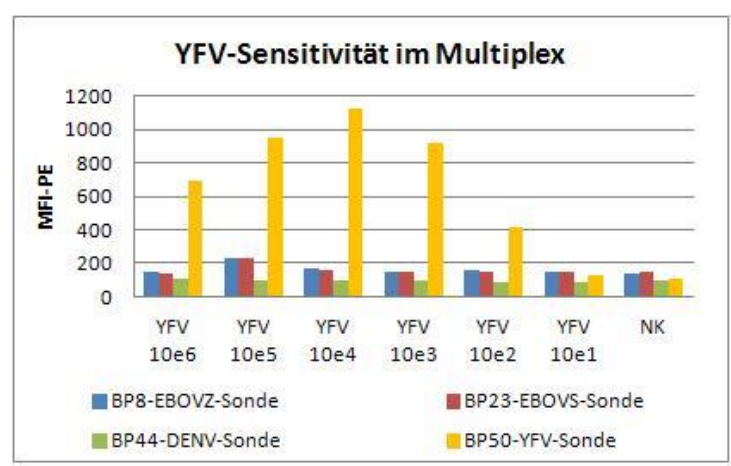

\begin{tabular}{lllll}
\hline & $\begin{array}{l}\text { BP8 } \\
\text { (EBOVZ) }\end{array}$ & $\begin{array}{l}\text { BP23 } \\
\text { (EBOVS) }\end{array}$ & $\begin{array}{l}\text { BP44 } \\
\text { (DENV) }\end{array}$ & $\begin{array}{l}\text { BP50 } \\
\text { (YFV) }\end{array}$ \\
\hline YFV10E6 & 145 & 136 & 103 & 690 \\
YFV 10E5 & 235 & 235 & 96 & 947 \\
YFV 10E4 & 167 & 156 & 96 & 1125 \\
YFV 10E3 & 147 & 153 & 93 & 916 \\
YFV 10E2 & 158 & 148 & 87 & 416 \\
YFV 10E1 & 144 & 144 & 91 & 125 \\
NK & 138 & 145 & 93 & 109 \\
\hline
\end{tabular}

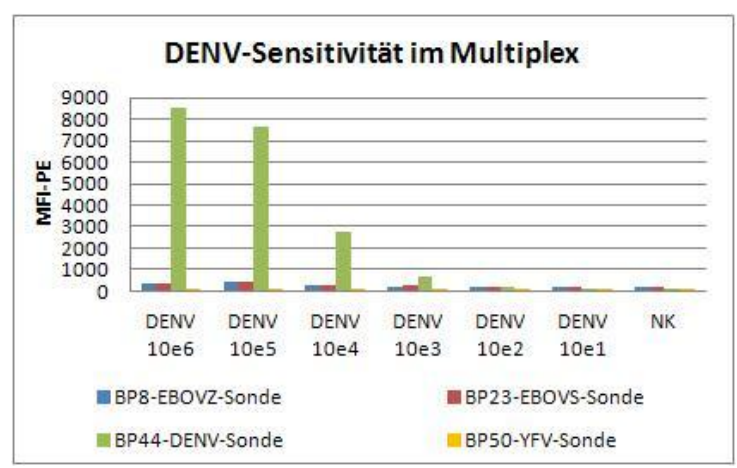

\begin{tabular}{lllll}
\hline & $\begin{array}{l}\text { BP8 } \\
\text { (EBOVZ) }\end{array}$ & $\begin{array}{l}\text { BP23 } \\
\text { (EBOVS) }\end{array}$ & $\begin{array}{l}\text { BP44 } \\
\text { (DENV) }\end{array}$ & $\begin{array}{l}\text { BP50 } \\
\text { (YFV) }\end{array}$ \\
\hline DENV10E6 & 360 & 353 & 8494 & 116 \\
DENV 10E5 & 409 & 418 & 7673 & 103 \\
DENV 10E4 & 258 & 292 & 2734 & 107 \\
DENV 10E3 & 202 & 239 & 659 & 135 \\
DENV 10E2 & 167 & 205 & 207 & 105 \\
DENV 10E1 & 162 & 210 & 87 & 118 \\
NK & 174 & 210 & 93 & 107 \\
\hline
\end{tabular}

Abb. 3.21:Sensitivitätsmessung im Multiplex-Hybridisierungsverfahren von Mix 2. Aufgetragen wurden die medianen Fluoreszenzintensitäten von Phycoerythrin (MFI-PE) der untersuchten Proben (pro Virus: $n=1$ ), die Ergnisse der spezifischen Sonde sind jeweils dick gedruckt. 


\subsubsection{Analyse der Ergebnisse und Grenzwertbestimmung}

In der vorliegenden Arbeit ist ein nukleinsäure-basierender CBA für sieben verschiedene HFV entwickelt und für die Verdünnungsstufen $10^{1}-10^{6}$ RNS-Moleküle/ $\mu$ l getestet worden. Dabei wurden die Ergebnisse im Uniplex-Hybridisierungsverfahren (s. Kap. 3.3.4, S.70) und im Multiplex-Hybridisierungverfahren (s. Kap. 3.3.5, S.73) ermittelt. Zur Bestimmung der analytischen Sensitivität des Verfahrens sollte nun ein Grenzwert (LOD, engl.: limit of detection) festgelegt werden, der die Mindestfluoreszenzsignale eines Analyten angab, die sicher von einer negativen Probe unterschieden werden können. Aufgrund der starken Inter-Assay-Variation der Fluoreszenzwerte, musste eine Methode entwickelt werden, die eine Grenzwertbestimmung für jeden Versuchsdurchgang individuell ermöglichte. Da die gemessenen Fluoreszenzen nur in Relation zueinander aussagekräftig waren, musste auch der Grenzwert in Relation zur Negativkontrolle interpretiert werden.

Zur Grenzwertbestimmung wurde der Mittelwert (MW) der MFI aller Negativkontrollen aus den Versuchsdurchläufen individuell für jedes Virus errechnet. Dazu wurde jeweils die sechsfache Standardabweichung (6x SD, engl: standard deviation) der Negativkontrollen addiert.

\section{Grenzwert (LOD) $=\mathrm{MW}(\mathrm{NK})+6 \mathrm{x}$ SD}

Wenn nur ein einziger Versuchsdurchlauf $(n=1)$ durchgeführt wurde, können zur Bestimmung des MW (NK) auch die Ergebnisse der unspezifischen Proben herangezogen werden, da sie genauso eine Aussage über unspezifisches Hintergrundrauschen geben wie die NK.

Bei der Bestimmung der Grenzwerte im Uniplex-Hybridisierungsverfahren (aus Kap. 3.3.4), $n=3$, ergaben sich für die sieben HFV folgende Grenzwerte: 
Tab. 3.2: Grenzwerte (LOD) der Viren aus Mix 1 und Mix 2

\begin{tabular}{|lr|lr|}
\hline \multicolumn{2}{|c|}{ MIX 1 } & \multicolumn{2}{c|}{ MIX 2 } \\
Same des & $\begin{array}{c}\text { Grenzwert } \\
\text { (LOD) }\end{array}$ & $\begin{array}{l}\text { Name des } \\
\text { Sonde }\end{array}$ & $\begin{array}{c}\text { Grenzwert } \\
\text { (LOD) }\end{array}$ \\
\hline RVFV & 313 & EBOVZ & 2411 \\
CCSSMW & 74 & EBOVS & 10470 \\
MARV & 500 & YFV & 910 \\
& & DENV & 289 \\
\hline
\end{tabular}

Bei der Anwendung dieser Grenzwerte im Uniplex-System sollte die Sensitivität demnach als die Mindestkonzentration definiert sein, die eine MFI-PE oberhalb des Grenzwertes aufwies:

Tab. 3.3: Sensitivität der Hybridisierungsreaktionen im Uniplex-System

\begin{tabular}{|ccc|cccc|}
\hline \multicolumn{3}{|c|}{ MIX 1 } & \multicolumn{4}{c|}{ MIX 2 } \\
RVFV & CCHFV & MARV & EBOVZ & EBOVS & YFV & DENV \\
\hline $10^{1}$ & $10^{1}$ & $10^{4}$ & $10^{2}$ & $10^{3}$ & $10^{1}$ & $10^{1}$ \\
\hline
\end{tabular}

Bei CCHFV gestaltete sich die Auswertung des Grenzwertes als schwierig, da eine NK außergewöhnlich hohe MFI-PE besaß und deshalb als „Ausreißer" definiert werden musste und aus der Analyse herausgenommen wurde. Die Bestimmung des Grenzwertes wurde deshalb nur mit den Ergebnissen der NK1 durchgeführt. Auf die gleiche Weise mussten auch die Ergebnisse von EBOVS ausgewertet werden, da auch hier die NK2 unerklärlich hohe Werte zeigte. Die Sensitivität, die anhand der Ergebnisse von NK1 errechnet wurde, lag bei einer Konzentration von $10^{3}$.

Das Verfahren zur Grenzwertbestimmung wurde auf dieselbe Weise auch für das Multiplex-Hybridisierungsverfahren angewendet. Die dabei verwendeten Ergebnisse stammten aus der Versuchsreihe zur Multiplex-Sensitivitätsbestimmung in Kap. 3.3.5 (S.73) $(n=1)$ :

Tab. 3.4: Sensitivität der Hybridisierungsreaktionen im Multiplex-System

\begin{tabular}{|ccc|cccc|}
\hline \multicolumn{3}{|c|}{ MIX 1 } & \multicolumn{4}{c|}{ MIX 2 } \\
RVFV & CCHFV & MARV & EBOVZ & EBOVS & YFV & DENV \\
\hline $10^{3}$ & $10^{5}$ & $10^{3}$ & $10^{2}$ & $10^{3}$ & $10^{2}$ & $10^{3}$ \\
\hline
\end{tabular}


Bei Mix 1 scheint MARV in der Multiplex-Hybridisierung $\left(10^{3}\right)$ bessere Sensitivitäten zu erreichen als in der Uniplex-Hybridisierung $\left(10^{4}\right)$. RVFV und CCHFV erreicht eine schlechtere Sensitivität in der Multiplex-Hybridisierung.

In Mix 2 weisen YFV und DENV eine leichte Verschlechterung der Sensitivität auf, EBOVZ und EBOVS, bleiben mit einer Sensitivität von $10^{2}$ bzw. $10^{3}$ unverändert.

Zur Bestimmung der statistischen Signifikanz der ermittelten LOD-Werte wurde der pWert mithilfe des Students-t-Tests bestimmt. Mithilfe des $\mathrm{p}$-Wertes konnte mit einer Wahrscheinlichkeit, die kleiner als $5 \%(<0,05)$ ist, ausgeschlossen werden, dass der gemessene Unterschied zwischen einer positiven Probe und der NK nur auf Zufall beruht.

Tab. 3.5: Statistische Signifikanz ( $p$-Wert) von MIX 1 Konzentrationen, deren $p$-Wert nicht $<0,05$ ist, sind durch dick gedruckte Schrift hervorgehoben

\begin{tabular}{|c|c|c|c|c|c|}
\hline \multicolumn{2}{|c|}{ RVFV } & \multicolumn{2}{|c|}{ CCHFV } & \multicolumn{2}{|c|}{ MARV } \\
\hline $\begin{array}{c}\text { Konz. } \\
\text { (Moleküle/ } \mu \text { ) }\end{array}$ & p-Wert & 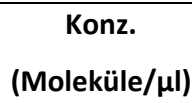 & p-Wert & $\begin{array}{c}\text { Konz. } \\
\text { Moleküle/ } \mu \text { l) }\end{array}$ & p-Wert \\
\hline $10^{1}$ & 0,0056 & $10^{1}$ & 0,7679 & $10^{1}$ & 0,1998 \\
\hline $10^{2}$ & 0,0060 & $10^{2}$ & 0,3533 & $10^{2}$ & 0,0087 \\
\hline $10^{3}$ & 0,0150 & $10^{3}$ & 0,3588 & $10^{3}$ & 0,0314 \\
\hline
\end{tabular}

Tab. 3 .6: Statistische Signifikanz (p-Wert) von MIX 2 Konzentrationen, deren $p$-Wert nicht $<0,05$ ist, sind durch dick gedruckte Schrift hervorgehoben

\begin{tabular}{|c|c|c|c|c|c|c|c|}
\hline \multicolumn{2}{|c|}{ EBOVZ } & \multicolumn{2}{|c|}{ EBOVS } & \multicolumn{2}{|c|}{ YFV } & \multicolumn{2}{|c|}{ DENV } \\
\hline 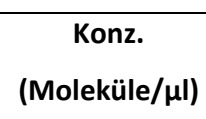 & p-Wert & 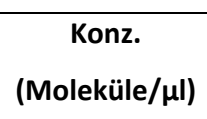 & p-Wert & 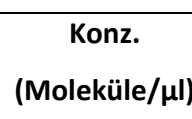 & p-Wert & $\begin{array}{c}\text { Konz. } \\
\text { (Moleküle/ } \mu \text { l) }\end{array}$ & p-Wert \\
\hline $10^{1}$ & 0,046 & $10^{1}$ & 0,167 & $10^{1}$ & 0,005 & $10^{1}$ & 0,000 \\
\hline $10^{2}$ & 0,002 & $10^{2}$ & 0,071 & $10^{2}$ & 0,041 & $10^{2}$ & 0,001 \\
\hline $10^{3}$ & 0,013 & $10^{5}$ & 0,087 & $10^{5}$ & 0,013 & $10^{5}$ & 0,012 \\
\hline
\end{tabular}


Lediglich CCHFV und EBOVS erreichen bei den Verdünnungen $<10^{3}$ keinen $p$-Wert $<0,05$. Auch bei MARV fällt auf, dass bei einer Konzentration von $10^{1}$ keine statistische Signifikanz vorliegt, da der $p$-Wert $>0,05$ ist. Für RVFV, EBOVZ, YFV und DENV hingegen konnte eine statistische Signifikanz bis zur kleinsten Verdünnungsstufe bestätigt werden. Bei dem Vergleich zwischen der statistischen Signifikanz und der analytischen Sensitivität, die mit dem LOD ermittelt wurde, ergaben sich folgenden Werte:

Tab. 3.7: Vergleich der Mindestkonzentration von statistischer Signifikanz mit der durch den LOD-ermittelten Sensitivität im Uniplex-System bei MIX 1 und 2.

\begin{tabular}{|c|c|c|c|}
\hline & & 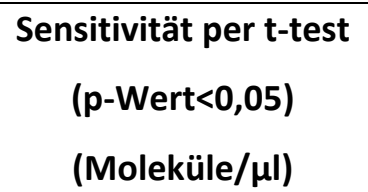 & $\begin{array}{c}\text { Sensitivität per } \\
\text { LOD } \\
\text { (Moleküle/ } \mu \mathrm{l} \text { ) }\end{array}$ \\
\hline \multirow[t]{3}{*}{ MIX1 } & RVFV & $10^{1}$ & $10^{1}$ \\
\hline & CCHFV & $>10^{7}$ & $10^{1}$ \\
\hline & MARV & $10^{3}$ & $10^{4}$ \\
\hline \multirow[t]{4}{*}{ MIX2 } & EBOVZ & $10^{1}$ & $10^{2}$ \\
\hline & EBOVS & $10^{4}$ & $10^{3}$ \\
\hline & YFV & $10^{1}$ & $10^{1}$ \\
\hline & DENV & $10^{1}$ & $10^{1}$ \\
\hline
\end{tabular}

Für RVFV, YFV und DENV entsprach die ermittelte Sensitivität $\left(10^{1}\right.$ Moleküle/ $\left.\mu \mathrm{l}\right)$ des CBAs der Mindestkonzentration mit einer statistischen Signifikanz ( $p$-Wert <0,05). Für MARV $\left(10^{3}\right.$ Moleküle $\left./ \mu \mathrm{l}\right)$ und EBOVZ $\left(10^{1}\right.$ Moleküle/ $\left.\mu \mathrm{l}\right)$ lässt sich selbst noch bei Konzentrationen unterhalb der Sensitivität $\left(10^{4}\right.$ bzw. $10^{2}$ Moleküle/ $\left.\mu \mathrm{l}\right)$ ein signifikanter Unterschied zur NK bestimmen. Die Mindestkonzentration der statistischen Signifikanz für EBOVS $\left(10^{4}\right.$ Moleküle/ $\left.\mu l\right)$ liegt allerdings oberhalb der Sensitivität im CBA $\left(10^{3}\right.$ Moleküle/ $\mu \mathrm{l})$. Die Ergebnisse für CCHFV zeigen, dass der CBA sogar bis zur höchsten Konzentration ( $10^{7}$ Moleküle/ $\left.\mu l\right)$ keine statistische Signifikanz aufweist, während mithilfe des Grenzwertes (LOD) eine Sensitivität bis zu $10^{1}$ Moleküle/ $\mu$ l determiniert wird. 


\subsubsection{Kreuzreaktionstestung im Multiplex-Hybridisierungsverfahren}

Um die Spezifität des CBAs zu bestimmen, sollten die Oligonukleotidsonden auf Kreuzreaktionen untersucht werden. In der Multiplex-Hybridisierung wurden die Kreuzreaktionen innerhalb der Mixe ausgeschlossen (s. Kap. 3.3.3, S.65). Lediglich die EBOVZ-Sonde wies eine leichte Kreuzreaktion bei dem EBOVS-Genom auf. In diesem Versuch sollten auch die Kreuzreaktionen mit den Genomen der Viren aus dem anderen Mix getestet werden.

Die Proben wurden, wie bei der Multiplex-Hybridisierung, mit den Beads des gesamten Mixes angesetzt. Dazu wurden zur Hybridisierung je PCR-Amplifikate von einem $10^{6}$ Standard eines unspezifischen Virus gegeben und nach dem Hybridisierungsverfahren in Kap. 2.2.2.3 (S.44) bei $60^{\circ} \mathrm{C}$ hybridisiert und zur Detektion in SARPE inkubiert.

Die Ergebnisse des Kreuzreaktionstestes mit den Oligonukleotidsonden aus Mix 1 und Mix 2 sind im Säulendiagramm in Abb. 3.22 dargestellt. Die spezifischen Sonden zeigen jeweils einen deutlichen Anstieg der MFI-PE-Signale. Bei keiner der unspezifischen Oligonukleotidsonden kann ein eindeutiger Anstieg der Fluoreszenz beobachtet werden. Zur Interpretation der Ergebnisse diente das Verhältnis zum MW der Negativkontrollen. Im Vergleich zum MFI-PE-MW der NK-Proben erreichte die RVFV-Sonde bei Zugabe der spezifischen Probe einen 14,4-fach höheren Wert, die CCSMW-Sonde einen 15,8-fach höheren Wert und die MARV einen 11,7-fachen Wert. Die Sonden des Mix 2 erreichten zum Teil noch sehr viel höhere Werte im Vergleich zur Kontrollprobe: EBOVZ-Sonde kam auf 44,1-fache Werte und die DENV-Sonde auf 57,8-fache Werte. Bei der EBOVS-Sonde war es weniger stark aber dennoch eindeutig mit einem 9,6-fach höheren Wert bei der spezifischen Probe. Bei der YFV-Sonde zeigte sich eine 17,9-fach höhere Fluoreszenzintensität.

Kreuzreaktivitäten wurden im CBA allgemein nicht beobachtet. Wie in der MultiplexHybridisierung (s. Kap. 3.3.3, S.65) kam es in der Probe der EBOVZ-Sonde bei der Zugabe von EBOVS zum wiederholten Male zu einem leichten Anstieg der MFI-PE, die immerhin 0,3-fach höher war als die MFI-PE der spezifischen EBOVS-Sonde.

Diese Daten demonstrieren eine gute Spezifität des CBAs und beweisen, dass keine unspezifischen Bindungen an die Oligonukleotidsonden stattgefunden haben. 


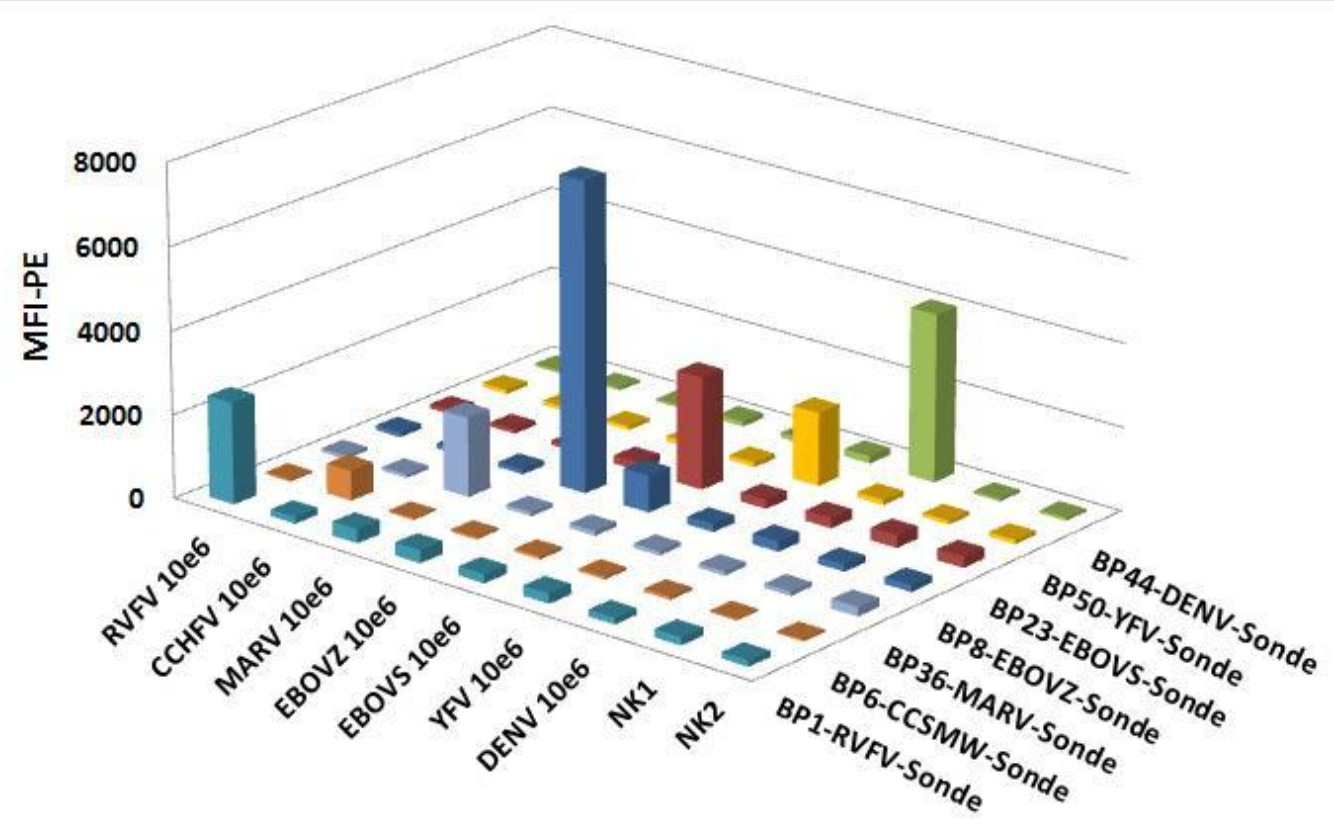

Abb. 3.22: Kreuzreaktionstest mit den Sonden von Mix 1 und Mix 2. Aufgetragen wurden die mittleren Fluoreszenzintensitäten von Phycoerythrin (MFI-PE) der untersuchten Proben (pro Virus: $n=1$ ).

\subsection{Vergleich der Sensitivität der verschiedenen Nachweisverfahren für hämorrhagische Fieberviren}

Um die Bedeutung des CBAs als Diagnostikmittel für HFV einzuschätzen, benötigt es einen Vergleich der Sensitivität des CBA zu der Sensitivität einer Real-Time-PCR für dieselben HFV hergestellt werden.

Für die Real-Time-PCR wurden die gleichen Primerpaare und Mixe verwendet. Die Sequenzen der TaqMan-Sonden entsprachen den Sequenzen der Oligonukleotidsonden, die an die Beads gekoppelten wurden. Das PCR-Protokoll entsprach dem Protokoll in Kap. 2.2.1.3.6 (S.39). In Tab. 3.8 werden die Sensitivitäten der qRT-PCR, der UniplexHybridisierung und der Multiplex-Hybridisierung zusammengefasst. Dafür werden die Referenzdaten für den CBA aus den statistischen Auswertung in Kap. 3.3.6 herangezogen. 
Tab. 3.8: Sensitivität für Mix 1 und Mix 2 von qRT-PCR und CBA im Uniplex- und im MultiplexSystem im Vergleich.

\begin{tabular}{|l|ccc|}
\cline { 2 - 4 } \multicolumn{1}{c|}{} & Uniplex-CBA & $\begin{array}{c}\text { Multiplex- } \\
\text { qRT-PCR }\end{array}$ & Multiplex-CBA \\
\hline RVFV & $10^{1}$ & $10^{3}$ & $10^{3}$ \\
\hline CCHFV & $10^{1}$ & $10^{3}$ & $10^{5}$ \\
\hline MARV & $10^{4}$ & $10^{3}$ & $10^{3}$ \\
\hline EBOVZ & $10^{2}$ & $10^{2}$ & $10^{2}$ \\
\hline EBOVS & $10^{3}$ & $10^{2}$ & $10^{3}$ \\
\hline YFV & $10^{1}$ & $10^{2}$ & $10^{2}$ \\
\hline DENV & $10^{1}$ & $10^{2}$ & $10^{3}$ \\
\hline
\end{tabular}

Beim Vergleich der Ergebnisse von beiden Diagnostikverfahren lässt sich erkennen, dass die Sensitivitäten bei ähnlichen Konzentrationen liegen.

Nur bei zwei Viren (MARV, EBOVS) erreicht die qRT-PCR bessere Ergebnisse als der CBA im Uniplex-System. Bei den übrigen Viren (RVFV, CCHFV, YFV, DENV) erweist sich der CBA als sensitiver oder als vergleichbar sensitiv (EBOVZ) zur qRT-PCR. Die Ergebnisse des CBA im Multiplex-System sind zwar weniger sensitiv als im Uniplex-System aber erreichen bei RVFV, MARV, EBOVZ und YFV immer noch Sensitivitäten, die mit denen der qRT-PCR vergleichbar sind. Die Ergebnisse des Multiplex-Hybridisierungsverfahren von EBOVS und DENV sind jeweils eine 10er-Potenz schwächer als in der qRT-PCR.

Die Ergebnisse von CCHFV müssen kritisch beurteilt werden, da bei der UniplexHybridisierung von CCHFV in der Grenzwertermittlung eine NK-Probe nicht berücksichtigt werden konnte und aus diesem Grund die SD nur sehr niedrig gewesen sind (s. Kap. 3.3.6, S.76).

Durch den Vergleich mit der qRT-PCR, einem bereits etablierten diagnostischen Verfahren für HFV, wird deutlich, dass das in dieser Arbeit entwickelte Verfahren meist nur leicht schwächere und zum Teil sogar gleiche Sensitivitäten erreichte und damit das Potential besitzt, in der Routinediagnostik als Diagnostikmittel verwendet zu werden. 


\section{Diskussion}

Als sensitives Multiplexverfahren ermöglicht der CBA die multiple Simultandetektion verschiedener Parameter aus einer einzigen Probe. Durch die Option, Antigene, Antikörper, Zytokine oder Oligonukleotidsonden an die Beads zu koppeln, ist der CBA vielfältig einsetzbar. Die Bindungskinetik in Flüssigkeit im Gegensatz zur Kinetik mit immobilisierten Bindungspartnern ist deutlich verbessert. Außerdem handelt es sich bei dem CBA um eine schnelle, einfach handhabbare und verlässliche Methode, die nur ein geringes Probenvolumen benötigt. Der CBA erfüllt also alle Bedingungen, die an ein molekulares Diagnostikverfahren für ein Multiplexsystem gestellt werden.

Im Rahmen dieser Arbeit ist ein CBA zum Nachweis der Nukleinsäuren von acht afrikanischen hämorrhagischen Fieberviren auf Basis von an Beads hybridisierten Oligonukleotidsonden entwickelt worden.

Virale hämorrhagische Fieber sind eine akute Infektion mit einer hohen Infektions- und Mortalitätsrate. Das Interesse an den Erregern der VHF ist in den letzten Jahren deutlich angestiegen. Einerseits hat das Potential zum Missbrauch als biologischer Kampfstoff zur größeren Beachtung der HFV beigetragen (Borio et al. 2002, Franz et al. 1997). Andererseits ist das Infektionsrisiko in Nicht-Epidemiegebieten aufgrund einer erhöhten Reisefreudigkeit angestiegen (CDC 2011).

Wie in Kap. 1.2.1 bereits beschrieben erfolgte die Routinediagnostik bislang üblicherweise durch die Kombination von Virusisolation (Slenczka 1999), serologischen (antigen-capture ELISA, IgM-/IgG-Antikörper-Detektion) (Gear et al. 1975) und molekularen Methoden (z.B. PCR, qRT-PCR) (Digoutte et al. 1992, Saluzzo, Le Guenno 1987). Dennoch müssen für die VHF Diagnostik mehrere besondere Herausforderungen bedacht werden: (1) bei Verdacht auf VHF muss eine Patientenprobe auf mehrere HFV getestet werden, da die Symptome der VHF nur unspezifisch sind und keine klinische Differentialdiagnose zulassen, (2) bei einem Ausbruch kann es zu einer schnellen Verbreitung der Infektion kommen, sodass eine frühe und simultane Analyse mehrerer Proben entscheidend ist und (3) um das gesamte diagnostische Fenster abzudecken, 
müssen molekulare und serologische Methoden miteinander kombiniert werden. Um auf diese Problematik einzugehen soll der CBA dieser Arbeit mit weiteren CBAs zur Detektion von Antikörpern und Zytokinen für die gleichen acht HFV kombiniert werden. Multiplex-CBAs zur Detektion von Antikörpern und Zytokinen für HFV-Infektionen werden im Institute Pasteur de Dakar im Senegal zur Zeit im Rahmen einer Kooperation mit dem Virologischen Institut der Georg-August-Universität (Multi-parameter and high throughput diagnostic platform for viral hemorrhagic fever, PTR 273 Projekt) entwickelt. Zur Detektion viraler Genome sind bereits verschiedene CBAs entwickelt worden: Respiratorische Viren (Horejsh et al. 2005, Letant et al. 2007), Papillomaviren (Jiang et al. 2006, Oh et al. 2007, Schmitt et al. 2006) (Wallace et al. 2005), Pestviren (Deregt et al. 2006) und HIV-1 Genotypen (Greve et al. 2009). Des Weiteren hat Taniuchi et al. im Jahr 2011 einen CBA zur Detektion von parasitären Genomen veröffentlicht (Taniuchi et al. 2011). Bezüglich HFV-Infektionen ist bisher lediglich ein CBA zum Antikörpernachweis für DENV entwickelt worden (Shu,Huang 2004). Ein molekulares Diagnostikverfahren, das der Detektion von HFV-Genomen im Multiplexsystem dient, ist bislang noch nicht beschrieben worden. Da der Nachweis von Antikörpern gegen HFV oftmals erst nach einigen Tagen durchgeführt werden kann, spielt der AK-Nachweis in der Akutphase der Erkrankung meist keine Rolle. Für die akute HFV-Erkrankung mit derart hoher Letalität und Infektiösität ist es wesentlich aussichtsreicher die Diagnostik innerhalb der ersten Tage nach Infektion durch den direkten Virusgenomnachweis durchzuführen.

Für die Entwicklung des CBAs in der vorliegenden Arbeit wurden anfangs Multiplex-RTPCRs etabliert. Die Kombination eines Multiplex-CBAs mit einer vorangegangenen Multiplex-PCR ist bereits mehrfach erfolgreich durchgeführt worden (Armstrong et al. 2000, Hindson et al. 2008, Lee et al. 2007, Letant et al. 2007, Taniuchi et al. 2011, Wallace et al. 2005). Die Diagnostik mit dem CBA ist durch diese synchrone Amplifikation mehrerer Produkte vereinfacht, zeitsparend und kostensparend.

Für die Multiplex-PCR in dieser Arbeit wurden spezifische Primerpaare synthetisiert, die im Anschluss zu drei Primermixen für die Multiplex-PCR kombiniert wurden (s. Kap.3.1.2). Zu den acht afrikanischen HFV, die mit dem CBA detektiert wurden, gehören: LASV (Arenaviridae), RVFV, CCHFV (Bunyaviridae), MARV, EBOVZ, EBOVS (Filoviridae), 
YFV, DENV (Flaviviridae). Dabei beruhten die RNS-Standards auf bereits veröffentlichten Ergebnissen (Weidmann 2004, 2008, 2010). Es mussten lediglich die Primer und Sonden für CCHFV und LASV neu entwickelt werden. Dabei wurden für die Entwicklung der Primer und der Sonde von CCHFV nur afrikanische Sequenzen berücksichtigt.

Zum Nachweis einer erfolgreichen Hybridisierungsreaktion an die gekoppelten Beads wurden biotinylierte RP verwendet. Durch das Biotin im PCR-Produkt war nach der Inkubation in SARPE eine Detektion in der Durchflusszytometrie möglich.

Die PCR hat sich in der Diagnostik als wichtiges Instrument etabliert, da sie eine schnelle, simultane Detektion von Pathogenen im Multiplexsystem erlaubt. Durch eine Kombination mehrerer spezifischer Primerpaare können Amplifikationsartefakte entstehen (Fan et al. 2006). Wie Broude et al. und Syvanen et al. bewiesen, sind in PCRs bis zu 10 simultane Amplifikationenreaktionen möglich, bevor es zur Akkumulation von unspezifischen Produkten kommt (Broude et al. 2001, Syvanen 2005). Dennoch präsentiert sich gerade die Multiplex-PCR als komplexes Diagnostikverfahren, sodass nur vergleichsweise wenige veröffentlichte Multiplex-PCRs existieren (Weidmann et al. 2008).

Die Primer und Sonden müssen perfekt aufeinander abgestimmt werden, wobei die Schmelztemperatur $\mathrm{T}_{\mathrm{MP}}$ der Primer, die Schmelztemperatur $\mathrm{T}_{\mathrm{MS}}$ der Sonden, die Länge der Amplikons und die Schmelztemperatur $\mathrm{T}_{\mathrm{MA}}$ des Amplikons berücksichtigt werden muss, um Primerdimerbildung zu verhindern. Durch verschiedene Programme (z.B. Primer Select, Primer Express, Oligo3, DNAsis) können Primerdimere vorausgesagt werden. Diese Prognosen sind jedoch nicht hundertprozentig verlässlich.

Um die Kompetition der Einzelreaktionen untereinander zu minimieren, wurden die Multiplex-PCRs in drei Primermischungen unterteilt. Taniuchi et al. beschrieb ebenfalls, dass die Aufteilung in 2- bzw. 3-plex-PCRs die Effektivität des Amplifikationsverfahrens für den CBA verbessert (Taniuchi et al. 2011), da auf diese Weise Kreuzreaktionen vermieden werden können.

Zur Ermittlung der optimalen Primerkombinationen wurden die verschiedenen Multiplex-Ansätze per SYBR-Green-qRT-PCR auf Primerdimerbildungen untersucht. 
Dabei stellten sich die Kombination von (1) RVFV, CCHFV und MARV und (2) EBOVZ, EBOVS und YFV als besonders effektiv heraus (s. Abb. 3.3, S.50), da sie kaum Primerdimerbildungen aufwiesen. DENV wurde erst im Anschluss in den Mix 2 aufgenommen, da sich im Agarosegel nach einer Multiplex-PCR mit Primermix 2 deutlichere spezifische Banden zeigten als bei der Kombination mit Primermix 1 (s. Abb. 3.4, S.51). Die LASV-Primer wurden als eigenständiger Mix 3 zusammen gefügt.

Wie Deregt et al. bereits für einen mRT-PCR-Luminex-CBA zur Detektion von Schweinefieber und Pestviren und Horejsh et al. bei der Entwicklung eines CBAs für 4 respiratorischen Viren untersucht hatten, wurde durch die Verwendung eines asymmetrischen Primerverhältnisses die Fluoreszenzintensität erhöht (Deregt et al. 2006, Horejsh et al. 2005). Als Begründung wurde von Deregt et al. und Horejsh et al. vermutet, dass die Ziel-DNS, die in der symmetrischen PCR entstand, durch Wiederanlagern der Einzelstränge zu Doppelsträngen die Hybridisierung der Oligonukleotidsonde verhinderte. Ein Vorteil der asymmetrischen PCR könnte also dadurch zustande kommen, dass bei einem Verhältnis, das zugunsten der RP verschoben wird, mehr einzelsträngige DNS generiert wird, die zur Oligonukleotidsonde komplementär ist, und deshalb die Effizienz der Hybridisierung an die bead-gekoppelten Sonden erhöht wird (Deregt et al. 2006).

Aus diesem Grund wurden in der vorliegenden Arbeit die Primer mit verschiedenen FP/RP-Verhältnissen (4:1 bzw. 1:4) in der Multiplex-RT-PCR getestet um das effizienteste Verhältnis für jeden Mix individuell zu bestimmen, wobei die Amplifikate im 2\%igen Agarosegel analysiert wurden.

Während im Mix 1 das 4:1-FP/RP-Verhältnis bei der Auswertung auf dem Agarosegel deutlichere spezifische Banden zeigte, erzielte das 1:4-RP/FP-Verhältnis im Mix 2 und Mix 3 bessere Resultate. Basierend auf den Ergebnissen von Deregt et al. und Horejsh et al. ist ein direkter Vergleich der Fluoreszenzintensität im Durchflusszytometer von PCRProdukten aus symmetrischer und asymmetrischer PCR nicht durchgeführt worden. Entgegen der Erwartungen können diese Ergebnisse mit der unterschiedlichen Polarität der Virusgenome nicht hinreichend erklärt werden. Mix 1 enthält Primer für die Bunyaviren RVFV und CCHFV sowie für das Filovirus MARV, deren Genome jeweils als 
negativer Einzelstrang (ss(-)RNS) vorliegen, d.h. die Replikation findet in $3^{\prime} \rightarrow 5^{\prime}-$ Leserichtung statt. Wie gezeigt erhöht das FP/RP-Verhältnis 4:1 zugunsten des FP aus diesem Grund die Effektivität der Amplifikation. Mix 2 hingegen enthält sowohl Primer für die Flaviviren YFV und DENV mit positivsträngigem Einzelstranggenom (ss(+)RNS) als auch Primer für die Filoviren EBOVZ und EBOVS mit negativsträngigem Einzelstranggenom (ss(-)RNS). Dennoch konnte nur das FP/RP-Verhältnis von 1:4 die Effektivität des Primermixes steigern. Mix 3 enthielt Primer für das LASV, einem Arenavirus mit negativem Einzelstranggenom (ss(-)RNS) und erzielte mit dem 1:4Primerverhältnis bessere Ergebnisse. Hier hätte man eher ein Ergebnis wie in Mix 1 erwartet.

Eine nahe liegende Begründung für die Tatsache, dass einige asymmetrische Primerverhältnisse effizienter sind als andere, könnten Primerinteraktionen mit dem RNS-Zielmolekül sein. Schließlich kann der Zugang der PCR zum RNS-Molekül durch die Ausbildung komplizierter Sekundärstrukturen wie Haarnadelstrukturen oder GQuadruplexen erschwert bis unmöglich gemacht werden (Kuo et al. 1997, Myers,Gelfand 1991).

Um spezifische PCR-Produkte nach der Multiplex-RT-PCR zu isolieren, wurden die PCRProdukte mit dem MinElute-Purification-Kit (QIAGEN) aufgereinigt. Durch die Aufreinigung wurden alle Nukleinsäuren, die $<70 \mathrm{bp}$ bzw. $>4 \mathrm{~kb}$ waren, und alle Proteine entfernt. Ergänzend wurde, während der Reinigung mit dem MinElute-Purification-Kit,

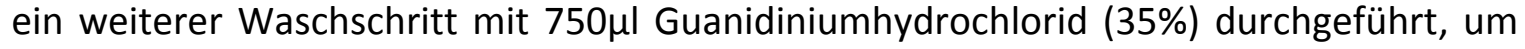
Primerdimere größer als 20bp zu entfernen.

Durch den Aufreinigungsvorgang mit dem MinElute-Purification-Kit ließ sich im Mix 1 eine Verbesserung der Fluoreszenzsignale im Durchflusszytometer erreichen, da nach der Aufreinigung der PCR-Amplifikate ein deutlich positiveres Fluoreszenzsignal messbar war. So ließ sich bei der Uniplex-Hybridisierung von RVFV bei einer Konzentration von $10^{6}$ Molekülen/ $\mu$ l ein 2-fach, bei MARV ein 2-fach und bei CCHFV ein 6-fach stärkeres MFI-PE-Signal messen. Eine Hybridisierung an die gekoppelten Sonden war im Mix 1 ohne MinElute-Purification-Kit nicht möglich. Bei den Proben der Mixe 2 und 3 war die Aufreinigung jedoch nicht nötig. Dies ließ darauf schließen, dass die Multiplex-PCR in Mix 
2 und Mix 3 besser aufeinander abgestimmt war und deshalb weniger Primerdimere entstanden. Der Vergleich der Primerdimerbildung in den Mixen 1, 2 und 3 in der SYBRGreen-qRT-PCR (s. Kap. 3.1.3, S.51) bewies, dass der Ct-Wert von Mix 1 (RVFV-CCHFVMARV) wesentlich niedriger (12) war, als der Ct-Wert von Mix 2 (EBOVZ-EBOVS-YFVDENV) (20) und Mix 3 (LASV) (26). Da ein niedriger Ct-Wert in der SYBR-Green-qRT-PCR auf eine starke Dimerbildung deutet, bestätigte dieses Ergebnis die Vermutung, dass die Primerdimerbildung in Mix 1 deutlich höher sein musste als in den anderen Mixen.

Bei der Analyse der FP von Mix 1 fällt auf, dass sich die Primer RVF-FP und der MBR-FP2, an den 3'-Enden in ihrer bp-Zusammenstellung ähneln. Die letzten 5 bp am 3'-Ende sind bis auf ein bp sogar identisch (RVF-FP: -AGCCA-3', MBR-FP2: -AGACA-3'). Da an diesem Ende die Elongation durch die Polymerase beginnt, ist dieser Abschnitt der Primer besonders entscheidend für die Spezifität der PCR. Aus diesem Grund kann es zu einer vermehrten unspezifischen Bindung in Mix 1 gekommen sein. Hier ist eventuell eine Optimierung durch Veränderung eines der Primer möglich.

Um die biotinylierten PCR-Produkte an die Beads zu binden, mussten zuvor aminierte Oligonukleotidsonden an die carboxylierten Kugeln gekoppelt werden. So konnten die PCR-Amplifikate anschließend an die immobilisierten Oligonukleotidsonden hybridisiert werden.

Die Kopplungsreaktion erfolgte über eine Carbodiimid-Reaktion, in der die funktionellen Carbonsäuregruppen der Beads durch den Kreuzvernetzer EDAC aktiviert wurden und daraufhin eine kovalente Bindung mit den freien Aminogruppen der DNS-Sonden eingingen. Für die Kontrolle der Kopplungsreaktion wurde eine CCHFV-Sonde verwendet, die mit dem Fluoreszenzfarbstoff Cy3 markiert war. Die übrigen von „TIB MOLBIOL" angebotenen Fluoreszenzfarbstoffe zur Markierung des 3'-Ende von Oligonukleotidsonden konnten aus verschiedenen Gründen nicht verwendet werden: TAMRA, ROX und Cy 5.5 können vom FACS Canto ${ }^{\text {TM }}$ II nicht detektiert werden und Cy5 (667 nm) überschneidet sich mit seinem Emissionsspektrum mit dem Spektrum von APC $(660 \mathrm{~nm})$, das in den Beads enthalten ist. Ein Nachteil des Cy3 blieb allerdings die Tatsache, dass es sich als Fluoreszenzfarbstoff zur Überprüfung der Kopplungsreaktion mit PE, dem Fluoreszenzfarbstoff zur Überprüfung der Hybridisierungsreaktion, im 
Emissionsmaximum überschnitt. Eine direkte Kontrolle der Kopplung war deshalb während einer Hybridisierungsreaktion nicht möglich. Insofern konnte eine misslungene Kopplung der Oligonukleotidsonde an die Beads nie als Fehlerquelle für falsch negative Fluoreszenzsignale ausgeschlossen werden.

Das Fluoreszenzsignal des Farbstoffes Cy3 von der CCHFV-Kontrollsonde wurde im PEKanal des Durchflusszytometers detektiert. Zum Vergleich diente eine Negativkontrolle mit Beads, zu denen $\mathrm{H}_{2} \mathrm{O}$ anstelle der Oligonukleotidsonden zugegeben wurde.

Das Fluoreszenzsignal der Probe mit den gekoppelten Sonden war 83-fach höher als das Signal der Negativkontrolle. Die erfolgreiche Kopplungsreaktion konnte damit bestätigt werden. Um die Zuverlässigkeit der Kopplungsreaktion zu überprüfen, wurde in den ersten Versuchsreihen jeweils eine Kopplungskontrolle mit einer Cy3-markierten-Sonde mitgeführt. Bei der Auswertung am FACS Canto ${ }^{T M}$ II zeigte sich, dass die Kopplungsreaktion zuverlässig funktionierte und nur geringen Schwankungen (MFI von 22242 - 39480, n=7) unterlag. Aus diesem Grund wurde die Kopplungskontrolle aus Kostengründen bei den späteren Versuchsreihen nicht mehr mitgeführt.

Die wiederholte Zugabe von EDAC war essentiell für die Kopplung. Eine ergänzende Zugabe von S-NHS (N-hydroxysulfosuccinimide), wie es vom Hersteller der Beads (Bio Rad Laboratories $\mathrm{GmbH}$ ) empfohlen wird, wurde in der vorliegenden Arbeit nicht verwendet. Die Kopplungsreaktion wurde ursprünglich mit S-NHS ausprobiert und lieferte keine positiven Ergebnisse. Erst durch die Entwicklung eines Kopplungsverfahrens, das ohne S-NHS aber mit zweifacher Gabe von EDAC durchgeführt wurde, konnte eine erfolgreiche Kopplungsreaktion nachgewiesen werden. Mehrfache EDAC-Zugabe während der Kopplungsreaktion ist schon aus verschiedenen Publikationen bekannt (Armstrong et al. 2000, Hindson et al. 2008, Rockenbauer et al. 2005, Taniuchi et al. 2011).

Wie Wittebolle et al. bereits gezeigt hatte, konnte bei der Kopplung von Oligonukleotiden an Beads durch die Verwendung eines MES-Borat-Puffers mit einem $\mathrm{pH}$ von 4,5 die Kopplungseffizienz drastisch angehoben (Wittebolle et al. 2006) und Hintergrundsignale minimiert werden. Inzwischen ist die Verwendung von MES (pH 4,5) ein etabliertes Verfahren zur Kopplung bei CBAs und wurde schon in mehreren 
Veröffentlichungen angewendet (Deregt et al. 2006, Letant et al. 2007, Oh et al. 2007, Schmitt et al. 2006), weshalb MES (pH 4,5) auch im Rahmen dieser Arbeit verwendet wurde.

Grundsätzlich bleibt das Kopplungsverfahren noch optimierbar. Eine deutliche Effizienzsteigerung wurde durch das Zufügen von BSA-Puffer erreicht, da auf diese Weise freie $\mathrm{COOH}-G r u p p e n$ abgesättigt wurden (s. Kap. 3.3.1.3., S.62). Eventuell könnte die Kopplungsreaktion durch ein besseres Verhältnis von Oligonukleotidsonden zu Beads oder durch Optimierung der Reaktionbedingungen (z.B.: Lagerungsbedingungen, erhöhte Zugabe von EDAC) effizienter gestaltet werden.

Für die Hybridisierungsreaktionen der PCR-Produkte an die Oligonukleotidsonden wurden die PCR-Amplifikate (1:2 mit Tris-EDTA, pH 8,0, verdünnt) nach einer 5minütigen Denaturierung bei $96^{\circ} \mathrm{C}$ für eine Stunde bei $60^{\circ} \mathrm{C}$ mit den gekoppelten Beads inkubiert. In der Literatur lassen sich verschiedene Angaben zum Hybridisierungsvorgang finden. Grundsätzlich bestehen die veröffentlichten Protokolle aus einer 2-10 min Denaturierungsphase vor einer Hybridisierungsphase von 30-120 min (Armstrong et al. 2000, Deregt et al. 2006, Jiang et al. 2006, Letant et al. 2007, Oh et al. 2007, Rockenbauer et al. 2005, Taniuchi et al. 2011, Wallace et al. 2005). Lediglich Schmitt et al. verwendete ein Protokoll mit einer Hybridisierungsreaktion unter dauerhafter Agitation ohne vorangegangene Denaturierungsphase (Schmitt et al. 2006). Als Puffer in der Hybridisierungsreaktion wurde Tween 20 (Jiang et al. 2006), TMAC (Tetramethylammoniumchlorid) (Deregt et al. 2006)(Schmitt et al. 2006)(Wallace et al. 2005), FACS Flow (Spülflüssigkeit des FACS Canto ${ }^{T M}$ ) (Horejsh et al. 2005), Etway Hybridsol und Triton X-100 (Oh et al. 2007), Tris NaCl (Letant et al. 2007) oder Phosphat Puffer (Rockenbauer et al. 2005) verwendet. Der qualitative Nachweis der Hybridisierung erfolgt durch die Bindung von SARPE $(1 \mu \mathrm{g} / 100 \mu \mathrm{l})$ an die biotinylierten PCR-Produkte (Deregt et al. 2006, Greve et al. 2009, Hindson et al. 2008, Jiang et al. 2006, Letant et al. 2007, Oh et al. 2007, Schmitt et al. 2006, Wallace et al. 2005). Dieses Fluoreszenzsignal konnte im Anschluss am Durchflusszytometer gemessen werden.

Der qualitative Nachweis der Hybridisierungsreaktion wurde durch eine erfolgreiche Hybridisierung im Uniplex-System (s. Kap. 3.3.2, S.63) und im Multiplex-System (s. Kap. 
3.3.3, S.65) für die acht afrikanischen HFV bestätigt. Die BP mit der spezifischen Sonde zeigte ein vielfach stärkeres Fluoreszenzsignal im Vergleich zu der BP mit der unspezifischen Sonde oder der BP mit der NK mit negativem Humanserum.

Im Anschluss an die Hybridisierungsreaktion erfolgte die Analyse der einzelnen Mixe (Mix 1-3) am FACS Canto ${ }^{\mathrm{TM}}$ II.

Dabei zeigten jeweils die Beads, an welche die spezifischen Sonden gekoppelt waren, ein deutlich höheres Signal als die Beads mit unspezifischen Sonden. Die MFI-PE-Werte der unspezifischen Sonden entsprachen denen der Negativkontrollen, bei denen negatives Humanserum anstelle von viraler RNS verwendet wurde. Auf diese Weise konnte bewiesen werden, dass lediglich die spezifischen Sonden eine Hybridisierung mit den PCR-Produkten eingingen.

Die absoluten Fluoreszenzwerte unterschieden sich meist deutlich im Inter-AssayVergleich, während die relativen Verhältnisse zwischen den spezifischen zu den unspezifischen Proben gleich blieben. Das bedeutete, dass die Fluoreszenzwerte jedes Versuchsdurchganges nur im Verhältnis zu den Ergebnissen der anderen Proben desselben Versuchsdurchganges analysiert werden können. Ein Vergleich der Fluoreszenzwerte zwischen verschiedenen Versuchsdurchgängen (Inter-Assay-Vergleich) war deshalb erschwert.

Beim Vergleich mit anderen veröffentlichten CBAs fiel auf, dass die Schwankungen dort meist geringer ausfielen, da mehr Versuchsdurchgänge ausgewertet wurden. Bei Lee et al. wurde zur Detektion von Viren, die Atemwegsinfektionen auslösen, der LOD z.B. anhand von 101 klinischen Proben (Rachenabstriche) evaluiert (Lee et al. 2007). In der statistischen Analyse fielen die Inter-Assay-Schwankungen aus diesem Grund nicht so ins Gewicht.

Auf Grund der Fluoreszenzunterschiede im Inter-Assay-Vergleich lassen sich in der

Literatur keine absoluten Werte zur LOD-Definition finden. Meist wurde der LOD in Abhängigkeit von der NK des jeweiligen Versuchsdurchganges ermittelt (Horejsh et al. 2005, Lee et al. 2007, Oh et al. 2007, Schmitt et al. 2006, Wallace et al. 2005).

Zur Begründung dieser Inter-Assay-Schwankungen können verschiedene Erklärungen in Betracht gezogen werden. So ist das Fluoreszenzsignal abhängig von der Größe, 
Sequenz, Sekundärstruktur und der Konzentration der PCR-Amplifikate. Besonders die Konzentration kann variieren, da sie ihrerseits abhängig ist von der Zuverlässigkeit der einzelnen PCR-Reaktionen. Eine regelmäßige Messung der Konzentration der PCRAmplifikate könnte zum Ausschluss dieser Fehlerquelle führen.

Genauso könnten auch temperaturabhängige Messfehler bei der Analyse im Durchflusszytometer zu Schwankungen der MFI-PE-geführt haben. Unterschiedliche Kompensationen zur Korrektur der spektralen Überlappung für die verschiedenen Fluoreszenzfarbstoffe können in dieser Arbeit ausgeschlossen werden, da alle Ergebnisse in der FACS-Diva-Software kompensationsunabhängig ausgewertet worden sind.

In einem weiteren Schritt sollte die analytische Sensitivität des Verfahrens im UniplexSystem $(n=3)$ ermittelt werden und mit der Sensitivität im Multiplex-System $(n=1)$ verglichen werden.

In diesem Fall wurden die PCR-Produkte von RNS-Standards bekannter Konzentrationen $\left(10^{1}-10^{7}\right.$ Moleküle/ $\left.\mu l\right)$ an die gekoppelten Oligonukleotidsonden hybridisiert. Die Ergebnisse wurden im Anschluss am FACS Canto $^{\text {TM }}$ ॥ gemessen und statistisch analysiert. Der Zusammenhang zwischen den unabhängigen Variablen wurde durch eine polynome Regressionsgerade definiert und in dem Bestimmtheitsmaß $R^{2}$ ausgedrückt. Je näher sich dabei das Bestimmtheitsmaß $R^{2}$ an 1 annäherte, desto eher ließ sich der Zusammenhang durch das polynome Regressionsmodell erklären.

Bei den HFV CCHFV, MARV, EBOVZ, EBOVS, YFV und DENV ergab sich ein $\mathrm{R}^{2}>0,93$, womit sich ein polynomer Wertezusammenhang vermuten ließ. Nur bei RVFV fiel $R^{2}$ deutlich niedriger aus $\left(R^{2}=0,36\right)$. Dies könnte durch eine frühe Sättigung der Oligonukleotidsonden erklärt werden. Schließlich wurden schon bei $10^{2}$ Molekülen/ $\mu \mathrm{l}$ die Maximalwerte erreicht. Die Hybridisierung scheint hier derartig optimal zu sein und zur Sättigung zu führen, dass für eine Optimierung der Hybridisierung entweder das Angebot an Sonden erhöht oder an eine Vorverdünnung des PCR-Produktes gedacht werden muss (Abb. 3.19).

Der LOD wurde zur Definition positiver Ergebnisse bei der 6-fachen SD oberhalb des Hintergrundrauschens (Mittelwert der NK) festgelegt. Eine statistische Analyse der Ergebnisse im Uniplex-System mit dem Student-t-Test zeigte, dass eine statistische 
Signifikanz ( $p$-Wert $<0,05$ ) bei den Viren RVFV, CCHFV, EBOVZ, YFV und DENV bis zu einer Konzentration von $10^{1}$ Moleküle/ $\mu$ l und bei MARV bis zu $10^{2}$ vorliegt (s. Tab. 3.5, S.78). Für LASV konnte keine statistische Analyse durchgeführt werden, da keine Hybridisierungen im Uniplex-System durchgeführt wurden.

Tab. 4.1: Durchschnittliche Viruslast nach HFV-Infektion im Vergleich zur erreichten Sensitivität im Uniplex-Verfahren des CBAs aus dieser Arbeit. Die aufgeführten Referenzwerte der durchschnittlichen Viruslast und die Sensitivität im CBA werden als Moleküle/ml angegeben.

\begin{tabular}{|c|c|c|c|c|}
\hline Virus & $\begin{array}{c}\text { Durchschnittliche } \\
\text { Viruslast nach Infektion } \\
\text { (Moleküle/ml) }\end{array}$ & $\begin{array}{c}\text { Post- } \\
\text { infektiöser } \\
\text { Tag }\end{array}$ & Quelle & $\begin{array}{c}\text { Sensitivität des } \\
\text { CBA im Uniplex- } \\
\text { System } \\
\text { (Moleküle/ml) }\end{array}$ \\
\hline RVFV & $8,6 \times 10^{6}$ & $k A$ & (Njenga et al. 2009) & $1 \times 10^{4}$ \\
\hline CCHFV & $1 \times 10^{6}$ & $6 . T a g$ & (Wolfel et al. 2007) & $1 \times 10^{4}$ \\
\hline MARV & $4,1 \times 10^{4}$ & $k A$ & (Weidmann et al. 2007) & $1 \times 10^{7}$ \\
\hline EBOV & $10^{8}-10^{9}$ & $6 . T a g$ & (Towner et al. 2004) & $1 \times 10^{5}$ \\
\hline YFV & $2,4 \times 10^{6}-3 \times 10^{7}$ & $k A$ & (Bae et al. 2005) & $1 \times 10^{4}$ \\
\hline DENV & $1 \times 10^{7}$ & $6 . T a g$ & (Gurukumar et al. 2009) & $1 \times 10^{4}$ \\
\hline LASV & $1 \times 10^{6}$ & $6 . T a g$ & (Schmitz et al. 2002) & $k A$ \\
\hline
\end{tabular}

Die durchschnittliche Viruslast nach einer HFV-Infektion kann stark variieren, da sie abhängig von der Schwere der Erkrankung, der Analysemethode und vom Zeitpunkt der Probenentnahme ist (Saksida et al. 2010). Bei der Analyse der Viruslast eines HFVPatienten muss folglich die Inkubationszeit berücksichtigt werden, da die Viruslast nach der Infektion zwar anfangs rapide steigt (virämische Phase), nach einigen Tagen allerdings wieder abfällt, zugunsten späterer Diagnostikparameter (Antikörper, Zytokine) (s. Abb. 1.7, S.17). Die in Tab. 4.1 aufgeführten Referenzwerte der durchschnittlichen Viruslast variieren von $10^{4}-10^{9}$ Molekülen/ml. Während bei CCHFV, EBOV, DENV und LASV konkrete Angaben zum Entnahmezeitpunkt der Proben gemacht wurden (6. Postinfektiöser Tag), fehlen jegliche Angaben dieser Art zu RVFV, MARV und YFV. Ein direkter Vergleich dieser Proben ist deshalb nur begrenzt möglich. Dennoch wird deutlich, dass der in dieser Arbeit entwickelte CBA im Uniplex-System mit einer Sensitivität von $10^{4}$ bzw. $10^{5}$ Moleküle/ml mindestens zum 6. Postinfektiösen Tag für RVFV, CCHFV, EBOV, YFV, DENV ausreicht um eine zuverlässige Diagnostik bei einer HFV- 
Infektion zu gewährleisten. Lediglich bei MARV liegt die durchschnittliche Viruslast unterhalb der signifikanten Sensitivität des CBA-Verfahrens.

Sowohl für EBOV als auch für CCHFV gilt eine Viruslast von $10^{8}$ Moleküle/ml als klinisch relevanter Grenzwert, mit dem ein tödlicher Ausgang der Infektion bis zu 90\% voraus gesagt werden kann (Saksida et al. 2010, Towner et al. 2004). Diese klinisch relevante Konzentration würde durch die Diagnostik mit dem CBA aus dieser Arbeit eindeutig erkannt werden.

Außerdem konnte mithilfe der statistischen Analyse bewiesen werden, dass der LOD eine eindeutige Trennung zum Hintergrundrauschen ermöglicht (Tab. 3.7, S.79). Dabei entsprachen die LOD-ermittelten sensitiven Konzentrationen weitestgehend den Konzentrationen, die auch durch den Student-t-Test als signifikant $(p<0,05)$ erkannt wurden. Bei EBOVS lag der LOD bei einer Konzentration von $10^{3}$ Molekülen/ $\mu$ l, obwohl bei dieser Konzentration noch keine statistische Signifikanz ( $p$-Wert=0,087) bestand. Allerdings lag der p-Wert für die Fluoreszenzintensität von EBOVS bei der nächsthöheren Konzentration $\left(10^{4}\right.$ Molekülen/ $\left.\mu \mathrm{l}\right)$, bei der auch die MFI-PE-Signale der nächsthöheren log-Stufe erreicht wurden, mit $p$-Wert=0,009 wieder im signifikanten Bereich. Bei der statistischen Analyse der Ergebnisse von CCHFV konnte keine Signifikanz bis zur höchsten Konzentration ( $10^{7}$ Moleküle/ $\mu$ l) bestätigt werden, obwohl aufgrund des LOD eine Sensitivität bis zu $10^{1}$ Moleküle/ $\mu$ l vorliegen sollte. Dabei muss bedacht werden, dass die Ergebnisse der Hybridisierungsreaktion von CCHFV bisher unbefriedigend waren. Eine konzentrationsabhängige Steigerung der MFI-PE von CCHFV im Durchflusszytometer war nicht erkennbar, wohingegen die Auswertung der MultiplexPCR auf dem Agarosegel eine erfolgreiche Amplifikation bewies. Aus diesem Grund muss der Assay für CCHFV verbessert werden. Eine Verbesserungsmöglichkeit besteht z.B. in der Herstellung neuer Sonden und Primer für CCHFV.

Im Multiplex-System ergaben sich für EBOVZ und EBOVS vergleichbare Sensitivitäten wie im Uniplex-System, für CCHFV, YFV und DENV war der CBA weniger sensitiv und für MARV und RVFV sogar sensitiver als im Uniplex-System. Es scheint also einen Unterschied zu machen, ob eine Oligonukleotidsonde oder mehrere Oligonukleotidsonde während der Hybridisierung in der Probe enthalten sind. Zu 
erwarten gewesen wäre eine vergleichbare Sensitivität. Dass sich die Fluoreszenzen zwischen dem Multiplex- und Uniplex-System unterscheiden, kann mehrere Gründe haben. Es ist denkbar, dass durch Kreuzreaktionen zwischen den verschiedenen Oligonukleotidsonden die Ergebnisse im Multiplex-System beeinflusst wurden. Ebenso verschiebt sich im Multiplex-System das Verhältnis Beads/PCR-Amplifikate (Mix 1: 1/3Verhältnis, Mix 2: 1/4-Verhältnis, Mix 3: 1/5-Verhältnis) durch die pipettierten anteiligen Volumina zugunsten der Beads, sodass eine Hybridisierung der PCR-Produkte an die spezifischen Sonden beeinflusst werden könnte.

Dennoch ist diese Verdünnung eher von geringfügiger Bedeutung und kann deswegen als Ursache ausgeschlossen werden. Eine mögliche Begründung für die verringerte Sensitivität könnte die vermehrte Kompetition der Oligonukleotidsonden untereinander sein. So könnten komplementäre Sequenzen der Sonden am 3'-Ende zu unspezifischen Hybridisierungen der Sonden miteinander geführt haben (z.B. in Mix 2: EBOVS-Sonde: 5'...AAGG-3', DENV-Sonde: 5'-...GACC-3').

Allerdings weist die Tatsache, dass die MFI-PE-Werte teilweise in einer Konzentration von $10^{5}$ Molekülen/ $\mu$ l höher sind als bei $10^{6}$ Molekülen/ $\mu$ l vermutlich darauf hin, dass durchaus bereits eine Sättigung aller Oligonukleotidsonden erreicht wurde.

Aufgrund der geringen Versuchszahl der Multiplexhybridisierung $(n=1)$ ist die Aussagekraft der Ergebnisse nur schwach. Für statistisch aussagekräftige Ergebnisse bei konkreteren Fragstellungen bezüglich der Fehlerquellen müssen weitere Versuche durchgeführt werden. Durch höhere Versuchszahl könnten Werteschwankungen, z.B. Inter-Assay-Schwankungen der Fluoreszenzsignale in der Uniplex- und MultiplexHybridisierung minimiert werden. Im Vergleich dazu finden sich in der Literatur wesentlich größere Versuchszahlen im CBA mit Patientenproben: 190-319 Proben (Taniuchi et al. 2011), 103 Proben (Lee et al. 2007), 132 Proben (Oh et al. 2007), 133 Proben (Jiang et al. 2006). Eine Testung mit HFV-Patientenproben wäre schwierig, da HFV-positive Patientenproben eine Rarität sind.

Um das Potential des CBA als Diagnostikverfahren in der Routinediagnostik einschätzen zu können, wurde die Sensitivität des Verfahrens im Uniplexsystem mit der Sensitivität einer qRT-PCR verglichen, in der die gleichen Primern verwendet worden sind. 
Dabei stellte sich heraus, dass die Uniplex-Hybridisierungsreaktion eine ähnliche Sensitivität wie die qRT-PCR aufwies. Für YFV und DENV waren die Ergebnisse im CBA sogar besser als in der qRT-PCR. Ein Vergleich mit CCHFV bleibt kritisch, da bei der Uniplex-Hybridisierung von CCHFV in der Grenzwertermittlung eine NK-Probe nicht berücksichtigt werden konnte und aus diesem Grund die SD nur sehr niedrig gewesen sind (s. Kap. 3.3.6, S.76).

Auch Taniuchi et al. führte einen Vergleich seines CBAs für sieben intestinale Parasiten (Taniuchi et al. 2011) mit den Ct-Werten aus qRT-PCR mit denselben Primern durch. Dabei wies der CBA bessere oder gleich gute Ergebnisse wie die qRT-PCR auf. Dennoch fiel auf, dass der Zusammenhang zwischen der Parasitenquantität und Ct-Werten aus der qRT-PCR linearer war, als der Zusammenhang zwischen der Parasitenquantität und der Fluoreszenzsignalen im CBA.

Obwohl die analytischen Sensitivitäten im CBA-Multiplex-System geringer waren als im CBA-Uniplex-System, waren sie dennoch mit den analytischen Sensitivitäten der qRTPCR-Verfahren vergleichbar. Die ermittelte Sensitivität des MultiplexHybridisierungsverfahren von RVFV, MARV, EBOVZ und YFV entsprach genau der Sensitivität in der qRT-PCR, die Sensitivität von EBOVS und DENV war jeweils nur eine 10er-Potenz schwächer als in der qRT-PCR und nur bei CCHFV nahm die Sensitivität im Multiplex-CBA um zwei 10er-Potenzen im Vergleich zur qRT-PCR ab.

Dabei sollte jedoch weiterhin bedacht werden, dass die verlängerte Hybridisierungsdauer im Multiplex-CBA (TaqMan-PCR: max. 1 min. und Multiplex-CBA: 1 Std.) zu einem erhöhten Risiko für Kreuzreaktivitäten führen kann.

Zur Untersuchung von Kreuzreaktivitäten zwischen den Oligonukleotidsonden und den PCR-Produkten aus Mix 1 und Mix 2 wurden die bead-gekoppelten Olignukleotidsonden jeweils mit PCR-Produkten aus beiden Mixen für eine Stunde bei $60^{\circ} \mathrm{C}$ inkubiert.

Dabei waren die Fluoreszenzsignale der Oligonukleotidsonde mit dem spezifischen PCRAmplifikat deutlich höher als die Fluoreszenzsignale der Sonden mit unspezifischen PCRProdukten, die den gemessenen Ergebnissen von NK ähnelten. Kreuzreaktivitäten wurden allgemein im CBA nicht beobachtet außer bei der EBOVZ-Sonde. Dort kam es zu einem leichten Anstieg der Fluoreszenzintensität bei der Zugabe von EBOVS-PCR- 
Amplifikaten. Die MFI-PE der EBOVZ-Sonde und dem EBOVS-Amplifikat war immerhin 0,3-fach so hoch wie die MFI-PE der spezifischen EBOVS-Sonde. Die Ursache könnte möglicherweise eine Kreuzreaktionen zwischen der EBOVZ-Sonde und dem EBOVS-PCRAmplifikat sein, die auf eine ähnliche Sequenz der eng verwandten Viren zurückgeführt werden kann. Bei der Analyse mit der „MegAlign-Software“ fiel auf, dass die Amplikons von EBOVZ und EBOVS zu 55,8\% identisch waren. Zum MARV-Amplikon z.B. gab es jeweils lediglich 33,3\%ige (EBOVS) bzw. 36,4\%ige (EBOVZ) Übereinstimmung. Die Daten der übrigen Sonden in der vorliegenden Arbeit demonstrierten eine gute Spezifität des CBAs und bewiesen, dass keine unspezifischen Bindungen an die Oligonukleotidsonden stattgefunden haben.

Kreuzreaktionen in Multiplex-CBAs sind bekannt. Taniuchi et al. Iösten das Problem, indem sie den CBA für sieben intestinale Parasiten in zwei Versuchsreihen aufteilten: eine Versuchsreihe für Protozoen und eine Versuchsreihe für Helminthen (Taniuchi et al. 2011). Bei der Detektion von Humanen Papillomaviren (HPV) mittels Multiplex-CBA fielen ebenfalls Kreuzreaktionen zwischen einigen HPV auf, die zur Verringerung der Fluoreszenzintensität führten (Oh et al. 2007, Wallace et al. 2005). Diese Problematik konnte durch Herabsetzen des Detektionsgrenzwertes (Oh et al. 2007) oder durch das Herausselektieren einiger HPV aus der Versuchsreihe umgangen werden (Wallace et al. 2005).

Dennoch ist der CBA, der in der vorliegenden Arbeit entwickelt wurde, eine mögliche Alternative zur quantitativen Real-Time-PCR, dem bisher meist verwendeten Diagnostikverfahren für HFV. 


\subsection{Ausblick}

Der in dieser Arbeit entwickelte CBA zur Detektion von acht afrikanischen HFV bietet eine gute Alternative zu bisher verwendeten Diagnostikverfahren (z.B. qRt-PCR).

Dennoch gibt es weitere Möglichkeiten den CBA zu optimieren wie die Verbesserungsansätze in Kap. 3.3.1 (S.60) zeigen: (1) Durch eine Lagerung der gekoppelten Beads bei $-20^{\circ} \mathrm{C}$ ü.N. konnten die Fluoreszenzintensitäten der Hybridisierungsergebnisse von MFI-PE: 50913 erreicht werden, die um den 3,5-fachen Wert höher waren als die Fluoreszenzintensitäten der Beads, die direkt nach Kopplungsreaktion zur Hybridisierung verwendet wurden (MFI-PE: 14654). (2) Die Spezifität der Fluoreszenzsignale konnte durch Verwenden eines Blockpuffers (z.B. BSA, SM) verbessert werden (s. Kap. 3.3.1.3, S.62). (3) Eine optimale Hybridisierungstemperatur zu ermitteln war ein notwendiger Schritt um einen CBA im Multiplex-System zu ermöglichen. Dabei musste berücksichtigt werden, dass die Hybridisierungstemperatur unterhalb der jeweiligen Schmelztemperatur $T_{M S}$ der einzelnen Sonden lag und dennoch hoch genug war, um unspezifische Hybridisierungen zu verhindern.

Weitere Möglichkeiten zur Verbesserung des CBAs wären die Zugabe von apolarem Formamid oder DMSO. In dieser Arbeit ist darauf jedoch verzichtet worden um das Verfahren nicht zu kompliziert zu machen.

Durch den hohen Verbrauch an Beads $\left(1,25 \times 10^{5}\right.$ Beads/Probe d.h. $\left.5 \mu l\right)$ waren die Kosten $(1,85 € / 5 \mu l)$ eines Multiplex-CBAs zu hoch verglichen mit anderen etablierten Verfahren wie z.B. qRT-PCR. Um den in dieser Arbeit entwickelten CBA in afrikanischen Laboren (z.B. Institute Pasteur de Dakar, Senegal) zu etablieren, müssen die Kosten zur Anwendung in der Routinediagnostik noch gesenkt werden. Eine Möglichkeit liegt in der Reduzierung der Beadkonzentration. Laut Hersteller (Biorad) kann eine statistisch relevante Evaluation schon mit 35 Beads/Probe erreicht werden. Dies gilt zumindest für das Bioplex-System von Biorad. Es sollte kritisch untersucht werden, ob es sich auf den CBA, bei dem bisher jeweils 1000 Beads/Probe ausgewertet wurden, übertragen lässt. Es müsste dabei die Effizienz der Hybridisierungsreaktion neu überprüft werden, da das 
veränderte Verhältnis der Beads zu den PCR-Produkten zur Abschwächung der Fluoreszenzsignale im Durchflusszytometer führen könnte. Es könnte dabei auch überlegt werden, ob nicht auch durch Umstellung auf ein anderes System, bzw. anderes Material, die Kosten gesenkt werden könnten. So könnte z.B. durch die Verwendung von magnetischen Beads der Beadverlust durch die Waschschritte minimiert werden und Kosten gesenkt werden.

Dennoch bleibt der Multiplex-CBA der qRT-PCR in einigen Punkten überlegen. Schließlich wird durch die kombinierte Detektion von Virusgenomen, Zytokinen und AK das gesamte diagnostische Fenster abgedeckt und die gesamte molekulare Diagnostik von acht afrikanischen HFV auf ein gemeinsames Verfahren beschränkt. 


\section{$5 \quad$ Zusammenfassung}

Ziel dieser Arbeit war die Entwicklung und Optimierung eines nukleinsäure-basierenden Cytometric Bead Array (CBA) zum Nachweis von hämorrhagischen Fieberviren. Um den CBA entwickeln zu können, wurden spezifische PCR-Amplifikate für acht hämorrhagischen Fieberviren (HFV) an bead-gekoppelte Oligonukleotidsonden hybridisiert. Bei den acht HFV handelte es sich um Rift-Valley-Fieber-Virus (RVFV), KrimKongo-Hämorrhagisches-Fieber-Virus (CCHFV), Marburg-Virus (MARV), Ebola-Zaire-Virus (EBOVZ), Ebola-Sudan-Virus (EBOVS), Gelbfieber-Virus (YFV), Dengue-Virus (DENV) und Lassa-Virus (LASV).

Im Rahmen dieser Arbeit wurden Multiplex-RT-PCRs für die ausgewählten Sequenzen der acht HFV entwickelt und in der qRT-PCR aufeinander abgestimmt. Die Oligonukleotidsonden wurden mithilfe von 1-Ethyl-3-(3-Dimethylaminopropyl)Carbodiimid (EDAC) an die carboxylierten Beads gekoppelt. Durch diese Oligonukleotidsonden konnten die spezifischen PCR-Amplifikate aus den Multiplex-RTPCRs an die Beads hybridisiert werden. Mit Hilfe von RNS-Standards bekannter Konzentrationen konnte die analytische Sensitivität der bead-gekoppelten Sonden ermittelt werden. Die Analyse erfolgte am Durchflusszytometer (FACS Canto ${ }^{\text {TM }}$ II). Die Spezifität der Oligonukleotidsonden konnte durch Abwesenheit von Kreuzreaktionen im Multiplex-Hybridisierungsverfahren bewiesen werden. Die Sensitivitäten des Cytometric Bead Array sind mit den Sensitivitäten einer qRT-PCR, dem meist verwendeten Verfahren zur HFV-Diagnostik, vergleichbar. Damit ist in der vorliegenden Arbeit ein Diagnostikverfahren entwickelt worden, das eine Alternative zur Routinediagnostik von HFV bietet. 


\section{Literaturverzeichnis}

Altamura LA, Bertolotti-Ciarlet A, Teigler J, Paragas J, Schmaljohn CS, Doms RW. (2007): Identification of a novel C-terminal cleavage of Crimean-Congo hemorrhagic fever virus PreGN that leads to generation of an NSM protein $J$ Virol;81(12):6632-6642.

Armstrong B, Stewart M, Mazumder A. (2000): Suspension arrays for high throughput, multiplexed single nucleotide polymorphism genotyping Cytometry; $40(2): 102-$ 108.

Auperin DD, McCormick JB. (1989): Nucleotide sequence of the Lassa virus (Josiah strain) $\mathrm{S}$ genome RNA and amino acid sequence comparison of the $\mathrm{N}$ and GPC proteins to other arenaviruses Virology;168(2):421-425.

Bae HG, Drosten C, Emmerich P, Colebunders R, Hantson P, Pest S, Parent M, Schmitz H, Warnat MA, Niedrig M. (2005): Analysis of two imported cases of yellow fever infection from Ivory Coast and The Gambia to Germany and Belgium J Clin Virol;33(4):274-280.

Bardi JS: Death Called A River, The Scripps Research Institute 2.1, Retrieved 2006-12-08, La Jolla 2002

Barrett AD, Higgs S. (2007): Yellow fever: a disease that has yet to be conquered Annu Rev Entomol;52:209-229.

Baskerville A, Satti A, Murphy FA, Simpson DI. (1981): Congo-Crimean haemorrhagic fever in Dubai: histopathological studies J Clin Pathol;34(8):871-874.

BD: Fluorescence Spectrum Viewer, BD Bioscience, New Jersey 2011, http://www.bdbiosciences.com/research/multicolor/spectrum_viewer/index.jsp

Bean WB. (1983): Landmark perspective: Walter Reed and yellow fever JAMA;250(5):659-662.

Bellisario R, Colinas RJ, Pass KA. (2001): Simultaneous measurement of antibodies to three HIV-1 antigens in newborn dried blood-spot specimens using a multiplexed microsphere-based immunoassay Early Hum Dev;64(1):21-25.

Blakqori G, Delhaye S, Habjan M, Blair CD, Sanchez-Vargas I, Olson KE, Attarzadeh-Yazdi G, Fragkoudis R, Kohl A, Kalinke U, et al. (2007): La Crosse bunyavirus nonstructural protein NSs serves to suppress the type I interferon system of mammalian hosts J Virol; $\underline{81(10)}$ :4991-4999.

Borio L, Inglesby T, Peters CJ, Schmaljohn AL, Hughes JM, Jahrling PB, Ksiazek T, Johnson KM, Meyerhoff A, O'Toole T, et al. (2002): Hemorrhagic fever viruses as biological weapons: medical and public health management JAMA;287(18):2391-2405.

Bray M, Huggins JW. (1998): Antiviral therapy of haemorrhagic fevers and arbovirus infections Antiviral Ther;3:53-79.

Bray M, Paragas J. (2002): Experimental therapy of filovirus infections Antiviral Res; 54(1):1-17.

Broude NE, Zhang L, Woodward K, Englert D, Cantor CR. (2001): Multiplex allele-specific target amplification based on PCR suppression Proc Natl Acad Sci U S A; $\underline{98(1): 206-211 . ~}$

Buckley SM, Casals J. (1970): Lassa fever, a new virus disease of man from West Africa. 3. Isolation and characterization of the virus Am J Trop Med Hyg;19(4):680-691.

Burger K, Friis E, Hubner R, Janisch K, Schimmelpfennig W, Schneider G, Theuer D, Wagner K, Zimmermann HB. (1971): [Surgical treatment of portal hypertension: 
indications for prophylactic emergency and interval-shunt] Dtsch Gesundheitswes;26(13):586-590.

Burney MI, Ghafoor A, Saleen M, Webb PA, Casals J. (1980): Nosocomial outbreak of viral hemorrhagic fever caused by Crimean Hemorrhagic fever-Congo virus in Pakistan, January 1976 Am J Trop Med Hyg;29(5):941-947.

Carhan A, Uyar Y, Ozkaya E, Ertek M, Dobler G, Dilcher M, Wang YJ, Spiegel M, Hufert F, Weidmann M. (2010): Characterization of a sandfly fever Sicilian virus isolated during a sandfly fever epidemic in Turkey J Clin Virol;48(4):264-269.

Carson RT, Vignali DA. (1999): Simultaneous quantitation of 15 cytokines using a multiplexed flow cytometric assay J Immunol Methods;227(1-2):41-52.

Casals J. (1969): Antigenic similarity between the virus causing Crimean hemorrhagic fever and Congo virus Proc Soc Exp Biol Med;131(1):233-236.

CDC: Yellow Fever in Brazil, Outbreak Notice, Centers for Disease Control and Prevention, Atlanta 2010, http://wwwnc.cdc.gov/travel/notices/outbreaknotice/yellow-fever-brazil.htm

CDC: Outbreak postings, Center for Disease Control and Prevention, Atlanta 2011, http://www.cdc.gov/ncidod/dvrd/spb/outbreaks/index.htm

Chambers TJ, Hahn CS, Galler R, Rice CM. (1990): Flavivirus genome organization, expression, and replication Annu Rev Microbiol;44:649-688.

Chomczynski P, Sacchi N. (1987): Single-step method of RNA isolation by acid guanidinium thiocyanate-phenol-chloroform extraction Anal Biochem;162(1):156-159.

Clegg JC, Wilson SM, Oram JD. (1991): Nucleotide sequence of the S RNA of Lassa virus (Nigerian strain) and comparative analysis of arenavirus gene products Virus Res;18(2-3):151-164.

Corso B, Pinto J, Beltrain-Alcrudo D, De Simone L, Lubroth J: Rift Valley fever outbreaks in Madagascar and potential risks to neighbouring countries, FAO EMPRES Watch., Food and Agriculture Organization of the United Nations, Rome, Italy 2008, ftp://ftp.fao.org/docrep/fao/011/aj213e/aj213e00.pdf

Dasso J, Lee J, Bach H, Mage RG. (2002): A comparison of ELISA and flow microspherebased assays for quantification of immunoglobulins J Immunol Methods;263(12):23-33.

Daubney R, Hudson JR, Garnham PC. (1931): Enzootic hepatitis of RVF, an undescribed virus disease of sheep, cattle and man from east africa J Pathol 34:545-579.

Davies FG. (2006): Risk of a rift valley fever epidemic at the haj in Mecca, Saudi Arabia Rev Sci Tech;25(1):137-147.

Demby AH, Chamberlain J, Brown DW, Clegg CS. (1994): Early diagnosis of Lassa fever by reverse transcription-PCR J Clin Microbiol;32(12):2898-2903.

Deregt D, Gilbert SA, Dudas S, Pasick J, Baxi S, Burton KM, Baxi MK. (2006): A multiplex DNA suspension microarray for simultaneous detection and differentiation of classical swine fever virus and other pestiviruses J Virol Methods;136(1-2):17-23.

Digoutte JP, Calvo-Wilson MA, Mondo M, Traore-Lamizana M, Adam F. (1992): Continuous cell lines and immune ascitic fluid pools in arbovirus detection Res Virol;143(6):417-422.

Drosten C, Gottig S, Schilling S, Asper M, Panning M, Schmitz H, Gunther S. (2002a): Rapid detection and quantification of RNA of Ebola and Marburg viruses, Lassa virus, Crimean-Congo hemorrhagic fever virus, Rift Valley fever virus, dengue virus, and yellow fever virus by real-time reverse transcription-PCR J Clin Microbiol;40(7):2323-2330. 
Drosten C, Minnak D, Emmerich P, Schmitz H, Reinicke T. (2002b): Crimean-Congo hemorrhagic fever in Kosovo J Clin Microbiol;40(3):1122-1123.

Dunster L, Dunster M, Ofula V, Beti D, Kazooba-Voskamp F, Burt F, Swanepoel R, DeCock KM. (2002): First documentation of human Crimean-Congo hemorrhagic fever, Kenya Emerg Infect Dis;8(9):1005-1006.

el-Azazy OM, Scrimgeour EM. (1997): Crimean-Congo haemorrhagic fever virus infection in the western province of Saudi Arabia Trans R Soc Trop Med Hyg;91(3):275278.

EMEA: CPMP guidance document on use of medicinal products for treatment and prophylaxis of biological agents that might be used as weapons of bioterrorism, EMEA London 2002, www.emea.eu.int

Endy TP, Chunsuttiwat S, Nisalak A, Libraty DH, Green S, Rothman AL, Vaughn DW, Ennis FA. (2002): Epidemiology of inapparent and symptomatic acute dengue virus infection: a prospective study of primary school children in Kamphaeng Phet, Thailand Am J Epidemiol;156(1):40-51.

Ergonul O. (2006): Crimean-Congo haemorrhagic fever Lancet Infect Dis; 6(4):203-214.

Expasy: ViralZone, Swiss Institute of Bioinformatics, Geneve 2011, http://viralzone.expasy.org/

Fan J, MS C, Gunderson K. (2006): Highly parallel genomic assays Nature Review Genetics; $\underline{7}: 632-644$.

Fauquet CM, Fargette D. (2005): International Committee on Taxonomy of Viruses and the 3,142 unassigned species Virol J;2:64.

Formenty P, Hatz C, Le Guenno B, Stoll A, Rogenmoser P, Widmer A. (1999): Human infection due to Ebola virus, subtype Cote d'Ivoire: clinical and biologic presentation J Infect Dis;179 Suppl 1:S48-53.

Frame JD, Baldwin JM, Jr., Gocke DJ, Troup JM. (1970): Lassa fever, a new virus disease of man from West Africa. I. Clinical description and pathological findings $\mathrm{Am} \mathrm{J}$ Trop Med Hyg;19(4):670-676.

Franz DR, Jahrling PB, Friedlander AM, McClain DJ, Hoover DL, Bryne WR, Pavlin JA, Christopher GW, Eitzen EM, Jr. (1997): Clinical recognition and management of patients exposed to biological warfare agents JAMA;278(5):399-411.

Freedman DO, Weld LH, Kozarsky PE, Fisk T, Robins R, von Sonnenburg F, Keystone JS, Pandey P, Cetron MS. (2006): Spectrum of disease and relation to place of exposure among ill returned travelers N Engl J Med;354(2):119-130.

Fuller F, Bhown AS, Bishop DH. (1983): Bunyavirus nucleoprotein, N, and a non-structural protein, NSS, are coded by overlapping reading frames in the S RNA $J$ Gen Virol;64 (Pt 8):1705-1714.

Gardner, Boilot P, Hines EL. Enhancing electronic nose performance by sensor selection using a new integer-based genetic algorithm approach. In: Selected Papers from the 10th International Symposium on Olfaction and Electronic Noses, Electrical and Electronic Engineering Division, School of Engineering, University of Warwick, Coventry, UK. 2004:114-121.

Gear JS, Cassel GA, Gear AJ, Trappler B, Clausen L, Meyers AM, Kew MC, Bothwell TH, Sher R, Miller GB, et al. (1975): Outbreake of Marburg virus disease in Johannesburg Br Med J;1975,4(5995):489-493.

Geisbert TW, Geisbert JB, Leung A, Daddario-DiCaprio KM, Hensley LE, Grolla A, Feldmann H. (2009): Single-injection vaccine protects nonhuman primates against infection with marburg virus and three species of ebola virus $J$ Virol;리(14):7296-7304. 
Geisbert TW, Lee ACH, Robbins M, Geisbert JB, Honko AN, Sood V, Johnson JC, de Jong S, Tavakoli I, Judge A, et al. (2010): Postexposure protection of non-human primates against a lethal Ebola virus challenge with RNA interference: a proof-ofconcept study Lancet;375(9729):1896-1905.

Giorgi C, Accardi L, Nicoletti L, Gro MC, Takehara K, Hilditch C, Morikawa S, Bishop DH. (1991): Sequences and coding strategies of the S RNAs of Toscana and Rift Valley fever viruses compared to those of Punta Toro, Sicilian Sandfly fever, and Uukuniemi viruses Virology; 180(2):738-753.

GloballncidentMap.com: Lassa Outbreaks, Steadfast Networks, Chicago 2011, http://outbreaks.globalincidentmap.com/home.php

Goehde W, Dittrich W. (1971): Impulszytometrie bei Einzelzellen in Suspension Z Naturforsch;르․

Greve B, Weidner J, Cassens U, Odaibo G, Olaleye D, Sibrowski W, Reichelt D, Nasdala I, Gohde W. (2009): A new affordable flow cytometry based method to measure HIV-1 viral load Cytometry A;75(3):199-206.

Gunther S, Emmerich P, Laue T, Kuhle O, Asper M, Jung A, Grewing T, ter Meulen J, Schmitz H. (2000): Imported Lassa fever in Germany: Molecular characterization of a new Lassa virus strain Emerg Infect Dis; 6(5):466-476.

Gurukumar KR, Priyadarshini D, Patil JA, Bhagat A, Singh A, Shah PS, Cecilia D. (2009): Development of real time PCR for detection and quantitation of Dengue Viruses Virol J;무:10.

Halstead SB. (1988): Pathogenesis of dengue: challenges to molecular biology Science;239(4839):476-481.

Halstead SB. (2007): Dengue Lancet;370(9599):1644-1652.

Helling RB, Goodman HM, Boyer HW. (1974): Analysis of endonuclease R-EcoRI fragments of DNA from lambdoid bacteriophages and other viruses by agarosegel electrophoresis J Virol;14(5):1235-1244.

Hindson BJ, Reid SM, Baker BR, Ebert K, Ferris NP, Tammero LF, Lenhoff RJ, NaraghiArani P, Vitalis EA, Slezak TR, et al. (2008): Diagnostic evaluation of multiplexed reverse transcription-PCR microsphere array assay for detection of foot-andmouth and look-alike disease viruses J Clin Microbiol;46(3):1081-1089.

Holmes GP, McCormick JB, Trock SC, Chase RA, Lewis SM, Mason CA, Hall PA, Brammer LS, Perez-Oronoz GI, McDonnell MK, et al. (1990): Lassa fever in the United States. Investigation of a case and new guidelines for management $N$ Engl J Med;323(16):1120-1123.

Horejsh D, Martini F, Poccia F, Ippolito G, Di Caro A, Capobianchi MR. (2005): A molecular beacon, bead-based assay for the detection of nucleic acids by flow cytometry Nucleic Acids Res;33(2):e13.

Hunter P, Bouloy M: Investigation of C13 RVF mutant as a vaccine strain, University of Pretoria, Stellenbosch/ South Africa 2001

Jahrling P, Hesse R, Eddy G, Johnson K, Callis R, Stephen E. (1980): Lassa virus infection of rhesus monkeys: pathogenesis and treatment with ribavirin $J$ Infect Dis;141(5):580-589.

Jahrling P: Viral hemorrhagic fevers, Office of the Surgeon General, Falls Church 1989 Jiang HL, Zhu HH, Zhou LF, Chen F, Chen Z. (2006): Genotyping of human papillomavirus in cervical lesions by L1 consensus PCR and the Luminex XMAP system J Med Microbiol; $\underline{55(\mathrm{Pt} \mathrm{6})}$ :715-720.

Kabra SK, Jain Y, Singhal T, Ratageri VH. (1999): Dengue hemorrhagic fever: clinical manifestations and management Indian J Pediatr;66(1):93-101. 
Kuo KW, Leung MF, Leung WC. (1997): Intrinsic secondary structure of human TNFR-I mRNA influences the determination of gene expression by RT-PCR Mol Cell Biochem;177(1-2):1-6.

Lee WM, Grindle K, Pappas T, Marshall DJ, Moser MJ, Beaty EL, Shult PA, Prudent JR, Gern JE. (2007): High-throughput, sensitive, and accurate multiplex PCRmicrosphere flow cytometry system for large-scale comprehensive detection of respiratory viruses J Clin Microbiol;45(8):2626-2634.

Leitmeyer KC, Vaughn DW, Watts DM, Salas R, Villalobos I, de C, Ramos C, Rico-Hesse R. (1999): Dengue virus structural differences that correlate with pathogenesis $J$ Virol; $73(6)$ : $4738-4747$.

Leroy EM, Kumulungui B, Pourrut X, Rouquet $P$, Hassanin A, Yaba P, Delicat A, Paweska JT, Gonzalez JP, Swanepoel R. (2005): Fruit bats as reservoirs of Ebola virus Nature; $438(7068): 575-576$.

Leroy EM, Epelboin A, Mondonge V, Pourrut X, Gonzalez JP, Muyembe-Tamfum JJ, Formenty P. (2009): Human Ebola outbreak resulting from direct exposure to fruit bats in Luebo, Democratic Republic of Congo, 2007 Vector Borne Zoonotic Dis; $\underline{9(6)}: 723-728$.

Letant SE, Ortiz JI, Bentley Tammero LF, Birch JM, Derlet RW, Cohen S, Manning D, McBride MT. (2007): Multiplexed reverse transcriptase PCR assay for identification of viral respiratory pathogens at the point of care $J$ Clin Microbiol;45(11):3498-3505.

Mackerras IM. (1946): Transmission of dengue fever by Aedes (Stegomyia) scutellaris Walk. in New Guinea Trans R Soc Trop Med Hyg;40(3):295-312.

McBride JH. (1999): Dengue fever. An Australian perspective Aust Fam Physician;28(4):319-323.

McCormick JB, Webb PA, Krebs JW, Johnson KM, Smith ES. (1987): A Prospective-Study of the Epidemiology and Ecology of Lassa Fever J Infect Dis;155(3):437-444.

McCormick JB, Fisher-Hoch S, Horvitz LA: Level 4: Virus Hunters of the CDC, Barnes \& Noble, New York 1999

Mertens PE, Patton R, Baum JJ, Monath TP. (1973): Clinical presentation of Lassa fever cases during the hospital epidemic at Zorzor, Liberia, March-April 1972 Am J Trop Med Hyg;22(6):780-784.

Modrow S, Dietrich F, Truyen U: Molekulare Virologie, Spektrum Akademischer Verlag, Heidelberg 2003

Molekulare Virologie Heidelberg: The Department for Infectious Diseases, Universität Heidelberg, Heidelberg 2010, http://molecular-virology.uni-hd.de

Monath TP, Mertens PE, Patton R, Moser CR, Baum JJ, Pinneo L, Gary GW, Kissling RE. (1973): A hospital epidemic of Lassa fever in Zorzor, Liberia, March-April 1972 Am J Trop Med Hyg;22(6):773-779.

Monath TP. (2001): Yellow fever: an update Lancet Infect Dis;1(1):11-20.

Muller R, Saluzzo JF, Lopez N, Dreier T, Turell M, Smith J, Bouloy M. (1995): Characterization of clone 13, a naturally attenuated avirulent isolate of Rift Valley fever virus, which is altered in the small segment Am J Trop Med Hyg;53(4):405411.

Mullis KB, Faloona FA. (1987): Specific synthesis of DNA in vitro via a polymerasecatalyzed chain reaction Methods Enzymol;155:335-350.

Myers TW, Gelfand DH. (1991): Reverse transcription and DNA amplification by a Thermus thermophilus DNA polymerase Biochemistry; 30(31):7661-7666. 
Nabeth P, Cheikh DO, Lo B, Faye O, Vall IO, Niang M, Wague B, Diop D, Diallo M, Diallo B, et al. (2004a): Crimean-Congo hemorrhagic fever, Mauritania Emerg Infect Dis;10(12):2143-2149.

Nabeth P, Thior M, Faye O, Simon F. (2004b): Human Crimean-Congo hemorrhagic fever, Senegal Emerg Infect Dis;10(10):1881-1882.

NCBI: GenBank, National Center for Biotechnology Information, Bethesda 2011a, http://www.ncbi.nlm.nih.gov/gquery/?term=gene\%20bank

NCBI: BLAST, National Center for Biotechnology Information, Bethesda 2011b, www.ncbi.nlm.nih.gov/BLAST/

Negredo A, Palacios G, Vázquez-Morón S, González F, Dopazo H, Molero F. (2011): Discovery of an Ebolvirus-Like Filovirus in Europe PLOS Pathogens;7(10):e1002304.

NICD: Rift Valley Fever Interim Report, South Africa, National Institute of Communicable Diseases, Johannesburg 2010, www.nicd.ac.za/assets/files/NICD\%20Communique\%200ctober\%202010.pdf

NICD: Interim Report on the 2011 Rift Valley Fever Outbreak in South Africa, National Institute for Communicable Diseases, Johannesburg 2011, http://www.sacids.org/kms/resources/RVF\%20Interim\%20Report\%20\%2020110510.pdf

$\mathrm{NIH}$ : Accelerated and Development of Vaccines, The Jordan Report. 20th Anniversary, US Department of Health and Human Services Bethesda 2002

Njenga MK, Paweska J, Wanjala R, Rao CY, Weiner M, Omballa V, Luman ET, Mutonga D, Sharif S, Panning M, et al. (2009): Using a field quantitative real-time PCR test to rapidly identify highly viremic rift valley fever cases J Clin Microbiol;47(4):11661171.

Ogbu O, Ajuluchukwu E, Uneke CJ. (2007): Lassa fever in West African sub-region: an overview J Vector Borne Dis;44(1):1-11.

Oh Y, Bae SM, Kim YW, Choi HS, Nam GH, Han SJ, Park CH, Cho Y, Han BD, Ahn WS. (2007): Polymerase chain reaction-based fluorescent Luminex assay to detect the presence of human papillomavirus types Cancer Sci;98(4):549-554.

Palacios G, Briese T, Kapoor V, Jabado O, Liu Z, Venter M, Zhai J, Renwick N, Grolla A, Geisbert TW, et al. (2006): MassTag polymerase chain reaction for differential diagnosis of viral hemorrhagic fever Emerg Infect Dis;12(4):692-695.

Panomics: Luminex Technology Overview, Affimetrix Inc., Santa Clara 2011, http://www.panomics.com

Papa A, Bino S, Llagami A, Brahimaj B, Papadimitriou E, Pavlidou V, Velo E, Cahani G, Hajdini M, Pilaca A, et al. (2002a): Crimean-Congo hemorrhagic fever in Albania, 2001 Eur J Clin Microbiol Infect Dis;21(8):603-606.

Papa A, Ma B, Kouidou S, Tang Q, Hang C, Antoniadis A. (2002b): Genetic characterization of the M RNA segment of Crimean Congo hemorrhagic fever virus strains, China Emerg Infect Dis;ㅇ⑴:50-53.

Papa A, Christova I, Papadimitriou E, Antoniadis A. (2004): Crimean-Congo hemorrhagic fever in Bulgaria Emerg Infect Dis;10(8):1465-1467.

Peters CJ, Reynolds JA, Slone TW, Jones DE, Stephen EL. (1986): Prophylaxis of Rift Valley fever with antiviral drugs, immune serum, an interferon inducer, and a macrophage activator Antiviral Res; $\underline{6(5): 285-297 .}$

Pierson TC, Diamond MS. (2008): Molecular mechanisms of antibody-mediated neutralisation of flavivirus infection Expert Rev Mol Med;10:e12. 
Pollitt E, Zhao J, Muscat P, Elliott RM. (2006): Characterization of Maguari orthobunyavirus mutants suggests the nonstructural protein NSm is not essential for growth in tissue culture Virology; $348(1): 224-232$.

QIAGEN: MinElute Purification Kit, Hilden 2010, http://www.qiagen.com/products/dnacleanup/gelpcrsicleanupsystems/minelute pcrpurificationkit.aspx

Richards GA, Murphy S, Jobson R, Mer M, Zinman C, Taylor R, Swanepoel R, Duse A, Sharp G, De La Rey IC, et al. (2000): Unexpected Ebola virus in a tertiary setting: clinical and epidemiologic aspects Crit Care Med;28(1):240-244.

Rockenbauer E, Petersen K, Vogel U, Bolund L, Kolvraa S, Nielsen KV, Nexo BA. (2005): SNP genotyping using microsphere-linked PNA and flow cytometric detection Cytometry $A ; 64(2): 80-86$.

Rosen L, Rozeboom LE, Sweet BH, Sabin AB. (1954): The transmission of dengue by Aedes polynesiensis Marks Am J Trop Med Hyg;3(5):878-882.

Saksida A, Duh D, Wraber B, Dedushaj I, Ahmeti S, Avsic-Zupanc T. (2010): Interacting roles of immune mechanisms and viral load in the pathogenesis of crimeancongo hemorrhagic fever Clin Vaccine Immunol;17(7):1086-1093.

Saluzzo JF, Le Guenno B. (1987): Rapid diagnosis of human Crimean-Congo hemorrhagic fever and detection of the virus in naturally infected ticks $J$ Clin Microbiol;25(5):922-924.

Sambrook J, E.F. Fritsch and T. Maniatis: Molecular Cloning: A Laboratory Manual, Cold Spring Habor Laboratory, New York 1989

Sanchez IJ, Ruiz BH. (1996): A single nucleotide change in the E protein gene of dengue virus 2 Mexican strain affects neurovirulence in mice J Gen Virol; 77 ( Pt 10):25412545.

Schmitt M, Bravo IG, Snijders PJ, Gissmann L, Pawlita M, Waterboer T. (2006): Beadbased multiplex genotyping of human papillomaviruses $J$ Clin Microbiol;44(2):504-512.

Schmitz H, Kohler B, Laue T, Drosten C, Veldkamp PJ, Gunther S, Emmerich P, Geisen HP, Fleischer K, Beersma MF, et al. (2002): Monitoring of clinical and laboratory data in two cases of imported Lassa fever Microbes Infect;4(1):43-50.

Schwarz TF, Nsanze H, Ameen AM. (1997): Clinical features of Crimean-Congo haemorrhagic fever in the United Arab Emirates Infection;25(6):364-367.

Seiler NF. Inkubationszeit und Übertragungsparameter der Ebolaviruskrankheit, Med. Diss. Eberhard-Karls-Universität Tübingen, 2008.

Sheikh AS, Sheikh AA, Sheikh NS, Rafi US, Asif M, Afridi F, Malik MT. (2005): Bi-annual surge of Crimean-Congo haemorrhagic fever (CCHF): a five-year experience Int J Infect Dis; $\underline{9(1)}: 37-42$.

Shu PY, Huang JH. (2004): Current advances in dengue diagnosis Clin Diagn Lab Immunol;11(4):642-650.

Slenczka WG. (1999): The Marburg virus outbreak of 1967 and subsequent episodes Curr Top Microbiol Immunol;235:49-75.

Smith DH, Johnson BK, Isaacson M, Swanapoel R, Johnson KM, Killey M, Bagshawe A, Siongok T, Keruga WK. (1982): Marburg-virus disease in Kenya Lancet; 1982,1(8276):816-820.

Sudiro TM, Zivny J, Ishiko H, Green S, Vaughn DW, Kalayanarooj S, Nisalak A, Norman JE, Ennis FA, Rothman AL. (2001): Analysis of plasma viral RNA levels during acute dengue virus infection using quantitative competitor reverse transcriptionpolymerase chain reaction J Med Virol;63(1):29-34. 
Swanepoel R, Shepherd AJ, Leman PA, Shepherd SP. (1985): Investigations following initial recognition of Crimean-Congo haemorrhagic fever in South Africa and the diagnosis of 2 further cases SAfr Med J; $\underline{68(9)}$ :638-641.

Swanepoel R, Gill DE, Shepherd AJ, Leman PA, Mynhardt JH, Harvey S. (1989): The clinical pathology of Crimean-Congo hemorrhagic fever Rev Infect Dis; 11 Suppl 4:S794-800.

Swanepoel R, Leman PA, Burt FJ, Zachariades NA, Braack LE, Ksiazek TG, Rollin PE, Zaki SR, Peters CJ. (1996): Experimental inoculation of plants and animals with Ebola virus Emerg Infect Dis;2(4):321-325.

Swanepoel R, Smit SB, Rollin PE, Formenty P, Leman PA, Kemp A, Burt FJ, Grobbelaar AA, Croft J, Bausch DG, et al. (2007): Studies of reservoir hosts for Marburg virus Emerg Infect Dis;13(12):1847-1851.

Syvanen AC. (2005): Toward genome-wide SNP genotyping Nat Genet;37 Suppl:S5-10. Taniuchi M, Verweij JJ, Noor Z, Sobuz SU, Lieshout L, Petri WA, Jr., Haque R, Houpt ER. (2011): High throughput multiplex PCR and probe-based detection with Luminex beads for seven intestinal parasites Am J Trop Med Hyg;4(2):332-337.

Ter Meulen J, Koulemou K, Wittekindt T, Windisch K, Strigl S, Conde S, Schmitz H. (1998): Detection of Lassa virus antinucleoprotein immunoglobulin $\mathrm{G}$ (IgG) and IgM antibodies by a simple recombinant immunoblot assay for field use $\mathrm{J}$ Clin Microbiol;36(11):3143-3148.

Timen A, Koopmans MP, Vossen AC, van Doornum GJ, Gunther S, van den Berkmortel F, Verduin KM, Dittrich S, Emmerich P, Osterhaus AD, et al. (2009): Response to imported case of Marburg hemorrhagic fever, the Netherland Emerg Infect Dis;15(8):1171-1175.

Towner JS, Rollin PE, Bausch DG, Sanchez A, Crary SM, Vincent M, Lee WF, Spiropoulou CF, Ksiazek TG, Lukwiya M, et al. (2004): Rapid diagnosis of Ebola hemorrhagic fever by reverse transcription-PCR in an outbreak setting and assessment of patient viral load as a predictor of outcome J Virol;78(8):4330-4341.

Towner JS, Sealy TK, Khristova ML, Albarino CG, Conlan S, Reeder SA, Quan PL, Lipkin WI, Downing R, Tappero JW, et al. (2008): Newly discovered ebola virus associated with hemorrhagic fever outbreak in Uganda PLoS Pathog;4(11):e1000212.

Towner JS, Amman BR, Sealy TK, Carroll SA, Comer JA, Kemp A, Swanepoel R, Paddock $C D$, Balinandi S, Khristova ML, et al. (2009): Isolation of genetically diverse Marburg viruses from Egyptian fruit bats PLoS Pathog;5(7):e1000536.

Tsai CJ, Kuo CH, Chen PC, Changcheng CS. (1991): Upper gastrointestinal bleeding in dengue fever Am J Gastroenterol;86(1):33-35.

Tsai TF, Vaughn D, Solomon T: Yellow fever, Dengue, Dengue hemorrhagic fever, Japanese encephalitis, West Nile encephalitis, St Louis encephalitis, tick-borne encephalitis, 6th ed, Elsevier Philadelphia 2005

van de Wal BW, Joubert JR, van Eeden PJ, King JB. (1985): A nosocomial outbreak of Crimean-Congo haemorrhagic fever at Tygerberg Hospital. Part IV. Preventive and prophylactic measures S Afr Med J; $\underline{68(10)}$ :729-732.

van Eeden PJ, van Eeden SF, Joubert JR, King JB, van de Wal BW, Michell WL. (1985): A nosocomial outbreak of Crimean-Congo haemorrhagic fever at Tygerberg Hospital. Part II. Management of patients S Afr Med J;68(10):718-721.

Volk D: Reaction scheme of carboxylic acid amine coupling mediated by a carbodiimide and NHS Citizendium, USA 2009, http://en.citizendium.org/wiki/File:Carbodiimide coupling via NHS ester.png 
Wagner D, de With K, Huzly D, Hufert F, Weidmann M, Breisinger S, Eppinger S, Kern WV, Bauer TM. (2004): Nosocomial acquisition of dengue Emerg Infect Dis;10(10):1872-1873.

Wallace J, Woda BA, Pihan G. (2005): Facile, comprehensive, high-throughput genotyping of human genital papillomaviruses using spectrally addressable liquid bead microarrays J Mol Diagn; $7(1): 72-80$.

Wamala JF, Lukwago L, Malimbo M, Nguku P, Yoti Z, Musenero M, Amone J, Mbabazi W, Nanyunja M, Zaramba S, et al. (2010): Ebola hemorrhagic fever associated with novel virus strain, Uganda, 2007-2008 Emerg Infect Dis;16(7):1087-1092.

Watts DM: Crimean-Congo hemorrhagic fever. The arbovirus: epidemiology and ecology, CRC Press, Boca Raton 1988

Weber F, Mirazimi A. (2008): Interferon and cytokine responses to Crimean Congo hemorrhagic fever virus; an emerging and neglected viral zonoosis Cytokine Growth Factor Rev;19(5-6):395-404.

Webster DP, Farrar J, Rowland-Jones S. (2009): Progress towards a dengue vaccine Lancet Infect Dis;9(11):678-687.

Weidmann M, Muhlberger E, Hufert FT. (2004): Rapid detection protocol for filoviruses J Clin Virol; 39 (1):94-99.

Weidmann M, Hufert FT, Sall AA. (2007): Viral load among patients infected with Marburgvirus in Angola J Clin Virol;39(1):65-66.

Weidmann M, Sanchez-Seco MP, Sall AA, Ly PO, Thiongane Y, Lo MM, Schley H, Hufert FT. (2008): Rapid detection of important human pathogenic Phleboviruses J Clin Virol;41(2):138-142.

Weidmann M, Faye O, Kranaster R, Marx A, Nunes MRT, Vasconcelos PFC, Hufert FT, Sall AA. (2010): Improved LNA probe-based assay for the detection of African and South American yellow fever virus strains J Clin Virol;48(3):187-192.

WHO. Ebola haemorrhagic fever in Zaire in 1976. In: Bulletin of the World Health Organization, World Health Organization, Geneva. 1978:271-293.

WHO: Lassa fever, Factsheet No 179, World Health Organization, Factsheet No 179, Geneva 2005a, www.who.int/mediacentre/factsheets/fs179/en

WHO: Lassa fever, Factsheet No 179, World Health Organization, WHO Newsletter, Geneva 2005b, http://www.who.int/mediacentre/factsheets/fs179/en/

WHO: End of the Ebola Outbreak in the Democratic Republic of the Congo, Global Alert and Response (GAR), World Health Organization, Geneva 2009a, http://www.who.int/csr/don/2009 02 17/en/index.html

WHO: Dengue and Dengue haemorrhagic fever, Factsheet No 117, Factsheet No117, World Health Organization, Geneva 2009b, http://www.who.int/mediacentre/factsheets/fs117/en/print.htm

WHO: Disease Outbreak News, World Health Organization, Geneva 2011, http://www.who.int/csr/don/en/

Williams RJ, Al-Busaidy S, Mehta FR, Maupin GO, Wagoner KD, Al-Awaidy S, Suleiman AJ, Khan AS, Peters CJ, Ksiazek TG. (2000): Crimean-congo haemorrhagic fever: a seroepidemiological and tick survey in the Sultanate of Oman Trop Med Int Health;5(2):99-106.

Wittebolle L, Verstuyft K, Verstraete W, Boon N. (2006): Optimisation of the aminocarboxy coupling of oligonucleotides to beads used in liquid arrays $\mathrm{J}$ Chem Technol Biot; $\underline{81(3)}$ :476-480.

Wolfel R, Paweska JT, Petersen N, Grobbelaar AA, Leman PA, Hewson R, GeorgesCourbot MC, Papa A, Gunther S, Drosten C. (2007): Virus detection and 
monitoring of viral load in Crimean-Congo hemorrhagic fever virus patients Emerg Infect Dis;13(7):1097-1100. 


\section{Danksagung:}

Zuerst möchte ich mich bei Prof. Dr. med. F.T. Hufert für die freundliche Aufnahme in seine Arbeitsgruppe und für die Ermöglichung zur Durchführung dieser Arbeit in der Abteilung Virologie des Universitätsklinikums bedanken.

Mein Dank gilt insbesondere weiterhin meinem Betreuer PD Dr. rer. nat. Manfred Weidmann für die Bereitstellung dieses spannenden Themas, für seine Hilfsbereitschaft während der gesamten Zeit meiner Dissertation und ganz besonders für die sorgfältigen Korrekturen an meiner Arbeit.

Mein ganz besonderer Dank gilt meinem Betreuer Dr. rer. nat. Meik Dilcher für die wunderbare Zusammenarbeit. Er hat dafür gesorgt, dass ich während der vielen Rückschläge und Frustrationen, welche die Laborarbeit mit sich bringt, nie die Motivation verloren habe. Es war sehr beruhigend, dass ich inn jederzeit um Rat und Tat bitten konnte und er immer ein offenes Ohr hatte für jedes Problem während der gesamten Zeit meiner Dissertation. Er war mit Sicherheit der beste Betreuer, den man sich für eine Doktorarbeit wünschen kann!

Weiterhin bedanken möchte ich mich bei allen Mitgliedern der Arbeitsgruppe Hufert, die mich so phantastisch unterstützt und mich in die praktische Laborarbeit eingeführt haben. Es gab immer jemanden, den ich um Rat fragen konnte, wenn ein Problem auftrat. Großen Dank schulde ich hier insbesondere Tanja Gall für die große Hilfe bei vielen Tätigkeiten der Laborarbeit. Ohne sie wäre diese Arbeit wohl nicht möglich gewesen. 